\title{
WestVirginiaUniversity
}

THE RESEARCH REPOSITORY @ WVU

Graduate Theses, Dissertations, and Problem Reports

2006

\section{Finite element analysis of low-profile FRP bridge deck (Prodeck 4)}

Siva Kumar Boyapati

West Virginia University

Follow this and additional works at: https://researchrepository.wvu.edu/etd

\section{Recommended Citation}

Boyapati, Siva Kumar, "Finite element analysis of low-profile FRP bridge deck (Prodeck 4)" (2006).

Graduate Theses, Dissertations, and Problem Reports. 3257.

https://researchrepository.wvu.edu/etd/3257

This Thesis is protected by copyright and/or related rights. It has been brought to you by the The Research Repository @ WVU with permission from the rights-holder(s). You are free to use this Thesis in any way that is permitted by the copyright and related rights legislation that applies to your use. For other uses you must obtain permission from the rights-holder(s) directly, unless additional rights are indicated by a Creative Commons license in the record and/ or on the work itself. This Thesis has been accepted for inclusion in WVU Graduate Theses, Dissertations, and Problem Reports collection by an authorized administrator of The Research Repository @ WVU. For more information, please contact researchrepository@mail.wvu.edu. 


\title{
Finite Element Analysis of Low-Profile FRP Bridge deck (Prodeck 4)
}

\author{
Siva Kumar Boyapati \\ Thesis Submitted to the \\ College of Engineering and Mineral Resources \\ at West Virginia University \\ in partial fulfillment of the requirements \\ for the degree of \\ Master of Science \\ in \\ Mechanical Engineering
}

Nithi T. Sivaneri, Ph.D., Chair

Hota V. GangaRao, Ph.D.

Kenneth H. Means, Ph.D.

Department of Mechanical and Aerospace Engineering

\author{
Morgantown, West Virginia \\ 2006
}

Keywords: Bridge deck, ANSYS, Micromechanics, Finite Element Modeling. 


\section{ABSTRACT \\ Finite Element Analysis of Low-Profile FRP Bridge deck (Prodeck 4) \\ Siva Kumar Boyapati}

FRPs (Fiber Reinforced Polymers) are lightweight and an innovative alternative to conventional materials like steel and concrete in Structural engineering. Pultruded FRP bridge decks have many advantages compared to conventional concrete decks especially in bridge engineering. In this study a finite element model of a 4"-thick low profile FRP bridge deck made of E-glass fiber and vinyl ester resin, having a fiber volume fraction of approximately $50 \%$ and weighing about $10 \mathrm{lb} / \mathrm{ft}^{2}$ is developed using the finite element software ANSYS. The bridge deck modeled is subjected to a central patch load, and the finite element results such as deflections, strains and equivalent flexural rigidity obtained are compared with previous experimental results. A good correlation is found to exist between the finite element and experimental results of Prodeck 4. A buckling analysis of Prodeck4 is carried out and the critical value of the buckling load of the deck is found to be around 600 kips. The models of Prodeck 4, which is used as a beam and a double beam, are also developed and their finite element results are compared to experimental results. A failure analysis is carried out on the deck and beams using maximum stress, maximum strain and Tsai-Wu failure criteria and first ply failure value is determined. A finite element model of two-module FRP deck system is generated, and the strain values at specific locations in the deck model when subjected to a central patch load are compared to the experimental values obtained at these locations. 


\section{ACKNOWLEDGEMENTS}

The road to my graduate degree has been long and winding, so I would like to thank some people. Firstly, I would like to thank my advisor Dr. Nithi T. Sivaneri, under whose supervision I chose this topic and began the thesis. He is the best advisor I could have wished for, without whose guidance and support this thesis would not have been possible. He is actively involved in the work of all of his students, and clearly has their best interest in mind.

I would also like to thank the members in my committee: Dr. Hota V. GangaRao and Dr. Kenneth H. Means for taking out time from their busy schedules to evaluate my thesis. Their suggestions were invaluable and their support throughout the entire process is greatly appreciated.

I am forever indebted to my parents and my brother for their love, support, encouragement and endless patience when it was most required. I am very grateful to my close friend Pramod, without whose inspiration this work would not have been finished.

Finally, I would also like to thank all my roommates and friends especially Bhyrav who helped me in completion of my graduate work.

I am very grateful for the time and effort so many people have dedicated to helping me succeed 


\section{TABLE OF CONTENTS}

ABSTRACT

ACKNOWLEDGEMENTS iii

LIST OF FIGURES viii

LIST OF TABLES X xiv

CHAPTER 1

INTRODUCTION

1.1 Introduction 1

1.2 Literature Review 6

1.3 Need for Current Research $\quad 16$

1.4 Objectives 16

$\begin{array}{ll}1.5 \text { Scope } & 17\end{array}$

$\begin{array}{lr}\text { CHAPTER 2 } & 18\end{array}$

DESCRIPTION OF PRODECK $4 \quad 18$

$\begin{array}{lr}\text { CHAPTER } 3 & 24\end{array}$

FINITE ELEMENT ANALYSIS $\quad 24$

$\begin{array}{ll}3.1 \text { Introduction } & \mathbf{2 4}\end{array}$

3.2 Type of Element $\quad \mathbf{2 4}$

3.2.1 Description of Solid46 Element $\quad \mathbf{2 5}$

3.3 Material Properties $\quad 26$

$\begin{array}{lll}\text { 3.3.1 } & \text { Fiber Volume Fraction } & \mathbf{2 7}\end{array}$

3.3.2 Lamina Properties $\quad \mathbf{2 8}$

3.3.3 Material Specifications of the Laminas used in Prodeck 4

3.4 Finite Element Model 33 
3.7 Design for Failure 39

3.7.1 Failure Properties of Lamina 39

3.7.2 Strength Ratio $\quad \mathbf{4 3}$

3.7.3 Failure Criteria $\quad \mathbf{4 3}$

3.7.3.1 Maximum Stress Criterion $\quad \mathbf{4 4}$

3.7.3.2 Maximum Strain Criterion $\quad \mathbf{4 5}$

3.7.3.3 Tsai-Wu Criterion $\quad \mathbf{4 6}$

$\begin{array}{lll}\text { 3.7.4 Failure Criteria in ANSYS } & \mathbf{4 7}\end{array}$

3.8 Results of Single Module of Prodeck $4 \quad \mathbf{4 8}$

$\begin{array}{lll}\text { 3.8.1 } & \text { Introduction } & \mathbf{4 8}\end{array}$

3.8.2 Deflection Analysis $\quad \mathbf{4 8}$

3.8.2.1 Bending stiffness and Young's modulus of the longitudinal components $\mathbf{5 2}$

3.8.3 Strain Analysis $\quad \mathbf{5 4}$

3.8.3.1 Computation of bending stiffness and Young's modulus based on strain $\quad \mathbf{6 0}$

$\begin{array}{ll}3.9 & \text { Failure Analysis } \\ & \mathbf{7 4}\end{array}$

3.10Buckling Analysis $\quad 79$

$\begin{array}{lll}\text { CHAPTER } 4 & 81\end{array}$

$\begin{array}{ll}\text { FRP BEAM ANALYSIS } & 81\end{array}$

$\begin{array}{lc}4.1 \text { Introduction } & \mathbf{8 1}\end{array}$

$\begin{array}{lll}\text { 4.2 Finite element Model } & \mathbf{8 1}\end{array}$

$\begin{array}{lr}4.3 \text { Boundary Conditions } & \mathbf{8 3}\end{array}$

$\begin{array}{lr}4.4 \text { Applied Loads } & \mathbf{8 4}\end{array}$

4.5 Results of FRP Beam $\quad \mathbf{8 5}$

$\begin{array}{lll}\text { 4.5.1 Introduction } & \mathbf{8 5}\end{array}$ 
4.5.2 Deflection Analysis of FRP Beam $\quad \mathbf{8 5}$

4.5.2.1 Computation of bending stiffness based on deflection $\quad \mathbf{8 8}$

$\begin{array}{llr}\text { 4.5.3 Strain Analysis } & \mathbf{8 9}\end{array}$

$\begin{array}{ll}\text { 4.5.3.1 Computation of bending stiffness based on strain } & 95\end{array}$

4.6 First Ply Failure Analysis $\quad 96$

$\begin{array}{ll}\text { CHAPTER } 5 & 101\end{array}$

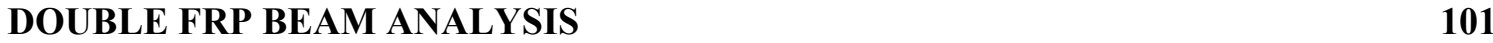

$\begin{array}{ll}5.1 \text { Introduction } & \mathbf{1 0 1}\end{array}$

5.2 Development of Finite Element Model $\quad \mathbf{1 0 1}$

5.3 Applied Boundary Conditions $\quad \mathbf{1 0 3}$

$\begin{array}{ll}5.4 \text { Applied loads } & \mathbf{1 0 4}\end{array}$

5.5 Results of Double FRP Beam $\quad \mathbf{1 0 5}$

$\begin{array}{lll}\text { 5.5.1 Introduction } & \mathbf{1 0 5}\end{array}$

5.5.2 Deflection Analysis of Double FRP beam 105

5.5.2.1 Bending Stiffness based on deflection $\quad \mathbf{1 0 8}$

$\begin{array}{lll}\text { 5.5.3 Strain Analysis } & \mathbf{1 0 9}\end{array}$

$\begin{array}{lll}\text { 5.5.3.1 } \quad \text { Bending stiffness based on strain } & \mathbf{1 1 4}\end{array}$

$\begin{array}{ll}\text { 5.6 First Ply Failure Analysis } & \mathbf{1 1 5}\end{array}$

CHAPTER 6 120

RESPONSE OF TWO-MODULE FRP DECK UNDER STATIC LOADING 120

6.1 Introduction $\quad \mathbf{1 2 0}$

6.2 Test Set-Up 121

6.3 Test Procedure 122

6.4 Finite Element Analysis of 2 Module FRP Deck 122

$\begin{array}{lll}\text { 6.4.1 Development of Finite Element Model } & 122\end{array}$

$\begin{array}{lll}\text { 6.4.2 Applied Boundary Conditions and loads } & \mathbf{1 2 3}\end{array}$ 
$\begin{array}{lll}6.4 .3 & \text { Results } & \mathbf{1 2 4}\end{array}$

$\begin{array}{lll}\text { 6.4.3.1 Introduction } & \mathbf{1 2 4}\end{array}$

$\begin{array}{lll}\text { 6.4.3.2 Deflection Analysis } & 124\end{array}$

6.4.3.2.1 Bending stiffness based on deflection 127

$\begin{array}{lll}\text { 6.4.4.3 Strain Analysis } & \mathbf{1 2 8}\end{array}$

6.4.4.3.1 Bending stiffness based on strain $\quad \mathbf{1 4 0}$

CHAPTER $7 \quad 142$

CONCLUSIONS AND RECOMMENDATIONS 142

7.1 Introduction 142

7.2 Conclusions 142

$\begin{array}{lll}7.3 \text { Recommendations } & \mathbf{1 4 4}\end{array}$

REFERENCES $\quad 145$ 


\section{LIST OF FIGURES}

Fig. 1.1 All-Composite foot bridge in Kolding, Denmark which erected in $1997 \quad 3$

Fig. 1.2 Most common FRP bridge decks in use $\quad 4$

Fig. 1.3 Diagram of pultrusion process 5

Fig. 1.4 Cross-sections of the four FRP decks analyzed by Bakeri and Sunder $\quad 7$

Fig. 1.5 FRP deck cross-sections investigated by Plecnik, Azar and Ahmed 8

Fig. 1.6 Partial sections of the four FRP deck panels analyzed by Zureick 9

Fig. 1.7 Cross section of first generation FRP bridge deck component $\quad \mathbf{1 0}$

Fig. 1.8 Cross section of second generation FRP bridge deck component 11

Fig. 1.9 Cross-section of FRP deck panel analyzed by Temeles 12

Fig. 1.10 Cross-section of polyester component analyzed by Howard 13

Fig. 1.11 Cross-section of vinyl ester component analyzed by Howard 13

Fig. 2.1 Cross-section of Low Profile FRP Bridge deck component 19

Fig. 2.2 Cross-section of Prodeck 4 used in experimental testing 20

Fig. 2.3 Cross-section of the finite element model of Prodeck $4 \quad 20$

Fig. 2.4 Orientation of global coordinate system of Prodeck 4

Fig. 2.5 Fiber architecture of vinyl ester component $\quad 22$

Fig. 3.1 Geometry of solid46 element $\quad 25$

Fig. 3.2 Solid model generated of Prodeck 4

Fig. 3.3 Meshed model generated of Prodeck 4 35

Fig. 3.4 Fiber orientations of individual layers of an element in Prodeck 36

Fig. 3.5 Graphical representation of element co-ordinate system 36 
Fig. 3.6 Pictorial representation of boundary conditions applied on the Prodeck 4

Fig. 3.7 Pictorial representation of 10"x 20" patch load applied on the Prodeck $4 \quad 38$

Fig. 3.8 Deformed shape of Prodeck4 under the central patch load of 20 kips 49

Fig. 3.9 Graphical plot between maximum deflection and central patch load $\mathbf{5 1}$

Fig. 3.10 Deflection plot of Prodeck 4 in direction of Y-axis under the load of 20kips 52

Fig. 3.11 Graphical plot between strain and central patch load $\quad 56$

Fig. 3.12 Contour plot of strain $\left(\varepsilon_{\mathrm{z}}\right)$ of Prodeck 4 for a central patch load of 20 kips $\quad 57$

Fig. 3.13 Side view of the contour plot of strain $\left(\varepsilon_{z}\right)$ of Prodeck 4 for a load of 20 kips 57

Fig. 3.14 Bottom view of the contour plot of Strain $\left(\varepsilon_{z}\right)$ for a load of 20 kips $\quad 58$

Fig. 3.15 Stress-strain curve for a central patch load $\quad 60$

Fig. 3.16 contour plot of Strain $\left(\varepsilon_{\mathrm{x}}\right)$ of Prodeck 4 for a central patch load of 20 kips $\mathbf{6 1}$

Fig. 3.17 sectional view of contour plot of Strain $\left(\varepsilon_{\mathrm{x}}\right)$ of Prodeck 4 for load of 20 kips 62

Fig. 3.18 sectional view of contour plot of Strain $\left(\varepsilon_{\mathrm{x}}\right)$ of Prodeck 4 for load of 20 kips 62

Fig. 3.19 contour plot of Strain $\left(\varepsilon_{\mathrm{y}}\right)$ of Prodeck 4 for a central patch load of 20 kips $\mathbf{6 3}$

Fig. 3.20 Bottom view of contour plot of Strain $\left(\varepsilon_{\mathrm{y}}\right)$ of Prodeck 4

Fig. 3.21 contour plot of shear strain $\left(\gamma_{x y}\right)$ of Prodeck 4 for a patch load of 20 kips $\quad 64$

Fig. 3.22 Side view of contour plot of shear strain $\left(\gamma_{x y}\right)$ for a patch load of 20 kips $\quad 64$

Fig. 3.23 contour plot of shear strain $\left(\gamma_{\mathrm{yz}}\right)$ of Prodeck 4 for a patch load of 20 kips $\quad 65$

Fig. 3.24 Side view of contour plot of shear strain $\left(\gamma_{\mathrm{yz}}\right)$ for a patch load of 20 kips $\quad \mathbf{6 5}$

Fig. 3.25 contour plot of shear strain $\left(\gamma_{x z}\right)$ of Prodeck 4 for a patch load of 20 kips $\quad 66$

Fig. 3.26 Side view of contour plot of shear strain $\left(\gamma_{x z}\right)$ for a patch load of 20 kips $\quad 66$

Fig. 3.27 contour plot of stress $\left(\sigma_{\mathrm{x}}\right)$ of Prodeck 4 for a central patch load of 20 kips $\quad 67$

Fig. 3.28 Bottom view of contour plot of stress $\left(\sigma_{\mathrm{x}}\right)$ of Prodeck 4 for a load of 20 kips 67 
Fig. 3.29 contour plot of stress $\left(\sigma_{\mathrm{y}}\right)$ of Prodeck 4 for a central patch load of 20 kips

Fig. 3.30 Side view of contour plot of stress $\left(\sigma_{\mathrm{y}}\right)$ of Prodeck 4 for a load of 20 kips $\quad 68$

Fig. 3.31 contour plot of stress $\left(\sigma_{z}\right)$ of Prodeck 4 for a central patch load of 20 kips

Fig. 3.32 Bottom view of contour plot of stress $\left(\sigma_{z}\right)$ of Prodeck 4 for a load of 20 kips 69

Fig. 3.33 contour plot of shear stress $\left(\tau_{\mathrm{xy}}\right)$ of Prodeck 4 for a patch load of 20 kips

Fig. 3.34 Bottom view of contour plot of shear stress $\left(\tau_{\mathrm{xy}}\right)$ for a patch load of $20 \mathrm{kips} \mathbf{7 0}$

Fig. 3.35 Contour plot of shear stress $\left(\tau_{\mathrm{yz}}\right)$ for a central patch load of $20 \mathrm{kips}$

Fig. 3.36 Side view of contour plot of shear stress $\left(\tau_{\mathrm{yz}}\right)$ for a load of $20 \mathrm{kips}$

Fig. 3.37 Contour plot of shear stress $\left(\tau_{\mathrm{xz}}\right)$ for a central patch load of 20 kips

Fig. 3.38 Bottom view of contour plot of shear stress $\left(\tau_{\mathrm{xz}}\right)$ for a load of $20 \mathrm{kips}$

Fig. 3.39 Failure plot of Prodeck 4 using maximum stress criterion

Fig. 3.40 Bottom view of the failure plot of Prodeck 4 using maximum stress criterion75

Fig. 3.41 Failure plot of Prodeck 4 using maximum strain criterion

Fig. 3.42 Bottom view of the failure plot of Prodeck 4 using maximum strain criterion77

Fig. 3.43 Failure plot of Prodeck 4 using Tsai-Wu criterion

Fig. 3.44 Bottom view of the failure plot of Prodeck 4 using Tsai-Wu criterion

Fig. 3.45 Buckled shape of Prodeck 4

Fig. 3.46 Buckled shape of the web of Prodeck 4

Fig. 4.1 Solid model of FRP beam

Fig. 4.2 Map meshed model of FRP beam

Fig. 4.3 Orientations of element coordinate systems in FRP beam

Fig. 4.4 Pictorial representation of boundary conditions applied on FRP beam

Fig. 4.5 Pictorial representation of 4"x 11" patch load applied on the on FRP beam 
Fig. 4.6 Deflection plot of FRP beam in direction of Y-axis under the load of 20 kips 86

Fig. 4.7 Graphical plot between maximum deflection and central patch load $\quad \mathbf{8 8}$

Fig. 4.8 Graphical plot between strain and central patch load $\quad 91$

Fig. 4.9 Contour plot of strain $\left(\varepsilon_{z}\right)$ of FRP beam subjected to a patch load of 20 kips 92

Fig. 4.10 Side view of the contour plot of strain $\left(\varepsilon_{z}\right)$ of FRP beam 92

Fig. 4.11 Bottom view of the contour plot of strain $\left(\varepsilon_{z}\right)$ of FRP beam 93

Fig. 4.12 Stress-strain curve for a central patch load 95

Fig. 4.13 Failure plot of FRP beam using maximum stress criterion 96

Fig. 4.14 Side view of failure plot of FRP beam using maximum stress criterion $\quad 97$

Fig. 4.15 Failure plot of FRP beam using maximum strain criterion $\quad 98$

Fig. 4.16 Side view of failure plot of FRP beam using maximum strain criterion $\quad 98$

Fig. 4.17 Failure plot of FRP beam using Tsai-Wu criterion 99

Fig. 4.18 Side view of failure plot of FRP beam using Tsai-Wu criterion $\quad 100$

Fig. 5.1 Solid model of double FRP beam $\quad 102$

Fig. 5.2 Map meshed model of double FRP beam $\quad 102$

Fig. 5.3 Pictorial representation of boundary conditions applied on double FRP beam 103

Fig. 5.4 Pictorial Representation of 6.5"x 11" patch load applied on double FRP beam104

Fig. 5.5 Deflection plot of double FRP beam under the patch load of 52 kips $\quad \mathbf{1 0 6}$

Fig. 5.6 Graphical plot between maximum deflection and central patch load $\quad \mathbf{1 0 8}$

Fig. 5.7 Graphical plot between strain and central patch load $\quad 111$

Fig. 5.8 Contour plot of strain $\left(\varepsilon_{z}\right)$ of double FRP beam under a patch load of 52 kips 111

Fig. 5.9 Side view of the contour plot of strain $\left(\varepsilon_{\mathrm{z}}\right)$ of double FRP beam 112

Fig. 5.10 Bottom view of the contour plot of strain $\left(\varepsilon_{\mathrm{z}}\right)$ of double FRP beam 112 
$\begin{array}{ll}\text { Fig. 5.11 Stress-strain curve for a central patch load } & \mathbf{1 1 4}\end{array}$

Fig. 5.12 Failure plot of double FRP beam using maximum stress criterion $\quad 115$

Fig. 5.13 Side view of the failure plot of double FRP beam 116

$\begin{array}{ll}\text { Fig. 5.14 Failure plot of double FRP beam using maximum strain criterion } & 117\end{array}$

Fig. 5.15 Side view of the plot of double FRP beam using maximum strain criterion 117

Fig. 5.16 Failure plot of double FRP beam using Tsai-Wu criterion $\quad 118$

Fig. 5.17 Side view of failure plot of double FRP beam using Tsai-Wu criterion 119

Fig. 6.1 Cross section of two-module FRP deck used in testing 120

Fig. 6.2 Test set-up for two-module FRP deck component 121

Fig. 6.3 Finite element model of two-module FRP deck system 122

Fig. 6.4 Pictorial representation of boundary conditions applied on two-module deck 123

Fig. 6.5 Pictorial representation of 10"x 20" patch load applied on two-module deck $\mathbf{1 2 4}$

Fig. 6.6 Deflection plot of two-module FRP deck under the patch load of 22 kips $\mathbf{1 2 5}$

Fig. 6.7 Graphical plot between maximum deflection and central patch load $\quad \mathbf{1 2 7}$

Fig. 6.8 Position of strain gauges on two-module FRP deck 129

Fig. 6.9 Graphical plot between central patch load and strain at gauge location \#7 131

Fig. 6.10 Variation of strain at the gauge \#1 location for a central patch load 134

Fig. 6.11 Variation of strain at the gauge \#2 location for a central patch load 134

Fig. 6.12 Variation of strain at the gauge \#9 location for a central patch load 135

Fig. 6.13 Variation of strain at the gauge \#10 location for a central patch load 135

Fig. 6.14 Variation of strain at the gauge \#3 location for a central patch load 136

Fig. 6.15 Variation of strain at the gauge \#4 location for a central patch load $\quad 136$

Fig. 6.16 Variation of strain at the gauge \#5 location for a central patch load $\quad 137$ 
Fig. 6.17 Variation of strain at the gauge \#6 location for a central patch load

Fig. 6.18 Stress-strain curve for central patch load

140 


\section{LIST OF TABLES}

Table 2.1 Specifications of CDBM3415 fabric used in Prodeck 4

Table 2.2 Specifications of DDBM4015 fabric used in Prodeck 4

Table 3.1 Layer properties of fibers and roving with fiber volume fraction of 0.5

Table 3.2 Layer properties of Mat with fiber volume fraction of 0.5

Table 3.3 Strength values for CDBM, DDBM and Rovings used in Prodeck 4

Table 3.4 Failure strain values for CDBM, DDBM and Rovings

Table 3.5 Maximum deflection values of Prodeck 4

Table 3.6 Bending stiffness and young's modulus values of the longitudinal component based on deflection

Table 3.7 Strain values of Prodeck 4 for central patch load

Table 3.8 Stress and strain values of Prodeck 4 for central patch load

Table 3.9 Bending stiffness and Young's modulus values of the longitudinal component based on strain

Table 4.1 Maximum deflection values of FRP beam

Table 4.2 Equivalent flexural rigidity of FRP beam component based on deflection

Table 4.3 Strain values of FRP beam for central patch load

Table 4.4 Stress and strain values of FRP beam for central patch load

Table 4.5 Equivalent flexural rigidity of FRP beam component based on strain

Table 5.1 Maximum deflection values of double FRP beam

Table 5.2 Equivalent flexural rigidity of double FRP beam based on deflection

Table 5.3 Strain values of double FRP beam for central patch load 
Table 5.4 Stress and strain values of double FRP beam for central patch load

Table 5.5 Bending stiffness of double FRP beam component based on strain

Table 6.1 Maximum deflection values of two-module FRP deck

Table 6.2 Equivalent flexural rigidity and young's modulus of two-module

FRP deck component based on deflection

128

Table 6.3 Strain values at the Strain Gage \#7 location for a central patch load

Table 6.4 Strain values at locations of strain gauges \#1, \#2, \#9 and \#10 for a central patch load

Table 6.5 Strain values at locations of strain gauges \#3, \#4, \#5 and \#6 for a central patch load 133

Table 6.6 Stress and strain values of two-module FRP deck for central patch load 139

Table 6.7 Equivalent flexural rigidity and young's modulus of the two-module FRP deck component based on strain 


\section{CHAPTER 1}

\section{INTRODUCTION}

\subsection{INTRODUCTION}

Today's composite technology is probably born with the introduction of the first thermosetting polymers in 1909: phenolics. The structural composite industry has begun to grow in the year 1940. Over the last thirty years composite materials have been the most dominant of emerging materials. The number of applications of composite materials has increased tremendously, penetrating and conquering new markets. ["FRP Bridge Decks with adhesively bonded connections - Martin Schollmayer"]

Composite materials or composites chiefly comprise of fibers and matrix. Most of the stiffness and strength are provided by the fibers where as the matrix helps in binding the fibers together keeping them intact thus providing load transfer between fibers.

Fiber Reinforced Polymers (FRP) are lightweight and an innovative alternative to conventional materials like steel and concrete in structural engineering. Pultruded FRP bridge decks have many advantages compared to conventional concrete decks especially in bridge engineering. Fiber reinforced polymers have been used in bridge engineering for about twenty years. The first bridges built using FRP bridge decks were for pedestrians but, pultruded FRP bridge decks in the construction of highway bridges found their way later.

A large number of concrete bridge decks are in inferior condition mainly due to aging and partly because of poor construction quality. Defective covering and the use of 
deicing salts increase the rate of corrosion of the steel reinforcement and even lead to spalling of surface concrete, eventually requiring renovations or replacements of many bridge decks. There are 580,000 bridges in United States and more than 180,000 bridges in them are considered deficient. ["FRP Bridge Decks with adhesively bonded connections - Martin Schollmayer"].

Due to many advantages of FRP bridge decks over reinforced concrete bridge decks, concrete bridge decks are, in a limited manner, getting replaced by FRP bridge decks. A lightweight modular FRP composite deck weighs approximately $80 \%$ less than the conventional concrete deck. This low dead load of the deck allows an increase to the allowable live load capacity of the bridge. ["Load Testing of an FRP Bridge Deck on a Truss Bridge - Sreenivas Alampalli, Jonathan Kunin (2001)’].

Some of the advantages of FRP composite decks are:

1. They are more durable, lightweight and easier to install than concrete bridge decks.

2. FRP bridge decks are more resistant to corrosion caused by deicing salts resulting in an increased service life of bridge.

3. Electromagnetic transparency.

4. Thermal insulation.

5. Capacity to carry increased live load due to the reduction in the dead load.

6. Superior fatigue performance.

For a number of years, researchers at the Constructed Facilities Center, West Virginia University (CFC-WVU) have focused on developing advanced Fiber Reinforced Polymer composites for infrastructure applications in highway structures. The research and development is driven by the fact that there is tremendous utilization of composites, 
especially in bridge construction. The CFC-WVU has even helped the West Virginia Department of Transportation (WVDOT) build or restore 24 bridges with FRP composite materials. Some of these bridges are being field monitored for in-service performance, and the FRP composite materials are found to be economical and durable. Approximately \$50 billion (USD) had been spent on highways and bridges in 1999 and $\$ 8.1$ billion in bridge projects were funded by the FWHA (Federal Highway Administration) in 2002 alone. [“Opening Doors for Composite Infrastructure (April 2004)”].

The first use of FRPs in the pedestrian bridge construction occurred in the early 1980s in USA and Canada. The first all-composite foot bridge in Europe is built in 1992 in Aberfeldy, Scotland. It is called an "all-composite" bridge because all components (pylons, cables, beams, bridge deck, and railing) are made of FRPs. Apart from the cables all components are produced by pultrusion. One all-composite bridge located in West Virginia is the Laurel Lick Bridge in Lewis County [GangaRao et.al (1999)]; that bridge was installed in the year 1997.

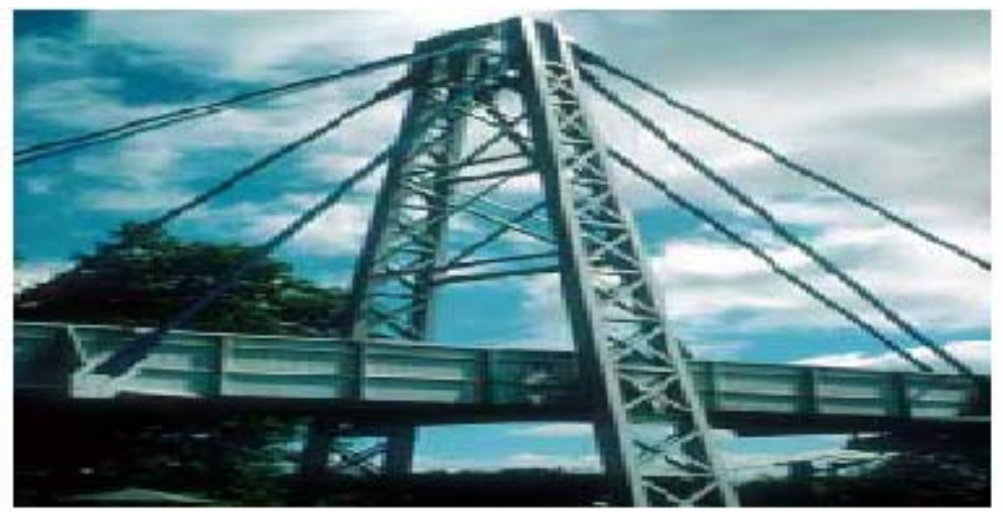

Fig. 1.1 All-Composite Foot Bridge in Kolding, Denmark. Erected in 1997 [Herbert (2004)] 
Once the relatively small sections of pedestrian bridges were made, bigger profiles and sandwich panels, which could serve as bridge deck, are developed. Some of the most common deck systems in use are shown in Fig. 1.2.

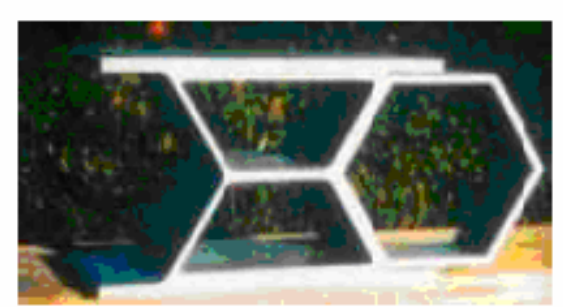

(a)

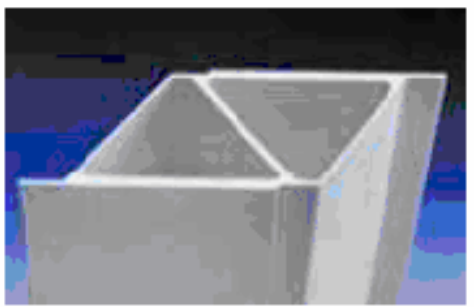

(b)

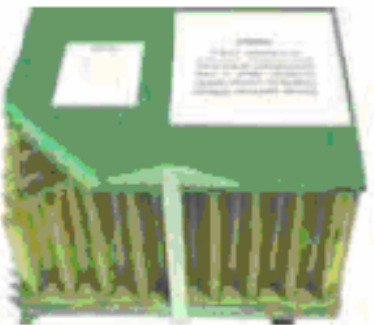

(c)

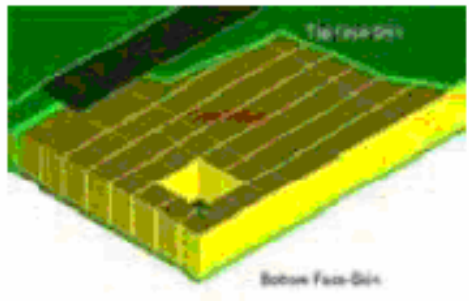

(d)

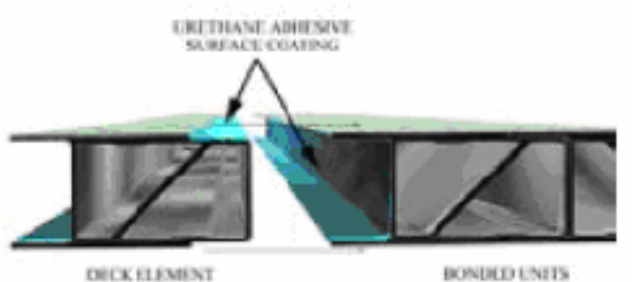

(e)

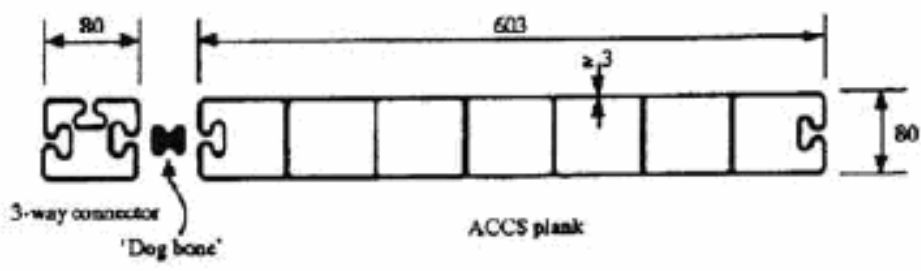

(f)

Fig. 1.2 FRP bridge decks: (a) Super deck, (b) ASSET, (c) Kansas, (d) Hardcore,

(e) DuraSpan ${ }^{\circledR}$ and (f) ACCS [Herbert (2004)]

The bridge decks shown above can be subdivided into two groups: pultruded profiles and sandwich panels.

All the pultruded bridge decks (a,b,e,f in Fig. 1.2) are made of glass fibers and polyester or vinyl ester matrices (thermoset matrices). All of the systems are based on several profiles adhesively bonded together. Pultrusion is a continuous manufacturing process used to manufacture constant cross-section shapes of any length. The fibers are 
continuously impregnated and pulled through a heated die, where they are shaped and cured. Both closed sections (e.g., box-beam) and open sections (e.g., I-beam) can be produced, but it is easier to produce closed sections. Closed sections, such as box beam, are fabricated using a mandrel cantilevered behind the entrance to the die. The pultrusion line can also be fitted with a rotating winder to apply reinforcements at an angle (usually $\pm \theta$ ) around the product. This is commonly used to fabricate pipe and drive shafts. Operational costs of this process are low and this process is ideally suited for high volume applications.

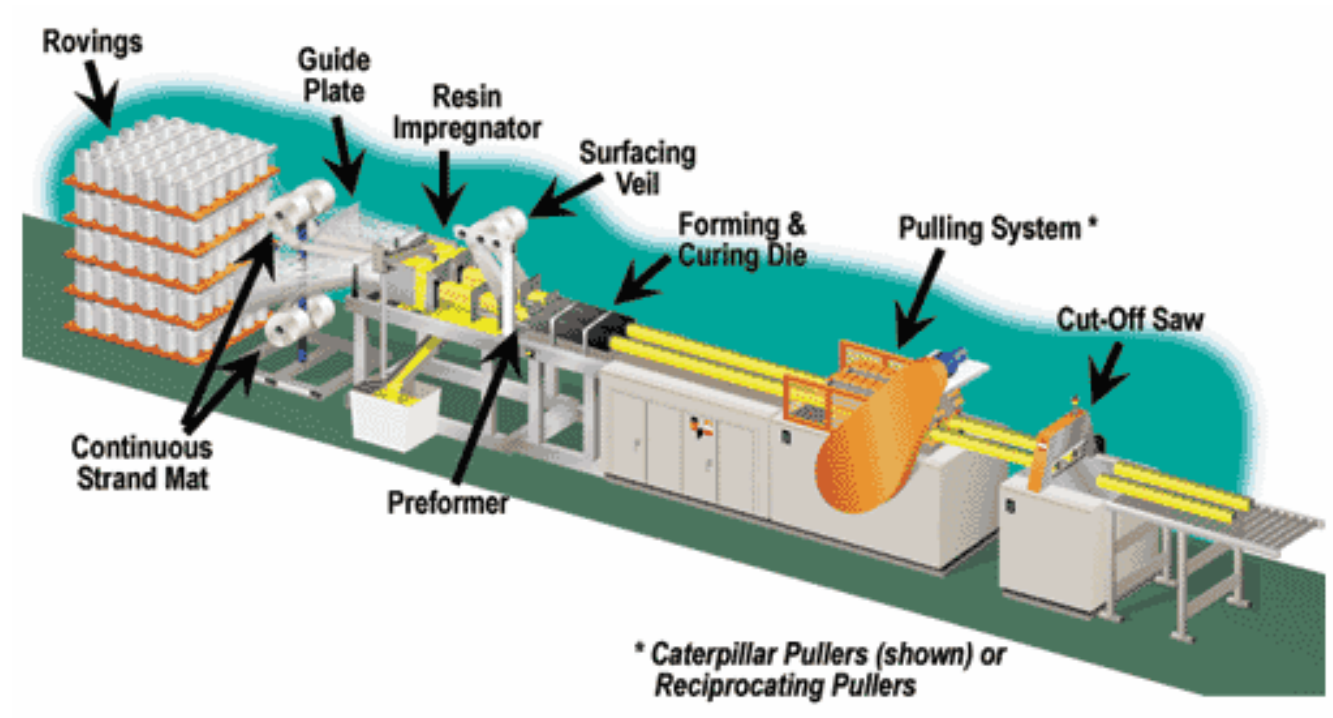

Fig. 1.3 Diagram of the pultrusion process [Herbert (2004)]

Despite having many advantages, FRP materials are not widely used in the civil infrastructural community because of lack of standardized test procedures, proper design criteria and reliable failure theory. Research and development is still being carried out in order to increase the performance and application in infrastructural community. 


\subsection{LITERATURE REVIEW}

Fiber Reinforced Polymers are relatively new materials that are used in constructions. Despite their high initial costs, they have several advantages over the conventional materials such as excellent durability, high weight strength to weight ratios and competitive life-cycle costs. Although FRP decks, hybrid systems, tendons and rebars are utilized in the bridge construction, the bridge decks have received most attention in the past few years, due to their inherent advantages in strength and stiffness per unit weight as compared to traditional steel reinforced concrete (RC) decks. FRP decks are being used in the constructions may be because of the fact that lightweight material is ideal for the rapid construction and reduction in dead load of superstructures thus increasing the load carrying capacity of the superstructure without having the girders strengthened. Research is being carried out to reduce the material cost and also to enhance the manufacturing process, design guide lines and specifications. This chapter gives a brief review of the characteristics and structural performance of FRP bridge decks both at component and system level. It is observed that very few of them have conducted finite element analyses on these decks.

Bakeri and Sunder (1990) generated structural models for two deck systems (considered system being a pultruded truss shaped deck with parabolically varying depth). The deck is 7 foot wide and had a thickness of 10.25 inches. Four variants of deck system considered are shown in Fig. 1.4. The author used finite element program ADINA to calculate stresses and deflections of the deck when subjected to HS20-44 truck loading. The results obtained indicated that the maximum deflections for all cases 
exceeded the L/100 (.105 inches) deflection index, but all the stresses are within the allowable limits for glass-reinforced plastic.

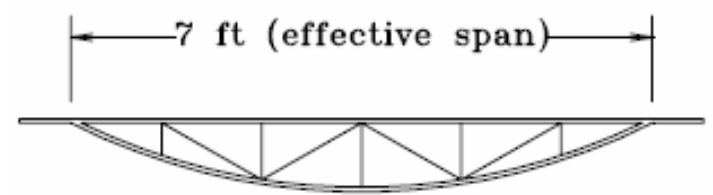

Deck 1

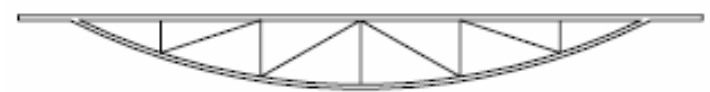

Deck 3

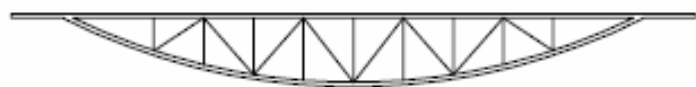

Deck 2

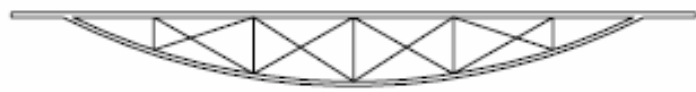

Deck 4

traffic moves "into" paper

Fig. 1.4 Cross-sections of the four FRP decks analyzed by Bakeri and Sunder

Among the few researchers who first published documents on FRP bridge decks are Plecnik and his co-workers (Ahmad and Azar) in 1991. They conducted research on the behavior of different FRP bridge deck cross-sections analytically (Fig. 1.5). Because of its lowest deflection when compared to other deck configurations Type II deck is chosen to be the best one. Later it is manufactured using a combination of filament winding and hand lay-up processes. 


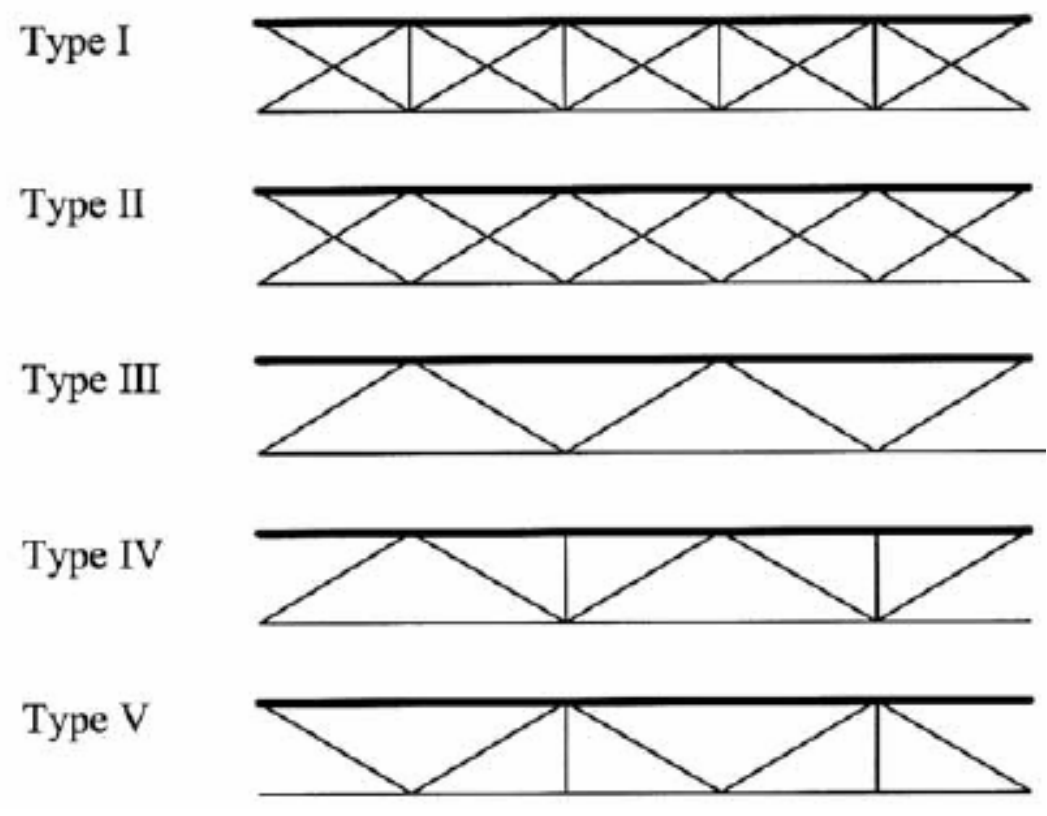

Fig. 1.5 FRP deck cross-sections investigated by Plecnik, Azar and Ahmed

Zureick (1997) conducted finite element analyses (using ANSYS and GTSTRUDL) on FRP decks with box shaped cells (Fig. 1.6). The decks considered are 8 feet long (traffic) and 11 inches thick. They are all simply supported on two stringers with a span of 40 feet. The decks are subjected to loading of one "wheel line" of an AASTHO HS20-44 truck. They had the properties of E-glass vinyl ester with fiber volume fraction of $45 \%$. He considered four different cases, where the variable parameters are fiber direction and orientation of cells. It is obvious that the design of this type of deck is always controlled by deflection. He observed that the deflections are very much lower for the two cases where the cells are aligned perpendicular to traffic. The author then used an optimization routine in ANSYS using four different cellular FRP deck models. The objective function of the optimization is the least volume (by weight) 
FRP deck. Zureick found the box-celled and the V-celled deck to be the most efficient sections.

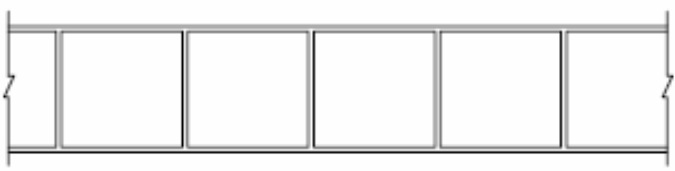

Deck 1: box-shaped cells

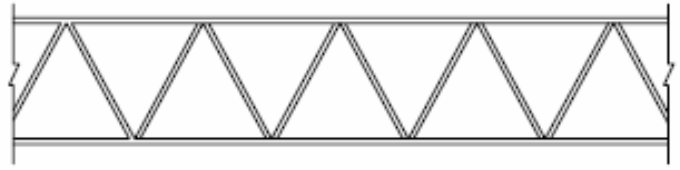

Deck 3: V-shaped cells

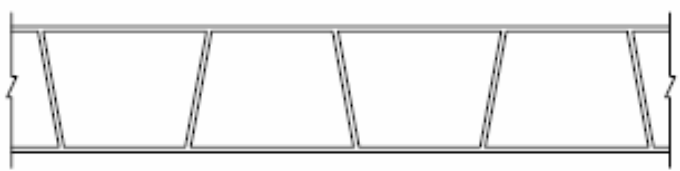

Deck 2: trapezoidal-shaped cells

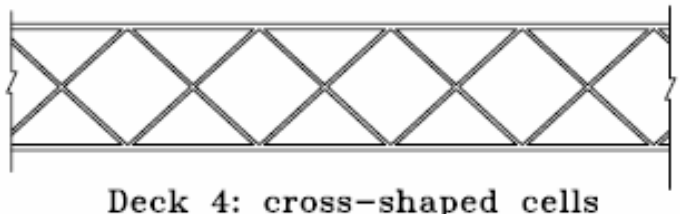

Fig. 1.6 Partial sections of the four FRP deck panels analyzed by Zureick

Zureick and Steffen (2000) in their paper provided an example of what is needed to develop these two items. One is the development of internationally accepted material specification for pultruded materials that would let users to determine material properties of interest to designers and the other is the development of a design code for pultruded structures which is incorporated into building and bridge codes such as the International Building Code and the American Association of State Highway and Transportation Officials (AASTHO) bridge code.

Shekar V. (2000) conducted experimental tests on unidirectional, 2-D and 3-D stitched fabrics at coupon level and FRP bridge decks at component level. The author found that the structural properties of composites with 3-D stitched fabrics are very much affected by its fiber architecture, stitch density, stitch material and manufacturing process. The failure modes of composite with 3-D stitched fabrics are also established. It 
is found that the composite with 3-D stitched fabrics have about 30\% 40\% strength enhancement over composite with 2-D stitched fabrics and the ultimate stress of composite with 3-D stitched fabrics is $95 \%$ more than that of conventional material (steel) (40 ksi). To compute the laminate properties at coupon level Classical Laminate Theory (CLT) is used and experimental test results has showed good correlation with the theoretical results. At component level the author found that modified fiber architecture enhanced the structural properties in second generation FRP bridge deck component. The weight of second generation FRP bridge deck component is reduced by $11 \%$ compared to first generation FRP bridge deck component. Bending stiffness value of second generation FRP bridge deck component is computed using Approximate Classical Lamination Theory (ACLT) and is almost same as that of the value of first generation FRP bridge deck component.

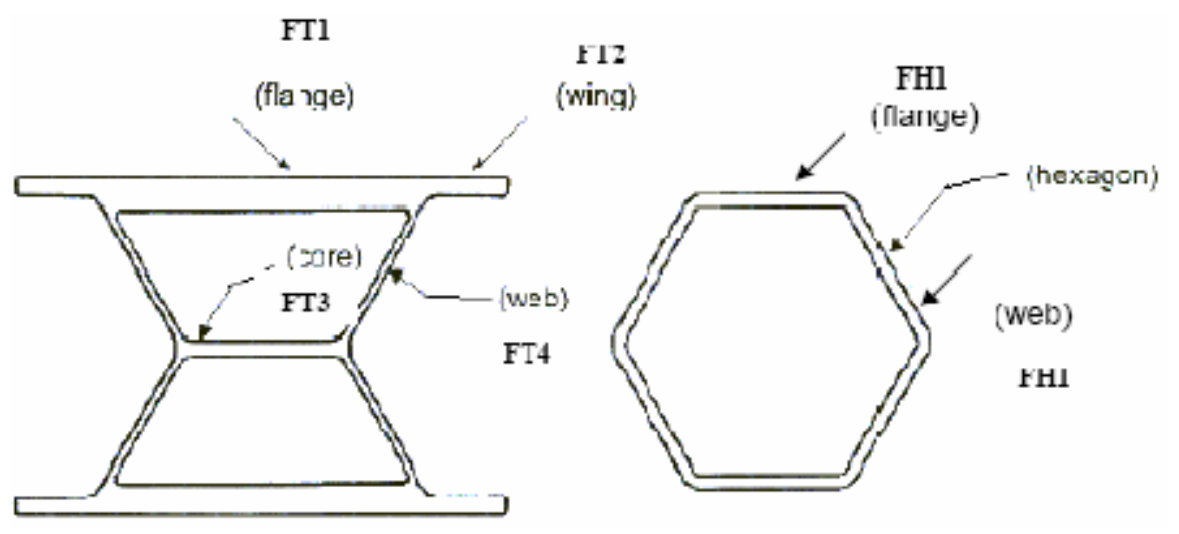

Fig. 1.7 Cross Section of First Generation FRP Bridge Deck Component 


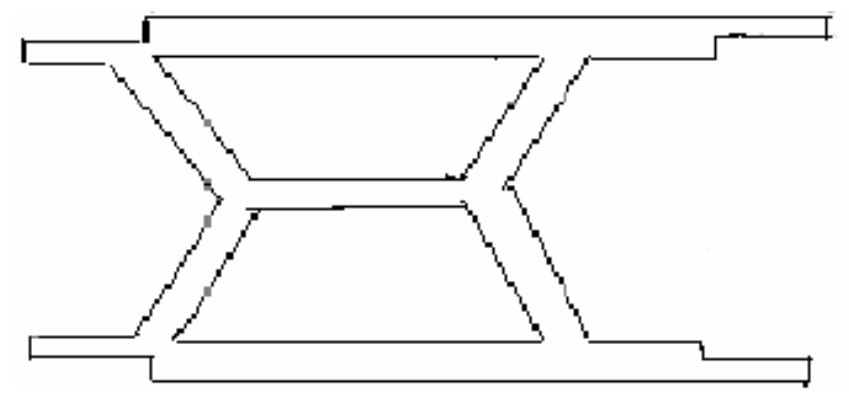

Fig. 1.8 Cross Section of Second Generation FRP Bridge Deck Component

Chadrashekara et al (2000) studied the structural behavior of all-composite bridge deck. They have conducted experiments and even performed finite element analysis on these decks. The dimensions of the FRP deck analyzed are 30'x 9' consisting of 3' square box cells with a thickness of 0.25 ”. The performance of the deck is evaluated through the experimental and analytical work conducted and the experimental results have showed a good correlation with the finite element results.

Temeles B. (2001) manufactured and tested two 7" deep FRP deck panels in a controlled service environment. The dimensions of FRP deck panels are $15^{\prime}$ by $5^{\prime}$ in plan and are composed of standard pultruded FRP tubes of ten 15 ' long, 6 " by 6 " by $3 / 8$ " in dimension. These tubes are sandwiched between two standard pultruded FRP plates which are of thickness 3/8" (Fig. 1.9). The materials used in manufacturing these decks are E-glass fibers and polyester matrix. When tested for strength the first deck panel has exhibited a safety factor with respect to legal truck loads of greater than 10 . Second deck panel when subjected to AASHTO design loads exhibited a maximum deflection of $\mathrm{L} / 470$. Second deck panel when tested in field after laboratory testing has recorded a maximum strain of approximately 600 micro strains, which is less than $15 \%$ of the ultimate tensile strain of FRP in its weakest direction. Even after it had been subjected to 
approximately 4 million load cycles over a period of 8 months, the deck showed no loss in stiffness.

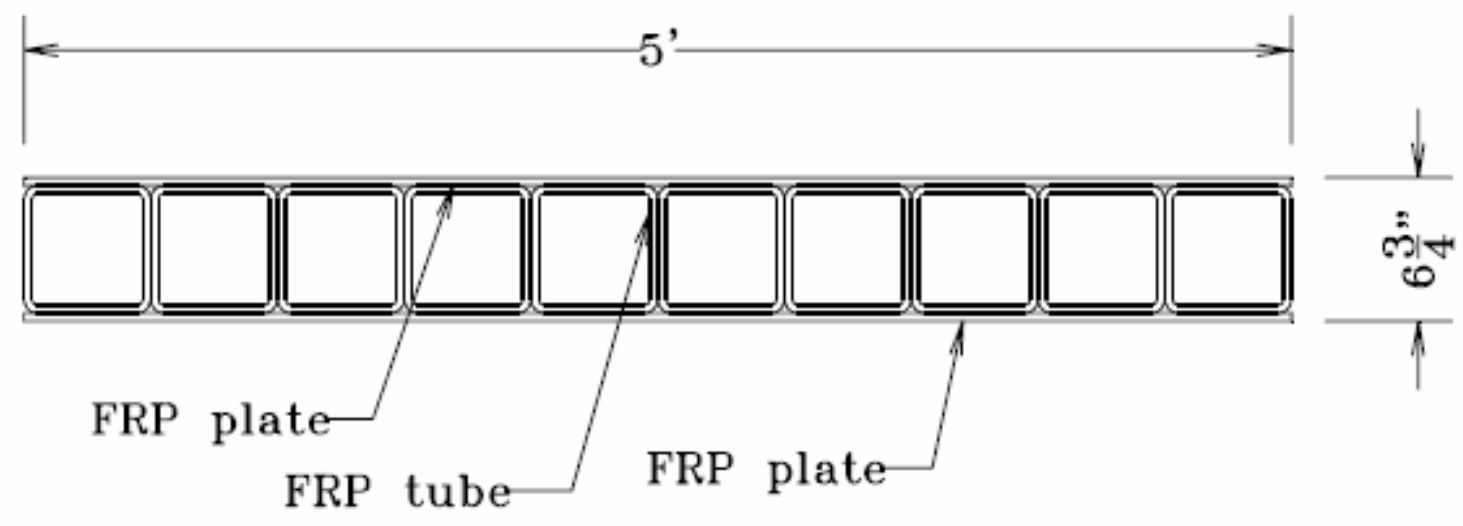

Fig. 1.9 Cross-section of FRP deck panel analyzed by Temeles

Howard (2002) developed and analyzed lightweight FRP bridge decks and determined their accuracy under AASHTO's HS25 loading case with minimum stringer spacing of five feet. Two different multicellular decks of fiber volume fraction approximately $54 \%$ are designed and tested. The average out-of-plane shear modulus $\left(\mathrm{G}_{\mathrm{yz}}\right)$ is found to be $0.53 \mathrm{e} 6 \mathrm{psi}$ which is $40 \%$ lesser than the theoretical value obtained using a combination of micro mechanics and approximate classical lamination theory. Failure of the specimens occurred in between 44-55 kips in buckling. Vinyl ester specimens have out performed the polyester specimens in buckling and their failure mode is less catastrophic. In longitudinal bending the components are loaded with 10 "x 20 " patch loads and the behavior of vinyl ester and polyester components is very similar, but when a patch load of 15 "x 24 " is applied, vinyl ester components had an ultimate stress of $18.7 \mathrm{ksi}$, which is $8 \mathrm{ksi}$ greater than the polyester component under same conditions. In 
case of transverse bending the elastic modulus $\left(\mathrm{E}_{\mathrm{y}}\right)$ is found to be approximately $1.1 \mathrm{e} 6$ psi which showed a good correlation with the theoretical value.

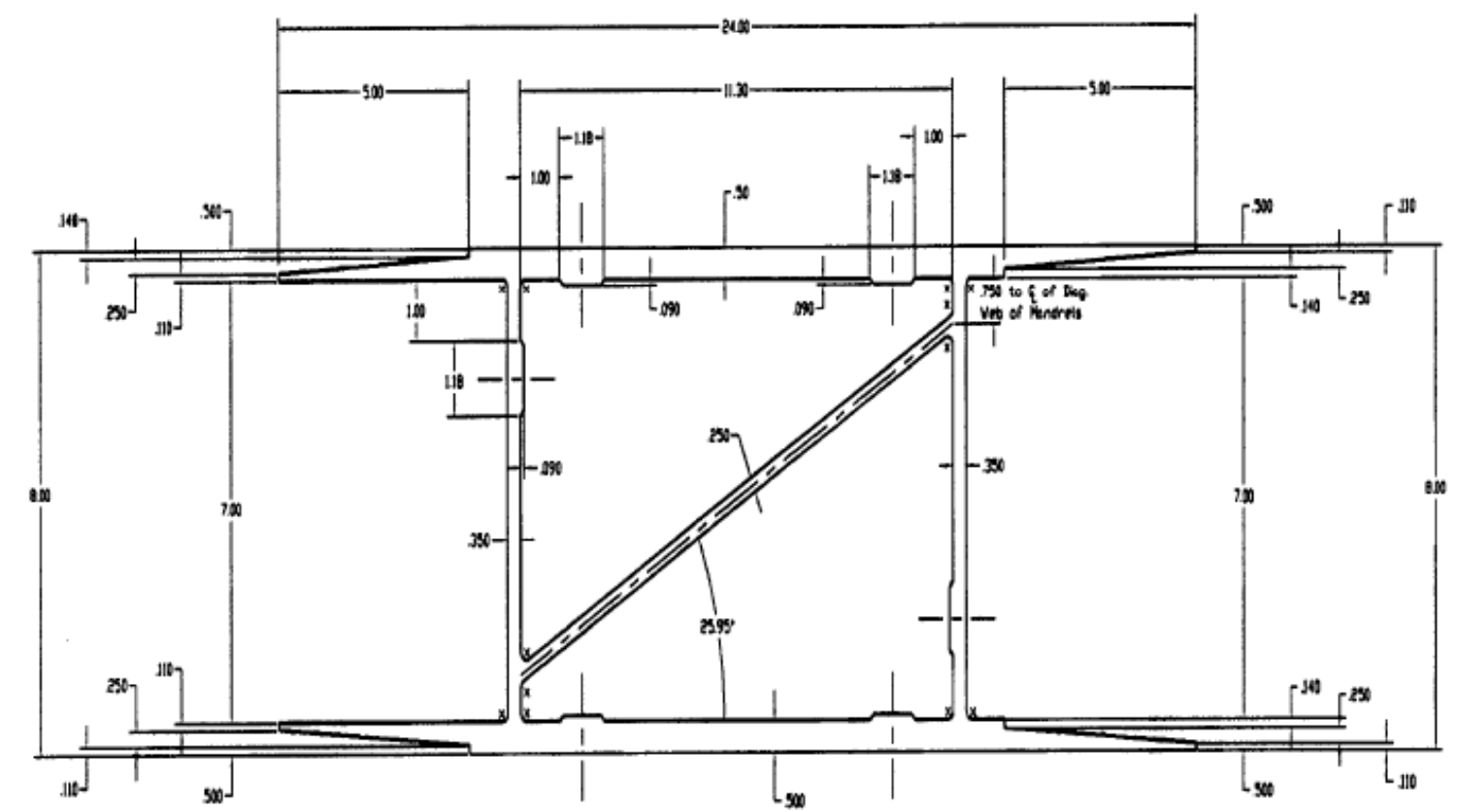

Fig. 1.10 Cross-section of polyester component analyzed by Howard

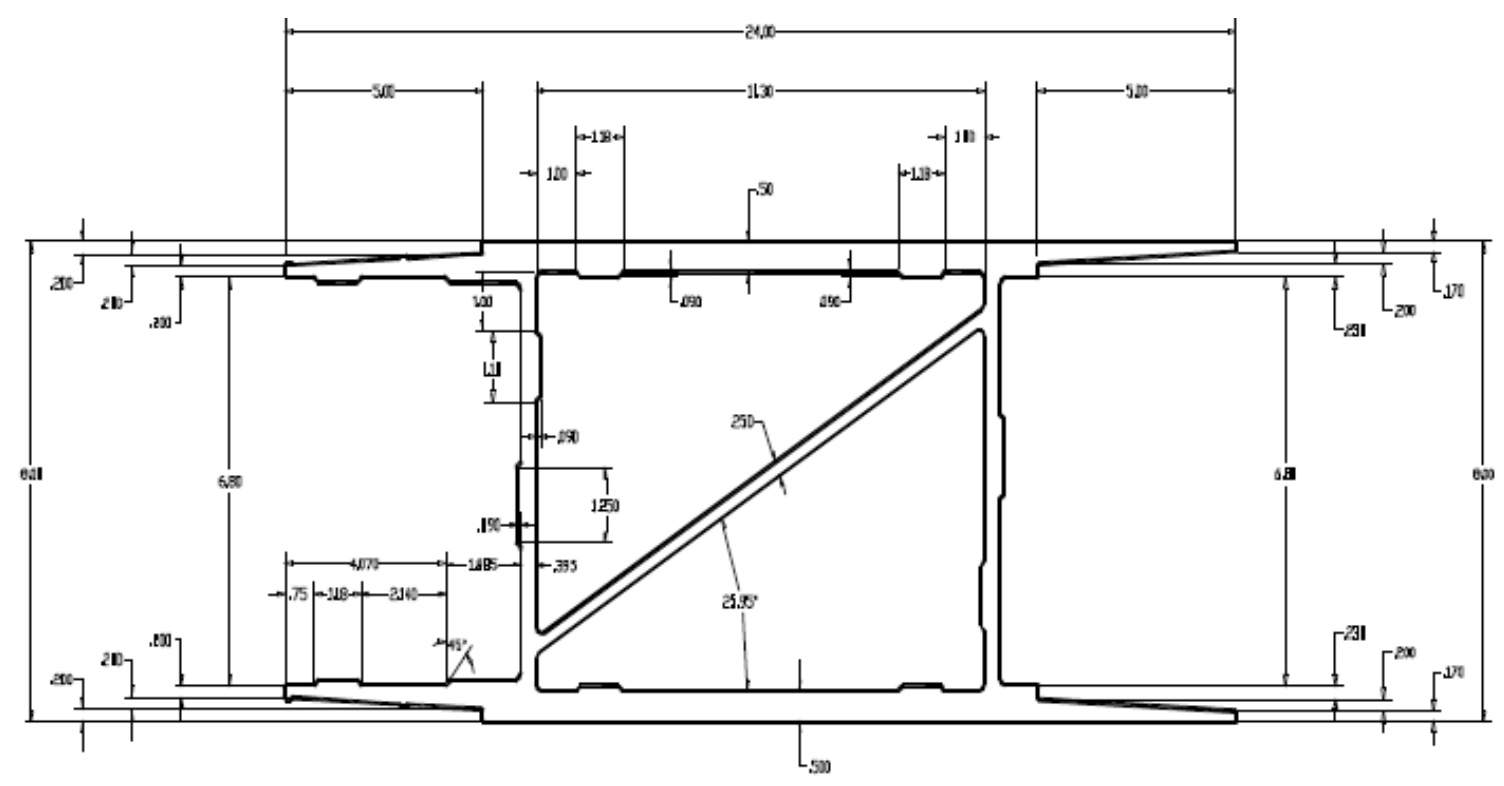

Fig. 1.11 Cross-section of vinyl Ester component analyzed by Howard 
Herbert W. (2004) has carried out experiments on two different bridge decks in order to determine the system properties for calculation of the load-bearing behavior of steel/FRP composite girders. The author has proposed a method for determining the inplane compression and shear modulus of the deck and this method can easily be applied to other bridge decks and sandwich decks as well. The above mentioned system properties are very much needed for calculation of the load behavior of steel/FRP composite girders. A design method is even developed to predict failure load of composite girders with ASSET or DuraSpan bridge decks. It is also shown that adhesive bonding is a feasible and reliable connection technique to build steel/FRP composite girders.

Punyamurthula (2004) performed static tests on multicellular shaped FRP composite deck, which can also be used as beam in FRP bridges. These decks are made of E-glass fibers and vinyl ester resin. The FRP deck has a fiber volume fraction of about 0.5 and is designed to adequately withstand AASTHO's HS25 loads. Three point bending tests are conducted on longitudinal and transverse FRP bridge deck components by applying a patch load of 10 ” 20 ". Bending stiffness and modulus of elasticity are calculated in both longitudinal and transverse directions. The stiffness values predicted using micro mechanics in conjunction with approximate classical lamination theory (ALCT) are within $20 \%$ of those obtained from experiments. Compression tests are carried out on FRP deck and web buckling stress is determined, which is found to be less then the allowable buckling stress. Longitudinal bending tests are carried out on single and double FRP beams within the elastic limit. The bending stiffness for double FRP 
beam is found to be twice as that of single FRP beam. Bending stiffness values predicted using micro mechanics in conjunction with approximate classical lamination theory (ALCT) are within $16-18 \%$ of those obtained from experiment. Two FRP bridge deck systems one riveted and the other glued are tested under static and fatigue loading. They are supported on two stringers with center-to-center spacing of 78 ". The riveted deck is fatigued for 1.5 million cycles and glued deck has failed after 495,000 cycles. The degradation of bending rigidity is around $9 \%$ for riveted deck system and around $4.6 \%$ for glued deck system.

Suraj Suraj (2005) has conducted analytical research on Prodeck 8 using ANSYS software. The analytical results obtained in the deflection analyses have showed excellent correlation with experimental results obtained by previous researcher. Even the strain values present at selected locations obtained in analytical research have showed good correlation with experimental strain results at selected locations. The equivalent flexural rigidity value when corrected for shear effects is nearly identical to the experimental value obtained. The equivalent flexural rigidity and Young's modulus values of Prodeck 8 based on strain values corresponding to the transverse load case are found to be $1.26\left(10^{9}\right) \mathrm{lb} \mathrm{x}^{2} \mathrm{in}^{2}$ and $4.21\left(10^{6}\right)$ psi respectively. Failure analysis is carried out and first ply failure was determined using maximum strain, maximum stress and Tsai-Wu criteria. Buckling analyses of Prodeck 8 is carried out and the critical load for buckling is found to be 183 kips which is very high compared to the experimentally determined critical load of 45 kips. In buckling analysis of web section the critical load obtained is 33 kips. 


\subsection{NEED FOR CURRENT RESEARCH}

This chapter has given a brief summary of the kind of research work that has been carried out on FRP bridge decks. From the above published work it is obviously clear that Prodeck 4 used for the bridge deck application has been checked experimentally. But since the structural analysis of Prodeck 4 has not yet been carried out using finite element model, the current study intends to fulfill this need for a numerical modeling and analysis of the Prodeck 4. This research mainly focuses on developing a finite element model of Prodeck 4 and the analytical results thus obtained are then compared to the existing experimental results of Prodeck 4.

\subsection{OBJECTIVES}

- To develop a composite bridge deck (Prodeck 4) using ANSYS software.

- To determine the equivalent flexural rigidity and Modulus of Elasticity (Young's modulus) of the deck.

- To develop finite element models of Single and Double FRP beams subjected to three point bending.

- To determine the bending stiffness and Young's modulus of both Single and Double FRP beams.

- To evaluate structural properties (stiffness and strength) of two-module FRP bridge deck this is glued at the center, under static loading (three point bending).

- To develop a finite element model of a two-module FRP bridge deck subjected to three point bending. 
- To Analytically determine the bending stiffness and Young's modulus of twomodule FRP bridge deck and compare that to experimental test results.

- To carry out failure analysis and determine first ply failure.

- To perform buckling analysis and determine the critical load.

\subsection{SCOPE}

- Chapter 2 gives a detail description of composite bridge deck (Prodeck 4) that is being analyzed.

- Chapter 3 shows the finite element model of Prodeck 4 that is generated, the type of element that is used in model generation and the loading conditions. It even shows the results obtained and its comparison with existing experimental results and the discussion of the results.

- Chapter 4 shows the finite element model of Single FRP beam, its loading conditions, results and comparison of those with existing experimental results.

- Chapter 5 presents the finite element model of double FRP beam, its loading conditions, results and their comparison with experimental results.

- Chapter 6 deals with structural performance of two modules FRP bridge deck. The bending stiffness and Young's modulus of the deck are evaluated in this chapter. This chapter also deals with the finite element model of two module FRP deck, its results and comparison of those with the obtained experimental results.

- Chapter 7 presents some conclusions of this research and recommends future work. 


\section{CHAPTER 2}

\section{DESCRIPTION OF PRODECK 4}

The multi-cellular shaped low-profile FRP bridge deck being described in this chapter is called Prodeck 4. It is made of E-glass fiber and Vinyl ester resin. Figure. 2.2 displays the cross section of the multi-cellular shaped FRP deck component used in experimental testing. Figure 2.3 displays the cross section of multi-cellular shaped low profile deck used for the finite element model in the current study. The multi-cellular deck in Fig. 2.2 has dimensions of 4" in height and 29" in width. The thicknesses of bottom and top flanges are 0.430 " each while that of the web is 0.375 ". The top and bottom flanges of the low-profile FRP bridge deck component are made of 24 layers each and web is made of 20 layers of $0^{\circ}$ fibers, $90^{\circ}$ fibers, $\pm 45^{\circ}$ fibers, continuous strand mat (CSM) and 56 Yield Rovings (4 per inch). The fibers continue from flange to the web and then again to the flange. The low-profile FRP deck has fiber volume fraction of approximately 0.5 and weighs about $10 \mathrm{lb} / \mathrm{ft}^{2}$.

The material properties of Prodeck 4 obtained from manufacturer are as follows:

Modulus of elasticity of fiber $\left(E_{f}\right)=10.5 \times 10^{6} \mathrm{psi}$

Modulus of elasticity of matrix $\left(E_{m}\right)=4.9 \times 10^{5} \mathrm{psi}$

Shear modulus of fiber $\left(G_{f}\right)=4.30 \times 10^{6} \mathrm{psi}$

Shear modulus of matrix $\left(G_{m}\right)=1.8 \times 10^{5} \mathrm{psi}$

Poisson's ratio of fiber $\left(v_{f}\right)=0.22$

Poisson's ratio of matrix $\left(v_{m}\right)=0.38$ 


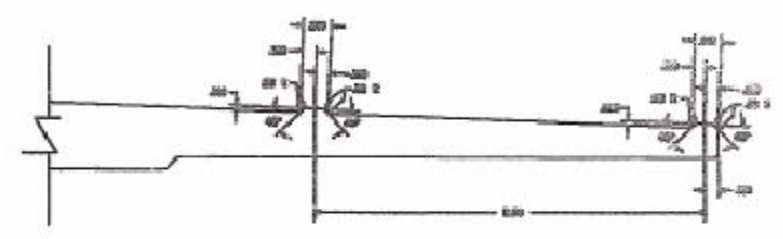

GLUE JINT DETAIL
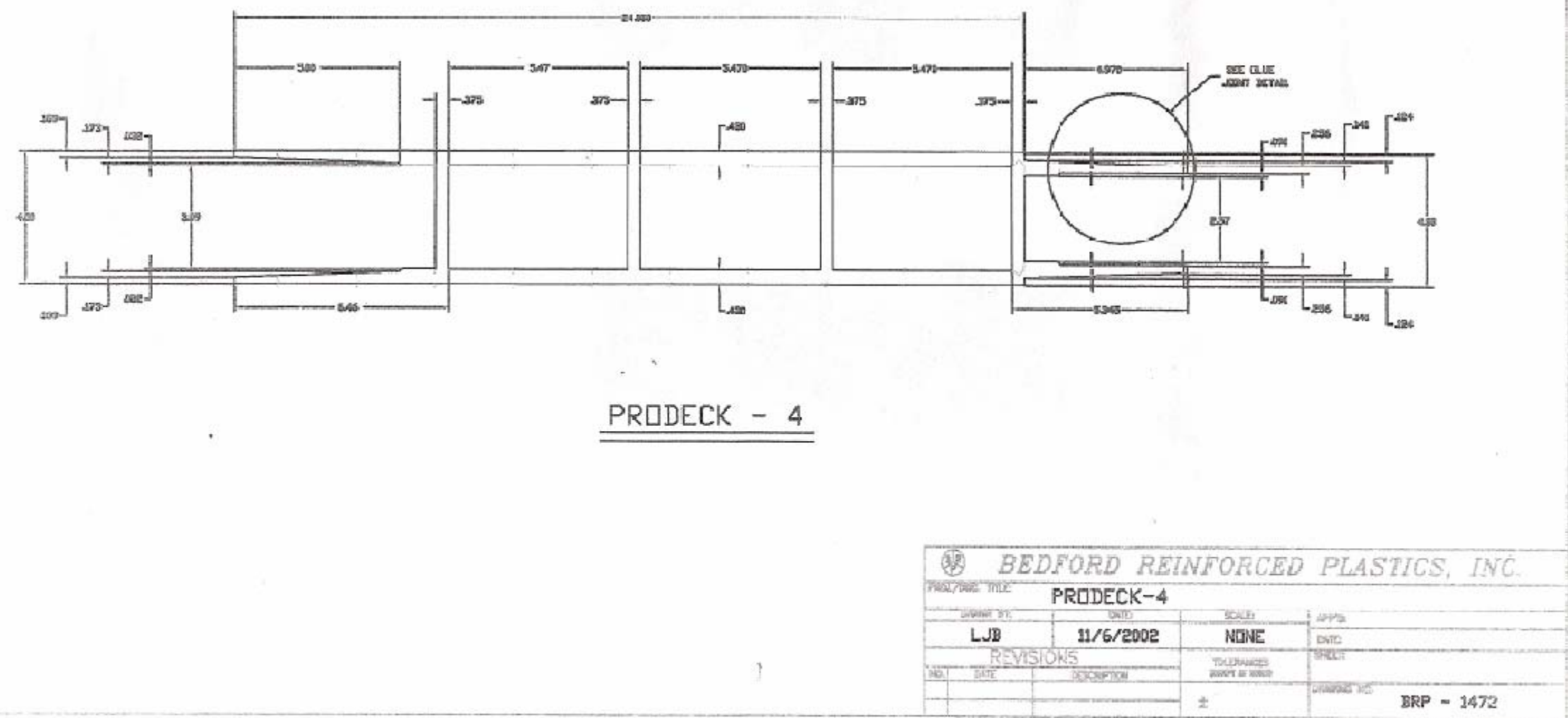

Fig. 2.1 Cross-section of low profile FRP bridge deck component 


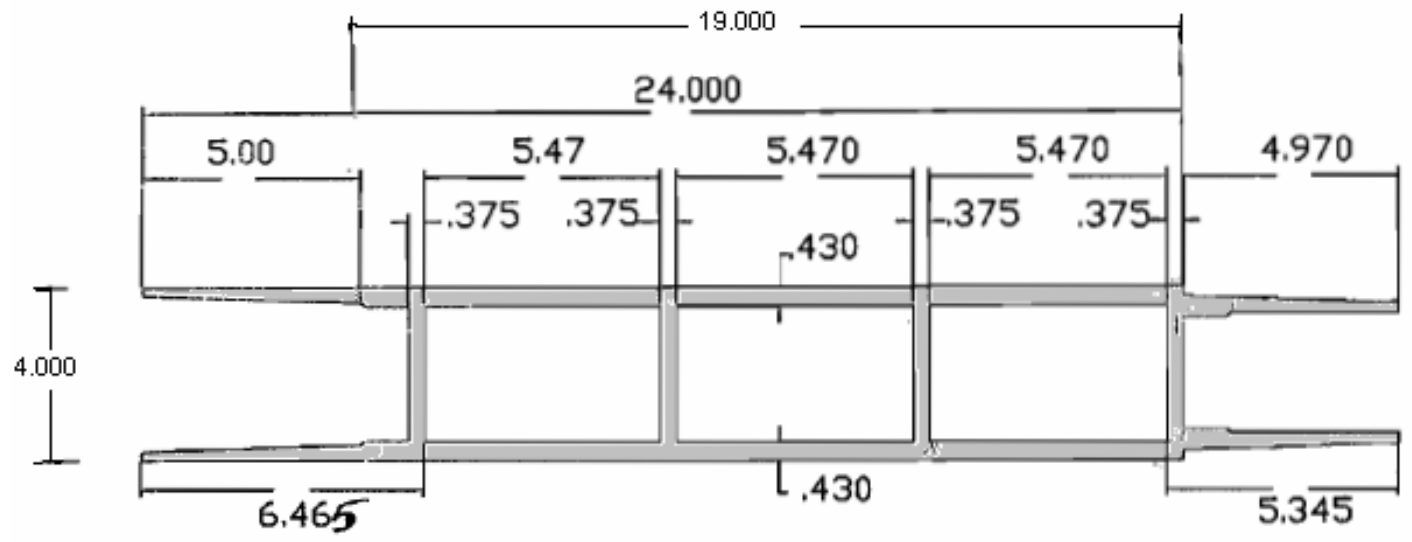

FRP Deck

All Dimensions are in Inches

Fig. 2.2 Cross-section of Prodeck 4 used in experimental testing

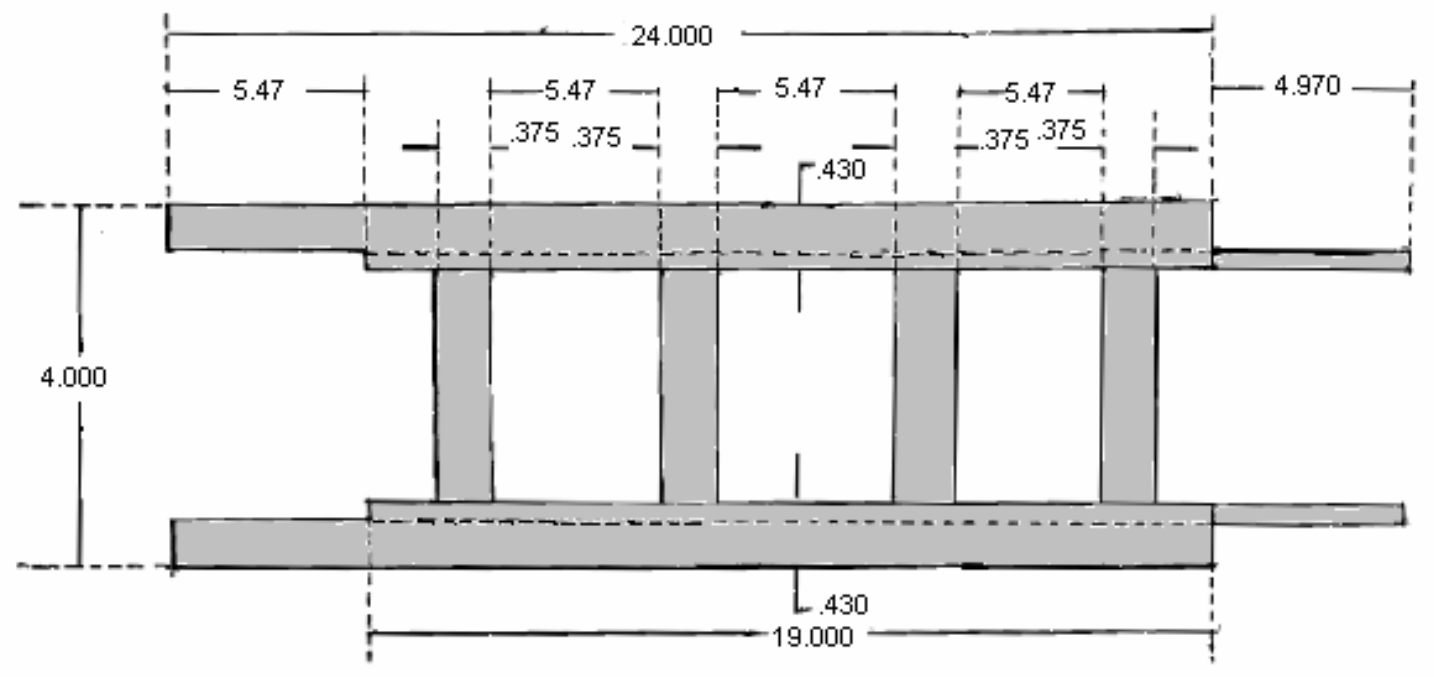

Fig. 2.3 Cross-section of the finite element model generated 


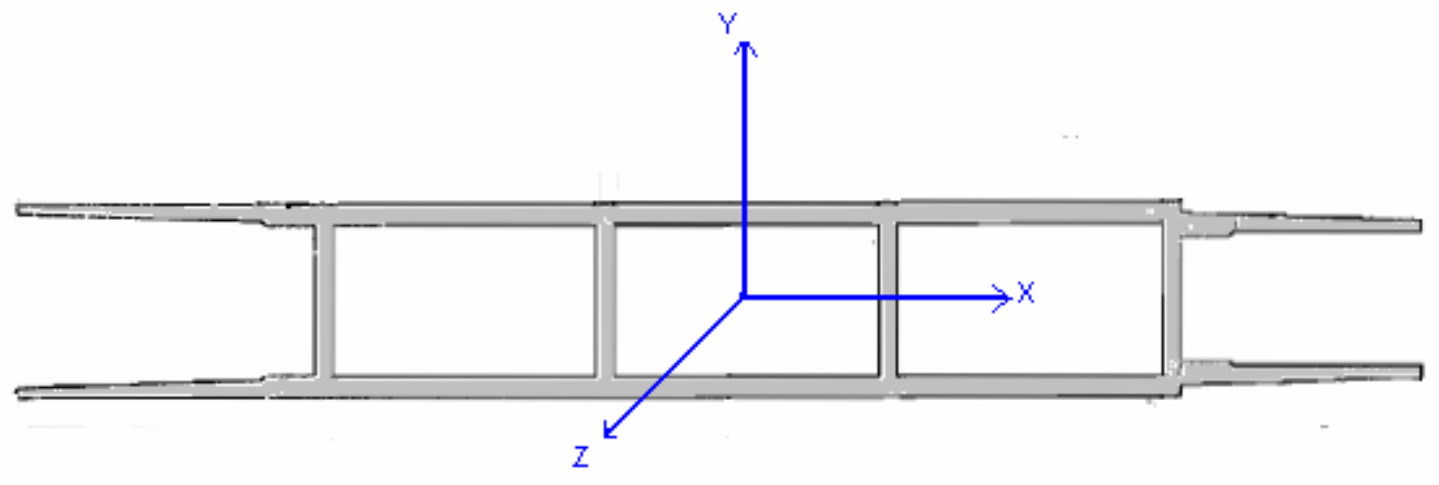

Fig. 2.4 Orientation of global coordinate system

The global coordinate system for Prodeck 4 is oriented as shown in the Fig. 2.4. The traffic moves in the direction along the $\mathrm{X}$-axis of the global coordinate system where as the $0^{0}$ fibers run in direction perpendicular to the direction of the traffic movement. 


\section{PRO DECK 4 \\ MATERIAL CONSTRUCTION MIDDLE SECTION prop. 5}
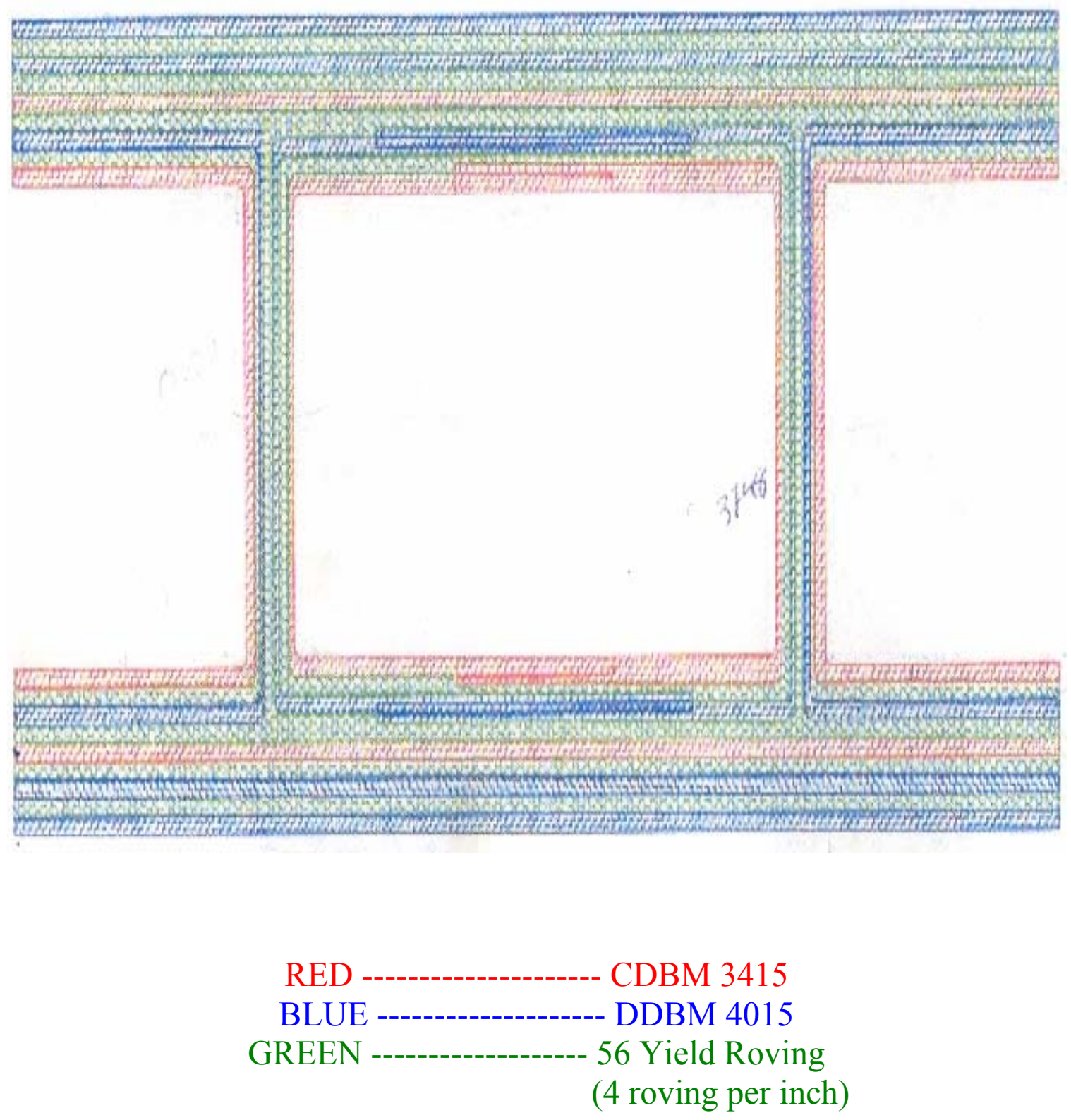

Fig. 2.5 Fiber architecture of Vinyl ester component 
The detailed description of CDBM3415 and DDBM4015 fabrics comprising of $0^{0}$ fibers, $\pm 45^{0}$ fibers and mat (CSM) are given below in the Tables 2.1 and 2.2 respectively.

Table 2.1 CDBM3415 fabric specifications

\begin{tabular}{|c|c|c|c|c|}
\hline Fiber type & $\begin{array}{c}\text { Nominal Wt. } \\
\left(\mathbf{o z} / \mathbf{y d}^{\mathbf{2}}\right)\end{array}$ & $\begin{array}{c}\text { Thickness } \\
\text { (in) }\end{array}$ & $\begin{array}{c}\mathbf{W}_{\mathbf{f}} \\
\mathbf{( I b )}\end{array}$ & $\begin{array}{c}\mathbf{L}_{\mathbf{v}} \\
\mathbf{( i n}^{\mathbf{3}} \mathbf{)}\end{array}$ \\
\hline $0^{0}$ fibers & 15.71 & 0.01610 & 0.109 & 2.31914 \\
\hline$+45^{0}$ fibers & 9.04 & 0.009308 & 0.063 & 1.34042 \\
\hline$-45^{0}$ fibers & 9.04 & 0.009308 & 0.063 & 1.34042 \\
\hline Mat (CSM) & 13.5 & 0.013851 & 0.09375 & 1.99468 \\
\hline Total & 47.29 & 0.048567 & 0.32875 & 6.99466 \\
\hline
\end{tabular}

Table 2.2 DDBM4015 fabric specifications

\begin{tabular}{|c|c|c|c|c|}
\hline Fiber type & $\begin{array}{c}\text { Nominal Wt. } \\
\left(\mathbf{o z} / \mathbf{y d} \mathbf{2}^{\mathbf{2}}\right.\end{array}$ & $\begin{array}{c}\text { Thickness } \\
\text { (in) }\end{array}$ & $\begin{array}{c}\mathbf{W}_{\mathbf{f}} \\
\mathbf{( I b )}\end{array}$ & $\begin{array}{c}\mathbf{L}_{\mathbf{v}} \\
\mathbf{( i n}^{\mathbf{3}} \mathbf{)}\end{array}$ \\
\hline$+45^{0}$ & 11.44 & 0.011731 & 0.0794 & 1.68936 \\
\hline $90^{0}$ & 17.28 & 0.017730 & 0.12 & 2.55319 \\
\hline$-45^{0}$ & 11.44 & 0.011731 & 0.0794 & 1.68936 \\
\hline Mat (CSM) & 13.5 & 0.013844 & 0.0937 & 1.99361 \\
\hline Total & 53.66 & 0.055036 & 0.3725 & 7.92552 \\
\hline
\end{tabular}

Where, $\mathrm{W}_{\mathrm{f}}=$ Weight of CSM/fabric per square foot $(\mathrm{lb}) / \mathrm{ft}^{2}$.

$$
\left.\mathrm{L}_{v}=\text { Volume of 1'x 1' composite laminate (in }{ }^{3}\right) \text {. }
$$

And the thickness of rovings (Green layer) is calculated to be approximately 0.04 ". 


\section{CHAPTER 3}

\section{FINITE ELEMENT ANALYSIS}

\subsection{INTRODUCTION}

The development of finite element model generation of the low-profile multicellular deck is described in this chapter. The description is in the form of explanations about the type of element used, boundary conditions applied, computation of lamina properties using a micro-mechanics approach and the failure analysis on Prodeck 4 using different failure criteria in finite element software ANSYS. One of the most important steps in a finite element model generation is the choosing of the type of element suitable for the model based on the application, type of results, etc.

\subsection{TYPE OF ELEMENT}

The common types of elements used in the modeling of composite structures are solid and shell elements. At first the two elements that have been considered for modeling the bridge deck are SHELL99 and SOLID46. The SHELL99 is an 8-node, 3-D shell element with six degrees of freedom at each node. Since SHELL99 element is designed to model thin and moderately thick plate and shell structures with a side-tothickness ratio of roughly 10 or greater as compared to SOLID46 element, which is designed to be used in structures with complex shapes and smaller side-to-thickness ratios (ANSYS Documentation Preview, 13.2. Modeling Composites), SOLID46 element 
is preferred over SHELL99 in modeling of layered composite bridge deck. Moreover SOLID46 element simulates the web-flange connectivity very well in Prodeck 4.

\subsubsection{Description of SOLID46 Element}

The SOLID46 element is a 3-D solid, 8-noded layered element with three degrees of freedom at each node (UX, UY, UZ), i.e., translations in the nodal $X, Y$ and $Z$ directions, respectively. This element is designed to model thick layered shells or layered solids and allows up to 250 uniform-thickness layers per element. As shown in Fig. 3.1 SOLID46 element is defined by eight nodes, layer thicknesses, layer material direction angles and orthotropic material properties. Every element has a default element or local coordinate system orientation associated with it. In the case of SOLID46 element, the default element $x$-axis is the projection of side $I-J$, side $M-N$, or their average onto to the reference plane and $z$-axis is along layer thickness direction as displayed in Fig. 3.1.

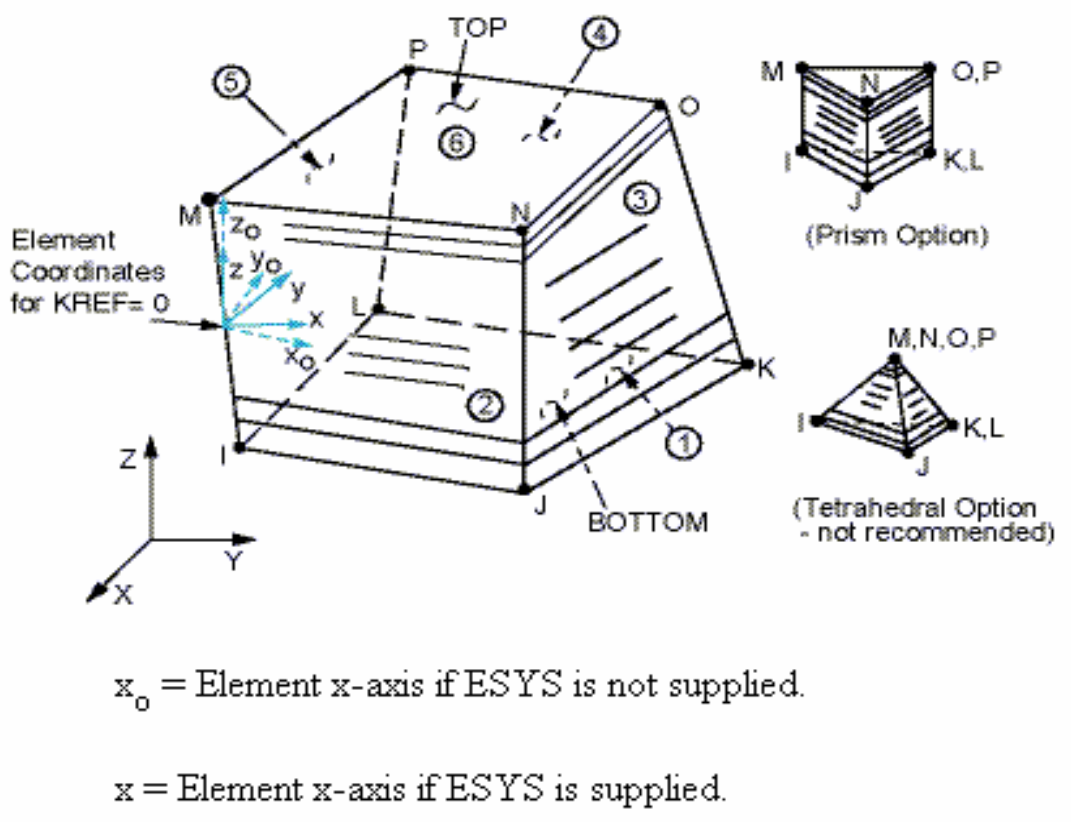

Fig. 3.1 SOLID46 Geometry [ANSYS Element Reference Manual] 
The orientation of the element coordinate system can be changed for area and volume elements by making it parallel to a previously defined local system after meshing. For SOLID46 element the input of material properties may be either in matrix form or layer form. For matrix form, the matrices must be computed outside of ANSYS. Thermal strains, most stresses and even the failure criteria are not available with matrix input [ANSYS Documentation Preview, Element Library].

Unlike isotropic materials that require only Young's modulus and Poisson's ratio to be defined, SOLID46 element used for orthotropic material requires various material properties to be defined.

Material properties that need to be given as input are:

- $\mathrm{E}_{1}, \mathrm{E}_{2}$ and $\mathrm{E}_{3}$ (Modulus of Elasticity in the $x, y$ and $z$ directions respectively).

- $\mathrm{PR}_{12}, \mathrm{PR}_{23}$ and $\mathrm{PR}_{13}$ (Poisson's ratio in the $x y, y z$ and $x z$ directions respectively).

- $\mathrm{G}_{12}, \mathrm{G}_{23}$ and $\mathrm{G}_{13}$ (Shear modulus in the $x y, y z$ and $x z$ directions respectively).

- THETA (Angle between the fiber orientation of the layer and $x$-axis of the element coordinate system in degrees).

- THK (Thickness of the layer in the positive $z$ direction).

\subsection{MATERIAL PROPERTIES}

The material properties of the layer are calculated using micromechanics formulas. In general, micromechanics is defined as the study of composite materials taking into account the interaction of the constituent materials in detail. It can be used to 
predict stiffness and strength of the composite materials. Properties of the composite ply are controlled by the fiber volume fraction $\left(V_{f}\right)$ of the material. [Barbero, (1998)].

\subsubsection{Fiber Volume Fraction}

The Fiber volume fraction $\left(V_{f}\right)$ of a composite ply is defined as the ratio of volume of the fiber to the total volume of the composite. The deck that is being considered here comprises of fabrics, continuous strand mat (CSM) and rovings. A strand is an untwisted bundle of continuous filaments (fibers) used as a unit, mat is formed by randomly oriented chopped filaments (chopped strand mat), short fibers, or swirled filaments (continuous strand mat, CSM) loosely held together with a very small amount of adhesive (binder) and roving is a collection of parallel continuous strands. [Barbero, (1998)].

The Fiber volume fractions for fabrics, rovings and CSM are calculated using the formulas given below:

For Continuous Strand Mat (CSM) and Fabric

$$
V_{f}=\frac{W_{f}}{\rho_{f} L_{v}}
$$

where,

$W_{f}=$ Weight of CSM/ fabric per square foot (lb)

$L_{v}=$ Volume of 1'x 1' ply of composite lamina (in. ${ }^{3}$ )

$\rho_{f}=$ Density of CSM or fabric (lb/ in. $\left.{ }^{3}\right)$ 
For Rovings

$$
V_{f}=\frac{n \pi D^{2}}{4 b t}
$$

where,

$n=$ Number of bundles

$b=$ Width of lamina (in.)

$t=$ Thickness of composite layer (in.)

$D=$ Diameter of fiber $=\sqrt{\frac{1}{\rho_{f} Y 9 \pi}}$

$\rho_{f}=$ Density of fiber $\left(\mathrm{lb} / \mathrm{in}^{3}\right)$

$Y=\mathrm{Yield}(\mathrm{yd} / \mathrm{lb})$

After finding the values of $V_{f}$ for the fabric, CSM and roving by using the above formulas, the properties of lamina are calculated as shown in the following section.

\subsubsection{Lamina Properties}

Some of the properties such as Modulus of elasticity $(E)$, Shear modulus $(G)$, and Poisson's ratio $(v)$ of the E-glass fiber and Vinyl ester matrix are provided by the manufacturer. These values are further required for the calculation of lamina properties.

The properties provided by the manufacturer are as follows:

Modulus of elasticity of fiber $\left(E_{f}\right)=10.5 \times 10^{6} \mathrm{psi}$

Modulus of elasticity of matrix $\left(E_{m}\right)=4.9 \times 10^{5} \mathrm{psi}$

Shear modulus of fiber $\left(G_{f}\right)=4.30 \times 10^{6} \mathrm{psi}$

Shear modulus of matrix $\left(G_{m}\right)=1.8 \times 10^{5} \mathrm{psi}$

From the above displayed properties Poisson's ratio can be calculated as 


$$
\begin{array}{ll}
\text { Poisson's ratio of fiber: } & v_{f}=\frac{E_{f}}{2 G_{f}}-1 \\
\text { Poisson's ratio of matrix: } & v_{m}=\frac{E_{m}}{2 G_{m}}-1
\end{array}
$$

The results obtained are $v_{f}=0.22$ and $v_{m}=0.38$.

\section{Computation of lamina properties}

\section{For fabric and rovings}

- Longitudinal Modulus:

The longitudinal modulus $\left(E_{1}\right)$ or modulus of elasticity in the fiber direction can be obtained by rule of mixtures (ROM) formula. The important assumption in this formulation is that the strains in the direction of the fibers are the same in the matrix and fiber, which signifies that the fiber and matrix bond is perfect. The R.O.M. formula for $E_{1}$ is

$$
E_{1}=E_{f} V_{f}+E_{m}\left(1-V_{f}\right)
$$

- Transverse Modulus:

The transverse modulus $\left(E_{2}\right)$ is the modulus in the direction transverse to the fibers. The main assumption in this formulation is that the stress is the same in the fiber and the matrix. This assumption is required to maintain equilibrium in the transverse direction. The resulting formula for $E_{2}$ is

$$
E_{2}=\frac{E_{f} E_{m}}{E_{f}\left(1-V_{f}\right)+E_{m} V_{f}}
$$


The above equation is known as inverse ROM. It is generally said that $E_{2}$ is a matrix dominated property. The inverse ROM equation does not predict accurately and so it is mostly used for qualitative evaluation of different candidate materials but not for design calculations.

The semiempirical Halpin-Tsai formula [Barbero, (1998)] given below gives a better prediction.

$$
E_{2}=E_{m}\left[\frac{1+\zeta \eta V_{f}}{1-\eta V_{f}}\right]
$$

where,

$$
\eta=\frac{\left(E_{f} / E_{m}\right)-1}{\left(E_{f} / E_{m}\right)+\zeta}
$$

And $\zeta$ is an empirical parameter obtained by curve fitting.

- Inplane Poisson's Ratio:

In general Poisson's ratio is defined as negative ratio of the resulting transverse strain to the applied strain.

$$
v_{i j}=-\frac{\varepsilon_{j}}{\varepsilon_{i}}
$$

The ROM equation for the inplane Poisson ratio derived from the mechanics of materials approach is given by

$$
v_{12}=v_{f} V_{f}+v_{m}\left(1-V_{f}\right)
$$

Then the minor Poisson's ratio $\left(v_{21}\right)$ is obtained from the formula

$$
v_{21}=\frac{v_{12} E_{2}}{E_{1}}
$$


- Inplane Shear Modulus:

The inplane shear modulus $\left(G_{12}\right)$ is also predicted by the inverse ROM equation:

$$
G_{12}=\frac{G_{f} G_{m}}{G_{f} V_{m}+V_{f} G_{m}}
$$

Even in this case, the inverse ROM gives a simple but inaccurate equation for the prediction of the inplane shear modulus.

- Interlaminar Shear Modulus:

The interlaminar shear modulus $\left(G_{23}\right)$ can be calculated with the semiempirical stress-partitioning parameter (SPP) technique:

$$
G_{23}=G_{m} \frac{V_{f}+\eta_{23}\left(1-V_{f}\right)}{\eta_{23}\left(1-V_{f}\right)+V_{f} G_{m} / G_{f}}
$$

where $\eta_{23}$ is given by

$$
\eta_{23}=\frac{3-4 v_{m}+G_{m} / G_{f}}{4\left(1-v_{m}\right)}
$$

The periodic microstructure model (PMM) gives better prediction than other formulas for all $E_{1}, E_{2}, G_{12}, G_{23}$ and $v_{12}$. Since the PMM method is complex [Barbero, (1998)] the details are not shown here.

\section{For Continuous Strand Mat}

Continuous strand mat (CSM) is a fiber system that contains randomly placed continuous rovings held together by a binder. The CSM is used to obtain bidirectional properties on pultruded composites where unidirectional rovings constitute the main reinforcement. The elastic properties of CSM can be predicted assuming that they are 
random composites. A layer of composite with randomly oriented fibers can be idealized as a laminate with large number of thin unidirectional layers, each with a different orientation from $0^{0}$ to $180^{\circ}$. The properties of the random composite are the average properties of this fictitious laminate.

The elastic modulus for CSM $\left(E_{c s m}\right)$ is given by

$$
E_{c s m}=\frac{3}{8} E_{1}+\frac{5}{8} E_{2}
$$

The shear modulus for CSM $\left(G_{c s m}\right)$ is given by

$$
G_{c s m}=\frac{1}{8} E_{1}+\frac{1}{4} E_{2}
$$

Poisson's ratio for CSM $\left(v_{c s m}\right)$ is given by

$$
v_{c s m}=\frac{E_{c s m}}{2 G_{c s m}}-1
$$

Where $E_{1}$ and $E_{2}$ are the longitudinal and transverse moduli of a fictitious unidirectional layer having the same fiber volume fraction as that of the CSM layer. One of the important things to be noted is that continuous strand mat is assumed to behave in an isotropic manner and so only one modulus value is required.

\subsubsection{Material Specifications of the Laminas used in Prodeck 4}

The Prodeck 4 consists of three layers namely CDBM3415, DDBM4015 and 56 Yield Rovings (4 roving per inch).

Both CDBM3415 and DDBM4015 layers are made of a set of 4 sub-layers each with different fiber configurations and orientations. This set of sub-layers has Mat included in it. The material properties for each layer are calculated using the 
micromechanics equations mentioned in the previous sections. These properties obtained are given as input to the ANSYS software for developing the finite element model of Prodeck 4. The CADEC software [Barbero, (1998)] is used to calculate some of these material properties. The properties of the lamina for Prodeck 4 that are calculated are displayed in the table below.

Table 3.1 Layer properties of fibers and roving with fiber volume fraction of 0.5

\begin{tabular}{|c|c|c|c|c|c|c|c|}
\hline Fiber type & $V_{f}$ & $E_{1}(\mathbf{m s i})$ & $E_{2}(\mathbf{m s i})$ & $v_{12}$ & $v_{23}$ & $G_{12}(\mathbf{m s i})$ & $G_{23}(\mathbf{m s i})$ \\
\hline Fibers/Roving & 0.5 & 5.49 & 1.54 & 0.37 & 0.58 & 0.482 & 0.484 \\
\hline
\end{tabular}

Table 3.2 Layer properties of Mat with fiber volume fraction of 0.5

\begin{tabular}{|c|c|c|c|c|}
\hline Fiber type & $\boldsymbol{V}_{\boldsymbol{f}}$ & $\boldsymbol{E}_{c s m}(\mathbf{m s i})$ & $\boldsymbol{v}_{c s m}$ & $\boldsymbol{G}_{c s m}(\mathbf{m s i})$ \\
\hline Mat (CSM) & 0.50 & 3.07 & 0.40 & 1.09 \\
\hline
\end{tabular}

\subsection{FINITE ELEMENT MODEL}

Once the material properties are calculated, a finite element model of Prodeck 4 is generated. First a solid model of Prodeck 4 is generated by creating key points at required co-ordinates in the global co-ordinate system and then defining volumes by selecting proper key points. The volumes thus formed are map meshed and the orientations of the layers are checked, reorientation is carried out if required. 
Figure 3.2 displays a solid model of Prodeck 4 that consists of 34 volumes, which are glued together. The gluing operation leads to merging of key points, nodes, elements and areas that volumes share along their common boundaries which even enables proper transfer of load to all volumes. This gluing operation redefines the volumes and so local co-ordinates are defined for all the volumes to enable proper orientation of the elements after meshing.

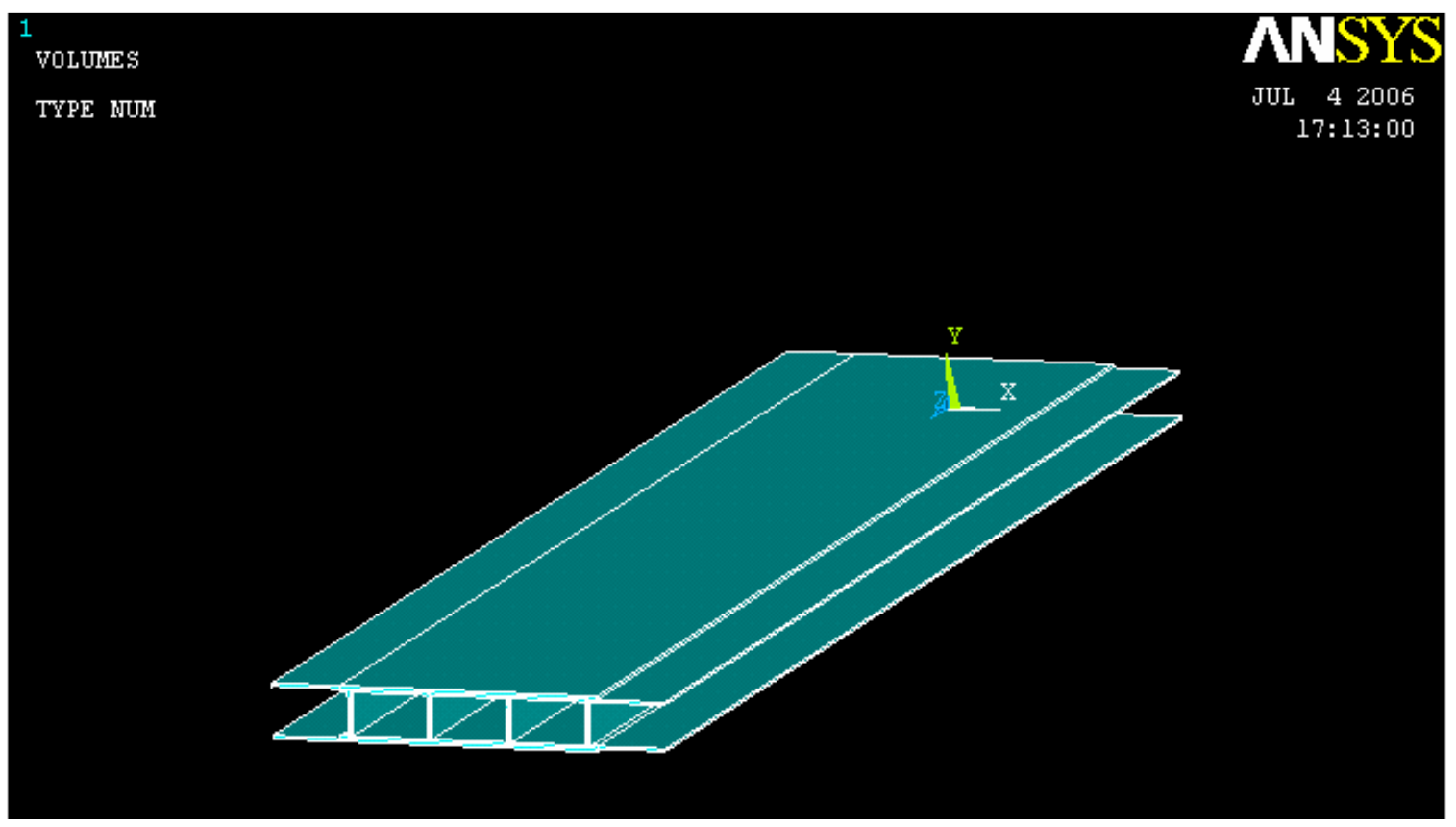

Fig. 3.2 Solid Model of Prodeck 4

Once a solid model of Prodeck 4 is generated, it is map-meshed which results in generation of total 6240 elements consisting of 10004 nodes. Figure 3.3 shows the mapped mesh of Prodeck 4. Elements in some of the volumes generated their own coordinate systems and so changes are manually made in the co-ordinate systems orientations in order to align the fiber directions. 


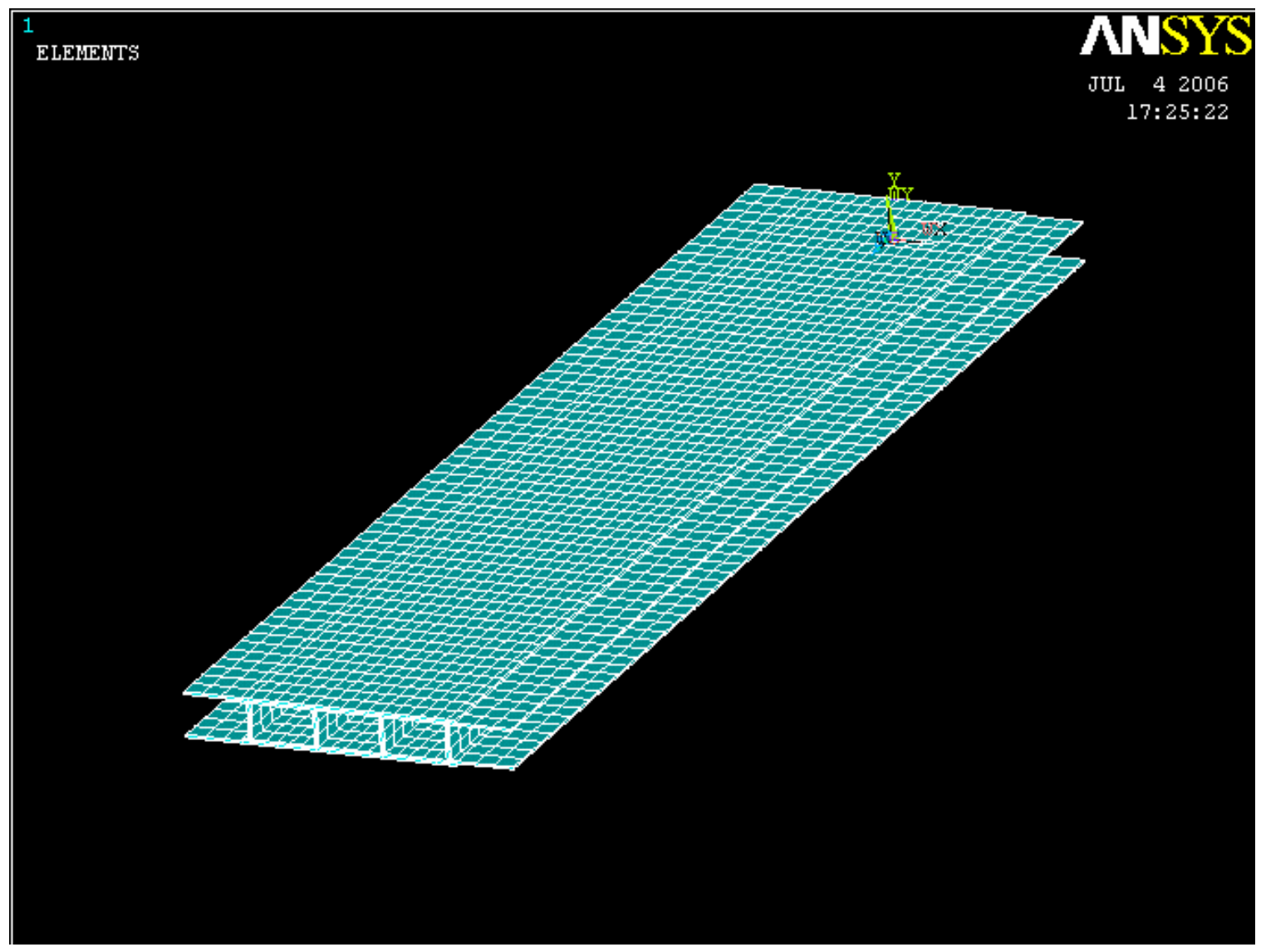

Fig. 3.3 Meshed Model of Prodeck 4

Figure 3.4 shows the total number of layers, their orientation and material number associated with each layer for a randomly selected element. The element orientations are with respect to the locally defined co-ordinate systems for all the elements. 


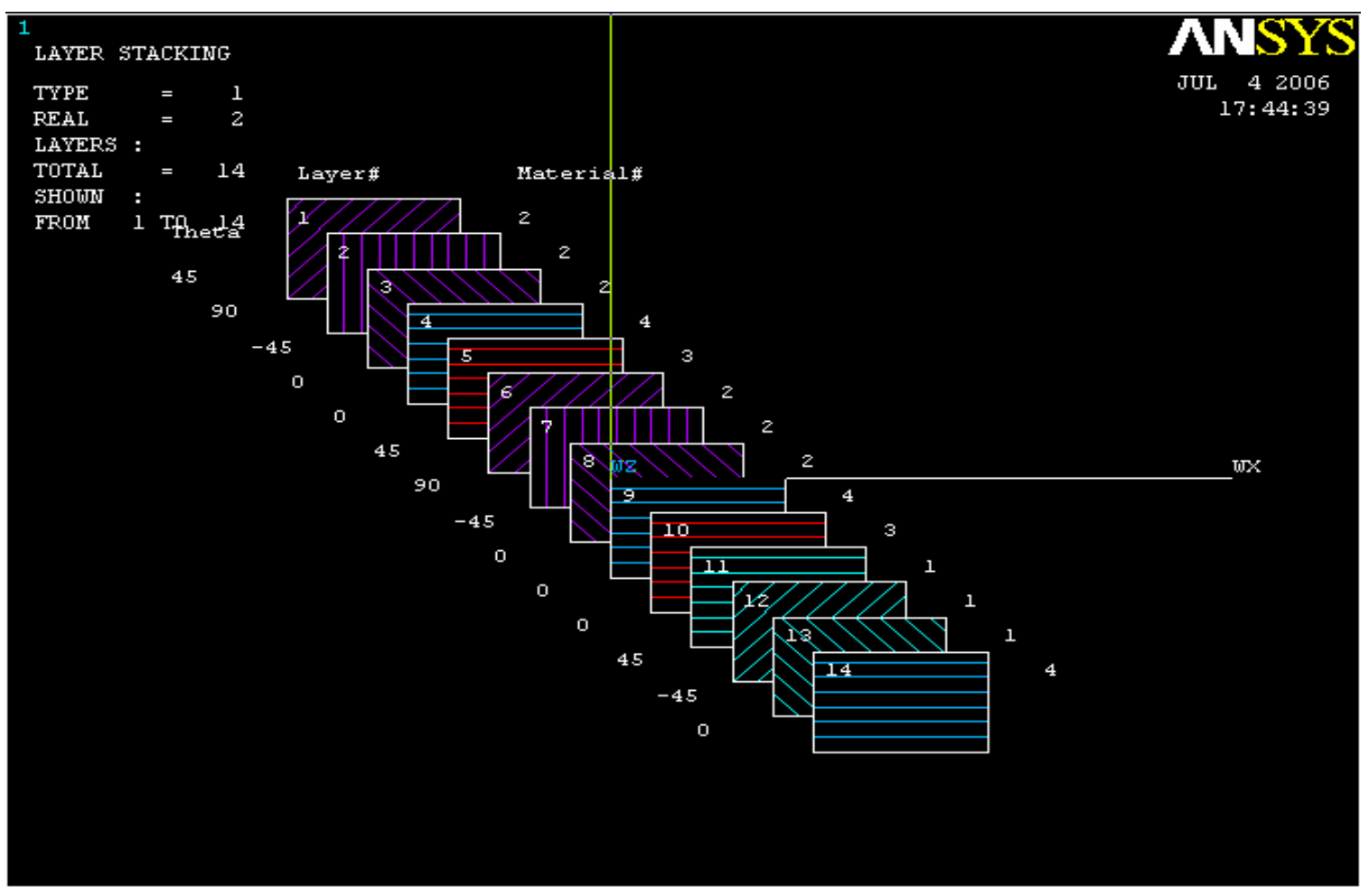

Fig. 3.4 Fiber Orientations of Individual Layers

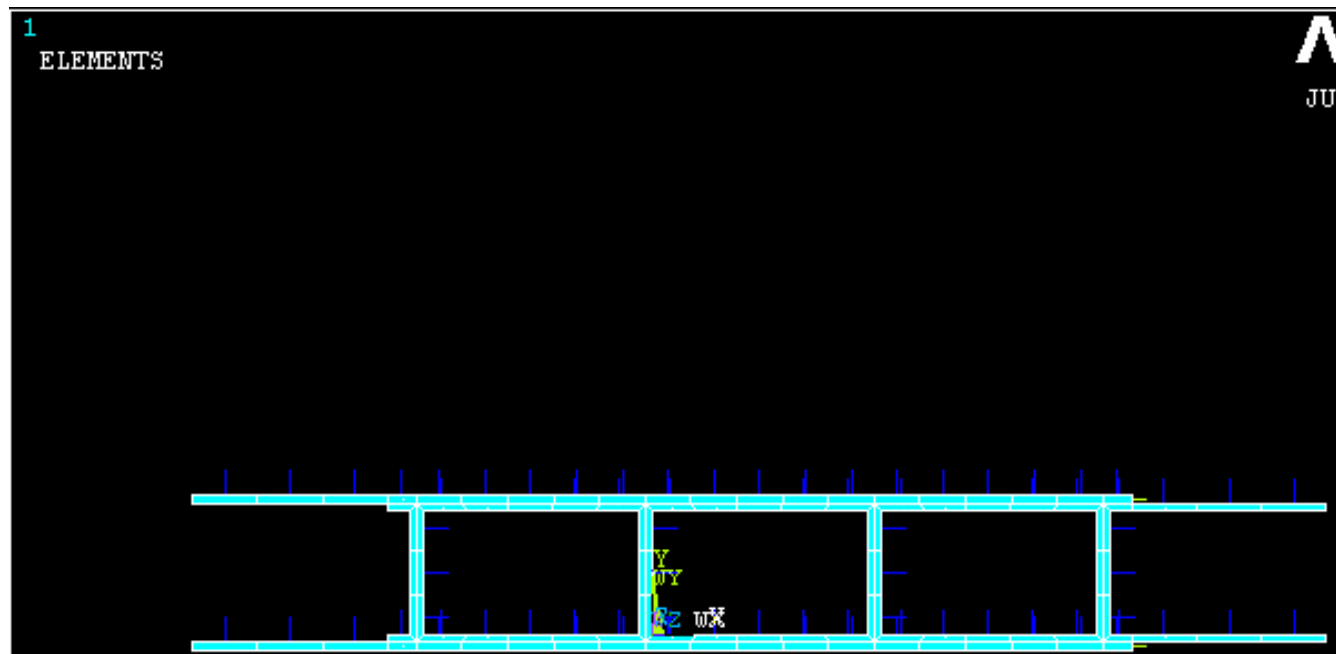

Fig. 3.5 Graphical Representation of Element Co-ordinate System 
Figure 3.5 shows how the local co-ordinate system of each element is graphically oriented. If there are any mis-orientations found in the graphical representation then changes are made in the orientation of local coordinate systems of elements accordingly.

\subsection{BOUNDARY CONDITIONS}

The boundary conditions applied on Prodeck 4 are shown in Fig. 3.6. As it is clear from the figure Prodeck 4 is simply supported with a clear span of 108". To get effect of steel plate that is used in patch loading, coupling restraints with a cross-section of 10 "x 20 " are applied at the center on the top flange of the deck to get equal displacement in the $Y$ direction, which is the loading direction. These coupling restraints are used with an assumption that the steel plate used for patch loading is considered to be rigid and does not deform when being loaded.

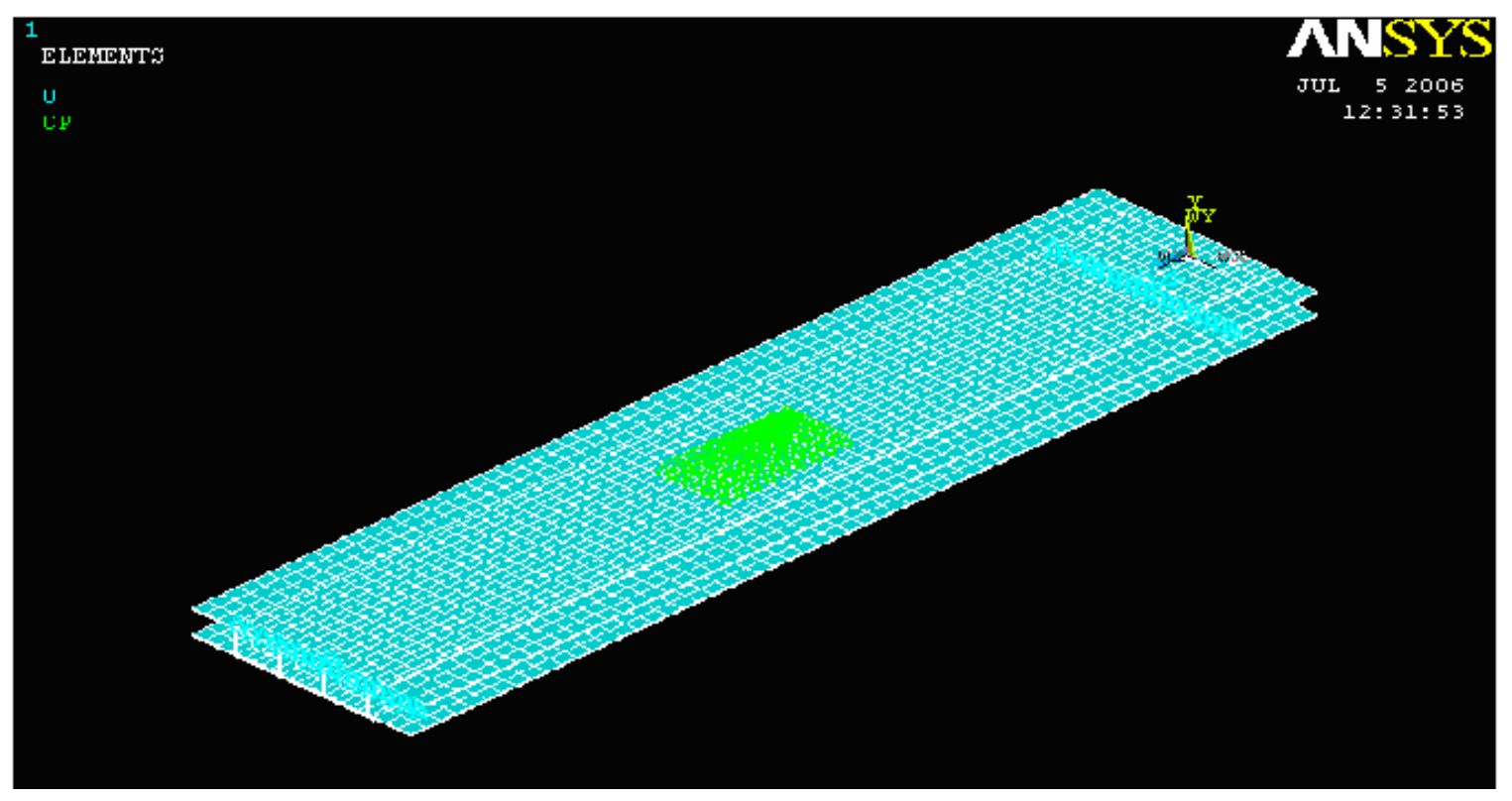

Fig. 3.6 Pictorial Representation of Boundary Conditions Applied on the Prodeck 4 


\subsection{APPLIED LOADS}

A surface load over an area of 10 "x 20 " is applied at the center on the top of the Prodeck 4. In experimental testing a steel plate of size 10 "x 20 " is used for patch loading to simulate the tire of a truck. In finite element model this is obtained by restricting those elements that are present in place of the steel plate used in experimental testing to have same deflection in the loading direction. This is under the assumption that the steel plate acts as a rigid body and is always in contact with the deck. The surface load applied is as shown in the Fig. 3.7.

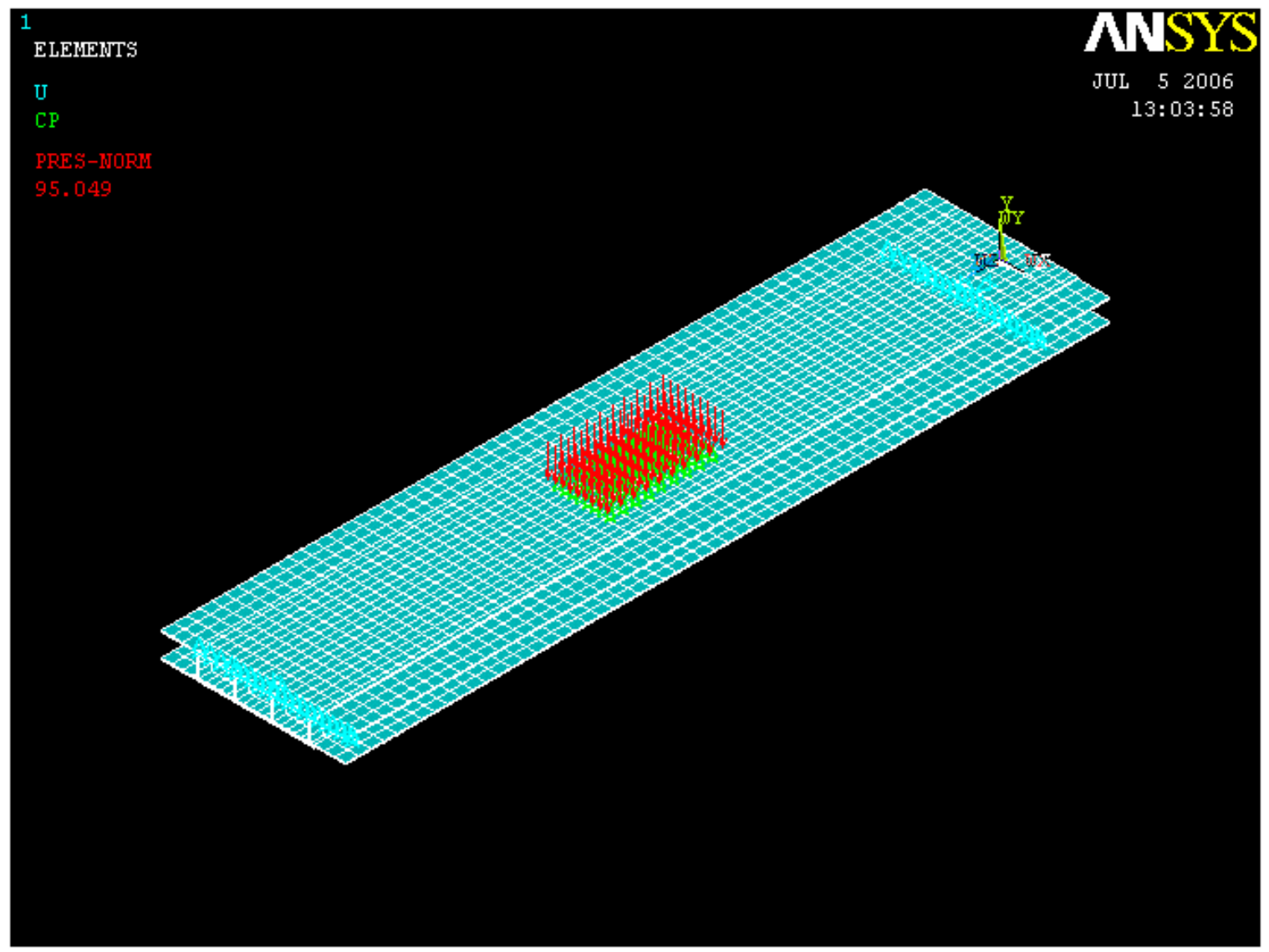

Fig. 3.7 Pictorial Representation of 10"x 20" Patch Load Applied on the Prodeck 4 


\subsection{DESIGN FOR FAILURE}

A structural element is said to have failed when its intended function is not properly performed by it. Even though excessive deflection lowers the performance of structural element, material fracture is one of the most common types of failure that often occurs. The structure need not collapse, even if it is partially damaged it may be considered as failed. [Barbero, (1998)]. There are several failure theories available for predicting the failure of composite materials but none of them are reliable and hence the analytical results must be verified with the experimental values. Strength critical composite structures are often designed with a large safety factor of about 4.5 (which includes safety factor of about 2.5 for structure's aging) due to the lack of a reliable failure theory. There are many contributing factors for the lack of a good failure theory because the internal constitutions of composites are complex, endowed with micron-scale entities materially and geometrically. [Wang, (2004)].

\subsubsection{Failure Properties of Lamina}

Since the experimental values are not available, micromechanics equations are used to determine the failure properties of lamina and are as following:

\section{- Longitudinal Tensile Strength $\left(F_{1 \mathrm{t}}\right)$}

The longitudinal tensile strength is controlled by the fiber strength and is given by

$$
F_{1 t}=\sigma_{f a}\left[V_{f}+\frac{E_{m}}{E_{f}}\left(1-V_{f}\right)\right]
$$

where, $\sigma_{f a}$ for E glass fiber is $3.45 \mathrm{Gpa}$ i.e. $500384.353 \mathrm{psi} \quad[1 \mathrm{pa}=1.45 \mathrm{e}-4 \mathrm{psi}]$ 
This equation assumes that all the fibers have same tensile strength equal to the average of the distribution, which is the fiber average strength ' $\sigma_{f a}$ '. Both the fibers and the matrix behave linearly up to failure, which is not true in case of most polymer matrices that exhibit either elastic nonlinear or plastic behavior after a certain elongation and the fibers are brittle with respect to the matrix and are stiffer than the matrix [Barbero, (1998)].

\section{- Longitudinal Compressive Strength $\left(F_{1 \mathrm{c}}\right)$}

Longitudinal compressive strength is given by the formula

$$
F_{1 c}=\left(\frac{\chi}{a}+1\right)^{b} G_{12}
$$

where,

' $\chi$ ' is a dimension less number and is given by $\chi=\frac{G_{12} \Omega}{F_{6}}$ and $a=0.21$ and $b=-0.69$ are two constants.

\section{- Transverse Tensile Strength $\left(F_{2 \mathrm{t}}\right)$}

The tensile strength in the direction perpendicular to the fibers is $F_{2 \text { t }}$. It is controlled by the matrix strength and is given by the formula

$$
F_{2 t}=\sigma_{m u} C_{v}\left[1+\left(V_{f}-\sqrt{V_{f}}\right)\left(1-\frac{E_{m}}{E_{f}}\right)\right]
$$

where,

$\sigma_{m u}$ is the tensile strength of the bulk matrix and $C_{v}$ is the reduction coefficient

which is given by $C_{v}=1-\sqrt{\frac{4 V_{v}}{\pi\left(1-V_{f}\right)}}$ where $V_{v}$ is the void volume fraction. 


\section{- Transverse Compressive Strength $\left(F_{2 \mathrm{c}}\right)$}

The compressive strength in the direction perpendicular to the fibers is $F_{2 \mathrm{c}}$. It may be obtained using the same Eq. (3.20), replacing the bulk tensile strength of the matrix $\sigma_{m u}$ with the bulk compressive strength of the matrix $\sigma_{m u c}$.

- Inplane Shear Strength $\left(F_{6}\right)$

The inplane shear strength $F_{6}$ is calculated using the equation similar to Eq. (3.20), replacing the bulk tensile strength of the matrix $\sigma_{m u}$ with the bulk shear strength of the matrix $\tau_{m u}$ as shown below.

$$
F_{6}=\tau_{m u} C_{v}\left[1+\left(V_{f}-\sqrt{V_{f}}\right)\left(1-\frac{G_{m}}{G_{f}}\right)\right]
$$

where $\tau_{m u}$ is the bulk shear strength of the matrix.

\section{- Failure Properties of Continuous and Chopped Strand Mat (CSM)}

The tensile strength $F_{c s m-t}$ for CSM is calculated by the formula

$$
\begin{aligned}
& F_{c s m-t}=\frac{4 \alpha F_{2 t}}{\pi}\left[1+\frac{1}{2} \ln \left(\frac{F_{1 t}}{\alpha^{2} F_{2 t}}\right)\right] \quad \text { for } \alpha \leq \sqrt{\frac{F_{1 t}}{F_{2 t}}} \\
& F_{c s m-t}=\frac{4 F_{2 t}}{\pi} \sqrt{\frac{F_{1 t}}{F_{2 t}}} \quad \text { for } \alpha>\sqrt{\frac{F_{1 t}}{F_{2 t}}}
\end{aligned}
$$

where,

$$
\alpha=\frac{F_{6}}{F_{2 t}}
$$

$F_{1 t}, F_{2 t}$ and $F_{6}$ are the longitudinal tensile, transverse tensile, and inplane shear strength of a fictitious unidirectional material containing the same fiber volume fraction 
as that of the CSM material. The compressive strength is assumed to be equal to the tensile strength, the inplane shear strength is taken as one-half of the tensile strength. [Barbero, (1998)].

\section{- Failure Strain Values}

Since the material is assumed to be linearly elastic up to failure, the strains to failure are directly related to the ultimate strength values and their relation is shown in the following section under maximum strain criteria.

The failure strength and strain values calculated for continuous fibers-reinforced composites with fibers of type CDBM, DDBM, Rovings and Mat separately by the above mentioned formulas are presented in the tables below.

Table 3.3 Strength values for CDBM, DDBM and Rovings

\begin{tabular}{|c|c|c|c|c|c|}
\hline Fiber type & $\boldsymbol{F}_{\mathbf{1 t}}(\mathrm{ksi})$ & $\boldsymbol{F}_{\mathbf{1 c}}(\mathbf{k s i})$ & $\boldsymbol{F}_{\mathbf{2 t}}(\mathbf{k s i})$ & $\boldsymbol{F}_{\mathbf{2 c}}(\mathrm{ksi})$ & $\boldsymbol{F}_{\mathbf{6}}(\mathrm{ksi})$ \\
\hline Fibers/Roving & 261.86 & 57.32 & 5.82 & 11.62 & 5.83 \\
\hline Mat $(\mathbf{C S M})$ & 25.01 & 25.01 & 25.01 & 25.01 & 12.50 \\
\hline
\end{tabular}

Table 3.4 Failure strain values for CDBM, DDBM and Rovings

\begin{tabular}{|c|c|c|c|c|c|}
\hline Fiber type & $\varepsilon_{1 t}$ & $\varepsilon_{1 c}$ & $\varepsilon_{2 t}$ & $\varepsilon_{2 c}$ & $\varepsilon_{6}$ \\
\hline Fibers/Roving & $4.76 \times 10^{-2}$ & $1.04 \times 10^{-2}$ & $3.07 \times 10^{-3}$ & $7.15 \times 10^{-3}$ & $1.03 \times 10^{-2}$ \\
\hline Mat (CSM) & $8.13 \times 10^{-3}$ & $8.13 \times 10^{-3}$ & $8.13 \times 10^{-3}$ & $8.13 \times 10^{-3}$ & $11.44 \times 10^{-3}$ \\
\hline
\end{tabular}




\subsubsection{Strength Ratio $(R)$}

Failure criteria can be used more efficiently with the strength ratio defined as the ratio of ultimate stress to applied stress. In terms of strain it is defined as the ratio of ultimate strain to applied strain.

$$
\begin{aligned}
& R=\frac{\sigma_{\text {ultimate }}}{\sigma_{\text {applied }}} \\
& R=\frac{\varepsilon_{\text {ultimate }}}{\varepsilon_{\text {applied }}}
\end{aligned}
$$

\subsubsection{Failure Criteria}

In composite materials damage and fracture may occur in wide variety of failure modes unlike in metals. The number of strength properties of the material needed depends on the failure criteria adopted. For an orthotropic material at least 9 strength properties are required, tensile and compressive strengths in the three principal directions of the material $F_{1 \mathrm{t}}, F_{1 \mathrm{c}}, F_{2 \mathrm{t}}, F_{2 \mathrm{c}}, F_{3 \mathrm{t}}, F_{3 \mathrm{c}}$, and shear strengths in these three directions $\tau_{23 u}$ $\left(F_{4}\right), \tau_{13 u}\left(F_{5}\right), \tau_{12 u}\left(F_{6}\right)$. Some criteria may require more properties than these. As most of the composites are used in the form of laminates, 2D stress states are adequate for most applications. Hence the above mentioned 9 strength properties are reduced to $F_{1 \text { t, }}$ $F_{1 \mathrm{c}}, F_{2 \mathrm{t}}, F_{2 \mathrm{c}}$ and $F_{6}$ in case of $2 \mathrm{D}$ problems. The difficulties in establishing and validating failure criteria for composites are associated with the definition of failure in composites, which is not always absolutely clear. [Li, (2002)]. Some of the most common criteria that are often used are presented in the following sections. 


\subsubsection{Maximum Stress Criterion}

According to this criteria failure occurs in a layer when at least one of the stresses in material coordinates $\left(\sigma_{1}, \sigma_{2}, \sigma_{6}, \sigma_{4}, \sigma_{5}\right)$ exceeds the corresponding experimental value of strength. According to this criterion failure occurs when any of the following conditions is true.

$$
\begin{array}{rlrl}
\sigma_{1} & >F_{1 \mathrm{t}} & & \text { if } \sigma_{1}>0 \\
\operatorname{abs}\left(\sigma_{1}\right) & >F_{1 \mathrm{c}} & & \text { if } \sigma_{1}<0 \\
\sigma_{2} & >F_{2 \mathrm{t}} & & \text { if } \sigma_{2}>0 \\
\operatorname{abs}\left(\sigma_{2}\right) & >F_{2 \mathrm{c}} & & \text { if } \sigma_{2}<0 \\
\operatorname{abs}\left(\sigma_{4}\right) & >F_{4} & \\
\operatorname{abs}\left(\sigma_{5}\right) & >F_{5} & \\
\operatorname{abs}\left(\sigma_{6}\right) & >F_{6} &
\end{array}
$$

where $F_{1 \mathrm{t}}, F_{1 \mathrm{c}}, F_{2 \mathrm{t}}, F_{2 \mathrm{c}}, F_{4}, F_{5}, F_{6}$ are ultimate strength values. It is to be noted is that compressive strength values are taken as positive numbers.

In terms of strength ratio, the maximum stress criterion is explained as follows

$$
\begin{array}{ll}
R_{1}=F_{1 t} / \sigma_{1} & \text { if } \sigma_{1}>0 \\
R_{1}=-F_{1 c} / \sigma_{1} & \text { if } \sigma_{1}<0 \\
R_{2}=F_{2 t} / \sigma_{2} & \text { if } \sigma_{2}>0 \\
R_{2}=-F_{2 c} / \sigma_{2} & \text { if } \sigma_{2}<0 \\
R_{4}=F_{4} / \operatorname{abs}\left(\sigma_{4}\right) & \\
R_{5}=F_{5} / \operatorname{abs}\left(\sigma_{5}\right) & \\
R_{6}=F_{6} / \operatorname{abs}\left(\sigma_{6}\right) &
\end{array}
$$


The strength ratio for the layer is the minimum of all the $R$ values calculated.

One of the advantages of using maximum stress criteria is that it gives information about the mode of failure. The minimum $R_{\mathrm{i}}$ corresponds to a particular mode of failure, which can be detected [Barbero, (1998)].

\subsubsection{Maximum Strain Criterion}

This is one of the most popular failure criterion used today. In terms of strength ratio it is defined as

$$
\begin{array}{ll}
R_{1}=\varepsilon_{1 t} / \varepsilon_{1} & \text { if } \varepsilon_{1}>0 \\
R_{1}=-\varepsilon_{1 c} / \varepsilon_{1} & \text { if } \varepsilon_{1}<0 \\
R_{2}=\varepsilon_{2 t} / \varepsilon_{2} & \text { if } \varepsilon_{2}>0 \\
R_{2}=-\varepsilon_{2 c} / \varepsilon_{2} & \text { if } \varepsilon_{2}<0 \\
R_{4}=\gamma_{4 u} / \operatorname{abs}\left(\varepsilon_{4}\right) & \\
R_{5}=\gamma_{5 u} / \operatorname{abs}\left(\varepsilon_{5}\right) & \\
R_{6}=\gamma_{6 u} / \operatorname{abs}\left(\varepsilon_{6}\right) &
\end{array}
$$

where $\varepsilon_{1 t}, \varepsilon_{1 c}, \varepsilon_{2 t}, \varepsilon_{2 c}, \gamma_{4 u}, \gamma_{5 u}, \gamma_{6 u}$ are strains to failure.

The strength ratio for the layer is the minimum of all the $R$ values computed. Note that compressive strains to failure are positive numbers and all $R$ values are positive.

If the material is assumed to be linear elastic up to failure, the strains to failure are directly related to the ultimate strength values as given below.

$$
\begin{aligned}
& \varepsilon_{1 t}=F_{1 t} / E_{1} \\
& \varepsilon_{1 c}=F_{1 c} / E_{1}
\end{aligned}
$$




$$
\begin{aligned}
& \varepsilon_{2 t}=F_{2 t} / E_{2} \\
& \varepsilon_{2 c}=F_{2 c} / E_{2} \\
& \gamma_{4 u}=F_{4} / G_{23} \\
& \gamma_{5 u}=F_{5} / G_{13} \\
& \gamma_{6 u}=F_{6} / G_{12}
\end{aligned}
$$

\subsubsection{Tsai-Wu Criterion}

This criterion can be written in the form of a quadratic expression that is used to draw a failure envelope that tries to fit the experimental data.

$$
\begin{gathered}
f_{1} \sigma_{1}^{f}+f_{2} \sigma_{2}^{f}+f_{11}\left(\sigma_{1}^{f}\right)^{2}+f_{22}\left(\sigma_{2}^{f}\right)^{2}+2 f_{12}\left(\sigma_{1}^{f} \sigma_{2}^{f}\right) \\
+f_{66}\left(\sigma_{6}^{f}\right)^{2}+f_{44}\left(\sigma_{4}^{f}\right)^{2}+f_{55}\left(\sigma_{5}^{f}\right)^{2}-1=0
\end{gathered}
$$

where $\sigma_{1}^{f}, \sigma_{2}^{f}, \sigma_{6}^{f}, \sigma_{4}^{f}, \sigma_{5}^{f}$ are the components of stress at any point of the failure envelope.

$$
\begin{aligned}
& f_{1}=\frac{1}{F_{1 t}}-\frac{1}{F_{1 c}} \\
& f_{2}=\frac{1}{F_{2 t}}-\frac{1}{F_{2 c}} \\
& f_{11}=\frac{1}{F_{1 t} F_{1 c}} \\
& f_{22}=\frac{1}{F_{2 t} F_{2 c}} \\
& f_{66}=\frac{1}{\left(F_{6}\right)^{2}}
\end{aligned}
$$




$$
\begin{gathered}
f_{44}=\frac{1}{\left(F_{4}\right)^{2}} \\
f_{55}=\frac{1}{\left(F_{5}\right)^{2}}
\end{gathered}
$$

Tsai-Wu criterion accounts for different behavior in tension and compression [Barbero, (1998)].

\subsubsection{Failure Criteria in ANSYS}

Failure criteria are used to assess the possibility of failure of a material. In ANSYS six different criteria can be used to evaluate the possible failure of a material of which three criteria maximum stress, maximum strain and Tsai-Wu criteria are predefined and the rest are user defined criteria. All these failure criteria are evaluated at the top and bottom (or middle) of each layer at each of the in-plane integration points. As the criteria are used for orthotropic materials, the failure stress or failure strain values for all directions must be input. By specifying a large number for failure stress or strain in a particular direction we need not check for them in that direction. By using these failure

criteria the failure values are determined in terms of $\xi$, where $\xi$ is related to strength ratio $R$ as

$$
\xi=\frac{1}{R}
$$




\subsection{RESULTS of SINGLE MODULE of PRODECK 4}

\subsubsection{Introduction}

Once the finite element model is done, a static analysis is carried out by applying a patch load of 10"x 20" at the center on the top flange of Prodeck 4. The values of maximum deflection and strain at particular locations and directions for varying load are noted. These analytical values obtained are then compared with the experimental values obtained earlier by previous researcher. The graphs for load versus maximum deflection and load versus maximum strain are plotted and presented in the following sections. Also the tables showing a comparison between the analytical and experimental results and contour plots of stress and strain are presented. A failure analysis using the maximum stress, maximum strain and Tsai-Wu criteria is carried out on Prodeck 4 which is also presented in the following sections.

\subsubsection{Deflection Analysis}

In this part of research a static analysis is performed on the finite element model of Prodeck 4 that is generated. The deck is simply supported with a span of 108 " between the supports, and a patch load of 10"x 20" is applied at the center on the top flange of the deck. The patch load applied is increased gradually from 0 to 20 kips in steps of 1 kip and the deflection values are noted for the corresponding load values. The deflected shape of the deck at the resultant load value of 20 kips is shown in Fig. 3.8. From Fig. 3.8 it is obvious that the maximum deflection is at the center of the span. Table 3.5 presents a 
comparison of the analytical and experimental maximum deflection values at the different load values.

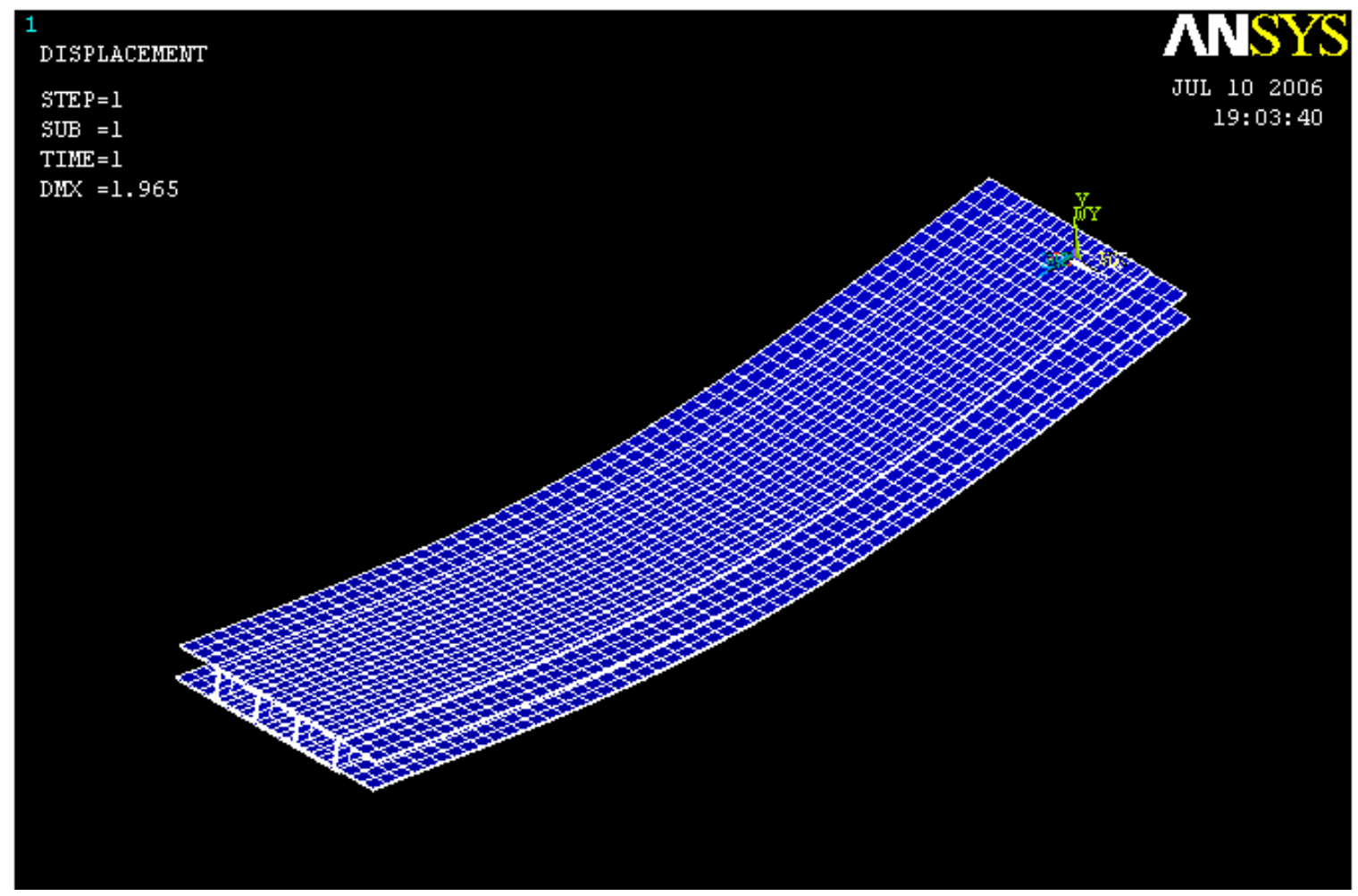

Fig. 3.8 Deformed shape of Prodeck4 under a central patch load of 20 kips 
Table 3.5 Maximum deflection values of Prodeck 4

\begin{tabular}{|c|c|c|}
\hline \multirow{2}{*}{ Applied load (kips) } & \multicolumn{2}{|c|}{ Maximum deflection (in.) } \\
\hline & Analytical & $\begin{array}{c}\text { Experimental } \\
\text { Punyamurthula (2004) }\end{array}$ \\
\hline 1 & 0.098 & 0.123 \\
\hline 2 & 0.196 & 0.235 \\
\hline 3 & 0.294 & 0.334 \\
\hline 4 & 0.392 & 0.447 \\
\hline 5 & 0.491 & 0.564 \\
\hline 6 & 0.589 & 0.674 \\
\hline 7 & 0.687 & 0.776 \\
\hline 8 & 0.785 & 0.888 \\
\hline 9 & 0.883 & 0.999 \\
\hline 10 & 0.981 & 1.120 \\
\hline 11 & 1.080 & 1.250 \\
\hline 12 & 1.178 & 1.400 \\
\hline 13 & 1.276 & 1.530 \\
\hline 14 & 1.374 & 1.640 \\
\hline 15 & 1.472 & 1.760 \\
\hline 16 & 1.570 & 1.880 \\
\hline 17 & 1.669 & 2.000 \\
\hline 18 & 1.767 & 2.120 \\
\hline 19 & 1.865 & 2.230 \\
\hline 20 & 1.963 & 2.360 \\
\hline 21 & 2.061 & 2.480 \\
\hline 22 & 2.159 & 2.620 \\
\hline 23 & 2.257 & 2.740 \\
\hline 24 & 2.356 & 2.870 \\
\hline
\end{tabular}


Figure 3.9 shows the same data in graphical form

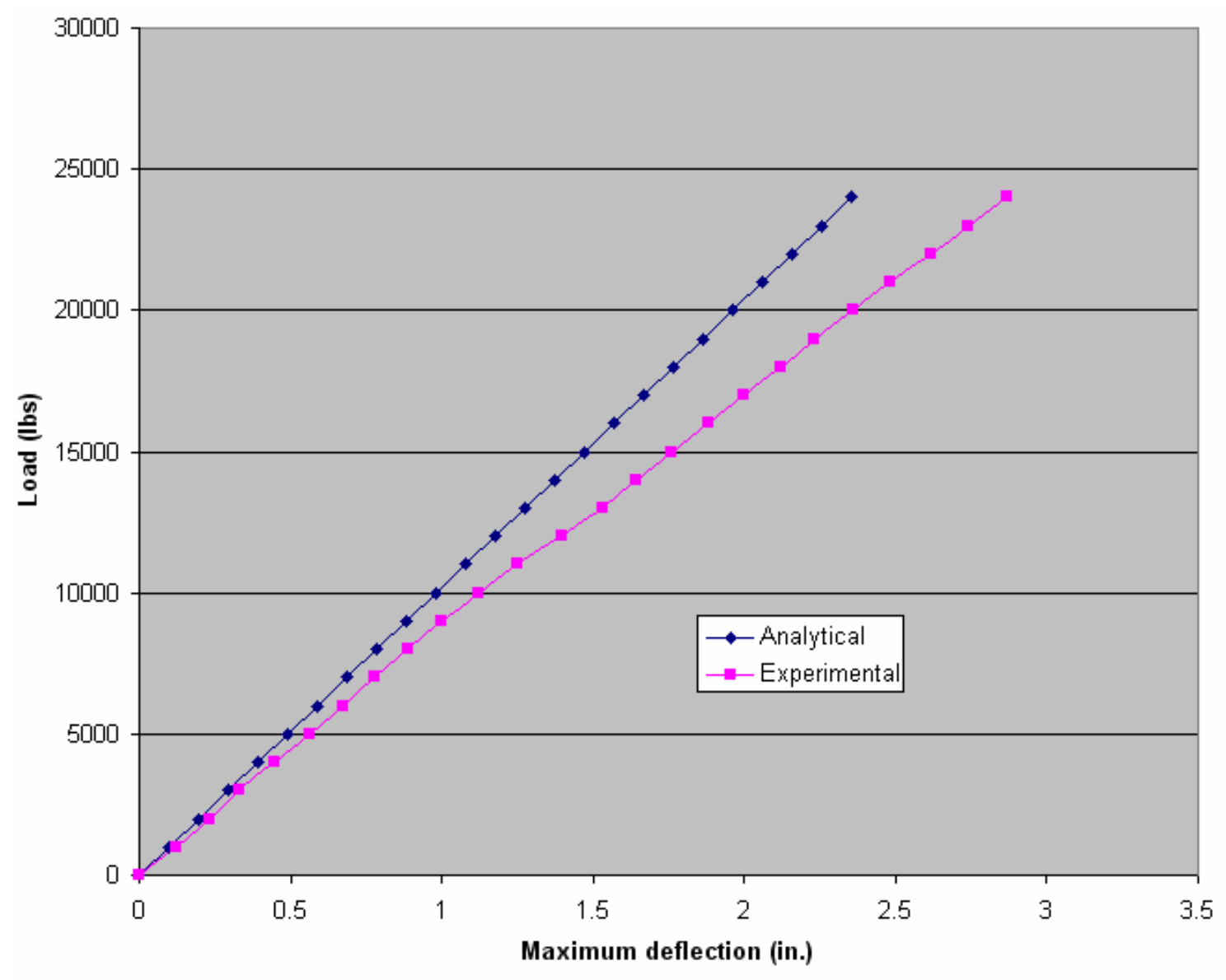

Fig. 3.9 Graph plotted between maximum deflection and central patch load

It is clear from Table 3.5 and Fig. 3.9 that the finite element deflection values are lower than the experimental ones signifying that the finite element model is stiffer than the real deck. It is well known that polymer-matrix composite materials have an elastic behavior up to fracture and hence the analytical curve is linear where as the experimental curve exhibits nonlinearity from around the load of 13 kips. 
Figure 3.10 shows the contour plot of the deflection of the deck under the central patch load of 20 kips. In the figure blue region marks the maximum deflection located in the mid portion of the deck.

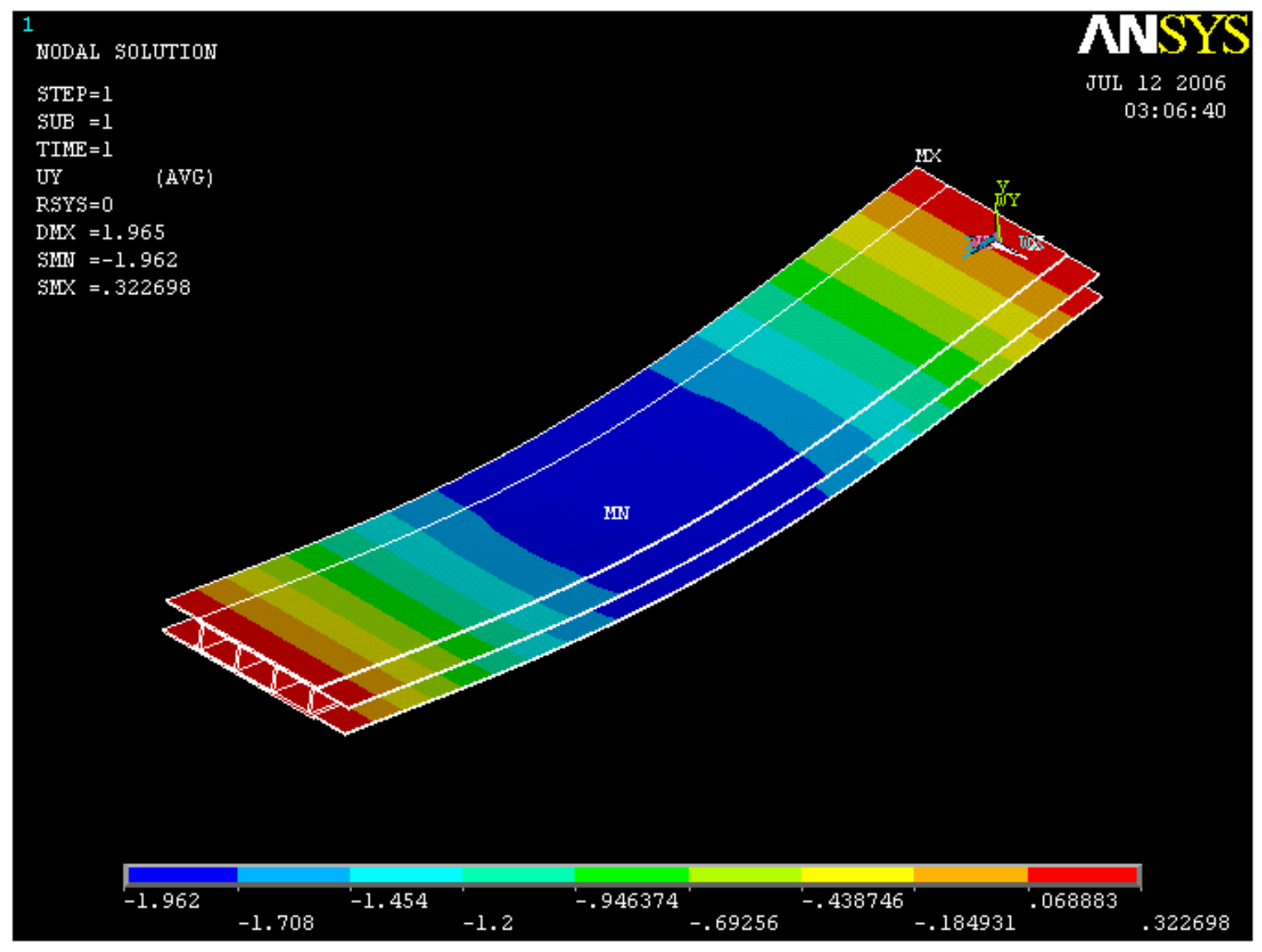

Fig. 3.10 Deflection plot of Prodeck 4 in direction of $Y$ axis under the load of 20kips

\subsubsection{Bending stiffness and Young's modulus of the longitudinal components}

The formulas for calculation of the equivalent bending stiffness (EI) and Young's modulus (E) use the basic strength of materials concepts for bending. Assuming a point load on a simply supported beam, the maximum deflection is given by

$$
\delta=\frac{P L^{3}}{48 E I}
$$


Equation (3.32) can be re-written as

$$
E I=\left(\frac{P}{\delta}\right)\left(\frac{L^{3}}{48}\right)
$$

Alternately, the equivalent bending rigidity, EI, can be calculated from the maximum strain observed as follows

$$
\sigma=\varepsilon E=\frac{M c}{I}
$$

By substituting $M=\frac{P L}{4}$ in Eq. (3.34) it can be re-written as

$$
E I=\left(\frac{P}{\varepsilon}\right)\left(\frac{L c}{4}\right)
$$

where,

$$
\begin{aligned}
& \frac{P}{\delta}=\text { Slope of the load versus maximum deflection curve } \\
& \frac{P}{\varepsilon}=\text { Slope of the load versus strain curve } \\
& L=\text { Clear span (9') } \\
& E=\text { Equivalent modulus of elasticity or Young's modulus } \\
& \left.I=\text { Moment of inertia of deck cross section (69.95 in }{ }^{4}\right) \\
& c=\text { Distance from the neutral axis to the outermost fiber (2”) }
\end{aligned}
$$

From Eq. (3.33) the values of the equivalent bending stiffness and Young's modulus are calculated and presented in Table 3.6. Since SOLID46 element takes shear deflection into account, the deflection analysis has shear effects present in it and the 
value of Young's modulus is obtained to be $3.82 \times 10^{6} \mathrm{psi}$ which is close to the experimental value $3.522 \times 10^{6}$ psi that includes shear reported by Punyamurthula (2004).

Table 3.6 Equivalent flexural rigidity and young's modulus based on deflection

\begin{tabular}{|c|c|c|c|}
\hline \multirow{2}{*}{ Type } & \multicolumn{2}{|c|}{ Experimental } & \multirow{2}{*}{ Analytical } \\
& [Punyamurthula (2004)] & \\
\cline { 2 - 4 } & Including shear & Excluding shear & \\
\hline Flexural rigidity & 2.46 & 2.73 & 2.67 \\
$\mathbf{E}_{\mathbf{z}} \mathbf{I}_{\mathbf{x}}\left(\mathbf{1 0}^{\mathbf{8}} \mathbf{~ l b}^{*} \mathbf{i n}^{\mathbf{2}}\right)$ & & & \\
\hline Young's Modulus & 3.522 & 3.9 & 3.82 \\
$\mathbf{E}_{\mathbf{z}}\left(\mathbf{1 0}^{\mathbf{6}} \mathbf{\text { psi) }}\right.$ & & & \\
\hline
\end{tabular}

\subsubsection{Strain Analysis}

The strain values for corresponding load values are obtained from the center location on the bottom flange in the $Z$ direction (cell direction) from the finite element model of the deck, which are then compared to the values obtained from the experimental tests carried out by Punyamurthula (2004).

A table consisting of both analytical and experimental strain values observed at the mid section in the bottom flange of the deck for the corresponding load values is presented below followed by the graphs plotted between load and corresponding strains at the mid section that are obtained both analytically and experimentally, with load on $Y$ axis and strain on $X$-axis. 
Table 3.7 Strain values of Prodeck 4 for central patch load

\begin{tabular}{|c|c|c|}
\hline Applied load (kips) & $\begin{array}{c}\text { Micro-strain }\left(\varepsilon_{z}\right) \\
\text { Analytical }\end{array}$ & $\begin{array}{c}\text { Micro-strain } \\
\text { Experimental } \\
\text { Punyamurthula (2004) }\end{array}$ \\
\hline 0 & 0 & 0 \\
\hline 1 & 171 & 192 \\
\hline 2 & 343 & 369 \\
\hline 3 & 514 & 556 \\
\hline 4 & 686 & 739 \\
\hline 5 & 857 & 901 \\
\hline 6 & 1029 & 1090 \\
\hline 7 & 1200 & 1280 \\
\hline 8 & 1371 & 1460 \\
\hline 9 & 1543 & 1650 \\
\hline 10 & 1714 & 1830 \\
\hline 11 & 1886 & 2010 \\
\hline 12 & 2057 & 2200 \\
\hline 13 & 2228 & 2410 \\
\hline 14 & 2400 & 2610 \\
\hline 15 & 2571 & 2820 \\
\hline 16 & 2743 & 3040 \\
\hline 17 & 2914 & 3250 \\
\hline 18 & 3086 & 3490 \\
\hline 19 & 3257 & 3720 \\
\hline 20 & 3428 & 3940 \\
\hline 21 & 3600 & 4160 \\
\hline 22 & 3771 & 4370 \\
\hline 23 & 3943 & 4620 \\
\hline 24 & 4114 & 4850 \\
\hline
\end{tabular}




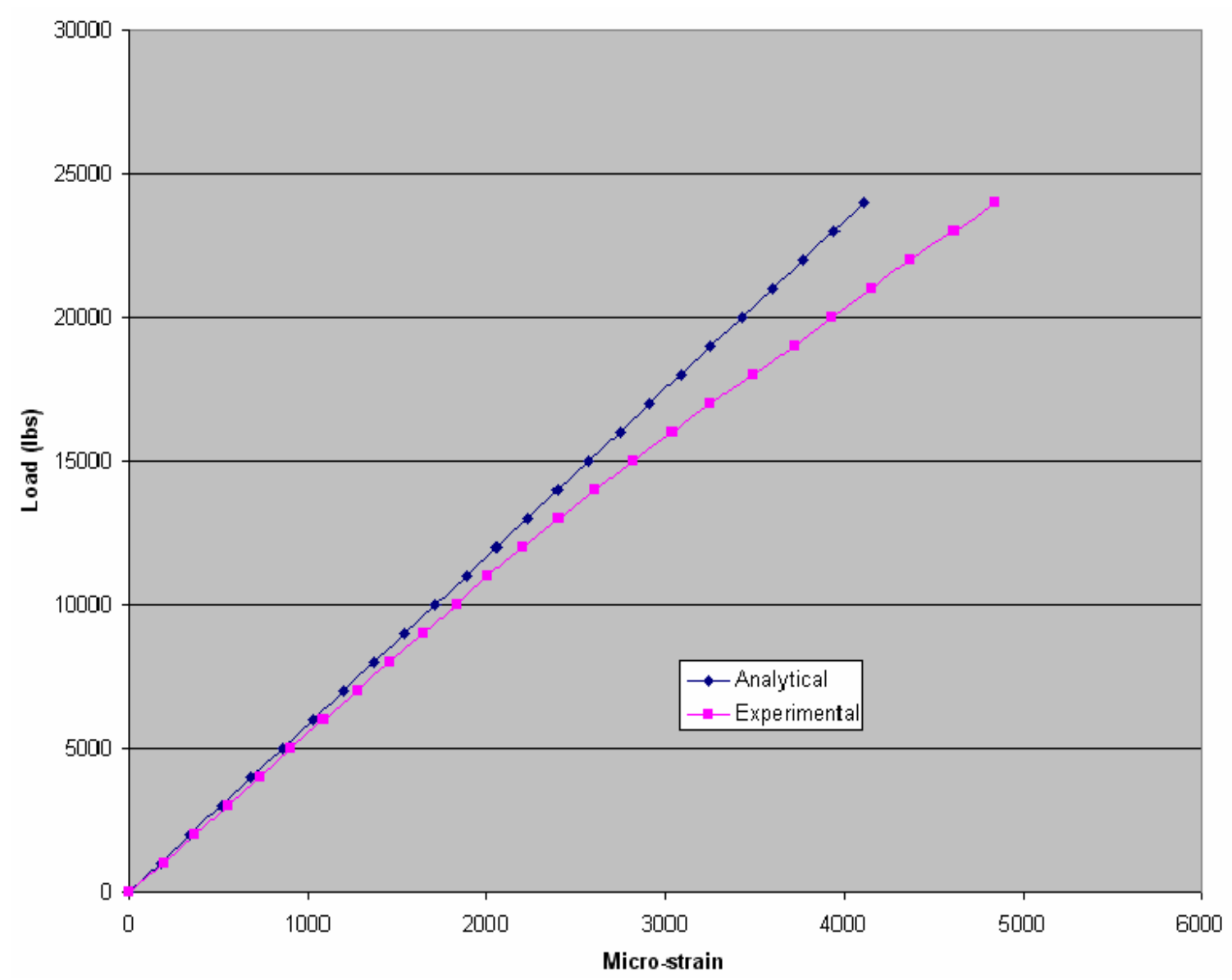

Fig. 3.11 Load-strain curve at mid span for a patch load

It is clear from the Fig. 3.11 that the finite element curve shows linear behavior where as the experimental curve behaves linearly up to load of $13000 \mathrm{lbs}$ and then starts to exhibit non linear behavior from there. This is perhaps because of progressive failure of some of the layers of the deck with increasing load values.

Figures $3.12,3.13 \& 3.14$ show the contour plots of the strains in the deck in the direction along $Z$-axis under the central patch load of 20 kips. 


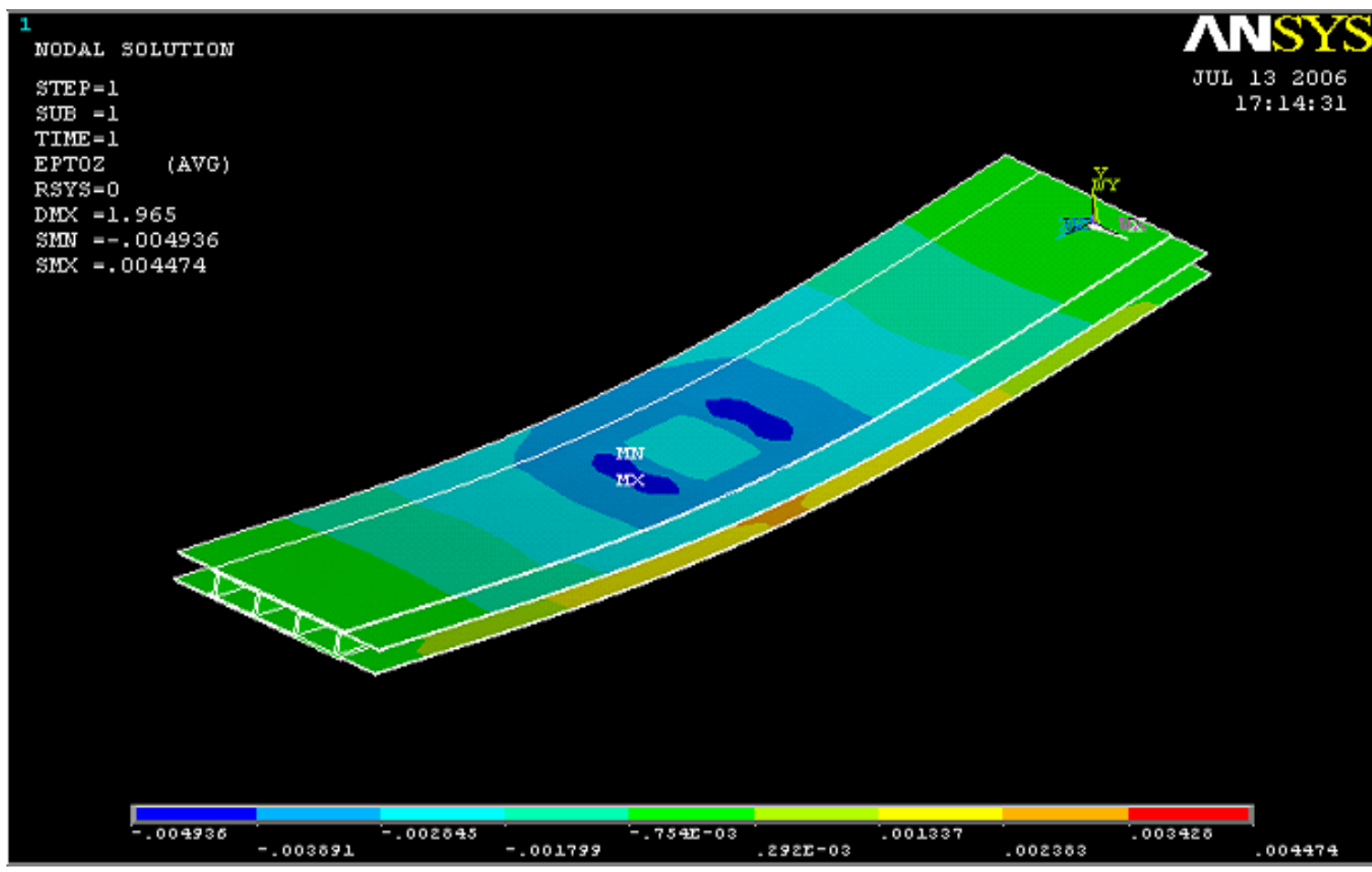

Fig. 3.12 Contour plot of strain $\left(\varepsilon_{z}\right)$ of Prodeck 4 for a central patch load of $20 \mathrm{kips}$

\section{NODAL SOLUTION}

STEP $=1$

SUB $=1$

TIME $=1$

EPTOZ (AVG)

RSYS $=0$

$\mathrm{DNX}=1.965$

SMN $=-.004936$

$\operatorname{sNX}=.004474$

s.t.

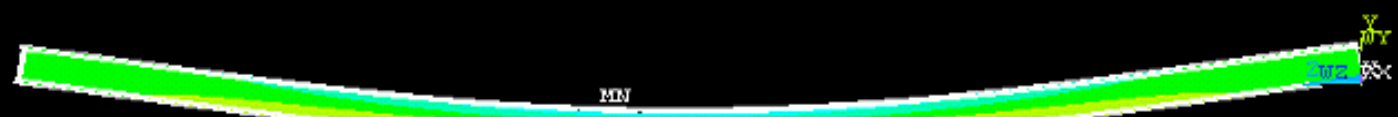

\begin{tabular}{|l|l|llllllll}
\hline-.004936 & -.003891 & -.002845 & -.001793 & $-.7542-03$ & $.2925-03$ & .001337 & .002353 & .003428 & .004474 \\
\hline
\end{tabular}

Fig. 3.13 Side view of the contour plot of Strain $\left(\varepsilon_{z}\right)$ of Prodeck 4 for a load of 20 kips 


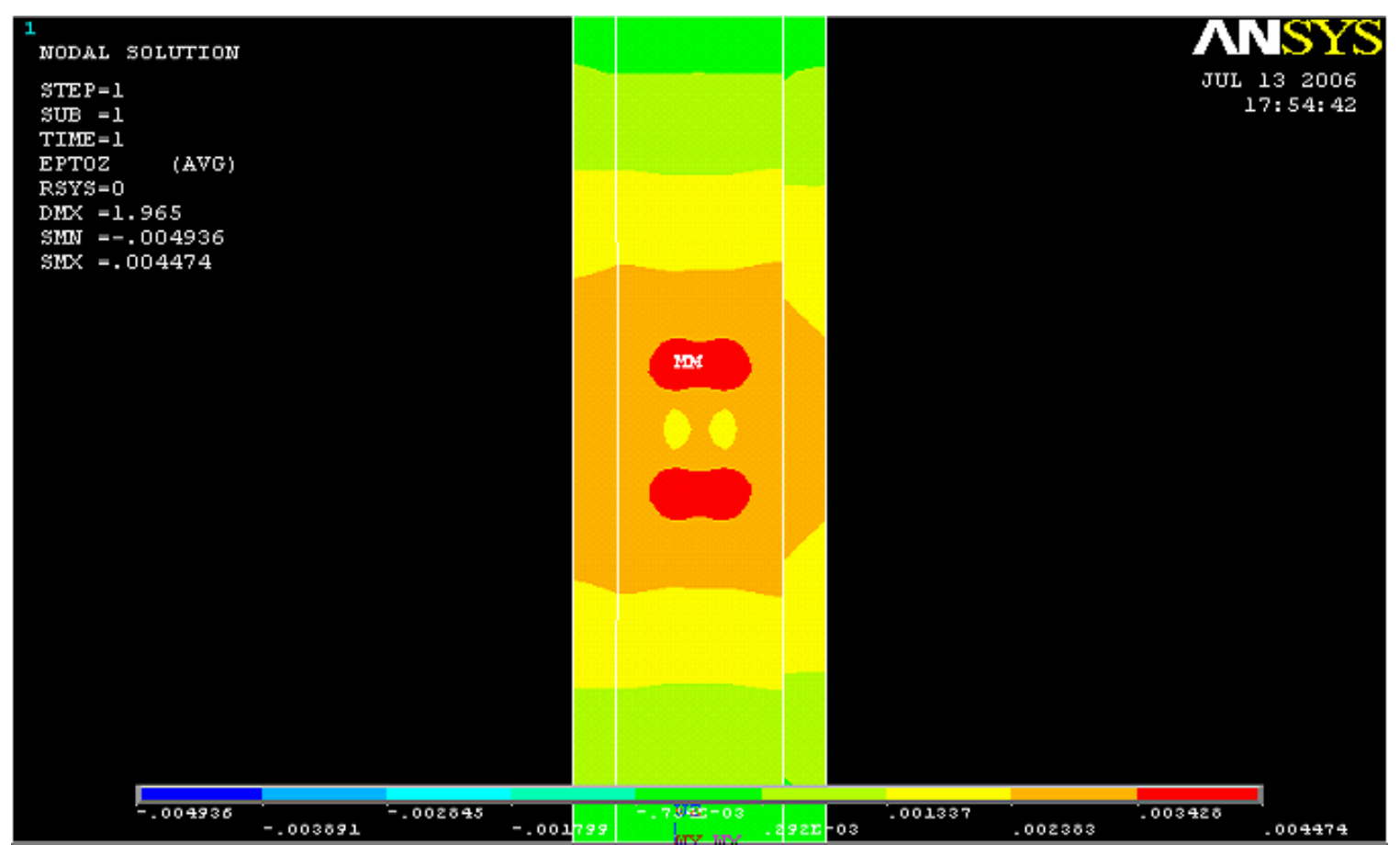

Fig. 3.14 Bottom view of the contour plot of Strain $\left(\varepsilon_{z}\right)$ for a load of 20 kips

It is clear from the above figure that the maximum strain in the Z-direction occurs in the bottom flange on the edges of patch load applied above.

A table consisting of analytical stress and strain values observed at the mid section in the bottom flange of the deck for the corresponding load values is presented below followed by the graph, plotted between stress and corresponding strain values at the mid section of the deck, with stress on $Y$-axis and strain on $X$-axis. 
Table 3.8 Stress and strain values of Prodeck 4 for central patch load

\begin{tabular}{|c|c|c|}
\hline Applied load (kips) & Stress (psi) & Micro-strain $\left(\varepsilon_{z}\right)$ \\
\hline 0 & 0 & 0 \\
\hline 1 & 246.90 & 171 \\
\hline 2 & 493.80 & 343 \\
\hline 3 & 740.70 & 514 \\
\hline 4 & 987.61 & 686 \\
\hline 5 & 1234.50 & 857 \\
\hline 6 & 1481.40 & 1029 \\
\hline 7 & 1728.30 & 1200 \\
\hline 8 & 1975.25 & 1371 \\
\hline 9 & 2222.10 & 1543 \\
\hline 10 & 2469.00 & 1714 \\
\hline 11 & 2715.95 & 1886 \\
\hline 12 & 2962.80 & 2057 \\
\hline 13 & 3209.70 & 2228 \\
\hline 14 & 3456.65 & 2400 \\
\hline 15 & 3703.50 & 2571 \\
\hline 16 & 3950.45 & 2743 \\
\hline 17 & 4197.35 & 2914 \\
\hline 18 & 4444.25 & 3086 \\
\hline 19 & 4691.15 & 3257 \\
\hline 20 & 4938.05 & 3428 \\
\hline 21 & 5184.95 & 3600 \\
\hline 22 & 5431.85 & 3771 \\
\hline 23 & 5678.75 & 3943 \\
\hline 24 & 5925.65 & 4114 \\
\hline
\end{tabular}




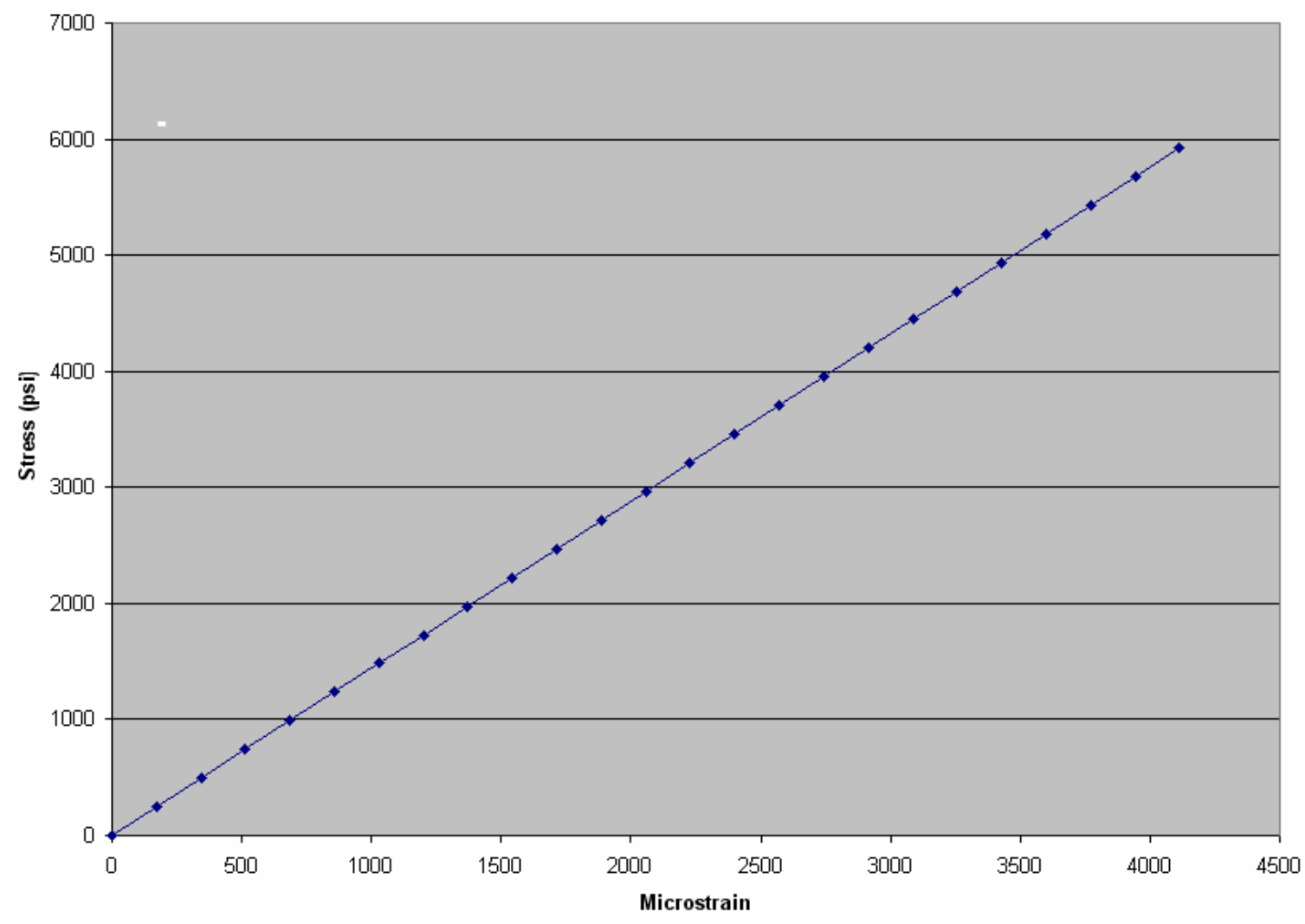

Fig. 3.15 Stress-strain curve for a central patch load

From the Fig. 3.15 it is clear that the analytical stress-strain curve is a linear curve that passes through the origin. The stress value increases linearly with increase in the strain value at the mid section in bottom flange of the deck.

\subsubsection{Computation of bending stiffness and Young's modulus based on strain}

The equivalent flexural rigidity and Young's modulus based on strain can be calculated using Eq. (3.35) and the slope from Fig. 3.11. The values obtained are then compared to the experimental values obtained by Punyamurthula (2004). It is observed that analytically obtained equivalent rigidity based on strain which is of $3.08 \times 10^{8} \mathrm{lb}^{*} \mathrm{in}^{2}$ is about $10 \%$ higher than that obtained in experimental tests based strain. It is about 
$10.5 \%$ higher than the one obtained analytically based on deflection. One thing to be noted is that the analytical deflection obtained even has shear deflection in it.

Table 3.9 Equivalent flexural rigidity and Young's modulus of the longitudinal component based on strain

\begin{tabular}{|c|c|c|}
\hline Type & $\begin{array}{c}\text { Experimental } \\
\text { Punyamurthula (2004) }\end{array}$ & Analytical \\
\hline $\begin{array}{c}\text { Equivalent Flexural } \\
\text { Rigidity, } \mathbf{E}_{\mathbf{z}} \mathbf{I}_{\mathbf{x}}\left(\mathbf{1 0}^{\mathbf{8}}\right) \mathbf{~ l b}^{* \mathbf{i n}^{2}}\end{array}$ & 2.7 & 3.08 \\
\hline $\begin{array}{c}\text { Equivalent Young's } \\
\text { Modulus, } \mathbf{E}_{\mathbf{z}}\left(\mathbf{1 0}^{\mathbf{6}}\right) \mathbf{p s i}\end{array}$ & 3.86 & 4.40 \\
\hline
\end{tabular}

Contour plots for the stress and strain components of Prodeck 4, which is subjected to a central patch load of 20 kips are given in the Figs. 3.16 - 3.38.

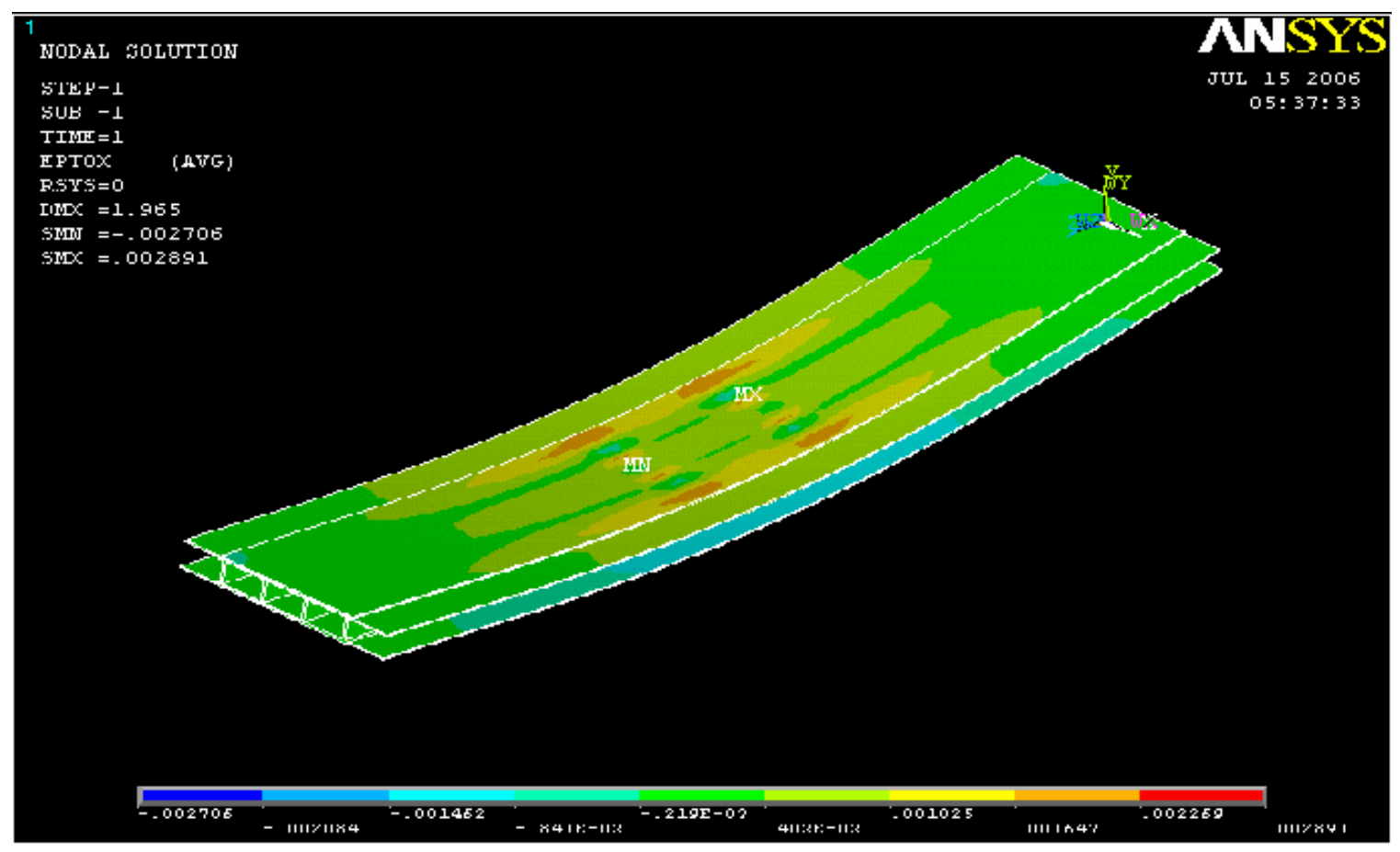

Fig. 3.16 Contour plot of Strain $\left(\varepsilon_{\mathrm{x}}\right)$ of Prodeck 4 for a central patch load of 20 kips 


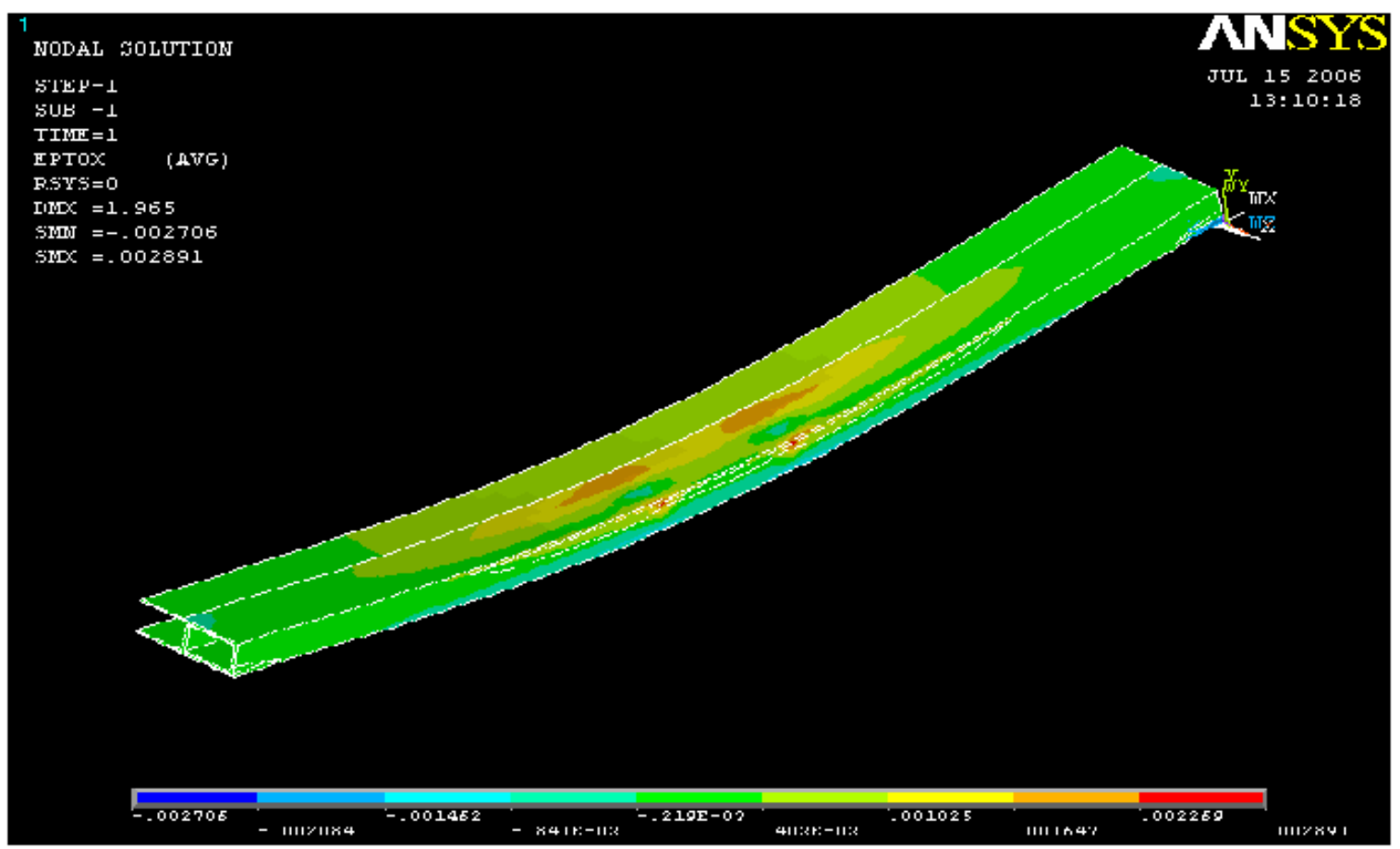

Fig. 3.17 Sectional view of contour plot of Strain $\left(\varepsilon_{\mathrm{x}}\right)$ of Prodeck 4 for load of 20 kips

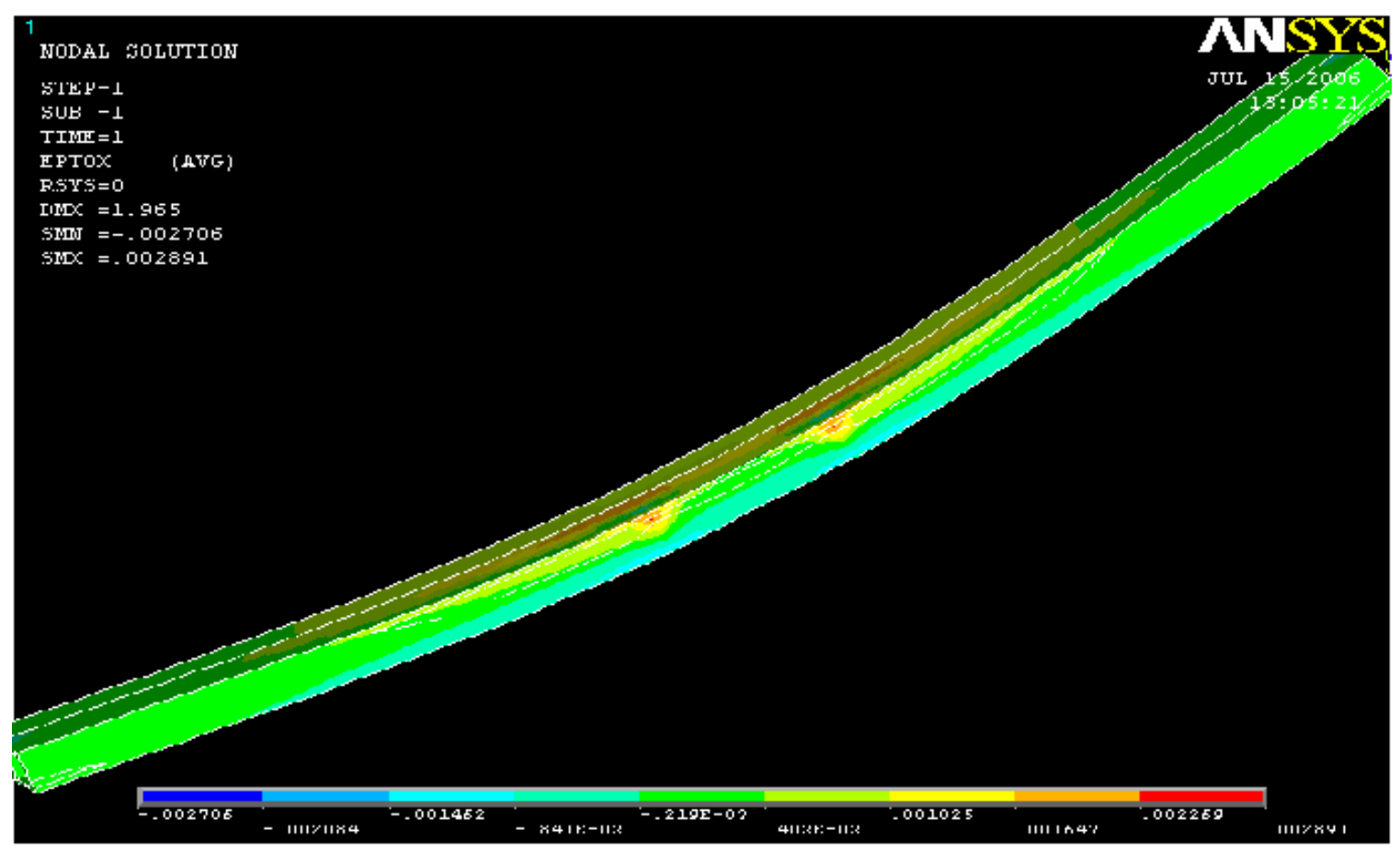

Fig. 3.18 Sectional view of contour plot of Strain $\left(\varepsilon_{\mathrm{x}}\right)$ of Prodeck 4 for load of 20 kips 


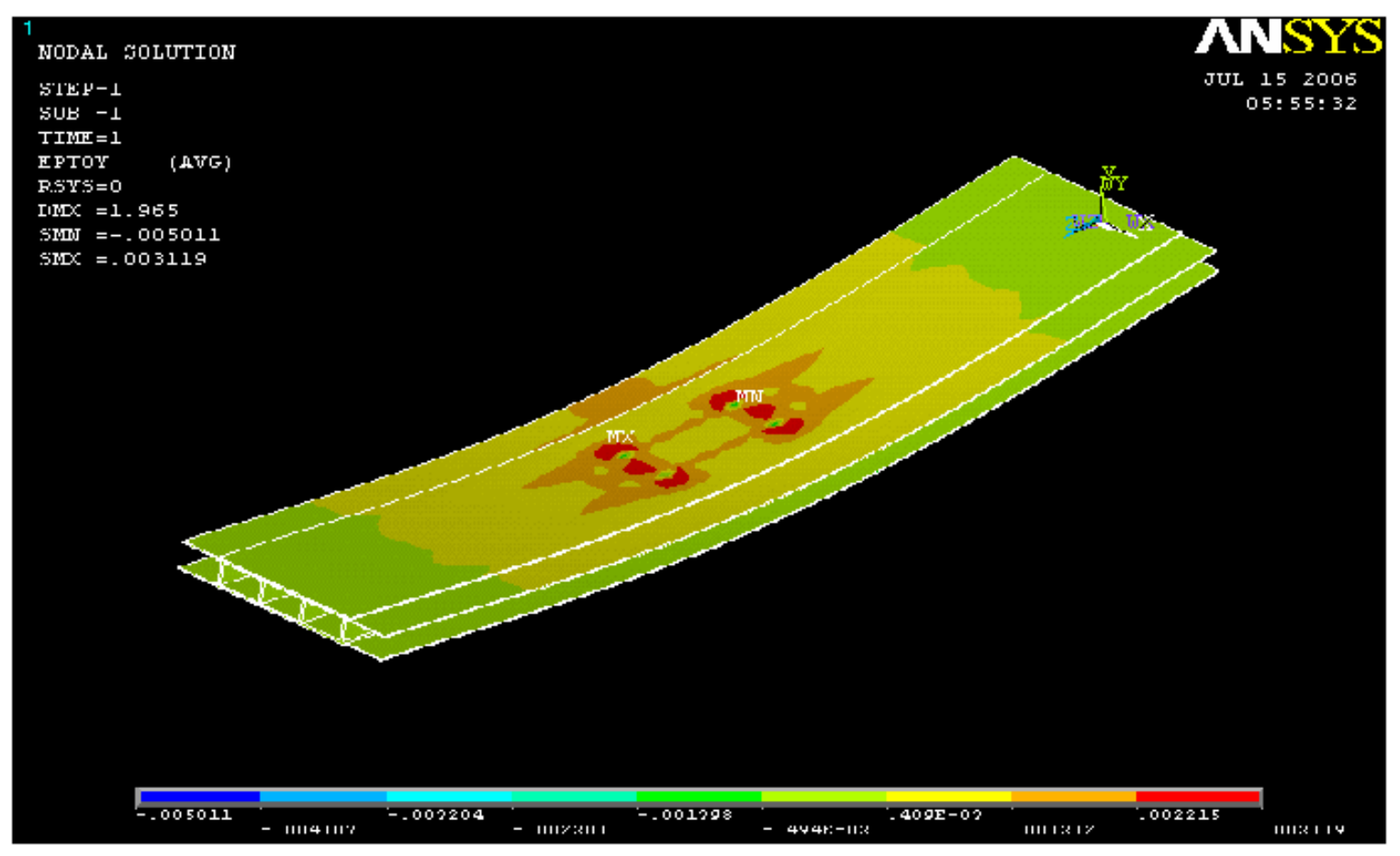

Fig. 3.19 Contour plot of Strain $\left(\varepsilon_{\mathrm{y}}\right)$ of Prodeck 4 for a central patch load of 20 kips

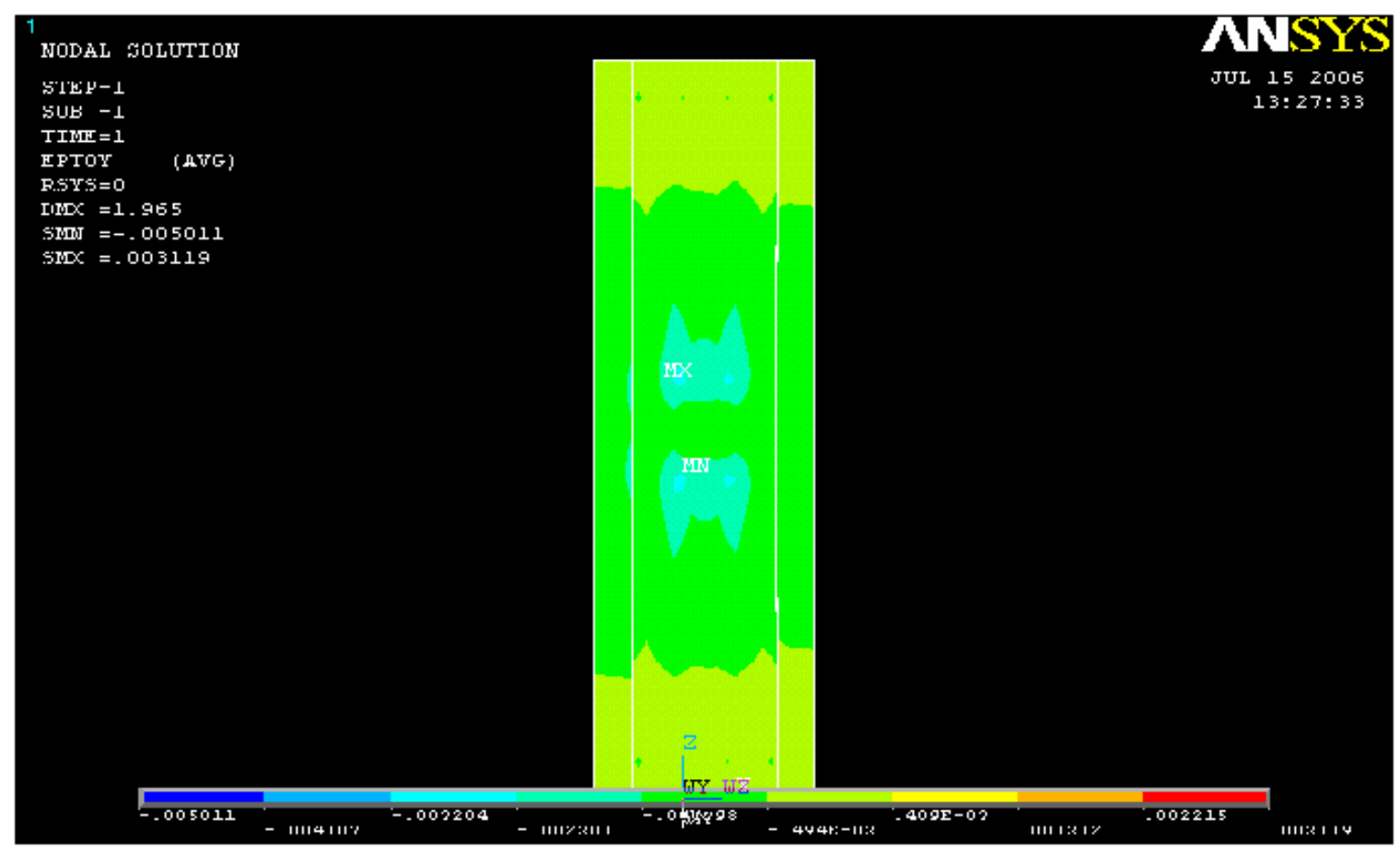

Fig. 3.20 Bottom view of contour plot of Strain $\left(\varepsilon_{\mathrm{y}}\right)$ of Prodeck 4 for a load of 20 kips 


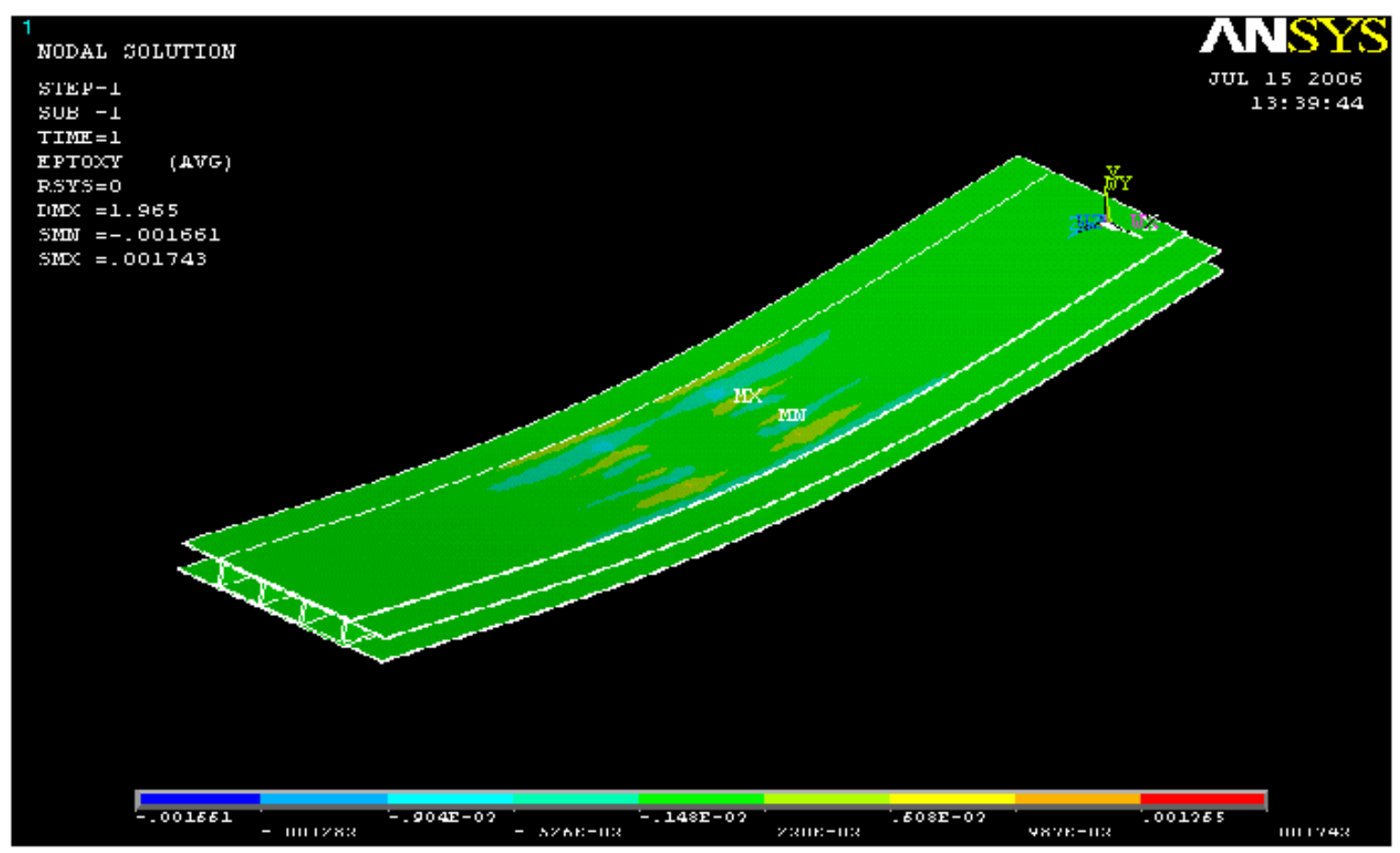

Fig. 3.21 Contour plot of shear strain $\left(\gamma_{x y}\right)$ of Prodeck 4 for a patch load of 20 kips

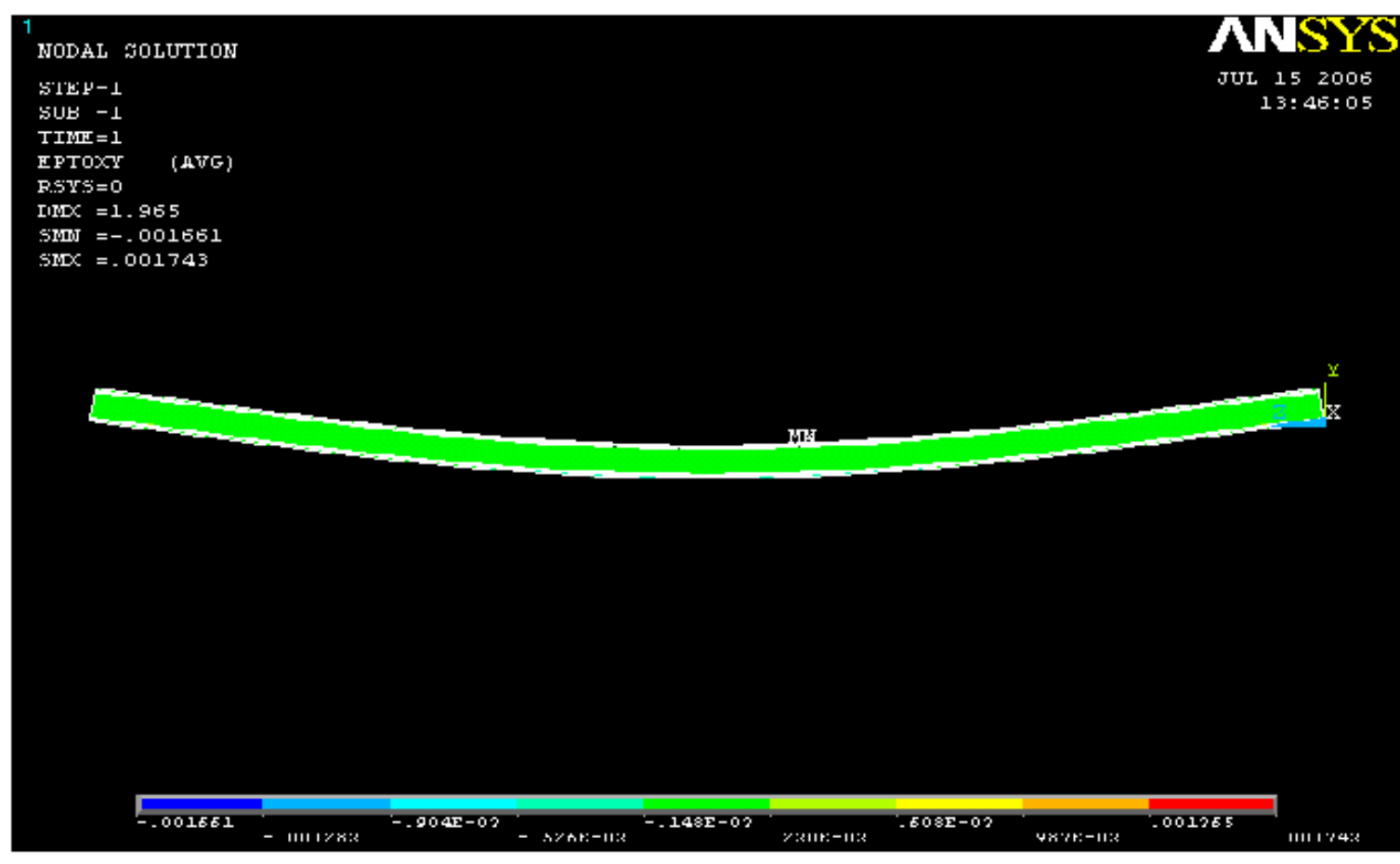

Fig. 3.22 Side view of contour plot of shear strain $\left(\gamma_{x y}\right)$ for a patch load of 20 kips 


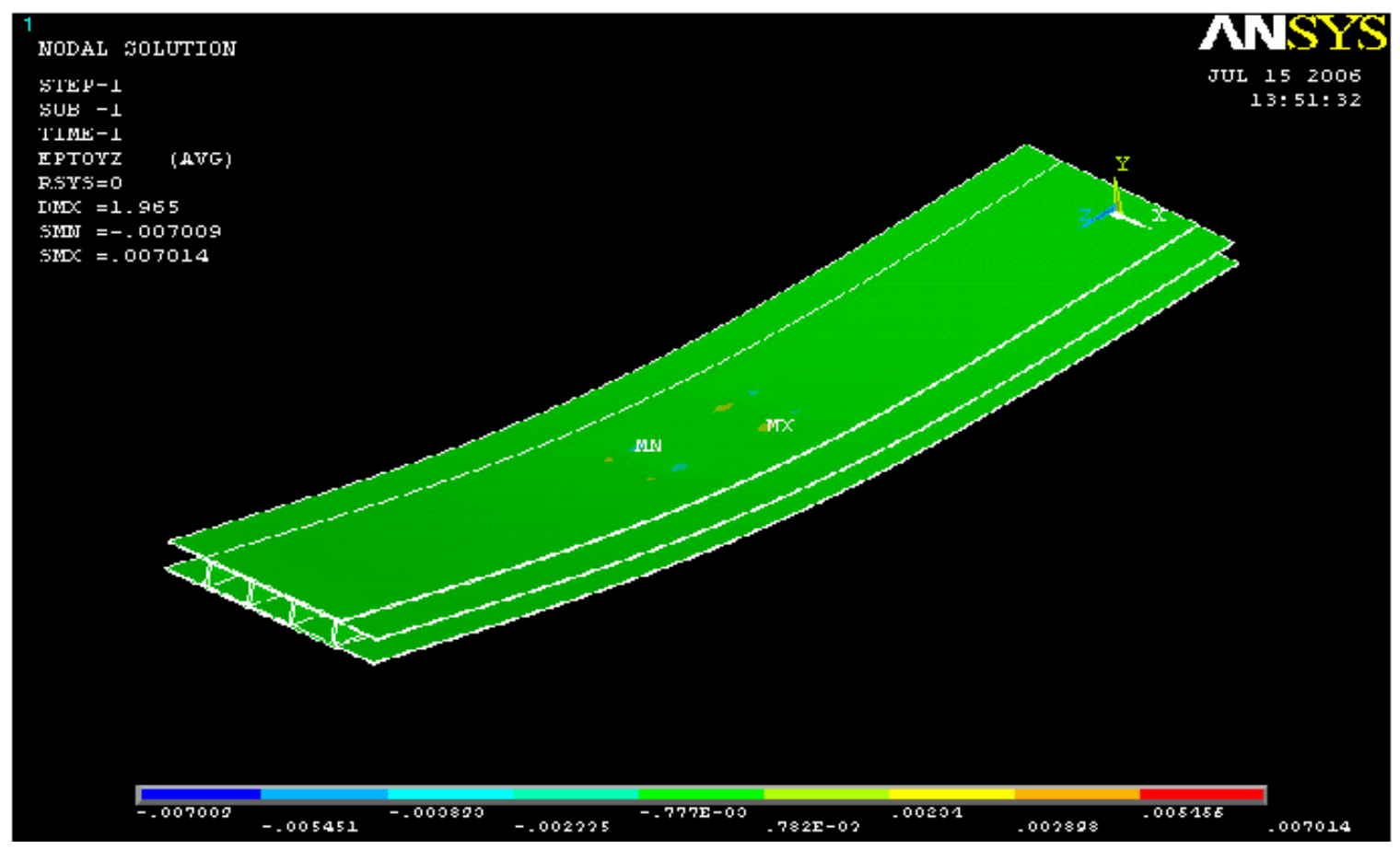

Fig. 3.23 Contour plot of shear strain $\left(\gamma_{\mathrm{yz}}\right)$ of Prodeck 4 for a patch load of 20 kips

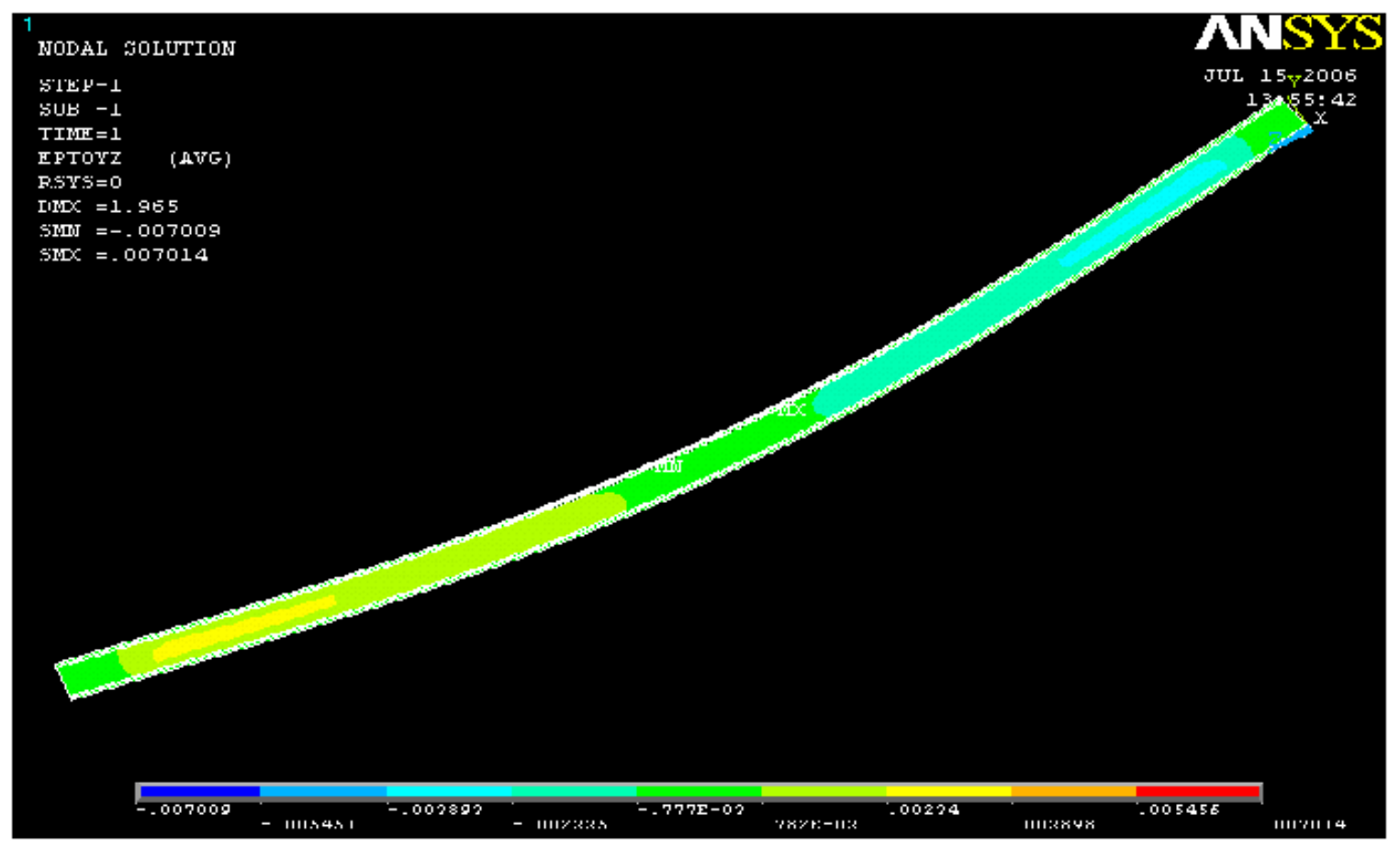

Fig. 3.24 Side view of contour plot of shear strain $\left(\gamma_{\mathrm{yz}}\right)$ for a patch load of $20 \mathrm{kips}$ 


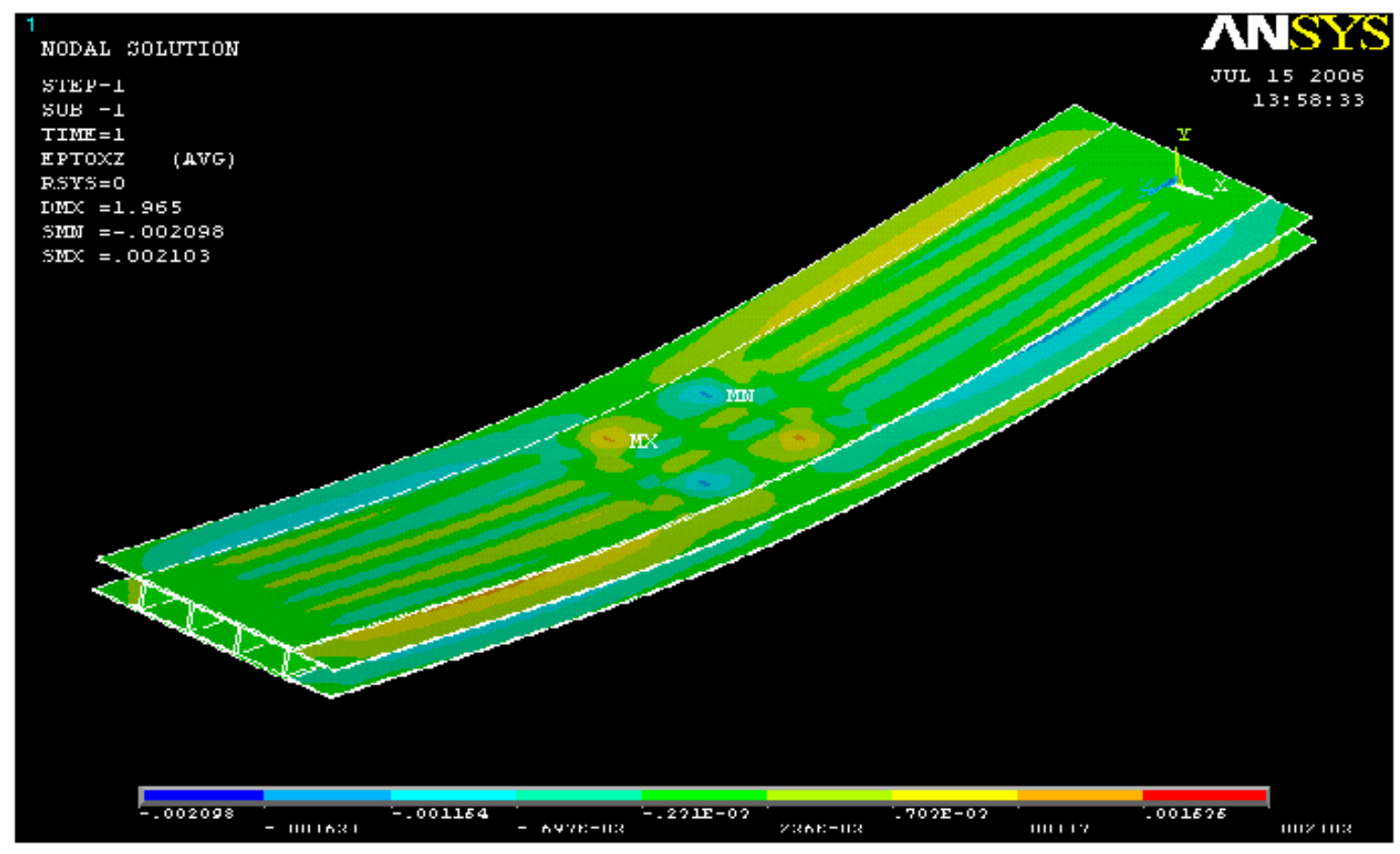

Fig. 3.25 Contour plot of shear strain $\left(\gamma_{x z}\right)$ of Prodeck 4 for a patch load of 20 kips

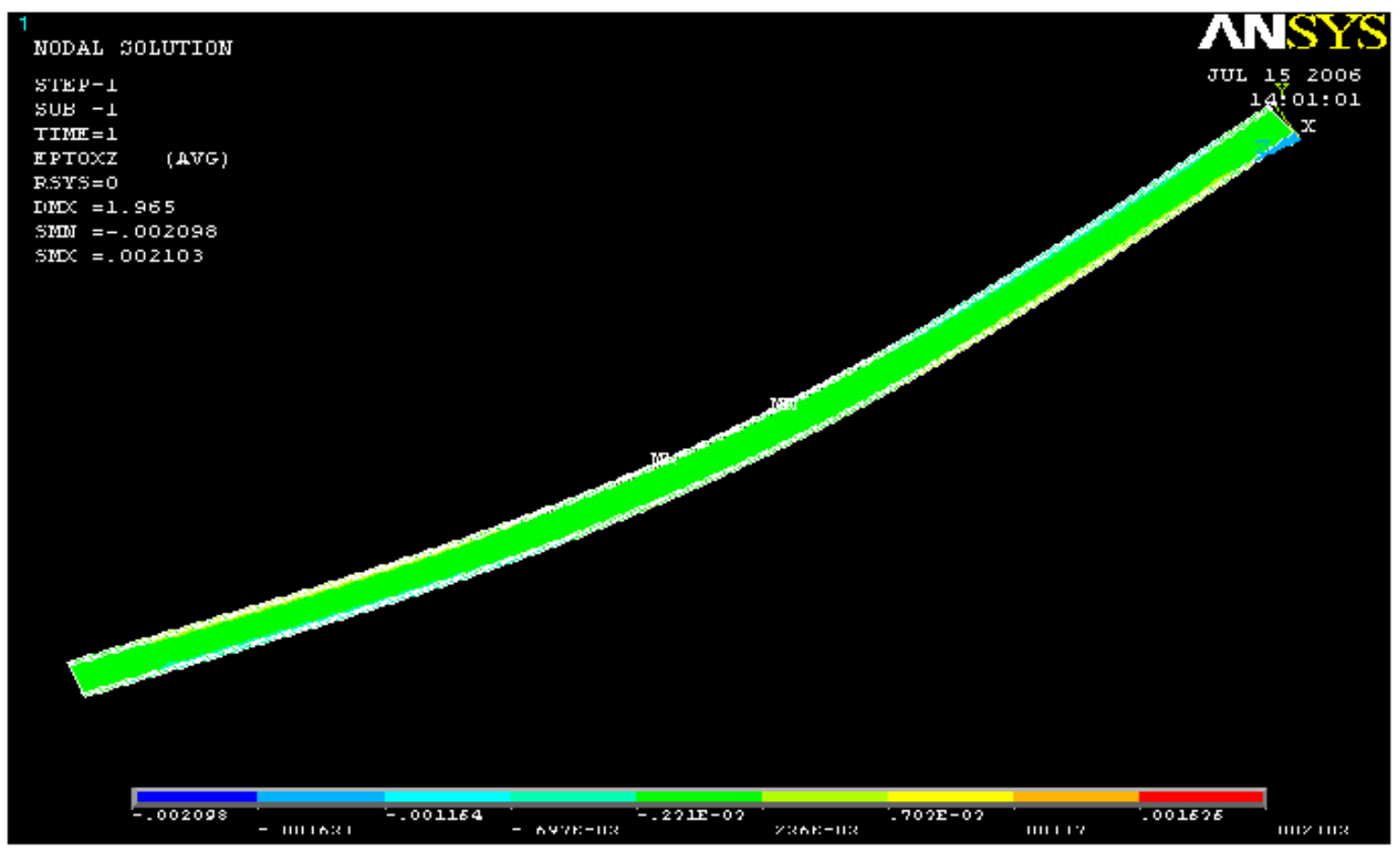

Fig. 3.26 Side view of contour plot of shear strain $\left(\gamma_{x z}\right)$ for a patch load of 20 kips 


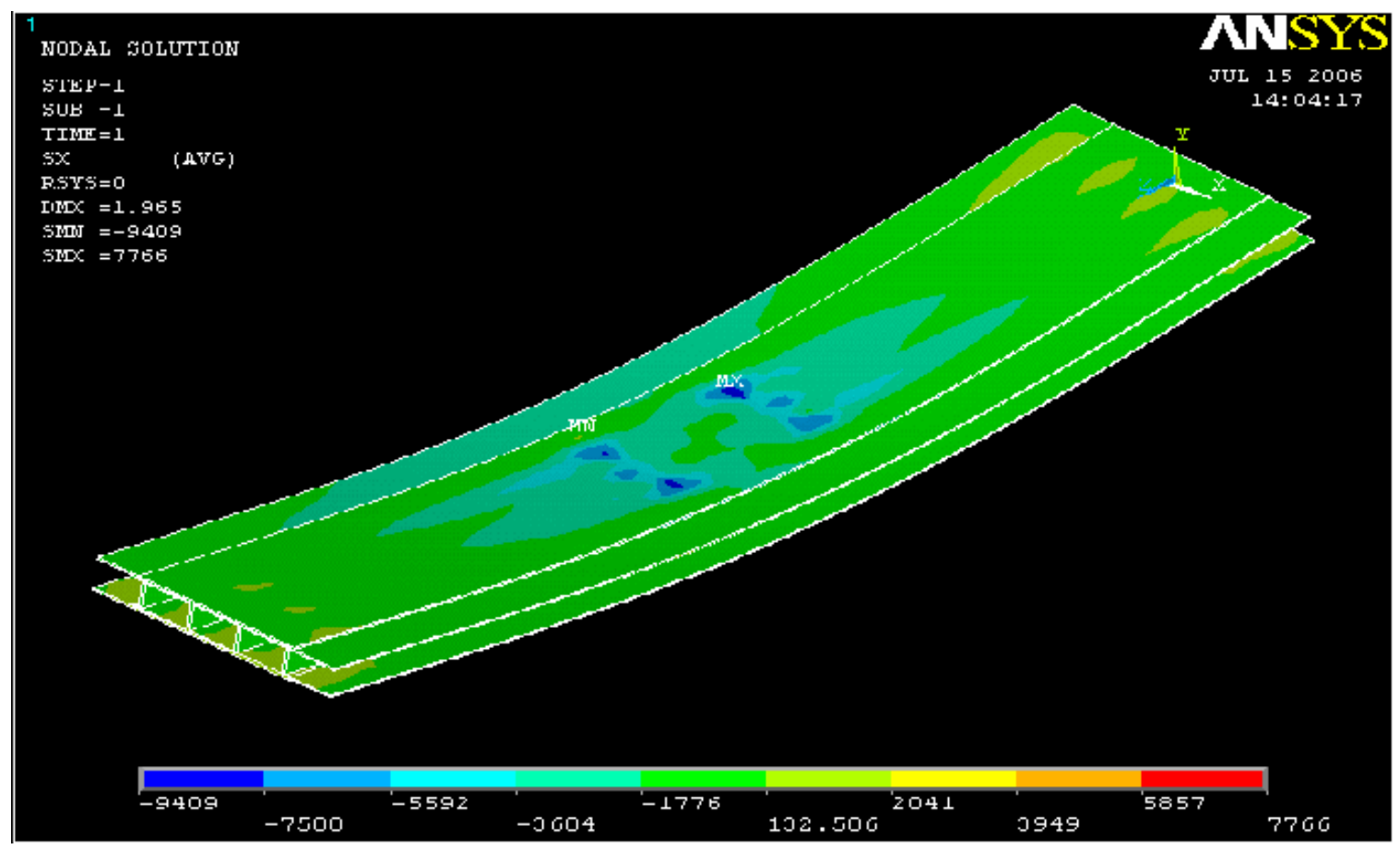

Fig. 3.27 Contour plot of stress $\left(\sigma_{\mathrm{x}}\right)$ of Prodeck 4 for a central patch load of $20 \mathrm{kips}$

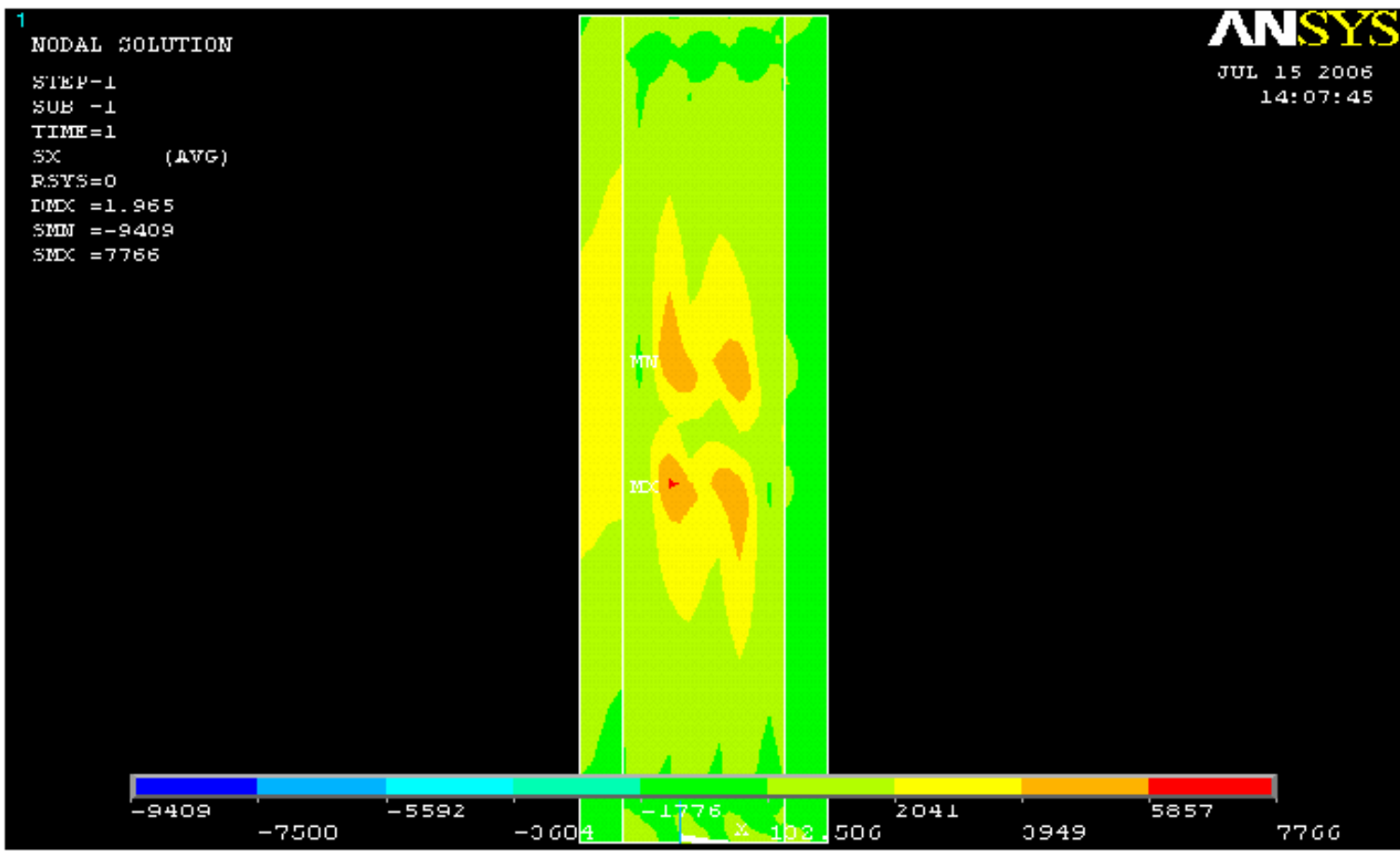

Fig. 3.28 Bottom view of contour plot of stress $\left(\sigma_{\mathrm{x}}\right)$ of Prodeck 4 for a load of 20 kips 


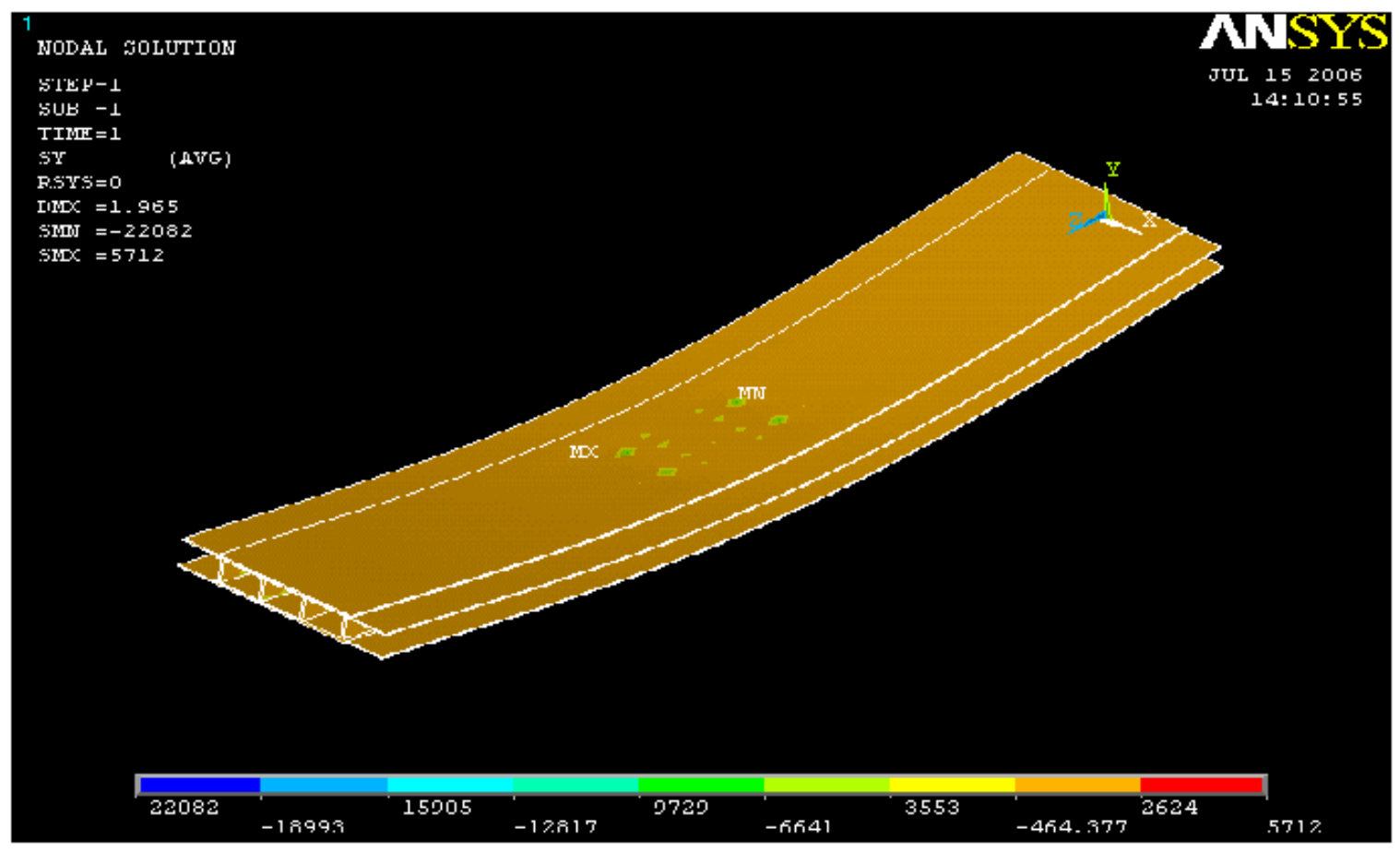

Fig. 3.29 Contour plot of stress $\left(\sigma_{\mathrm{y}}\right)$ of Prodeck 4 for a central patch load of $20 \mathrm{kips}$

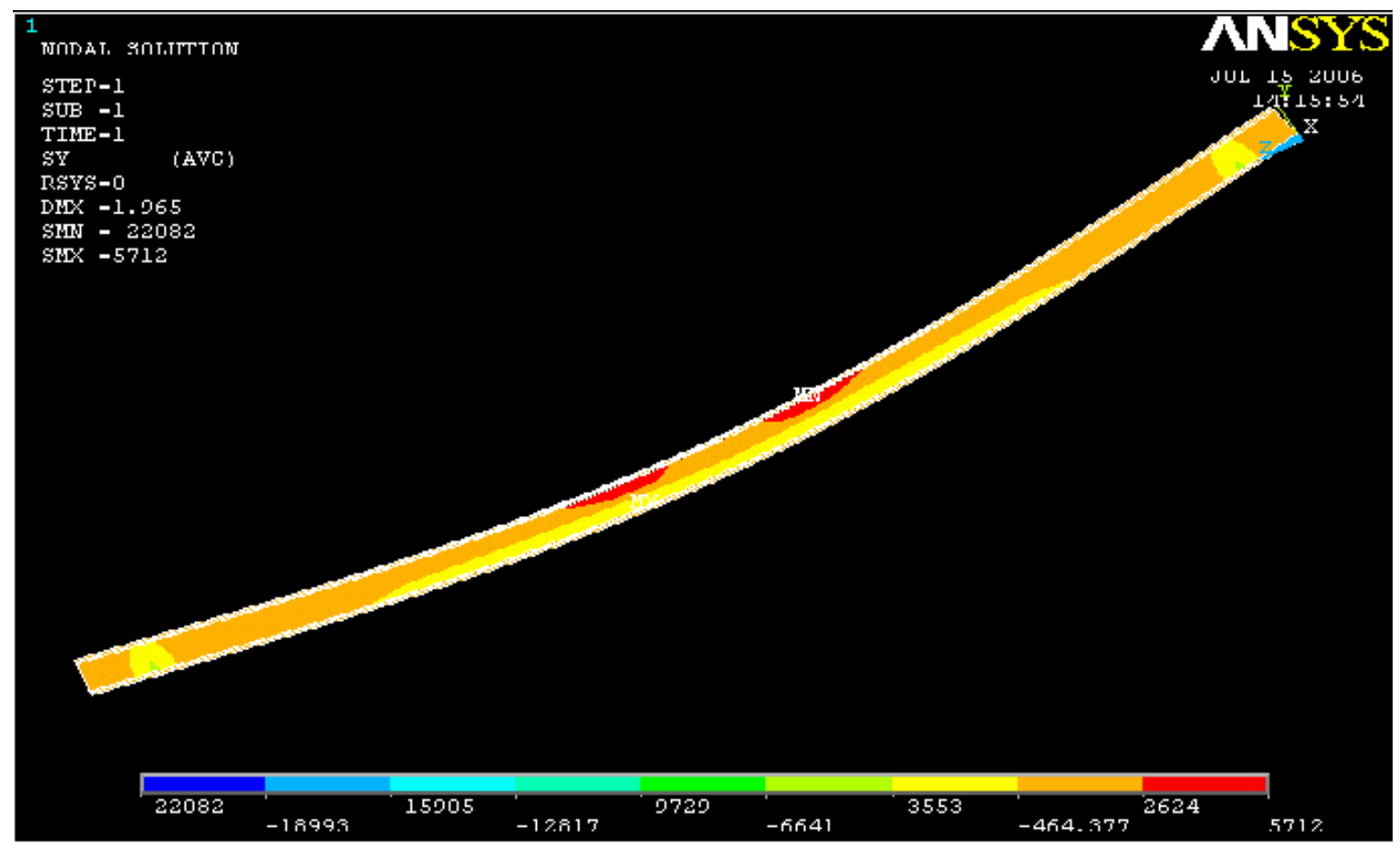

Fig. 3.30 Side view of contour plot of stress $\left(\sigma_{\mathrm{y}}\right)$ of Prodeck 4 for a load of 20 kips 


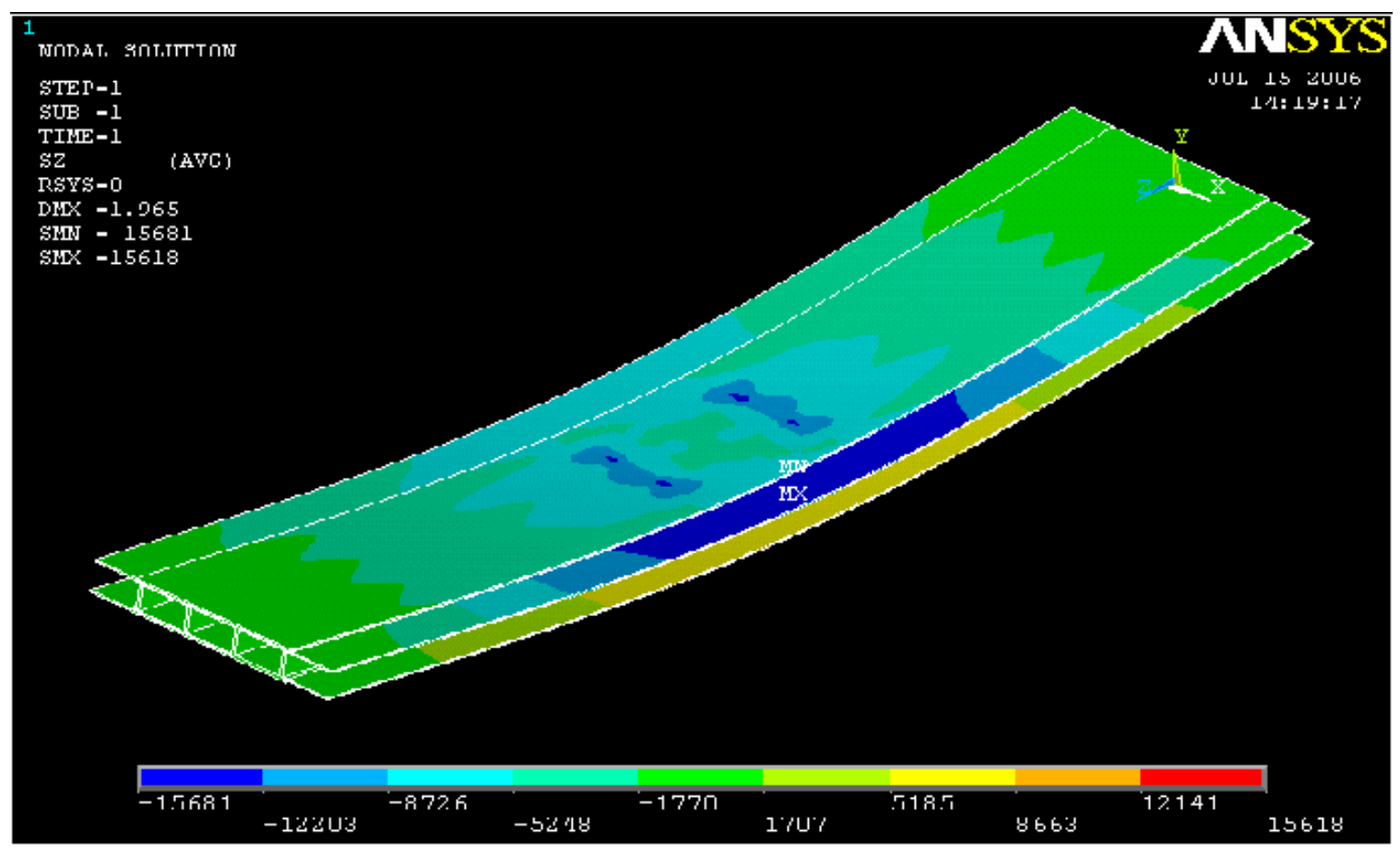

Fig. 3.31 Contour plot of stress $\left(\sigma_{z}\right)$ of Prodeck 4 for a central patch load of 20 kips

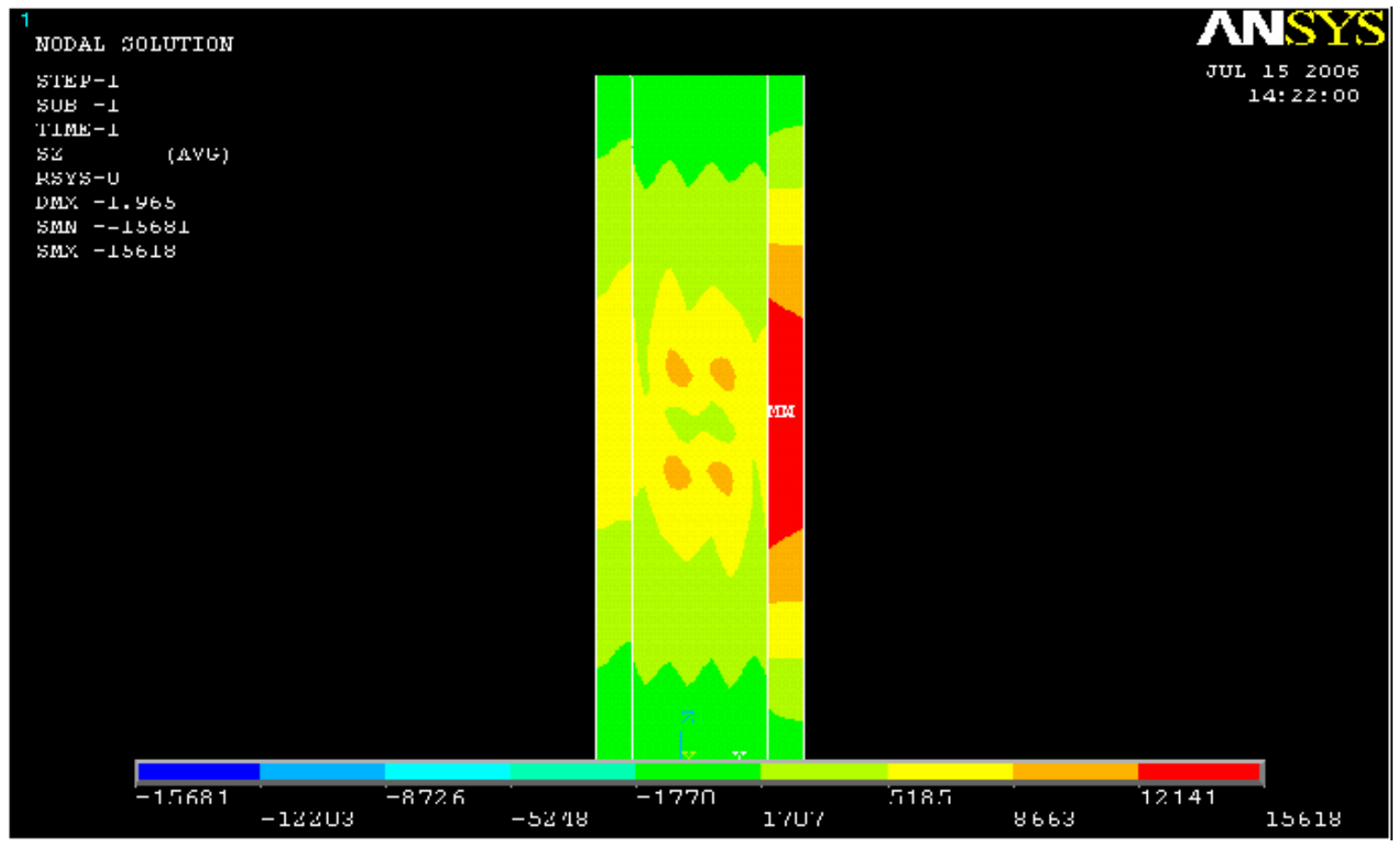

Fig. 3.32 Bottom view of contour plot of stress $\left(\sigma_{z}\right)$ of Prodeck 4 for a load of 20 kips 


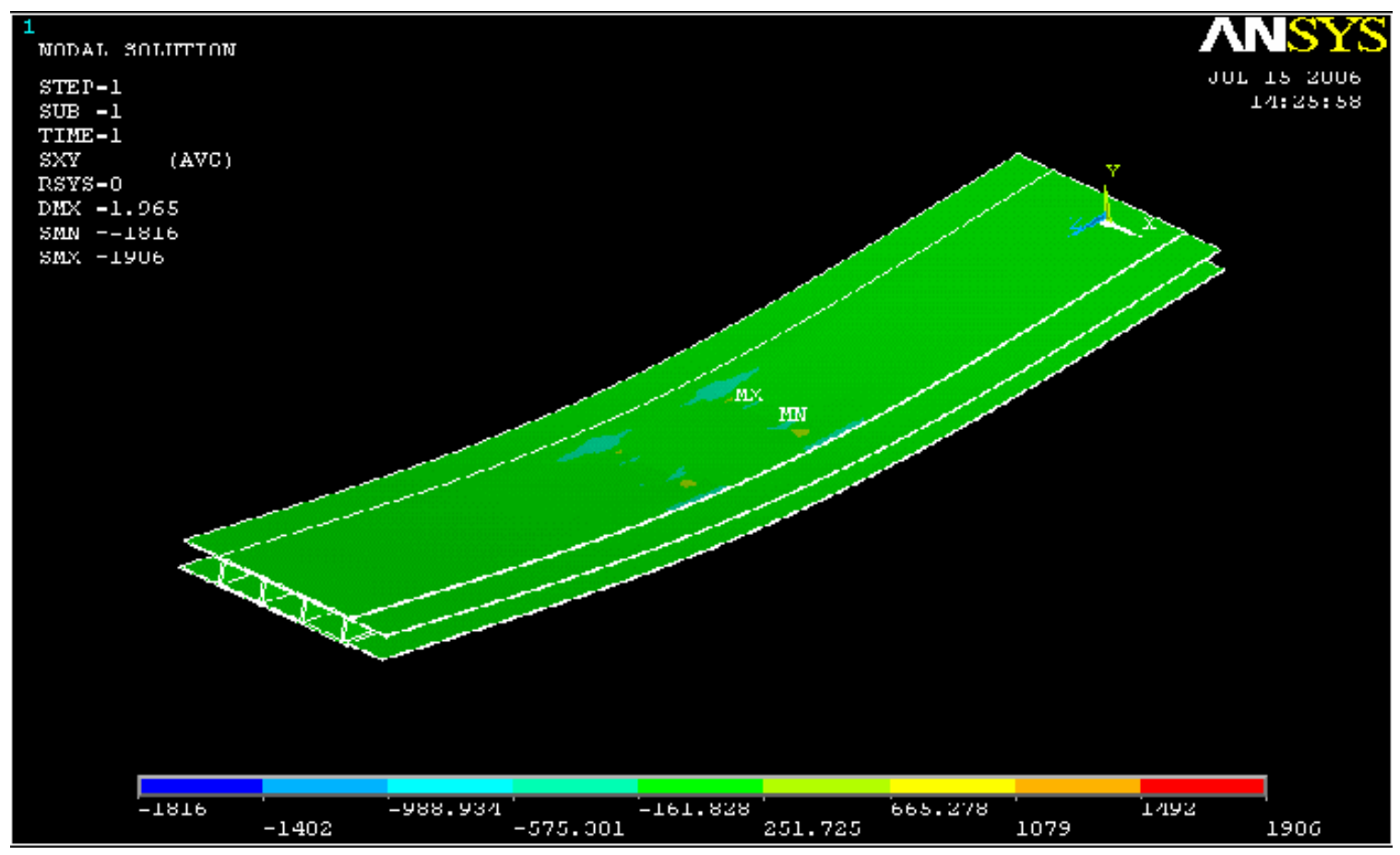

Fig. 3.33 Contour plot of shear stress $\left(\tau_{\mathrm{xy}}\right)$ of Prodeck 4 for a patch load of $20 \mathrm{kips}$

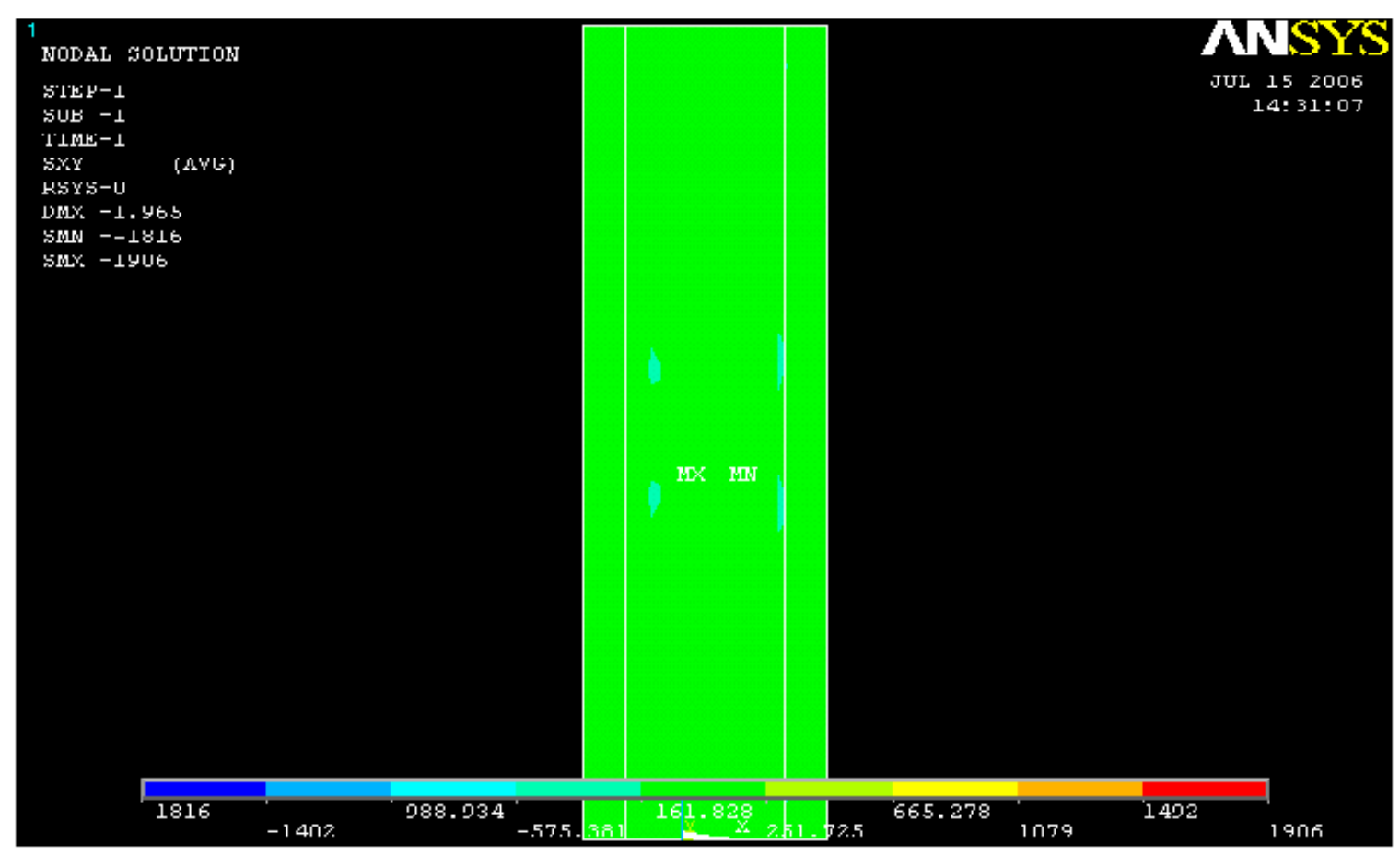

Fig. 3.34 Bottom view of contour plot of shear stress $\left(\tau_{\mathrm{xy}}\right)$ for a patch load of $20 \mathrm{kips}$ 


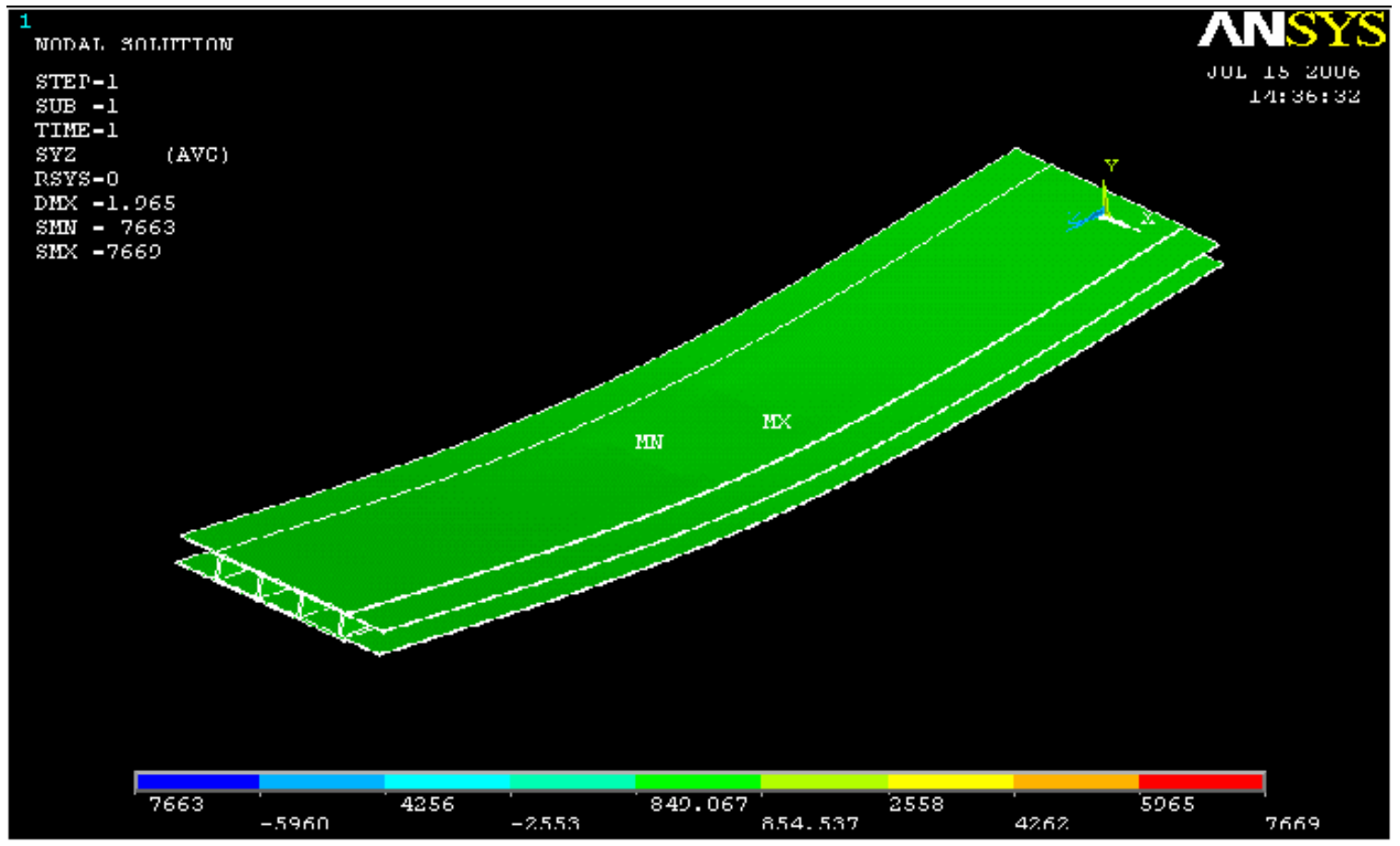

Fig. 3.35 Contour plot of shear stress $\left(\tau_{\mathrm{yz}}\right)$ for a central patch load of 20 kips

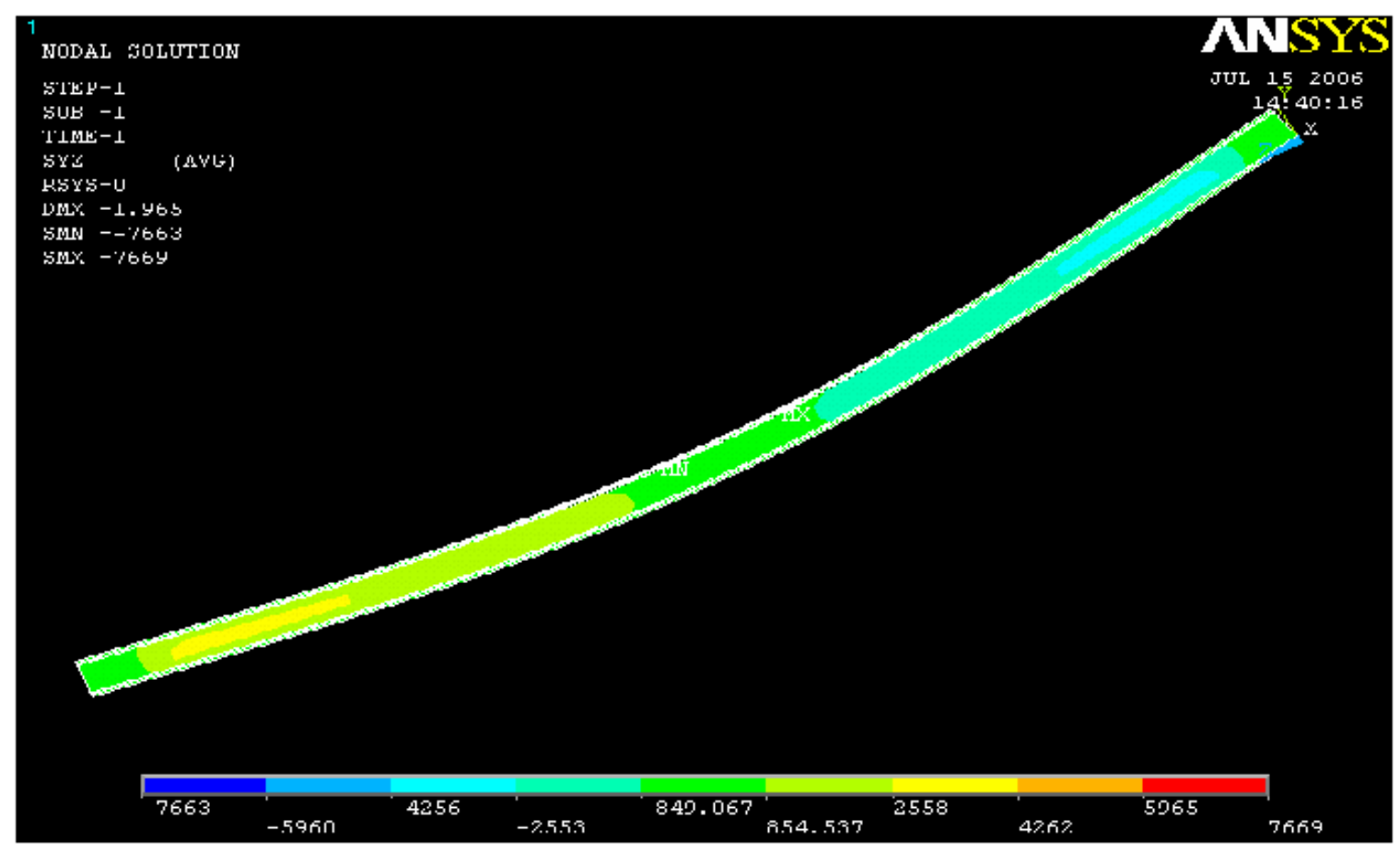

Fig. 3.36 Side view of contour plot of shear stress $\left(\tau_{\mathrm{yz}}\right)$ for a load of $20 \mathrm{kips}$ 


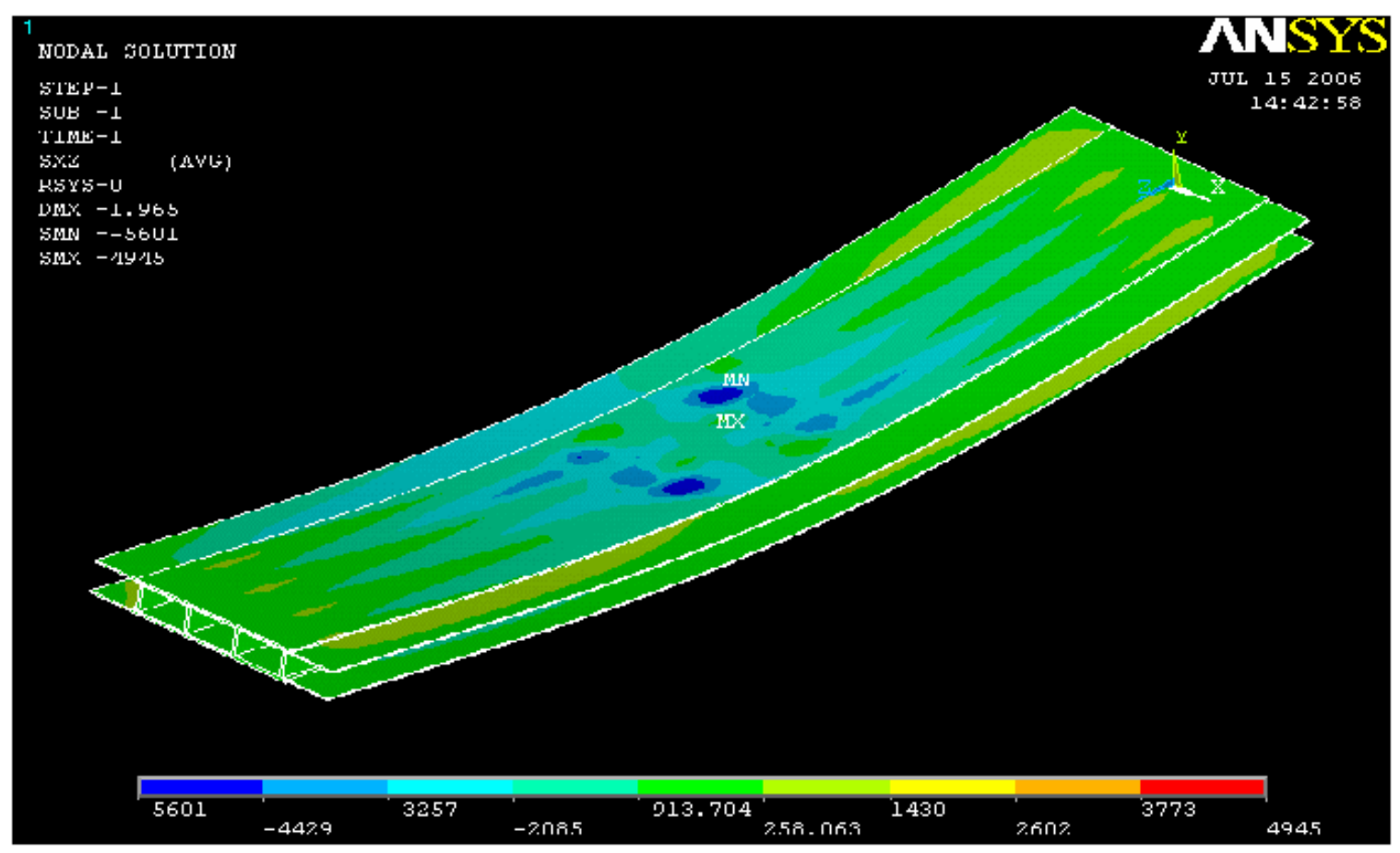

Fig. 3.37 Contour plot of shear stress $\left(\tau_{\mathrm{xz}}\right)$ for a central patch load of 20 kips

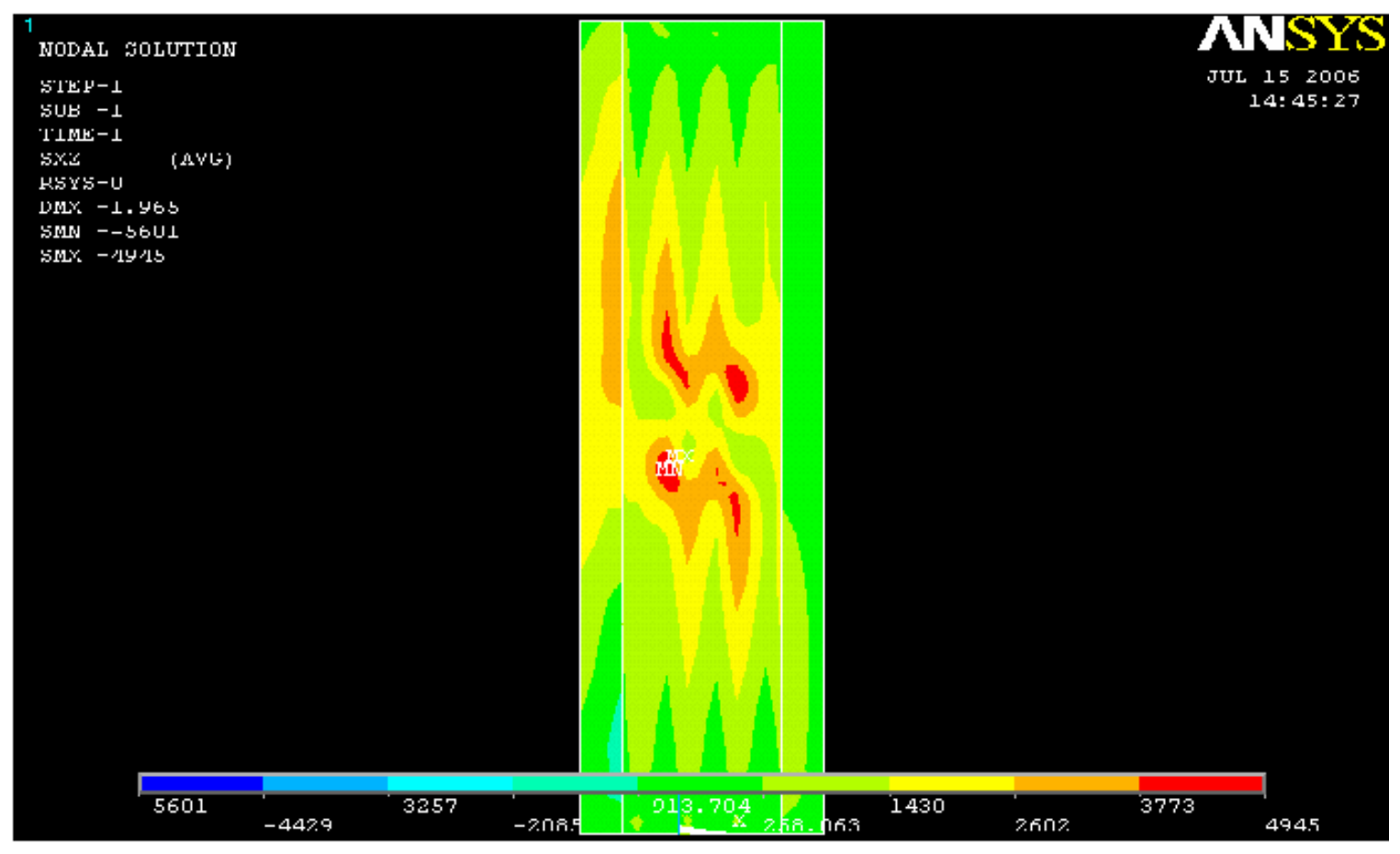

Fig. 3.38 Bottom view of contour plot of shear stress $\left(\tau_{\mathrm{xz}}\right)$ for a load of $20 \mathrm{kips}$ 
From the contour plots of the strain components $\varepsilon_{\mathrm{x}}, \varepsilon_{\mathrm{y}}, \varepsilon_{\mathrm{z}}, \gamma_{\mathrm{xy}}, \gamma_{\mathrm{yz}}$ and $\gamma_{\mathrm{xz}}$ shown above, it is clear that the top flange of the Prodeck 4 is under compression and the bottom flange is under tension. From the Figs. 3.12, 3.13 and 3.14 which show the longitudinal strain $\left(\varepsilon_{\mathrm{z}}\right)$ it is clear that the maximum absolute strain is occurring at the edges of the patch load in the bottom flange where as the maximum compressive strain of value 0.004936 is found to occur at the edges of the patch load in the top flange of Prodeck 4 . As shown in Figs. 3.16, 3.17 and 3.18 maximum value of the in-plane transverse normal strain $\left(\varepsilon_{\mathrm{x}}\right)$ equal to 0.002891 occurs at the corners of the patch load. From the sectional view of the deck in the Fig 3.18 the red region marks the region where the maximum value in-plane transverse normal strain $\left(\varepsilon_{\mathrm{x}}\right)$ occurs. Figures 3.19 and 3.20 show the maximum and minimum values of the out-of-plane transverse normal strain $\left(\varepsilon_{y}\right)$, which are equal to 0.0031 and -0.0051 that occur at the edges of the patch load on the top and the bottom flanges respectively. Figures 3.21-3.26 depict the contour plots of shear strain components $\gamma_{\mathrm{xy}}, \gamma_{\mathrm{yz}}$ and $\gamma_{\mathrm{xz}}$, where all are mainly concentrated near the loading zone. The maximum values of $\gamma_{\mathrm{xy}}$ and $\gamma_{\mathrm{xz}}$ are 0.0017 and 0.0021 respectively while that of $\gamma_{\mathrm{yz}}$ is 0.0070 .

Figures 3.27-3.38 show the stress plots of the Prodeck 4. It is clear from the Figs. 3.31 and 3.32 that $\sigma_{\mathrm{z}}$ the maximum compressive stress occurs at the mid span in the extended part of the top flange and the maximum tensile stress in the extended part of the bottom flange. The maximum absolute value is about 15600 psi. The maximum in-plane $\left(\sigma_{\mathrm{x}}\right)$ stress shown in Fig. 3.28 occurs in the bottom flange of the deck, where as the maximum transverse $\left(\sigma_{\mathrm{y}}\right)$ stress occurs in Fig. 3.30 occurs in the web section. Figs $3.33-$ 3.38 show the contours of shear stress plots of the deck. 


\subsection{FAILURE ANALYSIS}

As ANSYS software is limited to first-ply failure analysis and since an automatic progressive ply failure cannot be carried out in it, first ply failure analysis is carried out for a central patch load of 20 kips applied over an area of 10"x 20".

The failure plot obtained using maximum stress criterion for the Prodeck 4 under the central patch load of 20 kips applied over an area of 10 "x 20 " is as shown below in the Fig. 3.39. The values listed in this plot are the values of ' $\xi$ ', which is the inverse of the strength ratio (R) as defined earlier in Eq. (3.31). In Fig. 3.39 the maximum value of $\xi$ is shown to be 1.5532 , which implies that according to the maximum stress criterion the load value at which the first ply fails in Prodeck 4 is equal to $P=20 / 1.5532=12.8$ kips. In composite structures, failure of the first ply does not mean the failure of the whole structure. Generally, the first ply fails in the transverse direction due to the failure in the matrix but the structure is still capable of taking higher loads in the fiber direction. In Fig. 3.11, the experimental curve tends to exhibit non-linear behavior at a load of about 12 kips which is probably due to failure of first ply of Prodeck 4, which is also in good match with the value of first ply failure load obtained using maximum stress criterion. From Figs. 3.39 and 3.40 it is clear that the failure occurs in the bottom flange at the corners of the central patch load applied. 


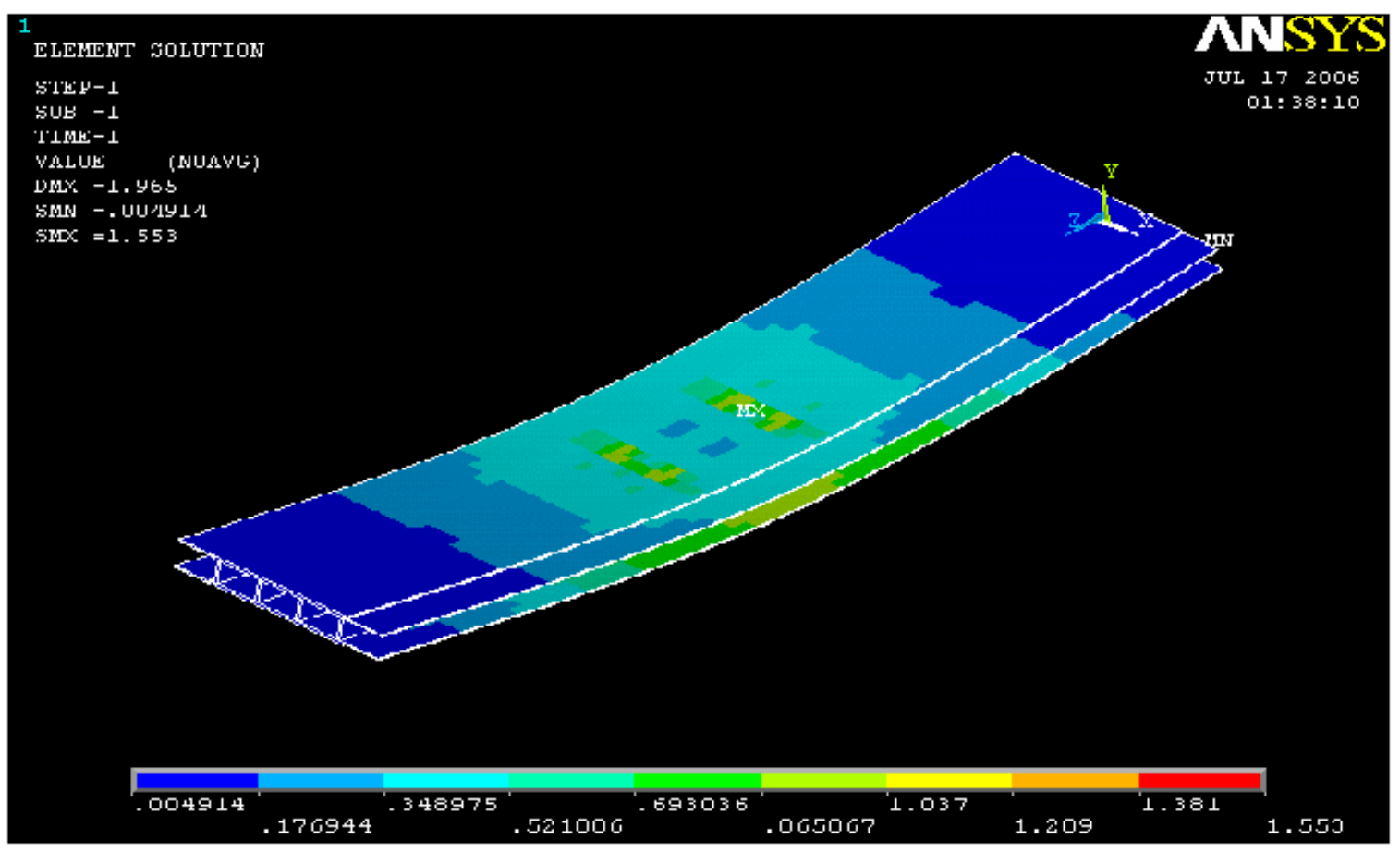

Fig. 3.39 Failure plot of Prodeck 4 using maximum stress criterion

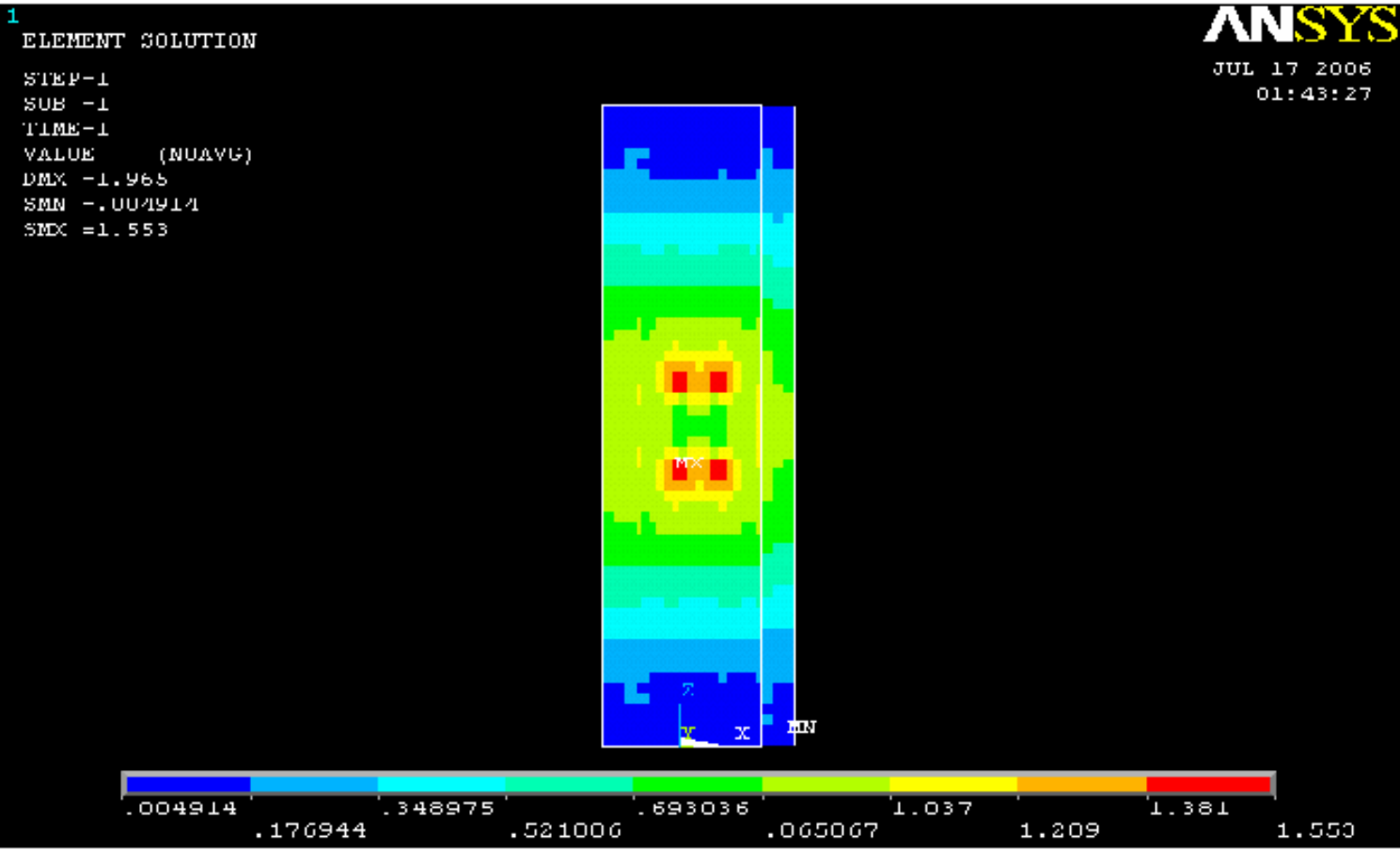

Fig. 3.40 Bottom view of the failure plot of Prodeck 4 using maximum stress criterion 
The failure plot obtained using maximum strain criterion is as shown in Figs. 3.41 and 3.42. Both maximum stress and maximum strain criteria failure plots predict the failure in the bottom flange at the corners of the central patch load and they even look similar. It is observed that the $90^{\circ}$ plies in the bottom flange fail first, they seem to fail in the transverse direction as failure strength value $F_{2 t}$ is the lowest among all the failure strengths. The maximum value of $\xi$ listed in the maximum strain criterion failure plot is 1.4553 as shown in the figure below, which implies that the first ply failure load predicted by using maximum strain criterion is equal to $\mathrm{P}=20 / 1.4553=13.7 \mathrm{kips}$, which is close to the value obtained using the maximum stress criterion.

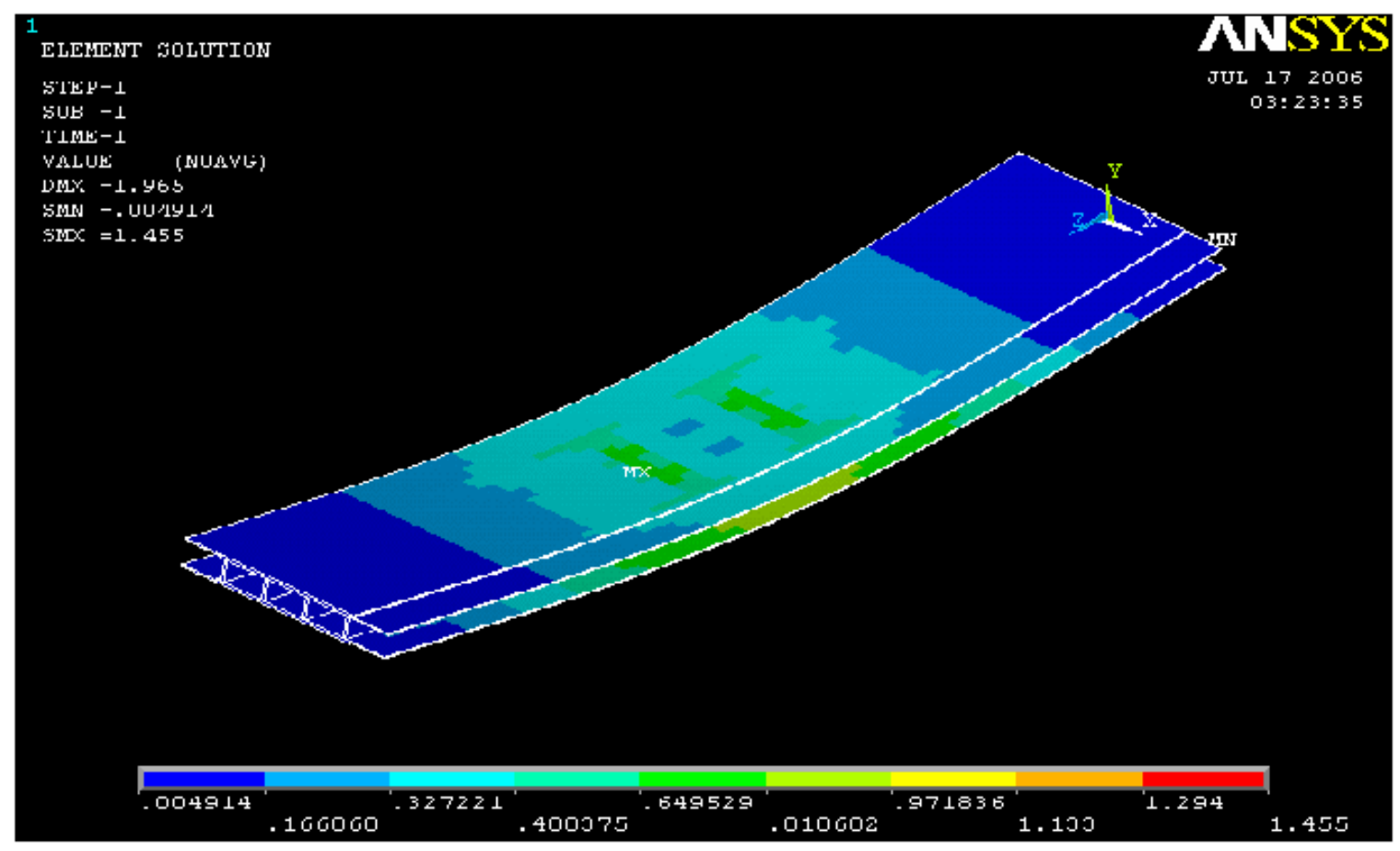

Fig. 3.41 Failure plot of Prodeck 4 using maximum strain criterion 


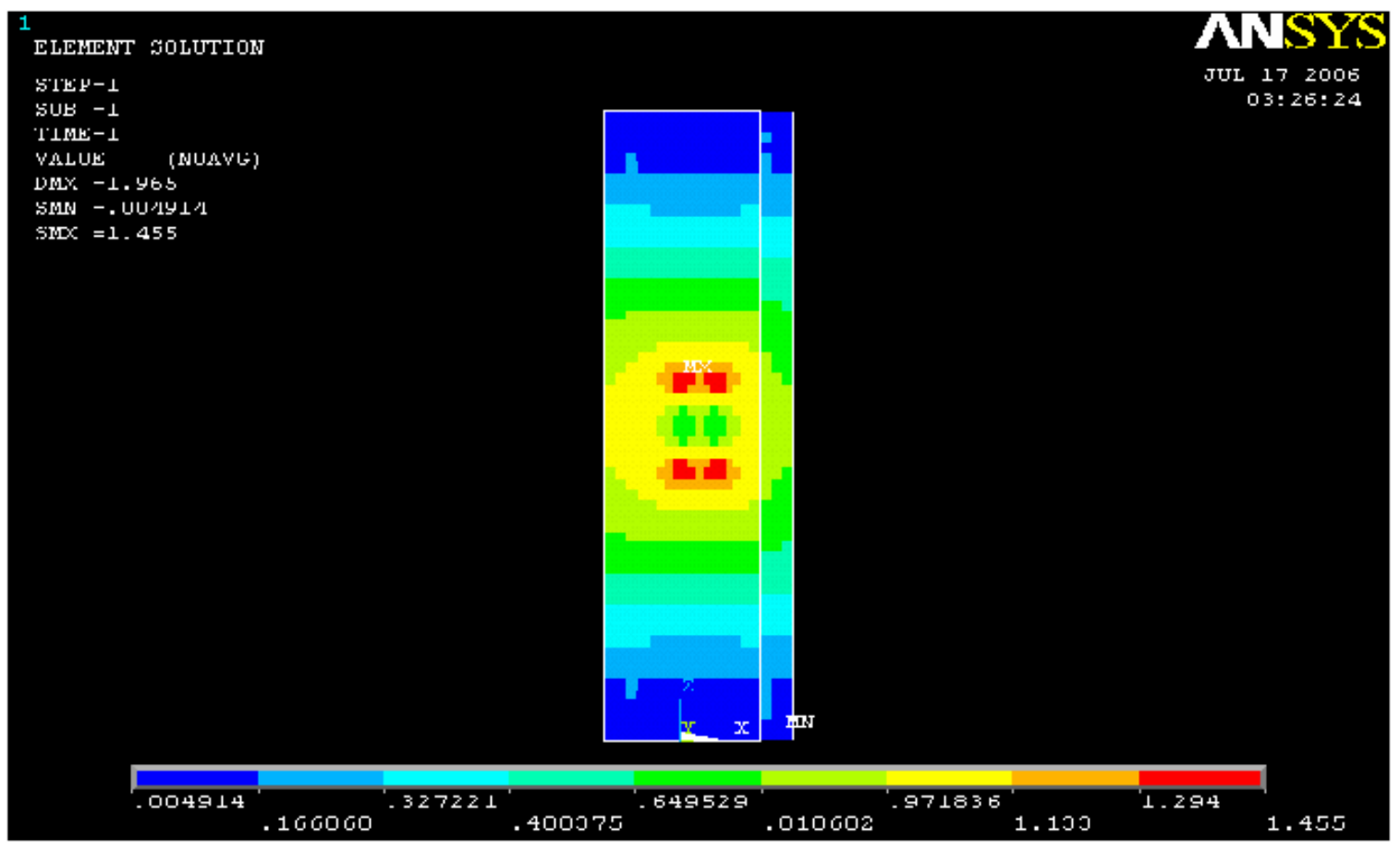

Fig. 3.42 Bottom view of the failure plot of Prodeck 4 using maximum strain criterion

The failure plot using Tsai-Wu criterion is shown below in Figs. 3.43 and 3.44. The maximum value of $\xi$ listed in the failure plot below is 1.8950 , which is greater than values obtained by both maximum stress and maximum strain criteria. The first ply failure load is found to be 10.5 kips and the failure occurs in the bottom flange at the corners of the central patch load applied as predicted by other two criteria. From the above predicted values it is observed that though Tsai-Wu criterion may not yield accurate results all the three criteria predicted the failure at about the same location in the deck. 


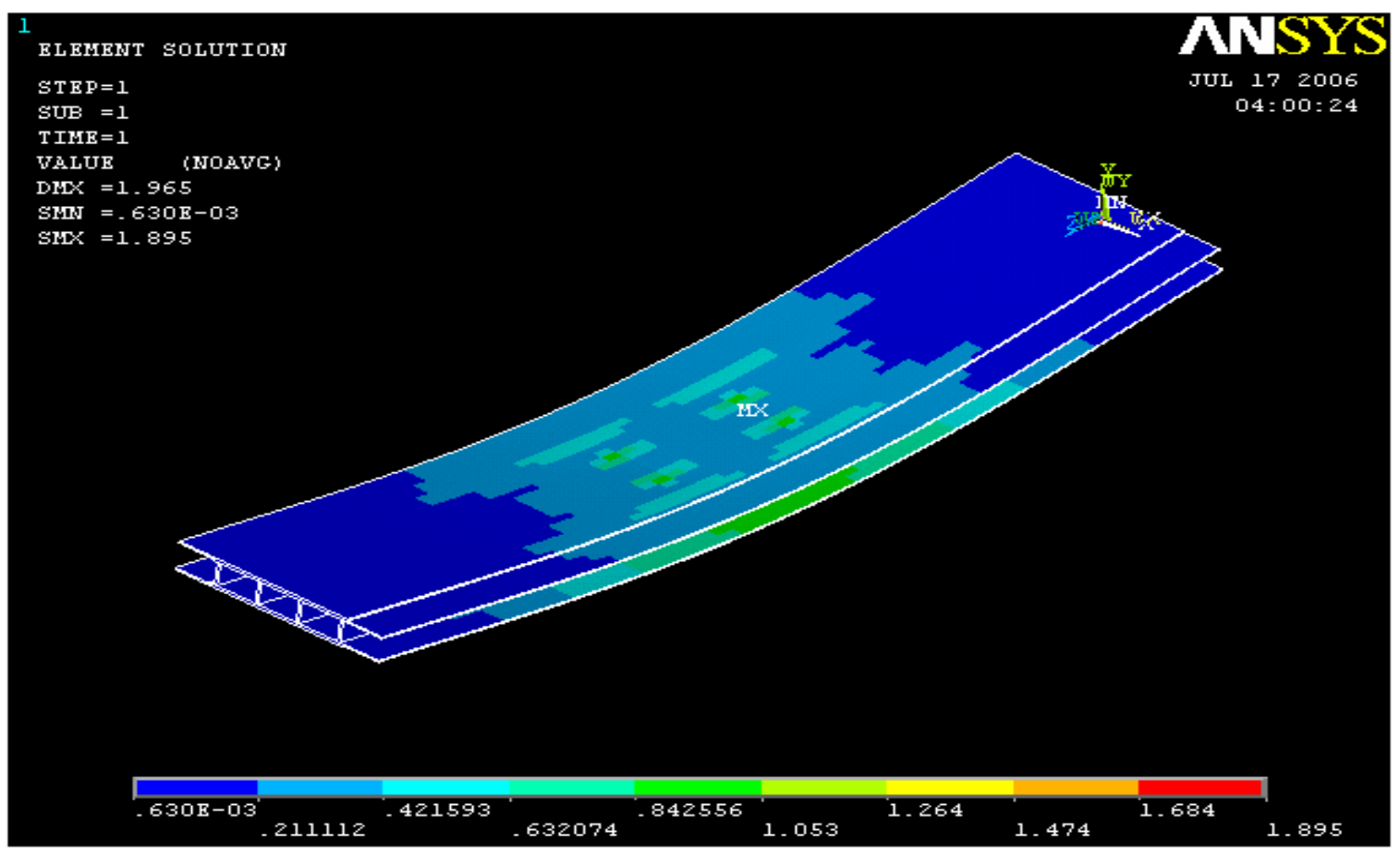

Fig. 3.43 Failure plot of Prodeck 4 using Tsai-Wu criterion

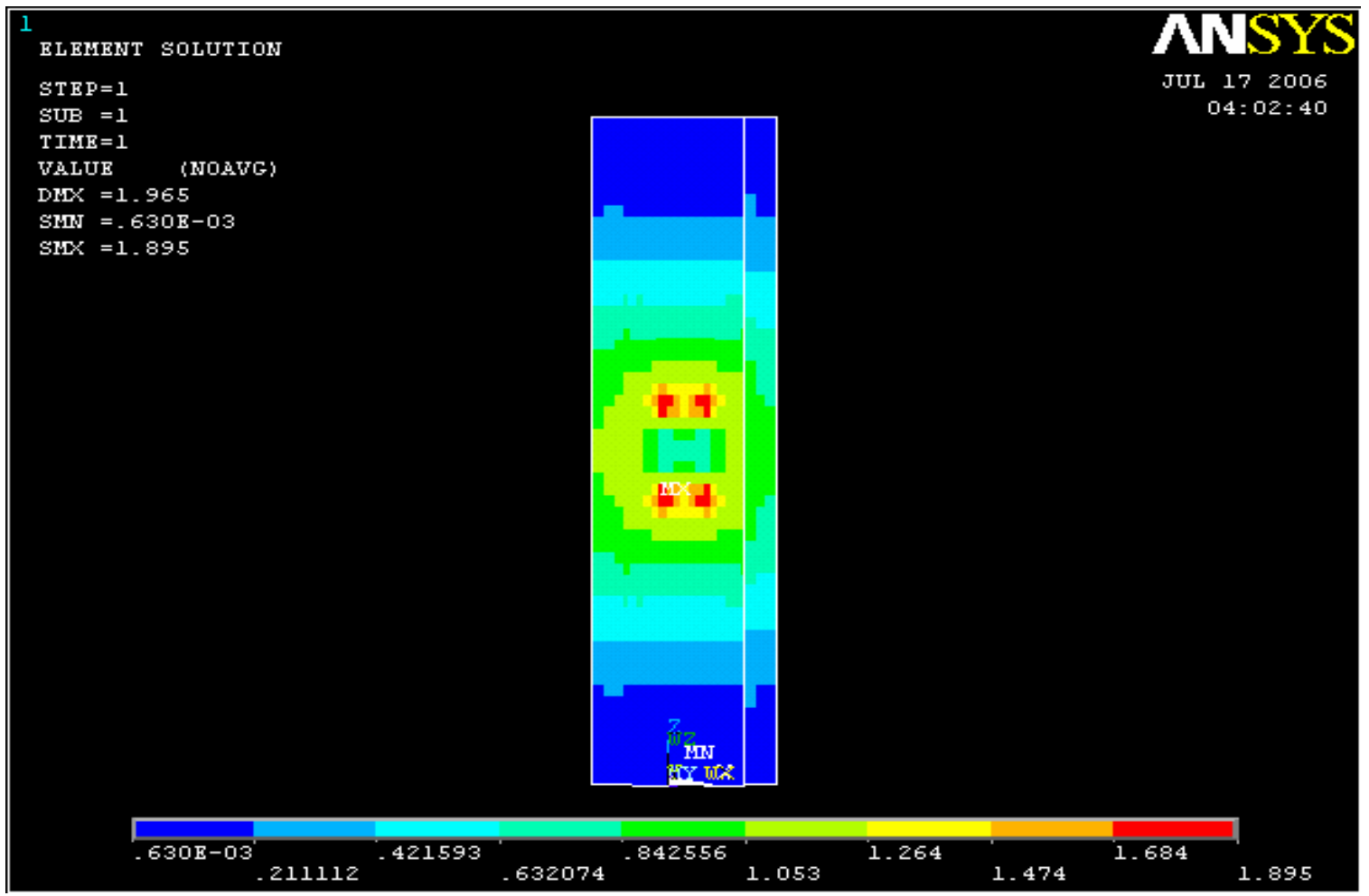

Fig. 3.44 Bottom view of the failure plot of Prodeck 4 using Tsai-Wu criterion 


\subsection{BUCKLING ANALYSIS}

A buckling analysis is carried out on the finite element model of Prodeck 4, which is of length 10". A patch load over an area of 20 "x 10 " is applied on the top flange of the deck. In this buckling analysis the eigen value buckling method is used to obtain the critical value of the buckling load of the deck. The critical value of buckling load for the first mode of buckling is found to be 601 kips. The buckled shape of the deck is shown in Fig. 3.45.

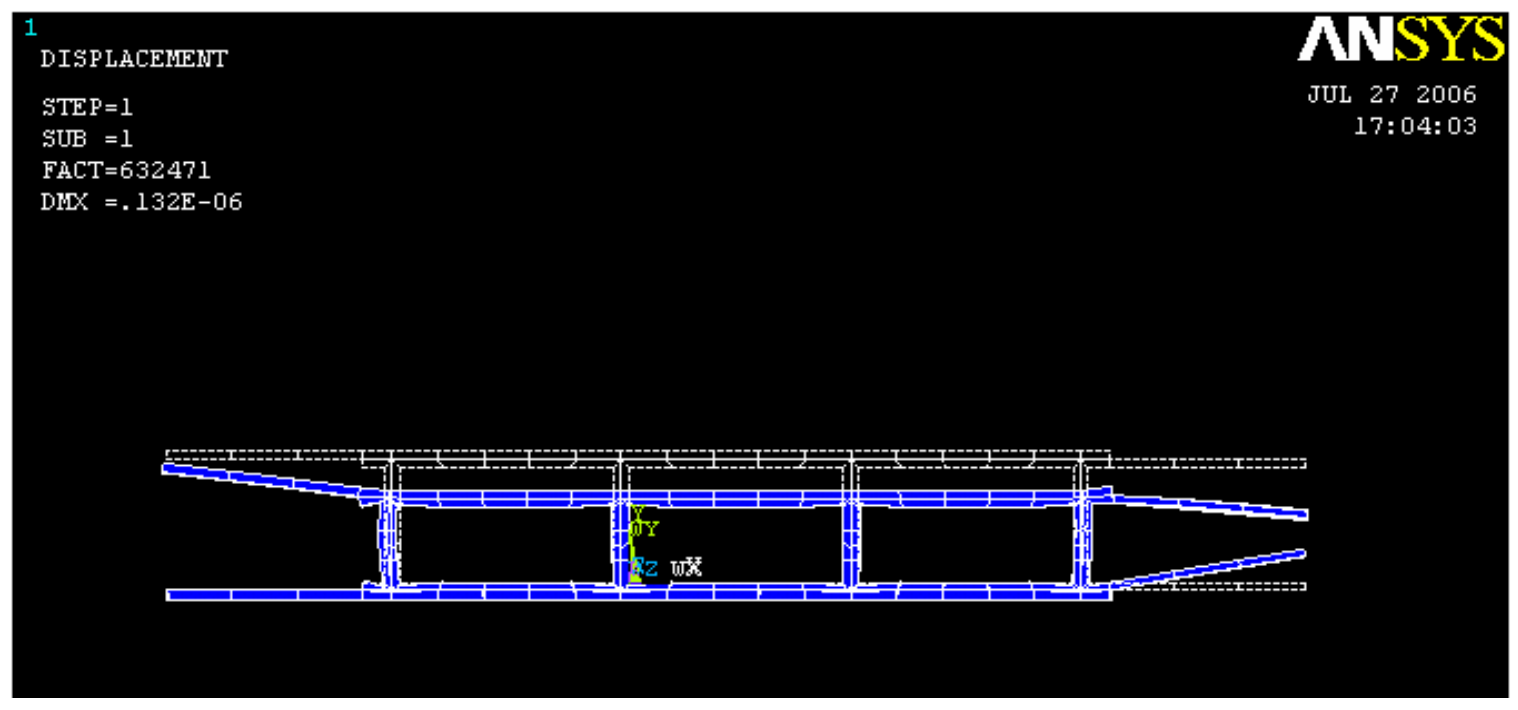

Fig. 3.45 Buckled shape of Prodeck 4

Buckling analysis is also carried out on just the web section of dimensions 3.14" in height, 0.375 " thick and 10 " in length. A patch load over an area of 10 "x 0.375 " is applied on the web. The critical load value of buckling for the first mode for the web is found to be around 100 kips. 


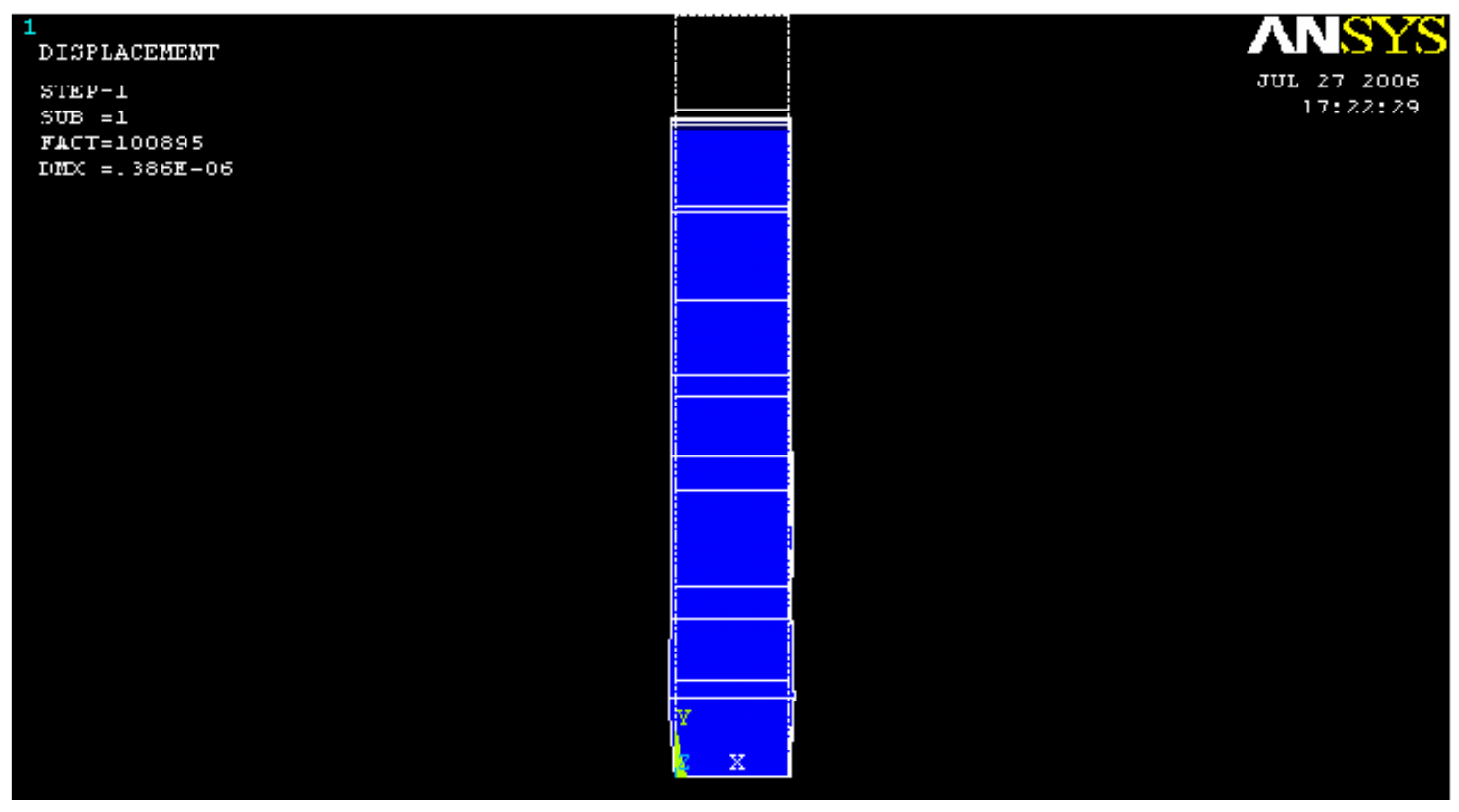

Fig. 3.46 Buckled shape of the web 


\section{CHAPTER 4}

\section{FRP BEAM ANALYSIS}

\subsection{INTRODUCTION}

This chapter deals with the development of a finite element model of the lowprofile FRP bridge deck as a beam and the results of the model are used to analytically evaluate the deck's flexural rigidity. The value thus obtained is then compared to the value obtained in experimental tests conducted by previous researchers.

\subsection{FINITE ELEMENT MODEL}

First a solid model of the FRP beam is generated by creating key points and then defining volumes by selecting key points. The volumes thus formed are map meshed and then the orientations of the layers are checked as mentioned earlier in Section 3.4.

Figure 4.1 displays a solid model of the FRP beam with the cross section dimensions of 24" x 4", which consists of 33 volumes that are glued together. The solid model when map meshed results in a total of 11024 elements consisting of 18900 nodes. The orientations of the coordinate systems of all the elements are checked to see if they are aligned in the fiber direction and changes in the orientations are manually made if necessary.

Figures 4.2 and 4.3 show the map meshed model of the FRP beam and orientations of element coordinate systems, respectively. The element orientations are with respect to the locally defined coordinate systems for all the elements. 


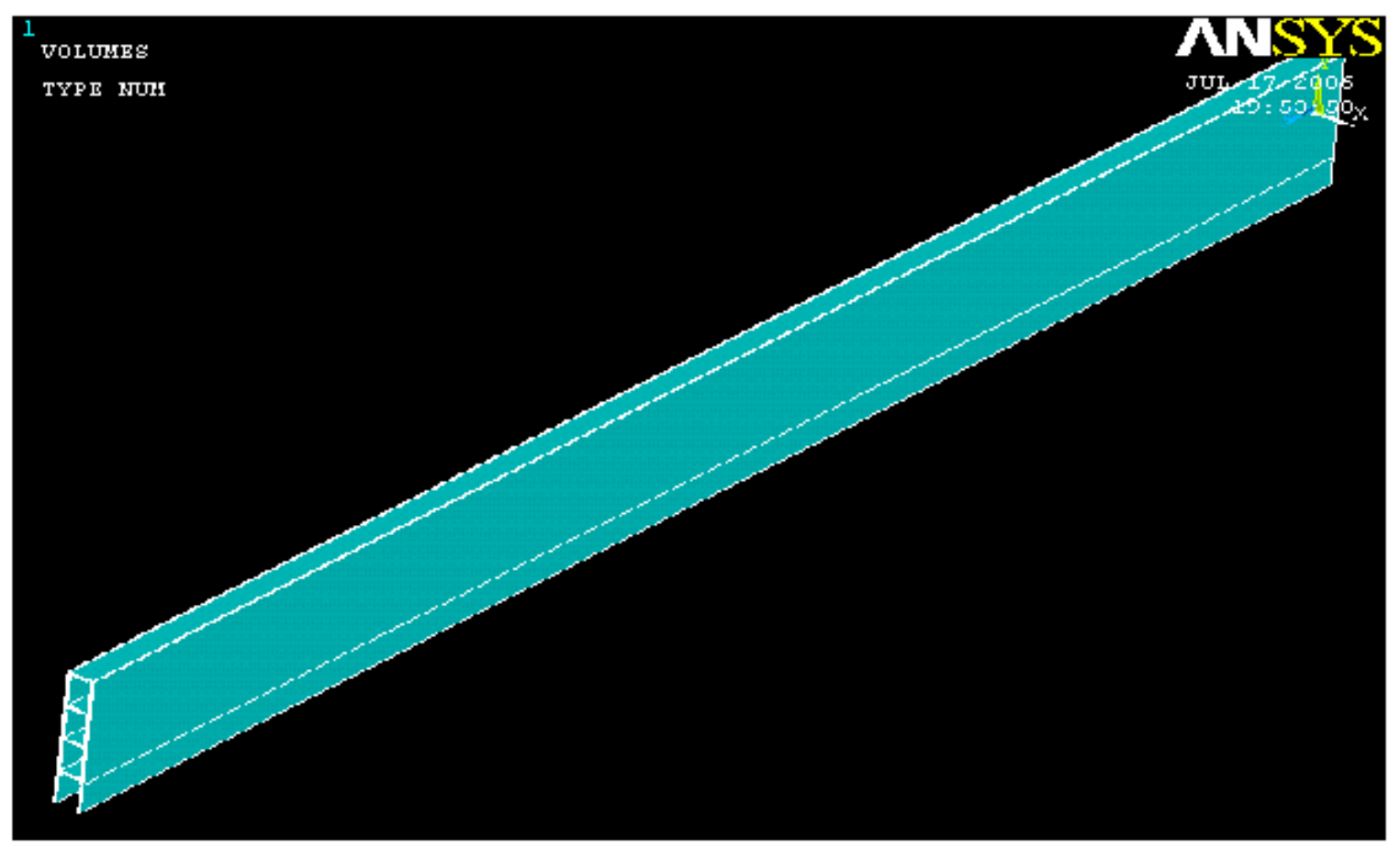

Fig. 4.1 Solid model of FRP beam

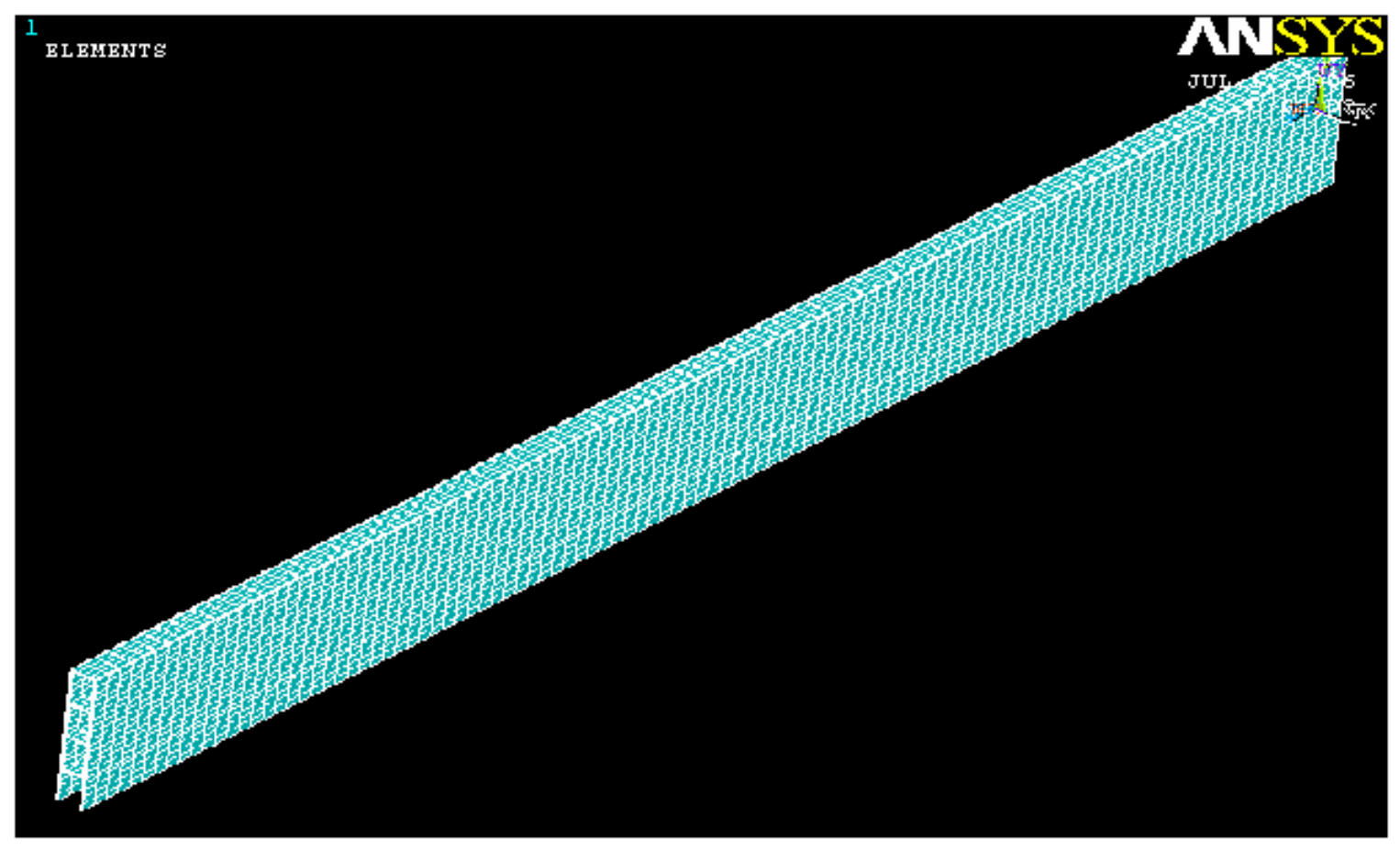

Fig. 4.2 Map meshed model of FRP beam 


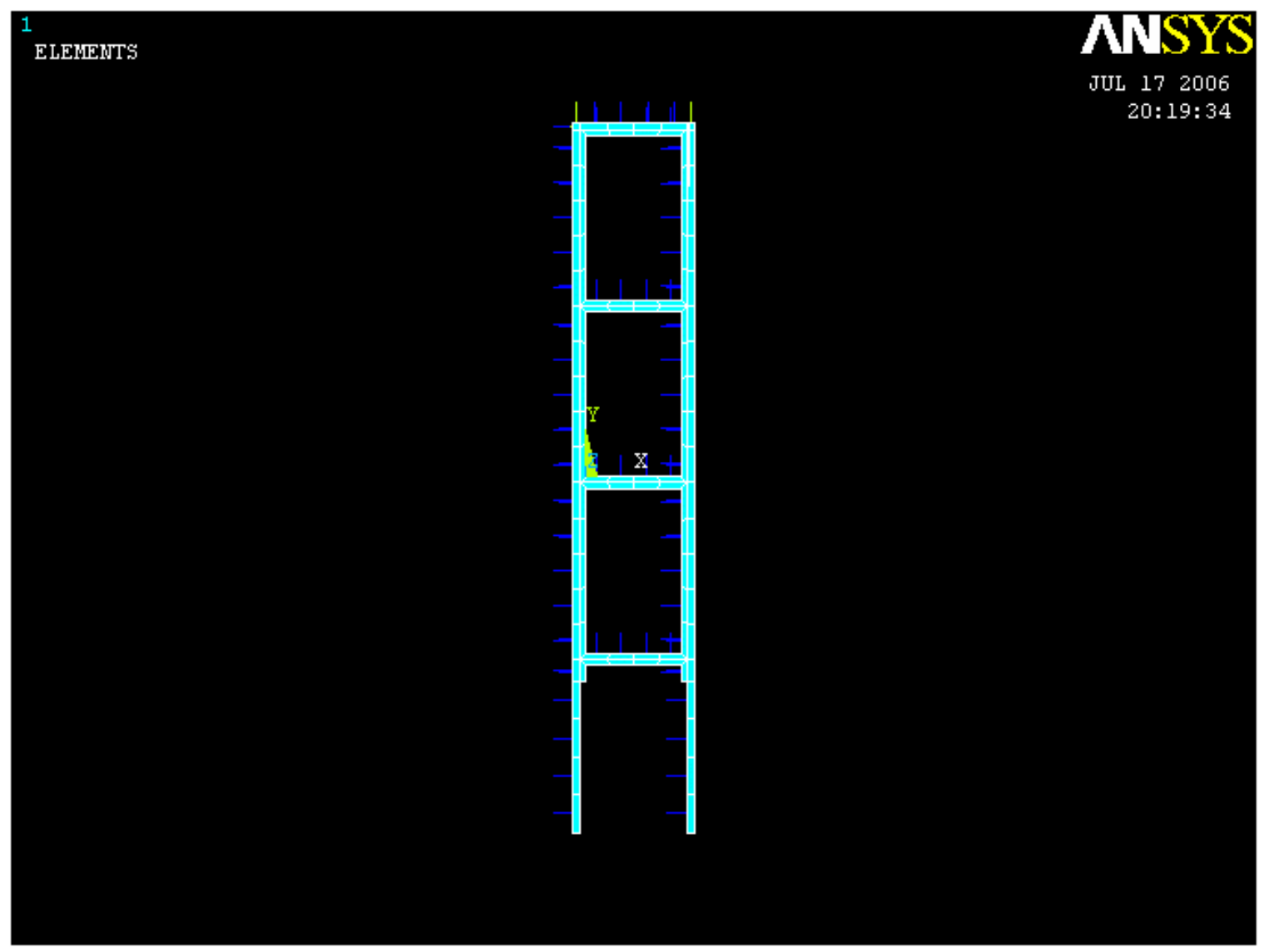

Fig. 4.3 Orientations of element coordinate systems in FRP beam

\subsection{BOUNDARY CONDITIONS}

The boundary conditions applied to the FRP beam model are as shown in Fig. 4.4. The beam is simply supported with a clear span of 227 ". To simulate the effect of the steel plate used in patch loading, coupling restraints over an area of 4"x 11" are applied at the center on the top flange of the beam as described earlier in Section 3.5. 


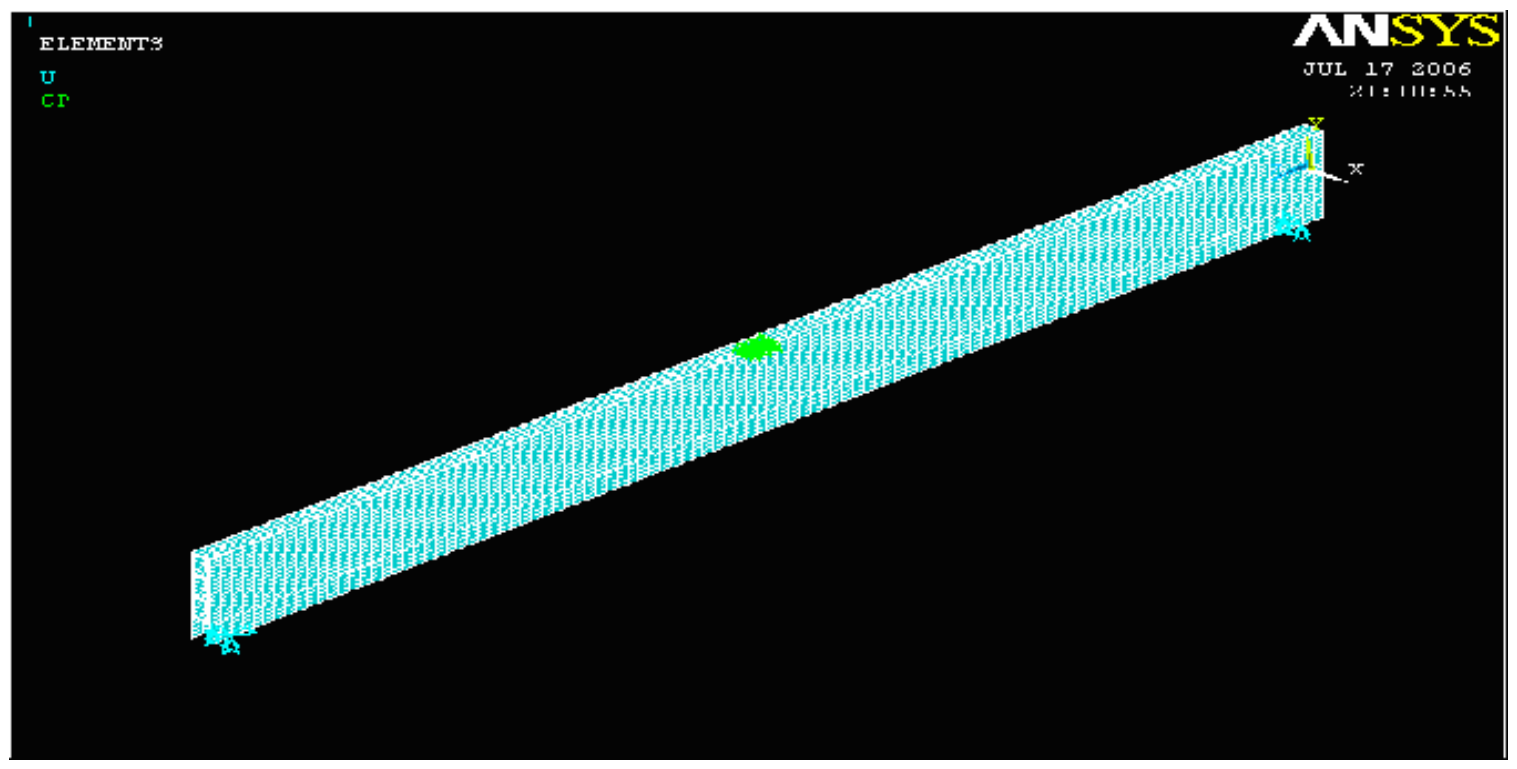

Fig. 4.4 Pictorial representation of boundary conditions applied on FRP beam

\subsection{APPLIED LOADS}

A uniformly distributed load is applied over an area of 4"x 11" at the center of the top flange as shown in Fig. 4.5.

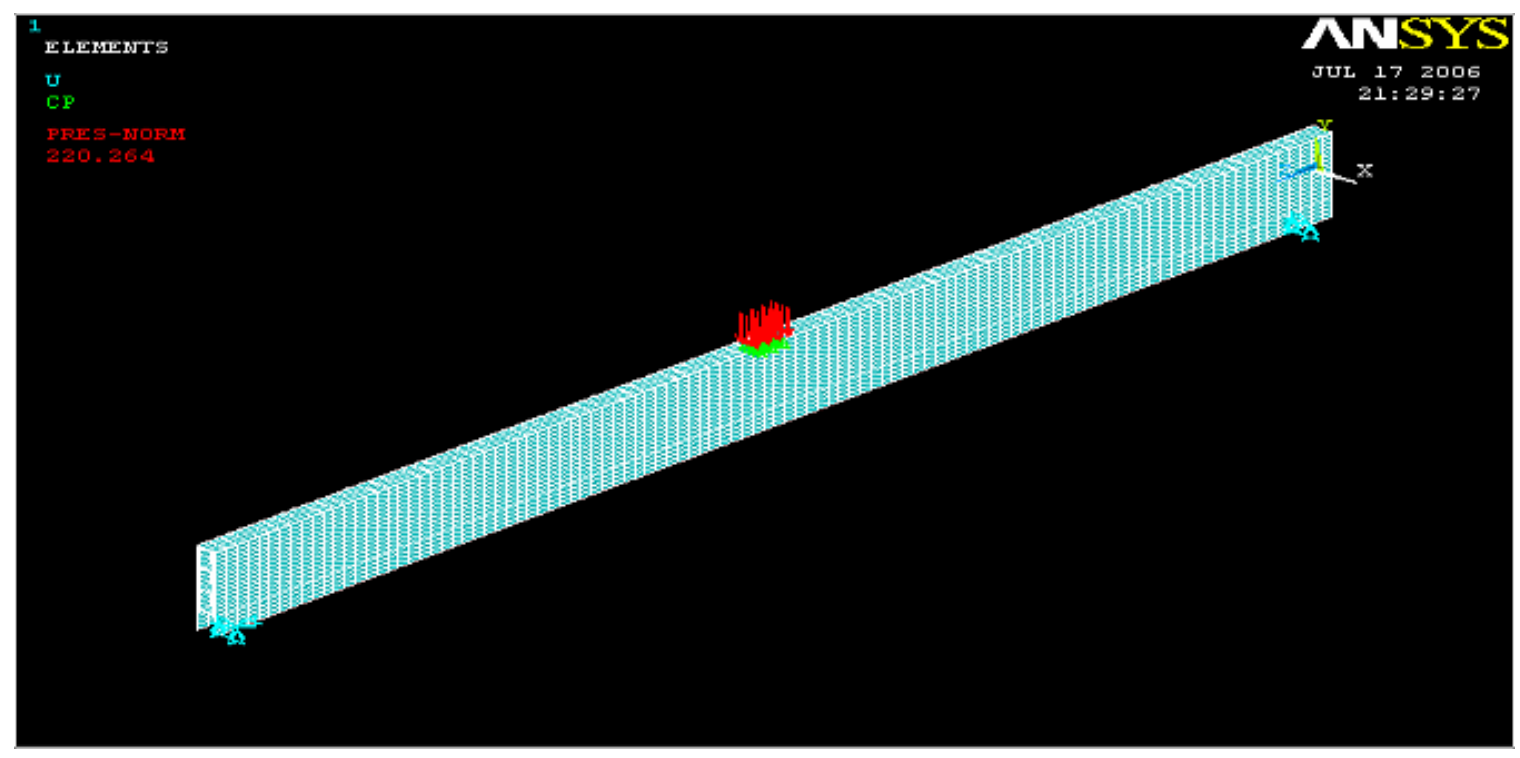

Fig. 4.5 Pictorial Representation of 4"x 11" Patch Load Applied on the on FRP beam 


\subsection{RESULTS OF FRP BEAM}

\subsubsection{Introduction}

The resultant of the patch load is varied from 0 to 20 kips and the values of maximum deflection and strain at each step of the load are noted. These analytical values obtained are then compared to values obtained in experimental tests from other researchers.

\subsubsection{Deflection Analysis of FRP Beam}

A static analysis is performed on the finite element model of the FRP beam that is generated. The beam is simply supported with a span of 227 " between the supports, and a patch load over an area of 4"x 11" is applied at the center on the top flange of the beam. The patch load applied is gradually increased from 0 to 20 kips and the corresponding values of maximum deflection are noted. The contour plot of deflected shape of the beam at the resultant load of 20 kips is shown in the Fig. 4.6. The maximum deflection occurs at the center of the span as expected. A table consisting of both analytical and experimental maximum deflection values for the corresponding load values is presented below. 


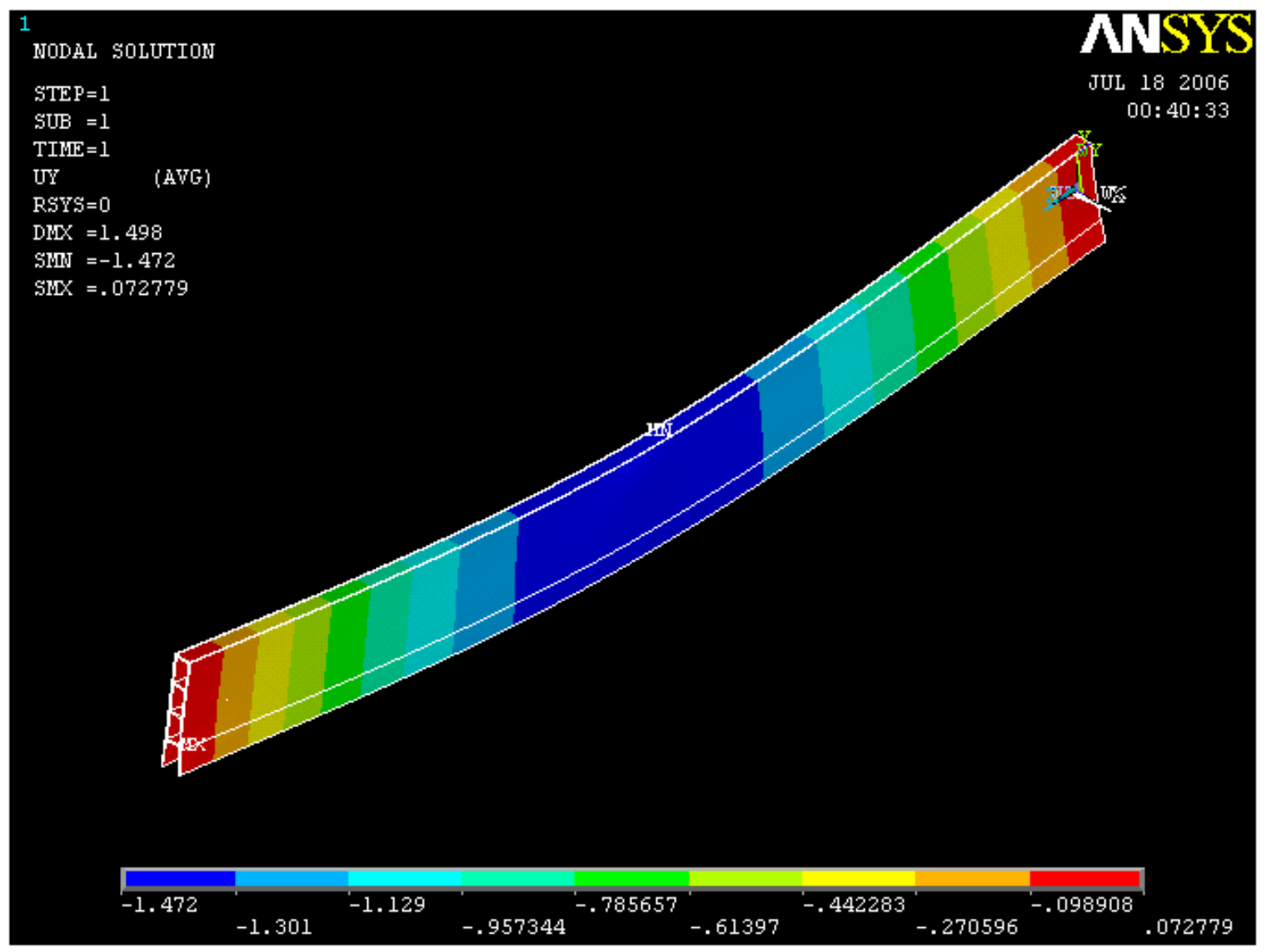

Fig. 4.6 Deflection plot of FRP beam in direction of Y-axis under the load of $20 \mathrm{kips}$ 
Table 4.1 Maximum deflection values of FRP beam

\begin{tabular}{|c|c|c|}
\hline Applied load (kips) & $\begin{array}{c}\text { Maximum deflection (in.) } \\
\text { Analytical }\end{array}$ & $\begin{array}{c}\text { Maximum deflection (in.) } \\
\text { Experimental } \\
\text { Punyamurthula (2004) }\end{array}$ \\
\hline 0 & 0 & 0 \\
\hline 1 & 0.0736 & 0.0838 \\
\hline 2 & 0.1462 & 0.2027 \\
\hline 3 & 0.2194 & 0.3148 \\
\hline 4 & 0.2925 & 0.3744 \\
\hline 5 & 0.3657 & 0.4322 \\
\hline 6 & 0.4388 & 0.4806 \\
\hline 7 & 0.5120 & 0.5533 \\
\hline 8 & 0.5851 & 0.6017 \\
\hline 9 & 0.6583 & 0.6576 \\
\hline 10 & 0.7314 & 0.7135 \\
\hline 11 & 0.8046 & 0.7749 \\
\hline 12 & 0.8777 & 0.8308 \\
\hline 13 & 0.9508 & 0.8923 \\
\hline 14 & 1.0240 & 0.9501 \\
\hline 15 & 1.0972 & 1.0134 \\
\hline 16 & 1.1703 & 1.0712 \\
\hline 17 & 1.2435 & 1.1326 \\
\hline 18 & 1.3166 & 1.1829 \\
\hline 19 & 1.3898 & 1.2556 \\
\hline 20 & 1.4629 & 1.3078 \\
\hline
\end{tabular}

Figure 4.7 shows the graphs plotted between load and maximum deflection that are obtained both analytically and experimentally. In the Fig. 4.7 it is clear that the analytical curve is linear where as the experimental curve obtained by Punyamurthula 
(2004) exhibits nonlinearity at early stages of loading around $1000 \mathrm{lbs}$. It is obvious from the Fig. 4.7 that the analytical deflection is more compared to experimental deflection obtained by Punyamurthula (2004) for varying loads from 9 kips and over.

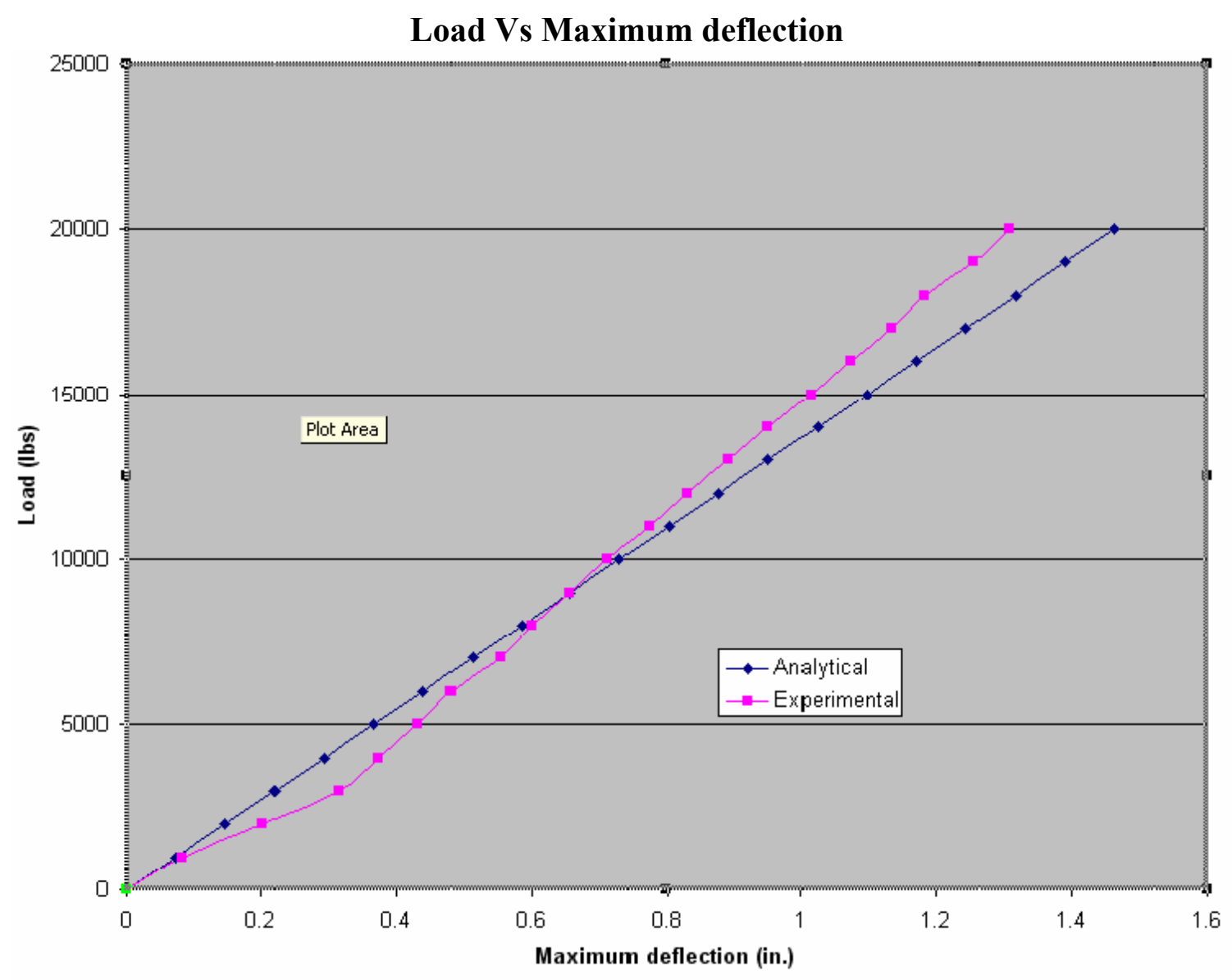

Fig. 4.7 Load Vs deflection under a central patch load of FRP deck

\subsubsection{Computation of bending stiffness based on deflection}

From Eq. (3.33) the value of bending stiffness for FRP beam is calculated to be $3.4 \times 10^{9} \mathrm{lb}^{*} \mathrm{in}^{2}$, where as the experimental value reported by Punyamurthula (2004) is $3.7 \times 10^{9} \mathrm{lb}^{*} \mathrm{in}^{2}$, which is $8.5 \%$ higher than the analytical value obtained. 
Table 4.2 Equivalent flexural rigidity of FRP beam component based on deflection

\begin{tabular}{|c|c|c|c|}
\hline \multirow{2}{*}{ Type } & \multicolumn{2}{|c|}{$\begin{array}{c}\text { Experimental } \\
\text { Punyamurthula (2004) }\end{array}$} & \multirow{2}{*}{ Analytical } \\
\cline { 2 - 3 } & $\begin{array}{c}\text { Including } \\
\text { shear }\end{array}$ & $\begin{array}{c}\text { Excluding } \\
\text { shear }\end{array}$ & \\
\hline $\begin{array}{c}\text { Equivalent flexural } \\
\text { rigidity, EI }\left(\mathbf{1 0}^{\mathbf{9}}\right) \mathbf{~ l b}^{*} \mathbf{i n}^{2}\end{array}$ & 3.71 & 4.11 & 3.4 \\
\hline
\end{tabular}

\subsubsection{Strain Analysis}

The strain values for corresponding load values are obtained from the center location on the bottom flange in the $Z$ direction (cell direction) from the finite element model of FRP beam, which are then compared to the values obtained from the experimental tests carried out by Punyamurthula (2004). Data consisting of both experimental and analytical strain values for the corresponding load values is presented in Table 4.3. 
Table 4.3 Strain values of FRP beam for central patch load

\begin{tabular}{|c|c|c|}
\hline Applied load (kips) & $\begin{array}{c}\text { Micro-strain }\left(\varepsilon_{z}\right) \\
\text { Analytical }\end{array}$ & $\begin{array}{c}\text { Micro-strain }\left(\varepsilon_{z}\right) \\
\text { Experimental } \\
\text { Punyamurthula(2004) }\end{array}$ \\
\hline 0 & 0 & 0 \\
\hline 1 & 115 & 0 \\
\hline 2 & 230 & 251.94 \\
\hline 3 & 346 & 362.99 \\
\hline 4 & 461 & 467.87 \\
\hline 5 & 576 & 585.09 \\
\hline 6 & 691 & 699.22 \\
\hline 7 & 807 & 801.02 \\
\hline 8 & 922 & 912.06 \\
\hline 9 & 1040 & 1023.11 \\
\hline 10 & 1150 & 1134.16 \\
\hline 11 & 1270 & 1245.21 \\
\hline 12 & 1380 & 1359.35 \\
\hline 13 & 1500 & 1485.82 \\
\hline 14 & 1610 & 1612.29 \\
\hline 15 & 1730 & 1711.00 \\
\hline 16 & 1840 & 1828.22 \\
\hline 17 & 1960 & 1948.53 \\
\hline 18 & 2070 & 2068.21 \\
\hline 19 & 2190 & 2188.52 \\
\hline 20 & 2300 & 2302.65 \\
\hline
\end{tabular}

A graph is plotted between load and corresponding analytical strain values and experimental strain values obtained by Punyamurthula (2004). It is evident from the Fig. 
4.8 that the analytical strain values for varying load values are in close match with the experimental strain values obtained by Punyamurthula (2004).

\section{Load Vs Micro-strain}

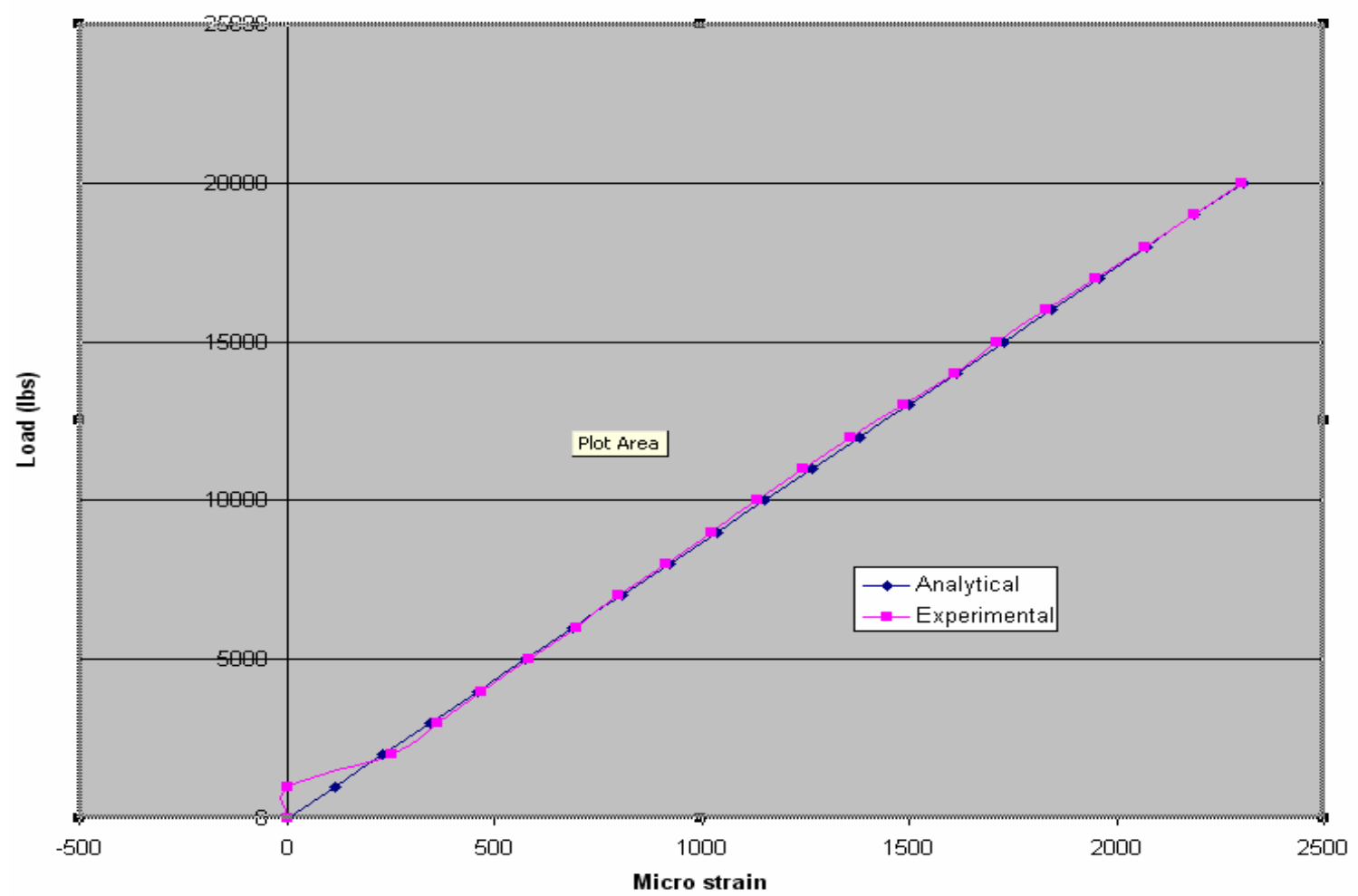

Fig. 4.8 Graphical plot between strain and central patch load

From the Fig. 4.8, it is evident that the analytical curve is a linear curve that passes through the origin. A discrepancy in the earlier stage of experimental curve is perhaps because of the malfunctioning of the equipment used in the experimental testing. From the table 4.3 it can be observed that the variation is very little between experimental and analytical values, hence there is very close match between the two curves. 


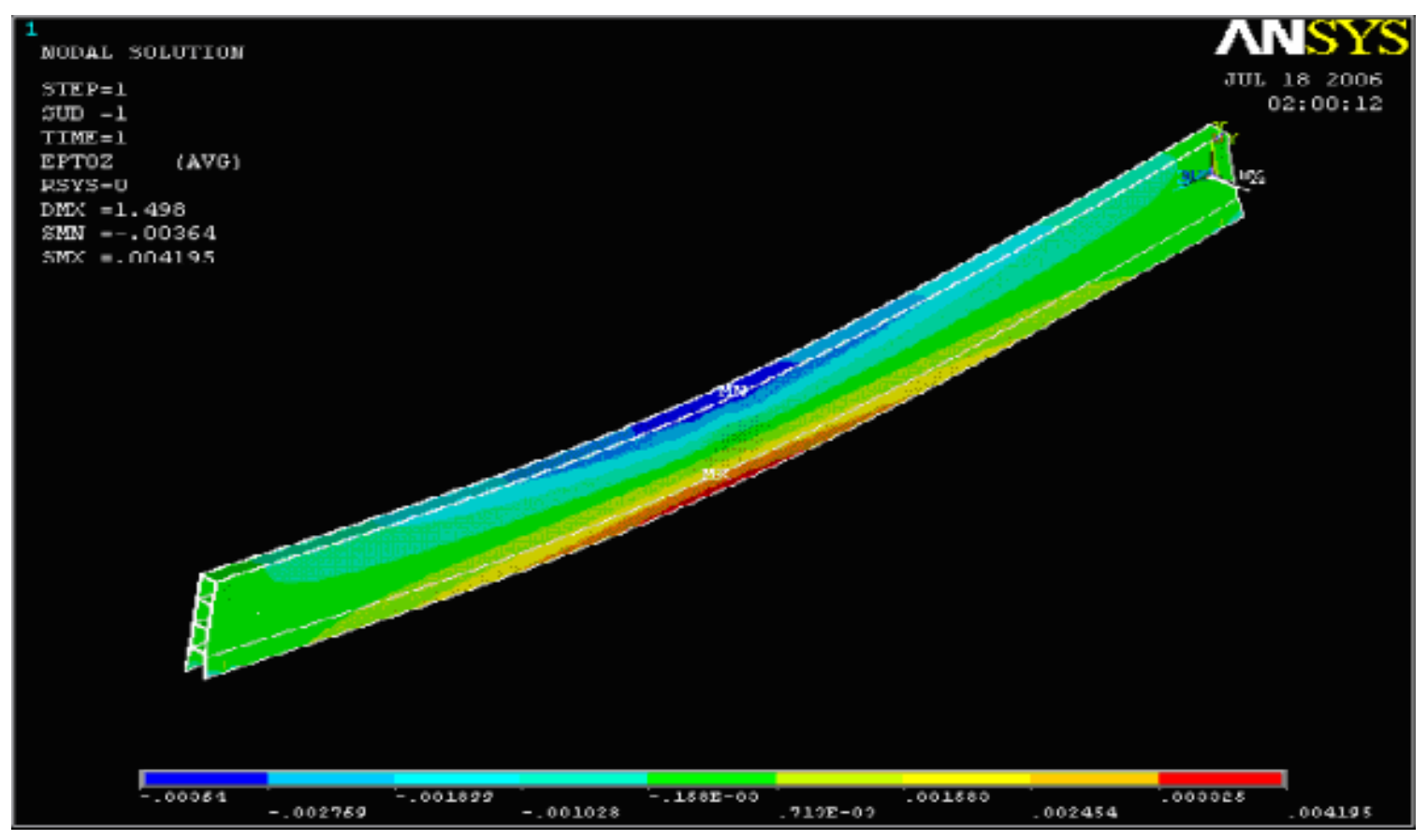

Fig. 4.9 Contour plot of strain $\left(\varepsilon_{z}\right)$ of FRP beam subjected to a patch load of $20 \mathrm{kips}$

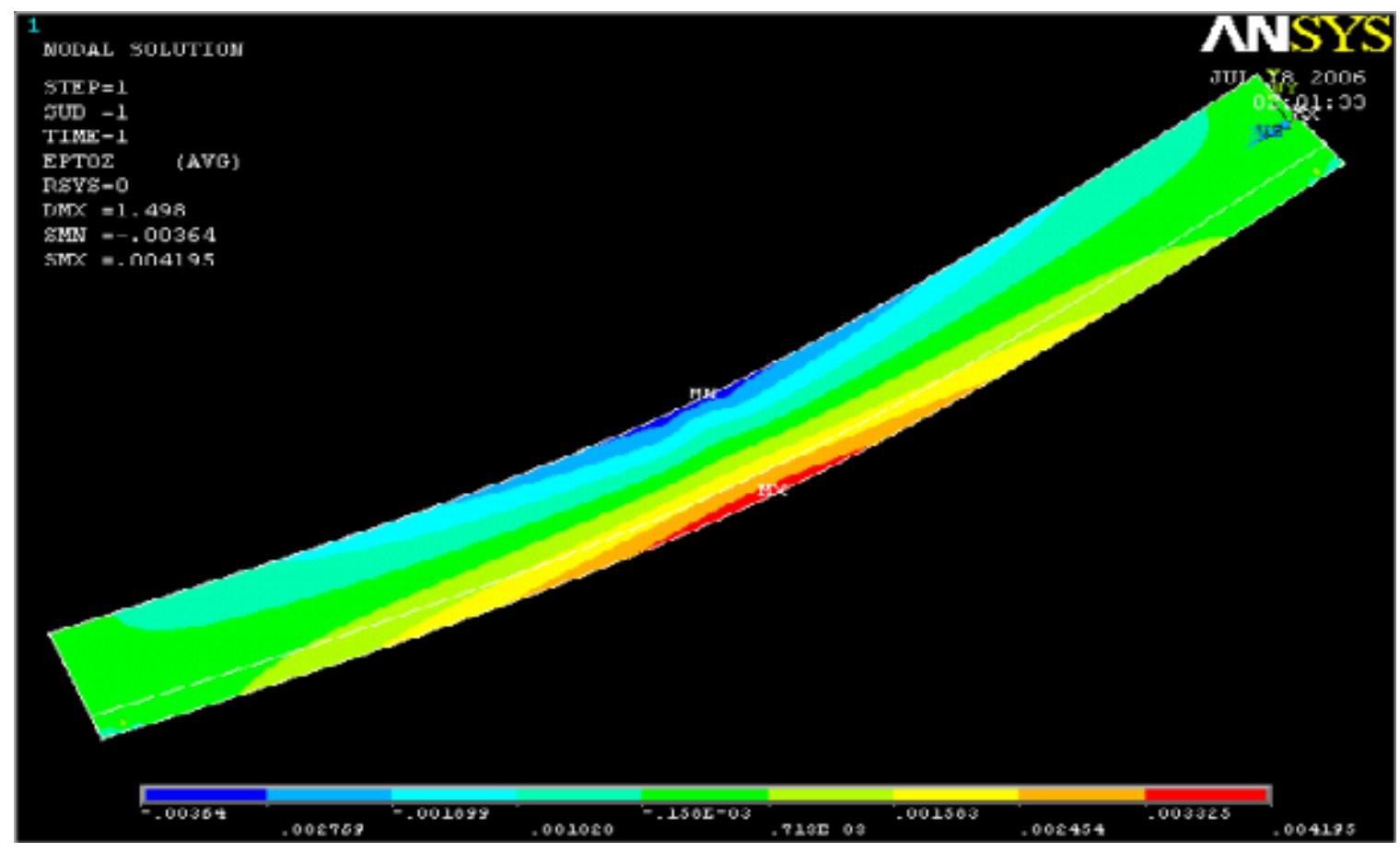

Fig. 4.10 Side view of the contour plot of strain $\left(\varepsilon_{z}\right)$ of FRP beam 


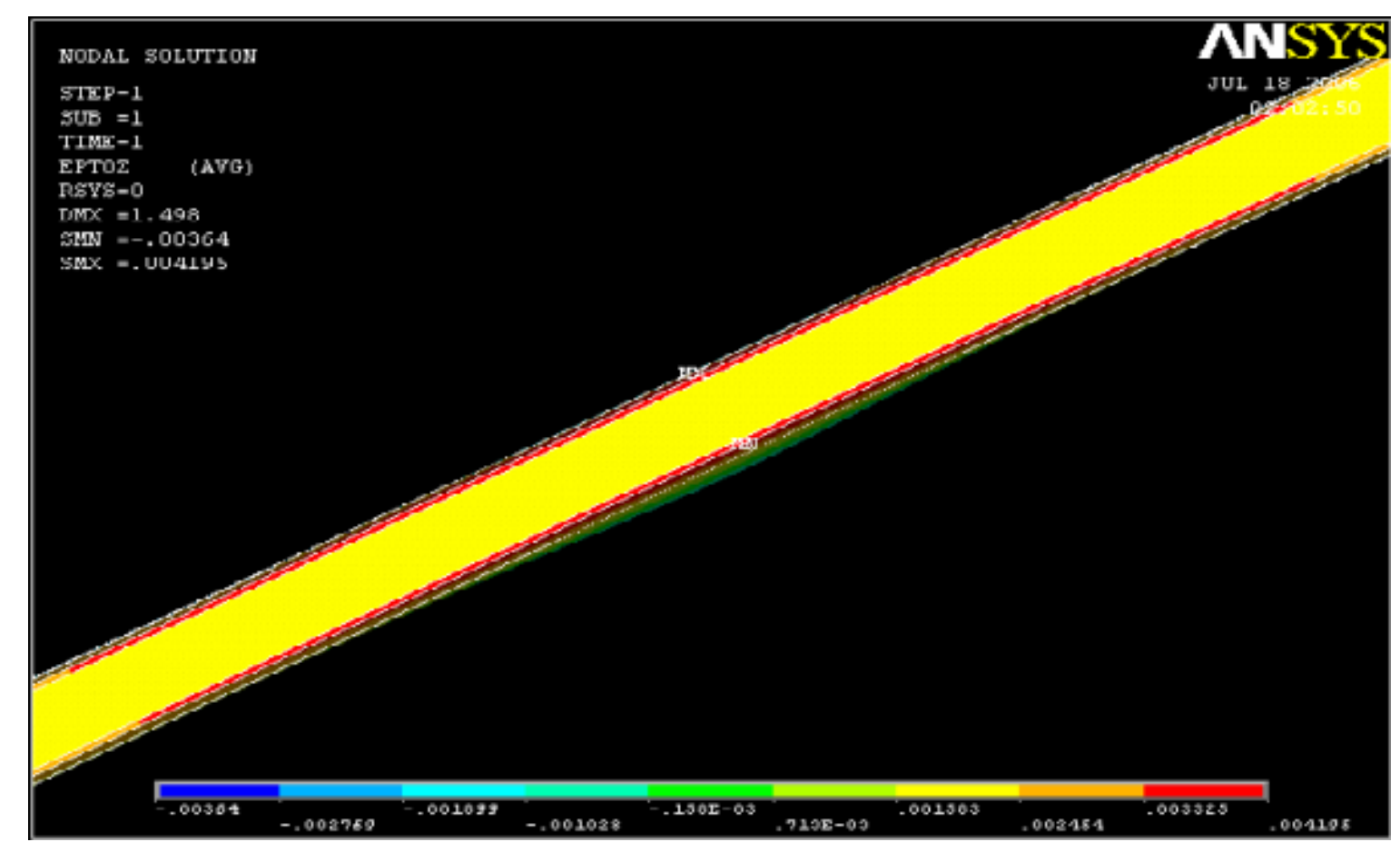

Fig. 4.11 Bottom view of the contour plot of strain $\left(\varepsilon_{\mathrm{z}}\right)$ of FRP beam

A table consisting of analytical stress and strain values observed at the mid section in the bottom flange of the FRP beam for the corresponding load values is presented below followed by the graph, plotted between stress and corresponding strain values at the mid section of the beam, with stress on $Y$-axis and strain on $X$-axis. 
Table 4.4 Stress and strain values of FRP beam for central patch load

\begin{tabular}{|c|c|c|}
\hline Applied load (kips) & Stress (psi) & Micro-strain $\left(\varepsilon_{z}\right)$ \\
\hline 0 & 0 & 0 \\
\hline 1 & 382.59 & 115.21 \\
\hline 2 & 765.19 & 230.43 \\
\hline 3 & 1147.80 & 345.64 \\
\hline 4 & 1530.40 & 460.86 \\
\hline 5 & 1913.00 & 576.07 \\
\hline 6 & 2295.60 & 691.28 \\
\hline 7 & 2678.20 & 806.50 \\
\hline 8 & 3060.70 & 921.71 \\
\hline 9 & 3443.30 & 1039.60 \\
\hline 10 & 3825.90 & 1152.10 \\
\hline 11 & 4208.50 & 1267.40 \\
\hline 12 & 4591.10 & 1382.60 \\
\hline 13 & 4973.70 & 1497.80 \\
\hline 14 & 5356.30 & 1613.00 \\
\hline 15 & 5738.90 & 1728.20 \\
\hline 16 & 6121.50 & 1843.40 \\
\hline 17 & 6504.10 & 1958.60 \\
\hline 18 & 6886.70 & 2073.90 \\
\hline 19 & 7269.30 & 2189.10 \\
\hline 20 & 7651.90 & 2304.30 \\
\hline
\end{tabular}




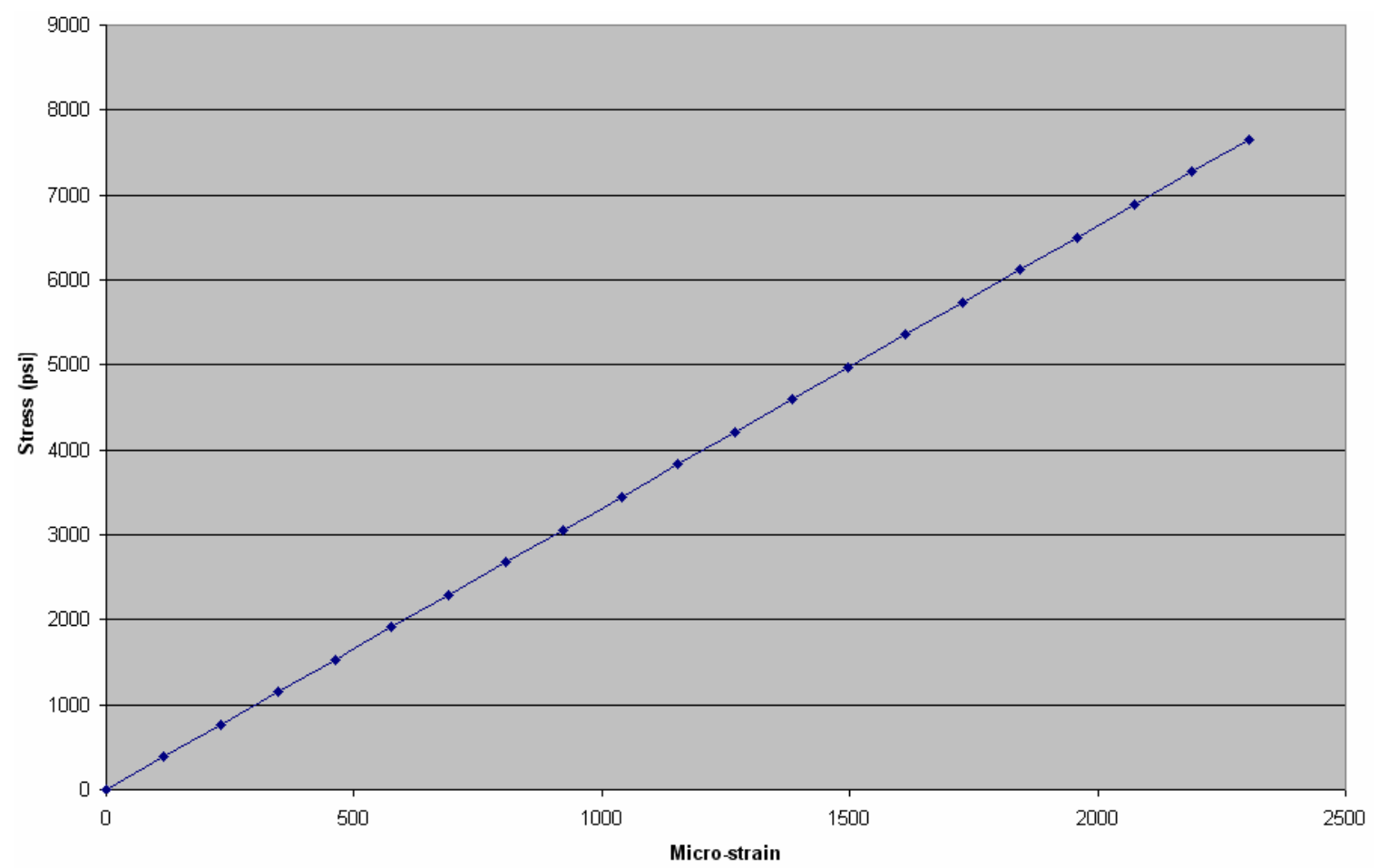

Fig. 4.12 Stress-strain curve for a central patch load

Figure 4.12 signifies that the curve is a linear curve starting from the origin. The stress value increases linearly with increase in the strain value at the mid section in bottom flange of the FRP beam.

\subsubsection{Computation of bending stiffness based on strain}

The equivalent flexural rigidity based on strain can be calculated using Eq. (3.35) and the slope from Fig. 4.8. The value obtained is then compared to the experimental value obtained by Punyamurthula (2004). The bending stiffness value $5.92 \times 10^{9} 1 b^{*} \mathrm{in}^{2}$, which is obtained analytically is in close match with the experimental value $5.98 \times 10^{9}$ lb*in ${ }^{2}$ obtained by Punyamurthula (2004). 
Table 4.5 Equivalent flexural rigidity of FRP beam component based on strain

\begin{tabular}{|c|c|c|}
\hline Type & $\begin{array}{c}\text { Experimental } \\
\text { Punyamurthula (2004) }\end{array}$ & Analytical \\
\hline $\begin{array}{c}\text { Equivalent Flexural } \\
\text { Rigidity, EI (10) } \mathbf{~ l b * i n ~}^{2}\end{array}$ & 5.98 & 5.92 \\
\hline
\end{tabular}

\subsection{FIRST PLY FAILURE ANALYSIS}

First ply failure analysis is carried out for the central patch load of 20 kips applied over an area of 4"x 11". The failure plot obtained using maximum stress criterion for FRP beam is as shown in Fig. 4.13. The maximum value of ' $\xi$ ' listed in this plot is shown to be 1.3357 , which implies that according to the maximum stress criterion the load at which the first ply fails is equal to $\mathrm{P}=20 / 1.3357=14.9$ kips. From the figure it is clear that the failure occurs at the mid span in the extended part of the web.

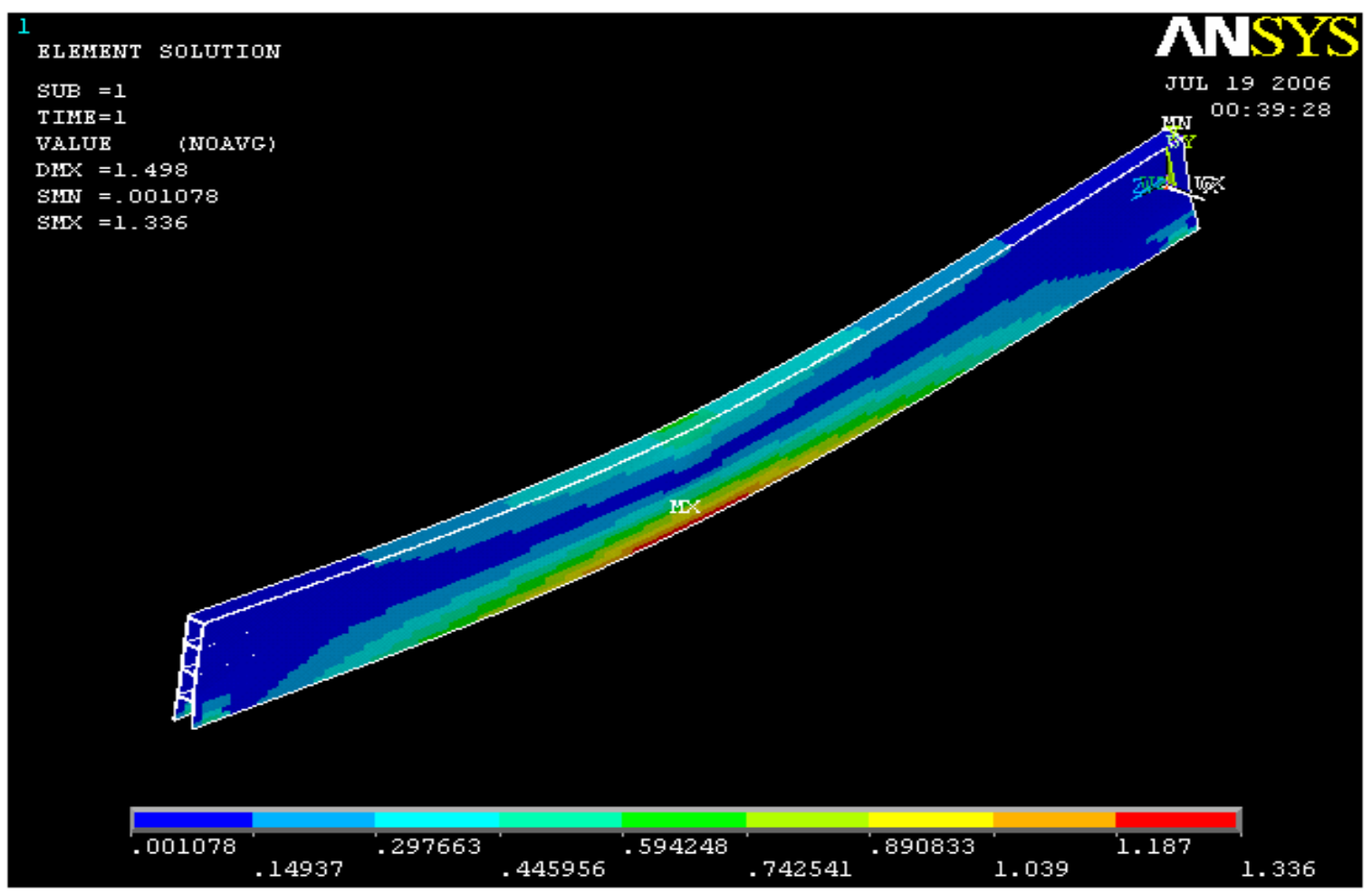

Fig. 4.13 Failure plot of FRP beam using maximum stress criterion 


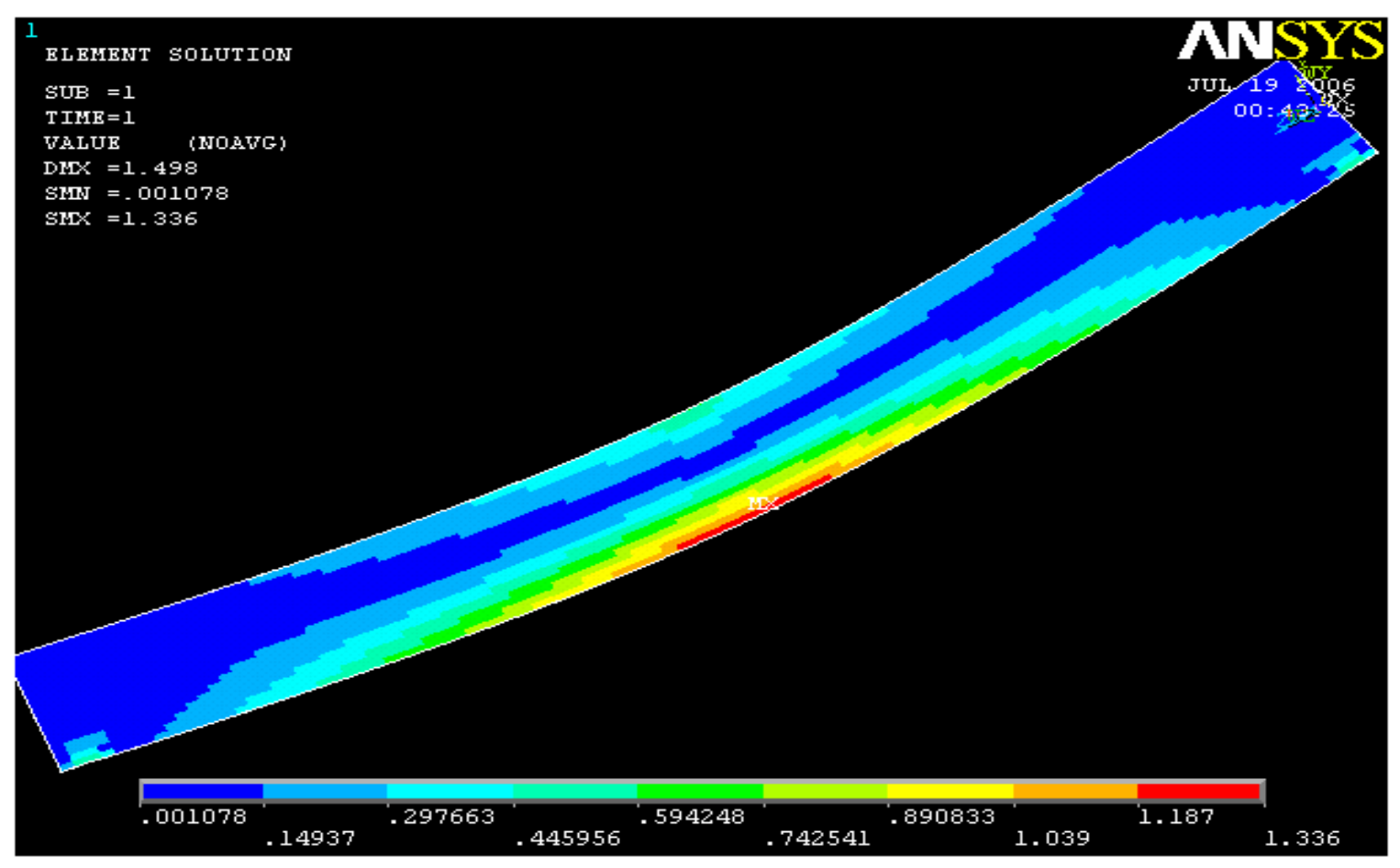

Fig. 4.14 Side view of failure plot of FRP beam using maximum stress criterion

The failure plot obtained using maximum strain criterion is as shown below in Fig. 4.15. Both the maximum stress and maximum strain criteria predict the failure at the same location. The first ply to fail is the $90^{\circ}$ ply, which seems to fail in the transverse direction. The maximum value of ' $\xi$ ' listed in the maximum strain criterion failure plot is 1.3331 as shown in the figure below, which implies that the first ply failure load predicted by using this criterion is equal to $\mathrm{P}=20 / 1.3331=15 \mathrm{kips}$, which is nearly the same as the value predicted by maximum stress failure criterion. 


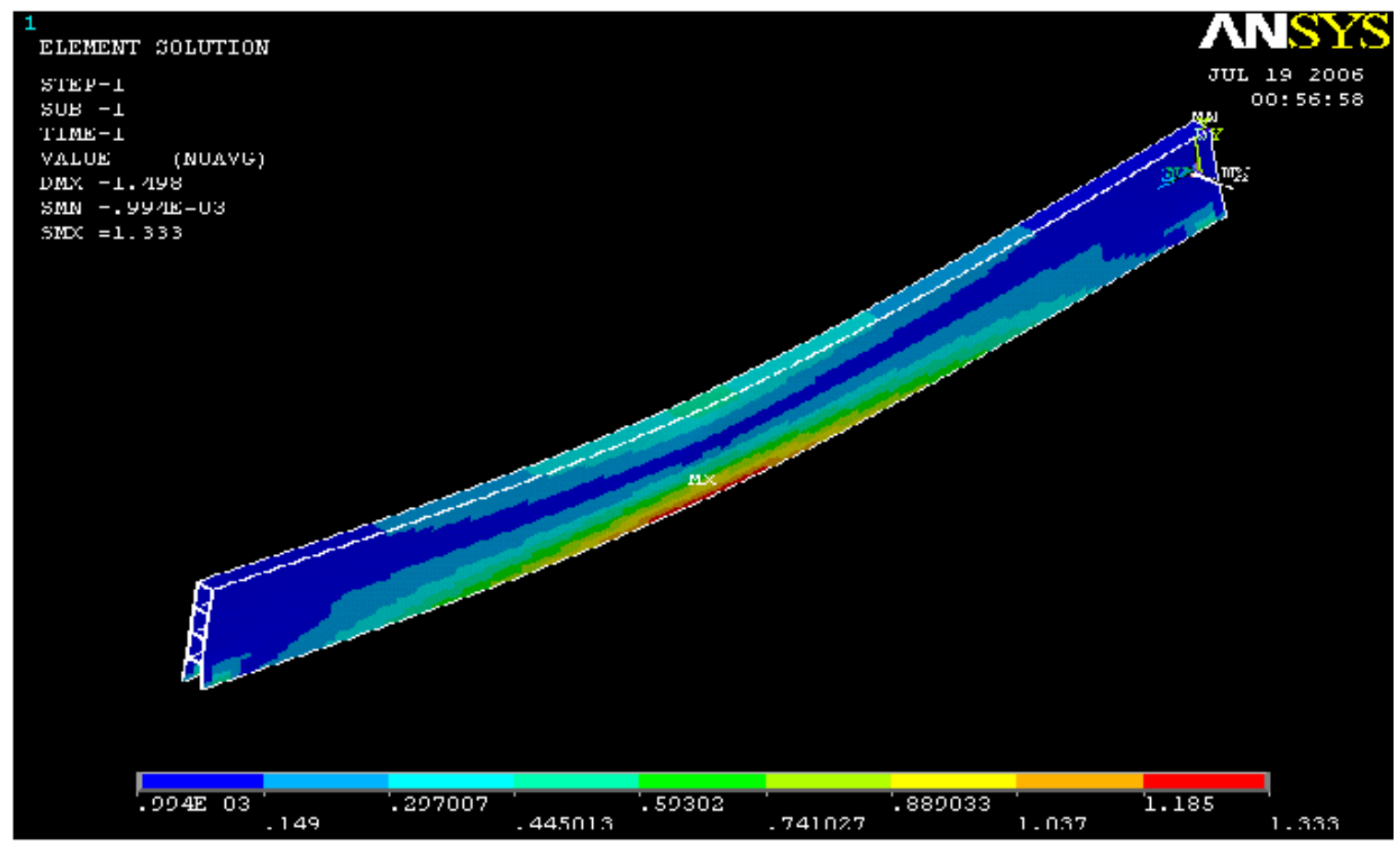

Fig. 4.15 Failure plot of FRP beam using maximum strain criterion

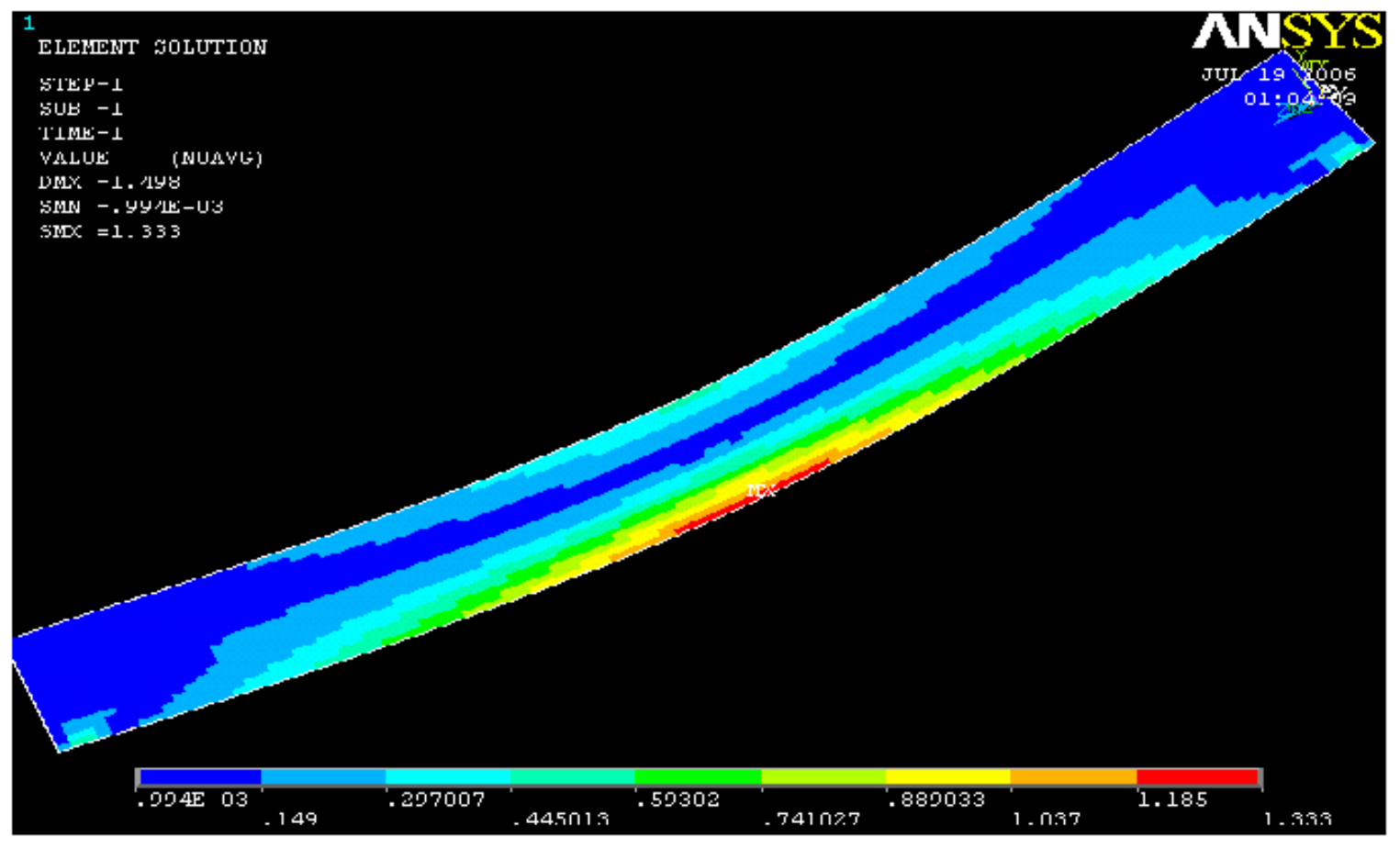

Fig. 4.16 Side view of failure plot of FRP beam using maximum strain criterion 
The failure plot using Tsai-Wu criterion is presented below in the Fig. 4.17. The maximum value of ' $\xi$ ' listed in the Tsai-Wu failure plot is 1.6473 , which implies that the first ply failure load is equal to 12.14 kips. The failure occurs in the same location as predicted by maximum stress and maximum strain criteria.

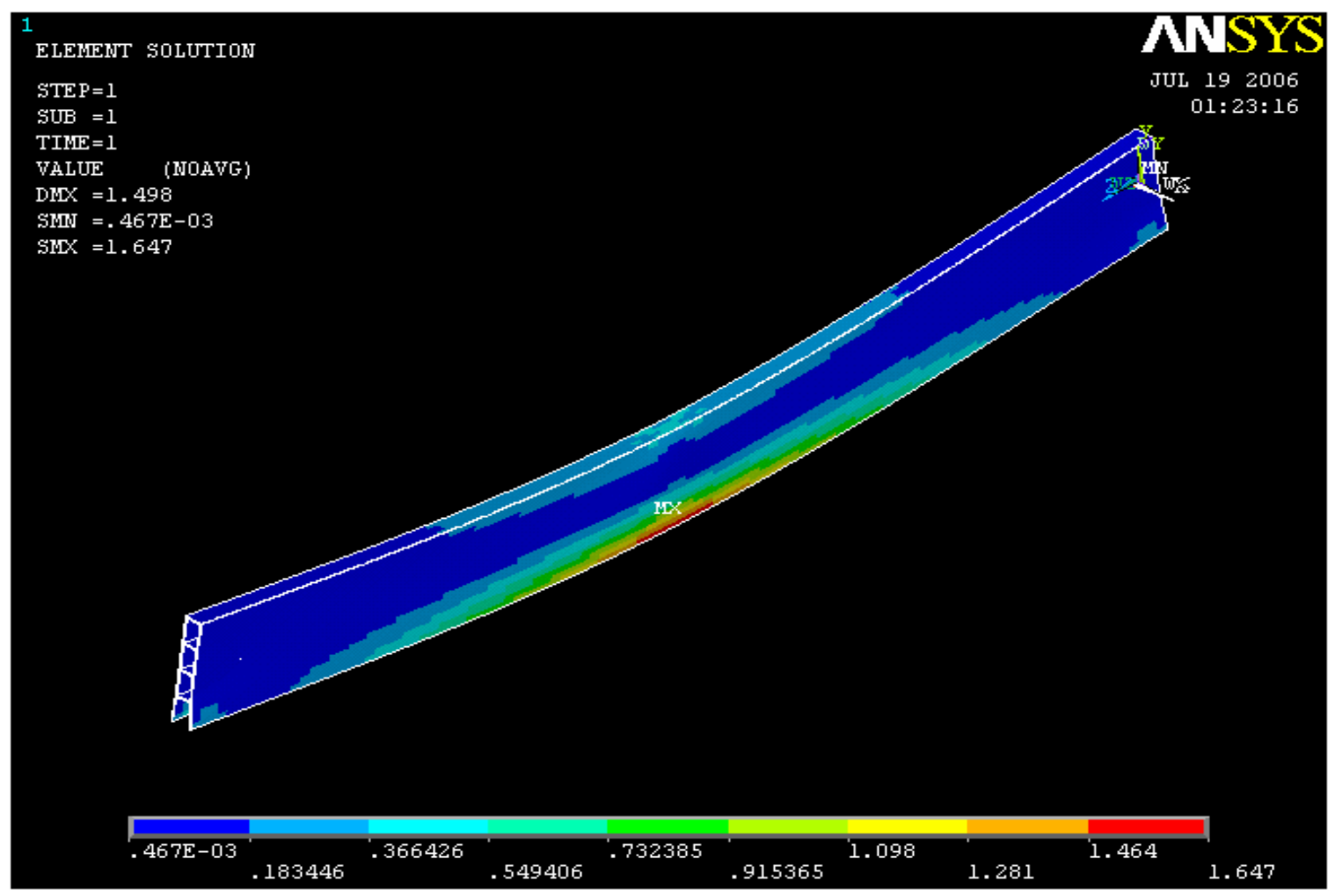

Fig. 4.17 Failure plot of FRP beam using Tsai-Wu criterion 


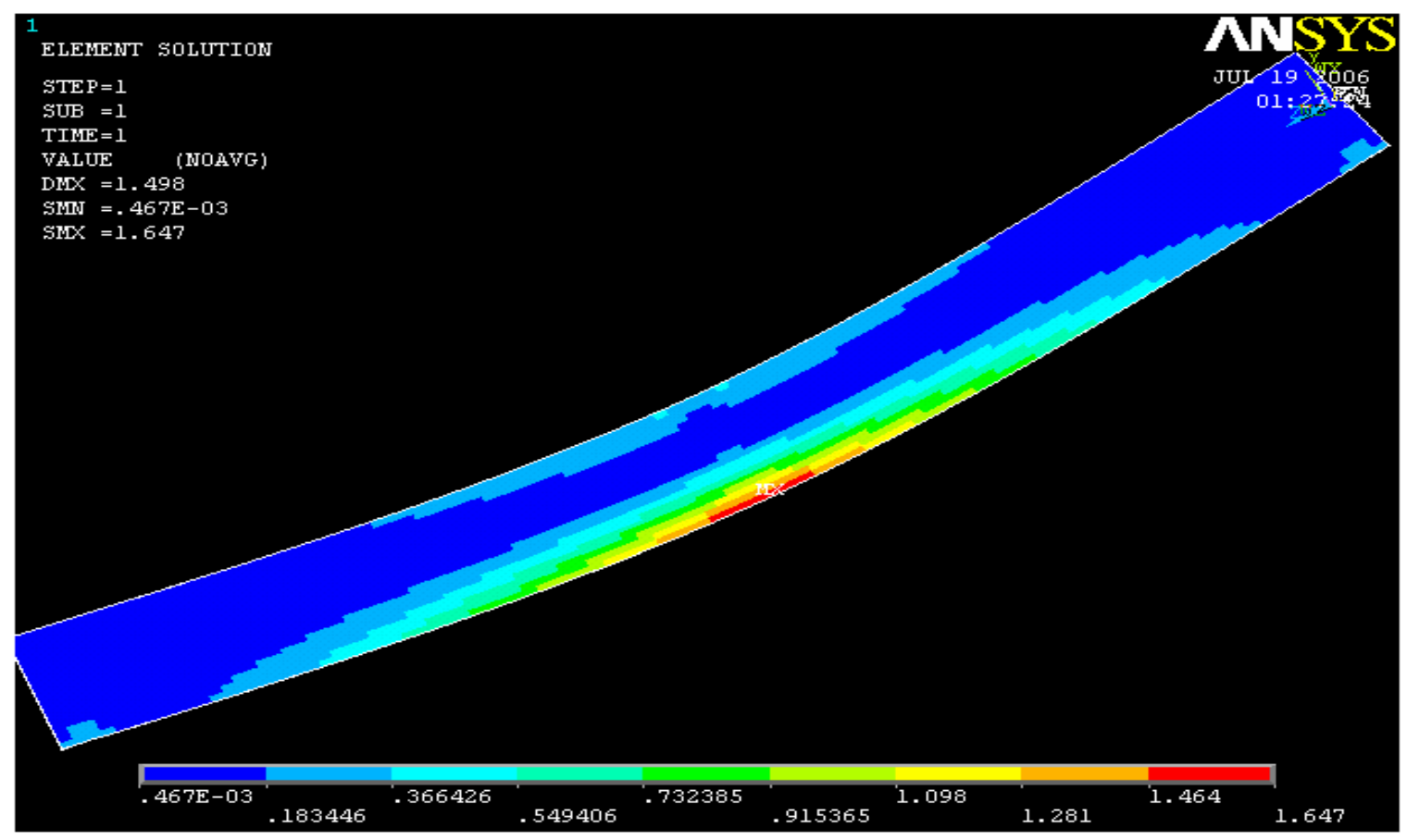

Fig. 4.18 Side view of failure plot of FRP beam using Tsai-Wu criterion 


\section{CHAPTER 5}

\section{DOUBLE FRP BEAM ANALYSIS}

\section{$5.1 \quad$ INTRODUCTION}

This chapter deals with the development of a finite element model of a double FRP beam and evaluation of its stiffness rigidity based on both displacement and strain. The values thus obtained are compared to the experimental values obtained by Punyamurthula (2004).

\subsection{DEVELOPMENT OF FINITE ELEMENT MODEL}

As mentioned earlier at first the solid model of double FRP beam is generated by creating key points and then defining volumes by selecting proper key points. The volumes thus formed are meshed properly and the orientations of the layers are checked.

The solid model of double FRP beam with cross section dimensions of 24"x 8", which consists of 76 volumes that are glued together, is as shown in Fig. 5.1. The solid model of double FRP beam is then map meshed, which results in the formation of 20800 elements with 31815 nodes in them.

Figure 5.2 displays the map meshed model of the double FRP beam. The orientations of the element coordinate systems of all elements are checked to see if they are aligned in the fiber direction. 


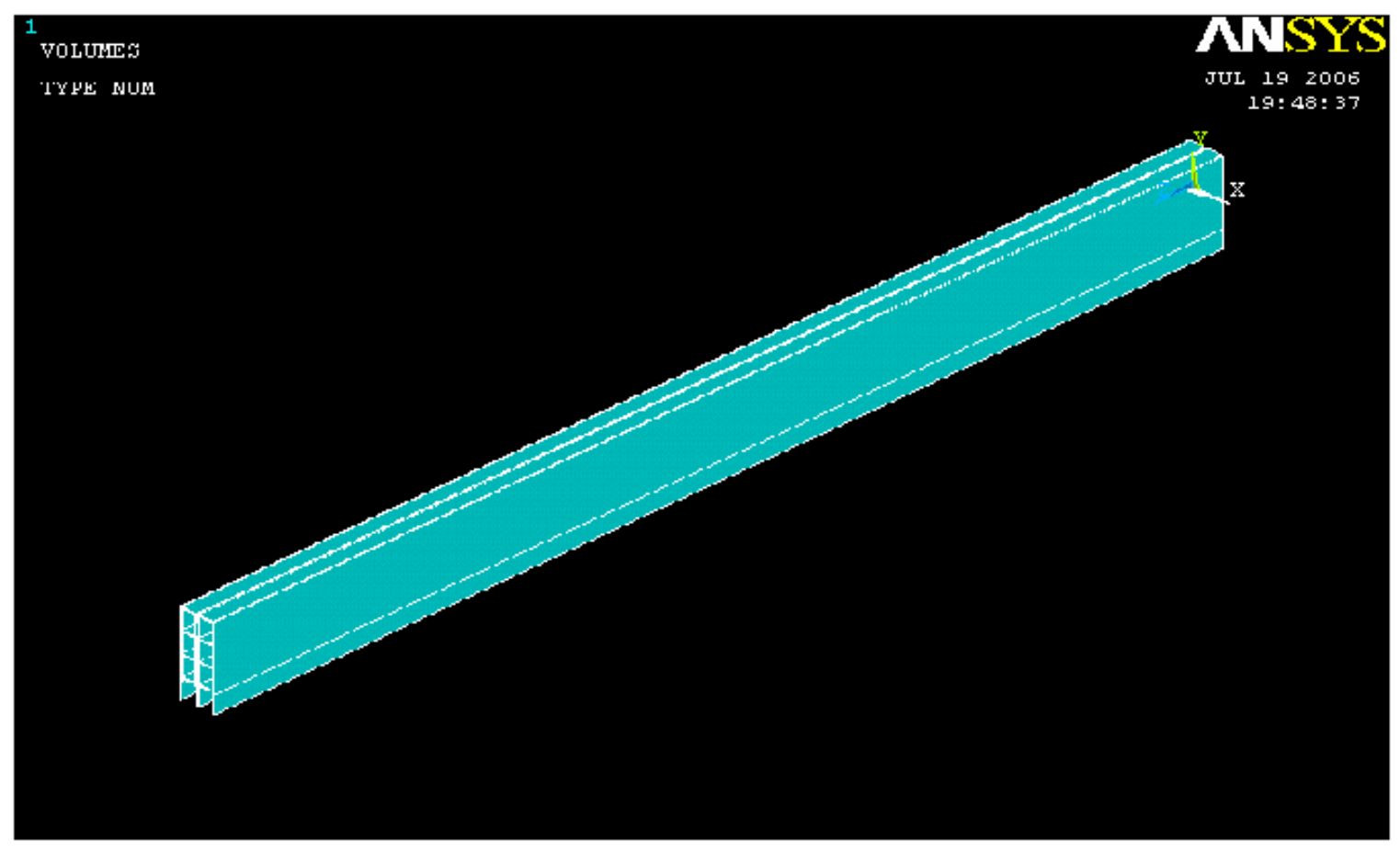

Fig. 5.1 Solid model of double FRP beam

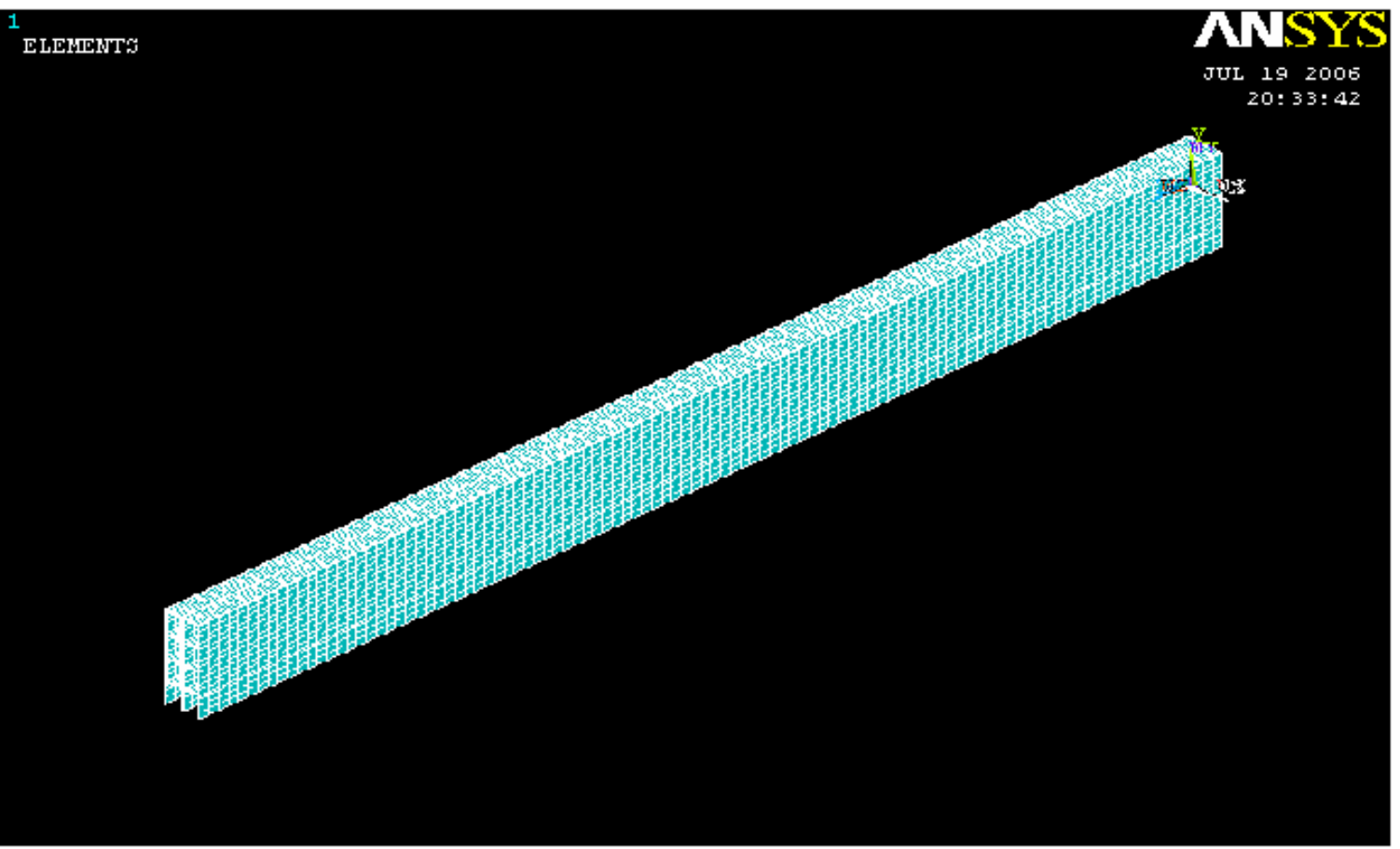

Fig. 5.2 Map meshed model of double FRP beam 


\subsection{APPLIED BOUNDARY CONDITIONS}

The double FRP beam is simply supported with a clear span of 228". A patch load over an area of 6.5" 10 " is applied. To simulate the effect of steel plate used in the patch loading, coupling restraints with the cross section of 6.5 " $\times 10$ " are applied at the center (mid-span) of the double FRP beam. Fig. 5.3 displays the boundary conditions applied on the double beam.

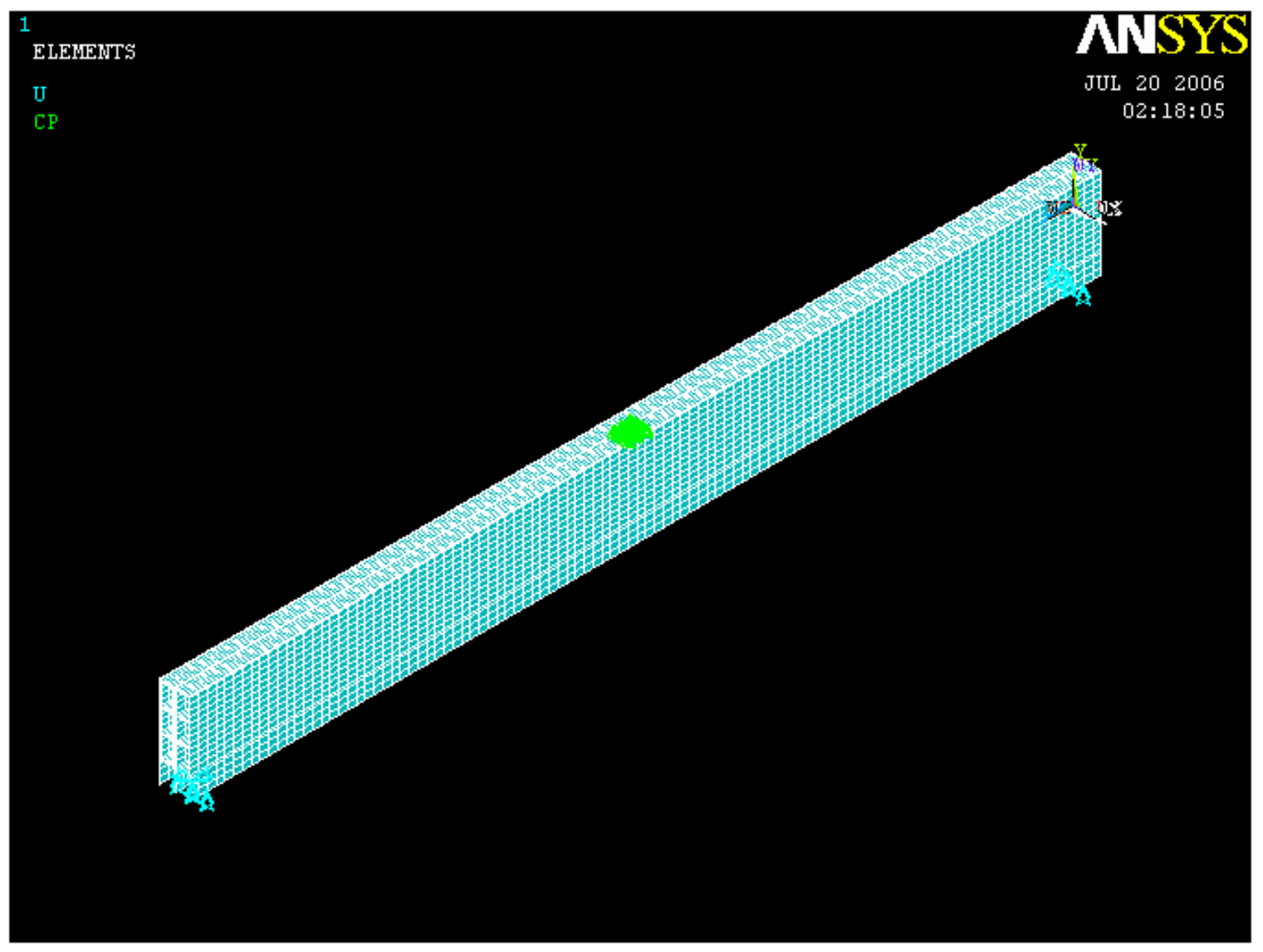

Fig. 5.3 Pictorial representation of boundary conditions applied on double FRP beam 


\subsection{APPLIED LOADS}

A uniformly distributed load is applied over an area of $6.5 \% \mathrm{x} 10$ " at the center (mid-span) on the top flange as shown in Fig. 5.4.

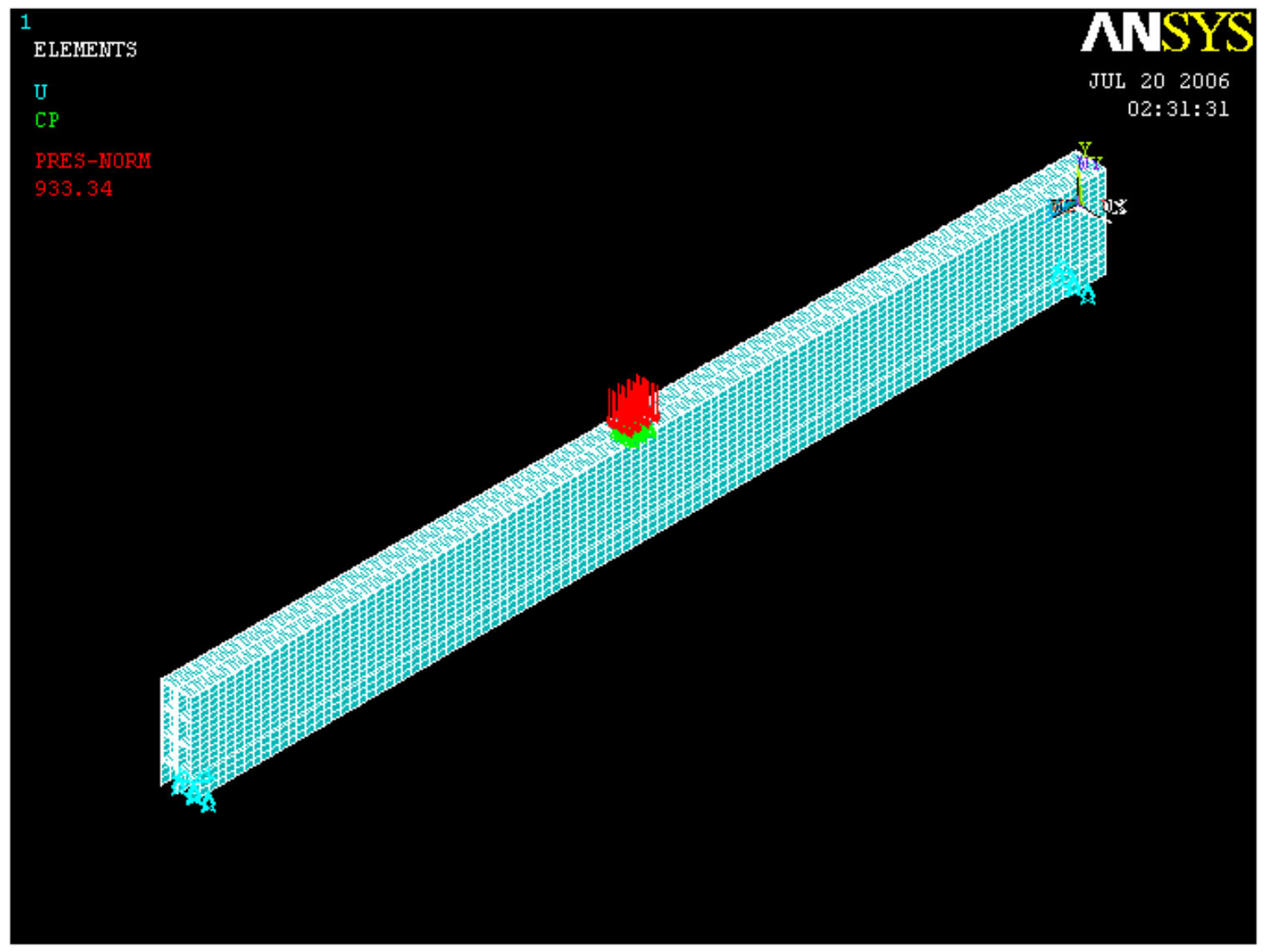

Fig. 5.4 Pictorial Representation of 6.5"x 11" Patch Load Applied on the double FRP beam 


\subsection{RESULTS OF DOUBLE FRP BEAM}

\subsubsection{Introduction}

After the finite element model is generated, a patch load, in steps of up to $52 \mathrm{kips}$, over an area of 6.5 "x 10 " is applied at the center on the top flange of the double beam. The values of maximum deflection and strain for varying load are noted, which are then compared to the experimental values obtained by Punyamurthula (2004).

\subsubsection{Deflection Analysis of double FRP beam}

As explained earlier, in this part of research the double FRP beam is simply supported with a span of 228 " between the supports. A patch load over an area of 6.5 "x 10 " is applied at the center on the top flange of the double beam. The patch load is gradually increased from 0 to 52 kips and the corresponding values of maximum deflection are noted. Figure 5.5 displays the contour plot of the deflected shape of the double FRP beam at the resultant load of 52 kips. 


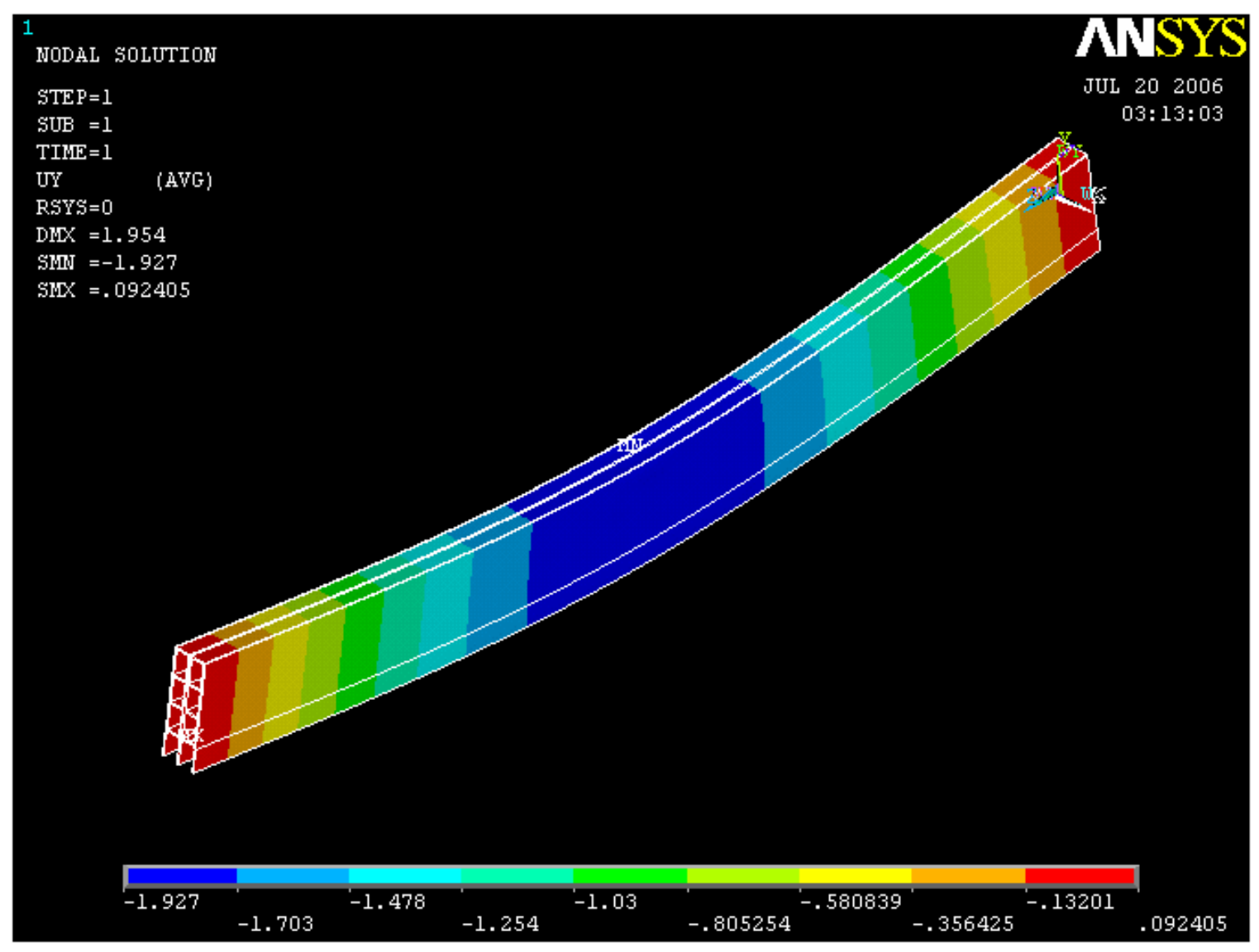

Fig. 5.5 Deflection plot of double FRP beam under a patch load of 52 kips

The analytical and experimental maximum deflection values for different load values are presented in Table 5.1. The same data in graphical form is shown in Fig. 5.6. It is clear from the Fig. 5.6 that the analytical deflection curve exhibits linearity while that of experimental curve obtained by Punyamurthula (2004) exhibits a slight nonlinearity. It is observed from the Fig. 5.6 that the analytical deflection values for varying load values are close to the experimental values obtained by Punyamurthula (2004). 
Table 5.1 Maximum deflection values of double FRP beam

\begin{tabular}{|c|c|c|}
\hline Applied load (kips) & $\begin{array}{c}\text { Maximum deflection (in.) } \\
\text { Analytical }\end{array}$ & $\begin{array}{c}\text { Maximum deflection (in.) } \\
\text { Experimental }\end{array}$ \\
\hline 0 & 0 & 0 \\
\hline 3 & 0.1101 & 0.1006 \\
\hline 6 & 0.2202 & 0.1937 \\
\hline 9 & 0.3304 & 0.2924 \\
\hline 12 & 0.4405 & 0.3893 \\
\hline 15 & 0.5506 & 0.4862 \\
\hline 18 & 0.6608 & 0.5775 \\
\hline 21 & 0.7706 & 0.6762 \\
\hline 24 & 0.8811 & 0.7712 \\
\hline 27 & 0.9912 & 0.8718 \\
\hline 30 & 1.1014 & 0.9687 \\
\hline 33 & 1.2115 & 1.0693 \\
\hline 36 & 1.3217 & 1.1695 \\
\hline 39 & 1.4318 & 1.2699 \\
\hline 42 & 1.5419 & 1.3668 \\
\hline 45 & 1.6521 & 1.4674 \\
\hline 48 & 1.7622 & 1.5755 \\
\hline 51 & 1.8723 & 1.6761 \\
\hline 52 & 1.9091 & 1.7059 \\
\hline
\end{tabular}




\section{Load Vs Maximum deflection}

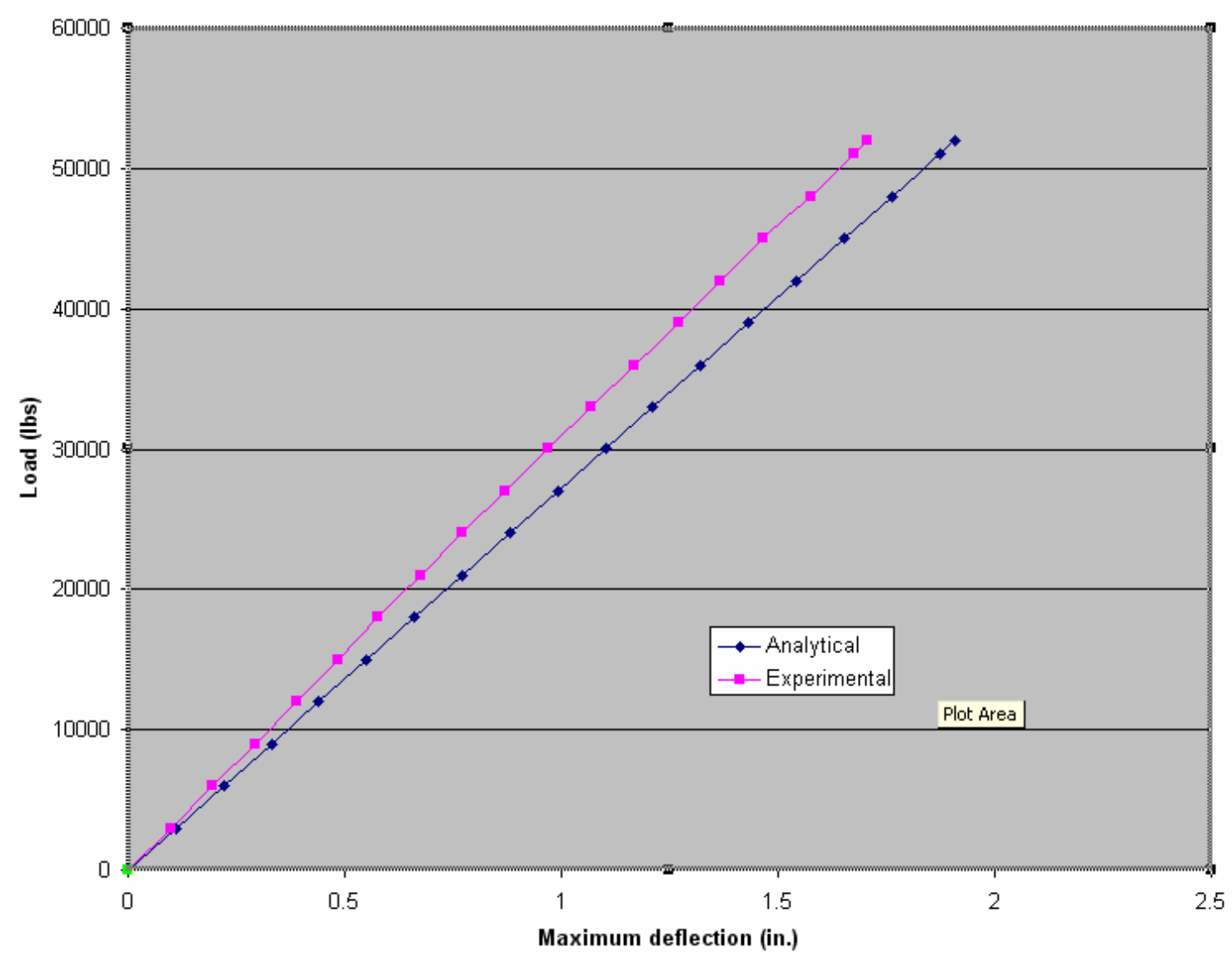

Fig. 5.6 Graph plotted between maximum deflection and central patch load

\subsubsection{Bending stiffness based on deflection}

Using Eq. (3.33) the bending stiffness value for double beam is found to be $6.8 \mathrm{x}$ $10^{9} \mathrm{lb}^{*} \mathrm{in}^{2}$, where as the value reported by Punyamurthula (2004) is $7.5 \times 10^{9} 1 \mathrm{~b}^{*} \mathrm{in}^{2}$. Since SOLID46 element takes shear deflection into account, the analytical flexural rigidity value is compared to the experimental flexural rigidity value obtained by Punyamurthula (2004) that includes shear in it. The experimental value is found to be about $10 \%$ higher than the analytical value obtained. 
Table 5.2 Equivalent flexural rigidity of double FRP beam based on deflection

\begin{tabular}{|c|c|c|c|}
\hline \multirow{2}{*}{ Type } & \multicolumn{2}{|c|}{$\begin{array}{c}\text { Experimental } \\
\text { Punyamurthula (2004) }\end{array}$} & \multirow{2}{*}{ Analytical } \\
\cline { 2 - 3 } & $\begin{array}{c}\text { Including } \\
\text { shear }\end{array}$ & $\begin{array}{c}\text { Excluding } \\
\text { shear }\end{array}$ & \\
\hline $\begin{array}{c}\text { Equivalent flexural } \\
\text { rigidity, EI }\left(\mathbf{1 0}^{\mathbf{9}} \mathbf{~ b}^{*} \mathbf{i n}^{2}\right)\end{array}$ & 7.5 & 8.4 & 6.8 \\
\hline
\end{tabular}

\subsubsection{Strain Analysis}

The strain values obtained at the mid span on the bottom flange in the $Z$ (cell) direction for the corresponding load values are noted down, which are then compared to the experimental values obtained by Punyamurthula (2004). The experimental and analytical strain values for different load values are presented in Table 5.3. 
Table 5.3 Strain values of double FRP beam for central patch load

\begin{tabular}{|c|c|c|}
\hline Applied load (kips) & $\begin{array}{c}\text { Micro-strain }\left(\varepsilon_{z}\right) \\
\text { Analytical }\end{array}$ & $\begin{array}{c}\text { Micro-strain }\left(\varepsilon_{z}\right) \\
\text { Experimental }\end{array}$ \\
\hline 0 & 0 & 0 \\
\hline 3 & 174.19 & 171.12 \\
\hline 6 & 348.38 & 346.94 \\
\hline 9 & 522.57 & 541.28 \\
\hline 12 & 696.76 & 726.36 \\
\hline 15 & 870.95 & 908.36 \\
\hline 18 & 1045.1 & 1105.78 \\
\hline 21 & 1219.3 & 1293.95 \\
\hline 24 & 1393.5 & 1491.37 \\
\hline 27 & 1567.7 & 1691.88 \\
\hline 30 & 1741.9 & 1895.47 \\
\hline 33 & 1916.1 & 2095.98 \\
\hline 36 & 2090.3 & 2296.48 \\
\hline 39 & 2264.5 & 2496.99 \\
\hline 42 & 2438.7 & 2693.48 \\
\hline 45 & 2612.9 & 2893.99 \\
\hline 48 & 2787.1 & 3106.83 \\
\hline 51 & 2961.2 & 3319.68 \\
\hline 52 & 3019.3 & 3406.05 \\
\hline
\end{tabular}

A graph plotted between load and corresponding strain values that are obtained both analytically and experimentally is presented in Fig. 5.7. It is clear from the Fig. 5.7 that the analytical curve is linear but the experimental curve exhibits nonlinearity, this is perhaps because of the internal failure of some of the plies in the deck while loading. 


\section{Load Vs Micro-strain}

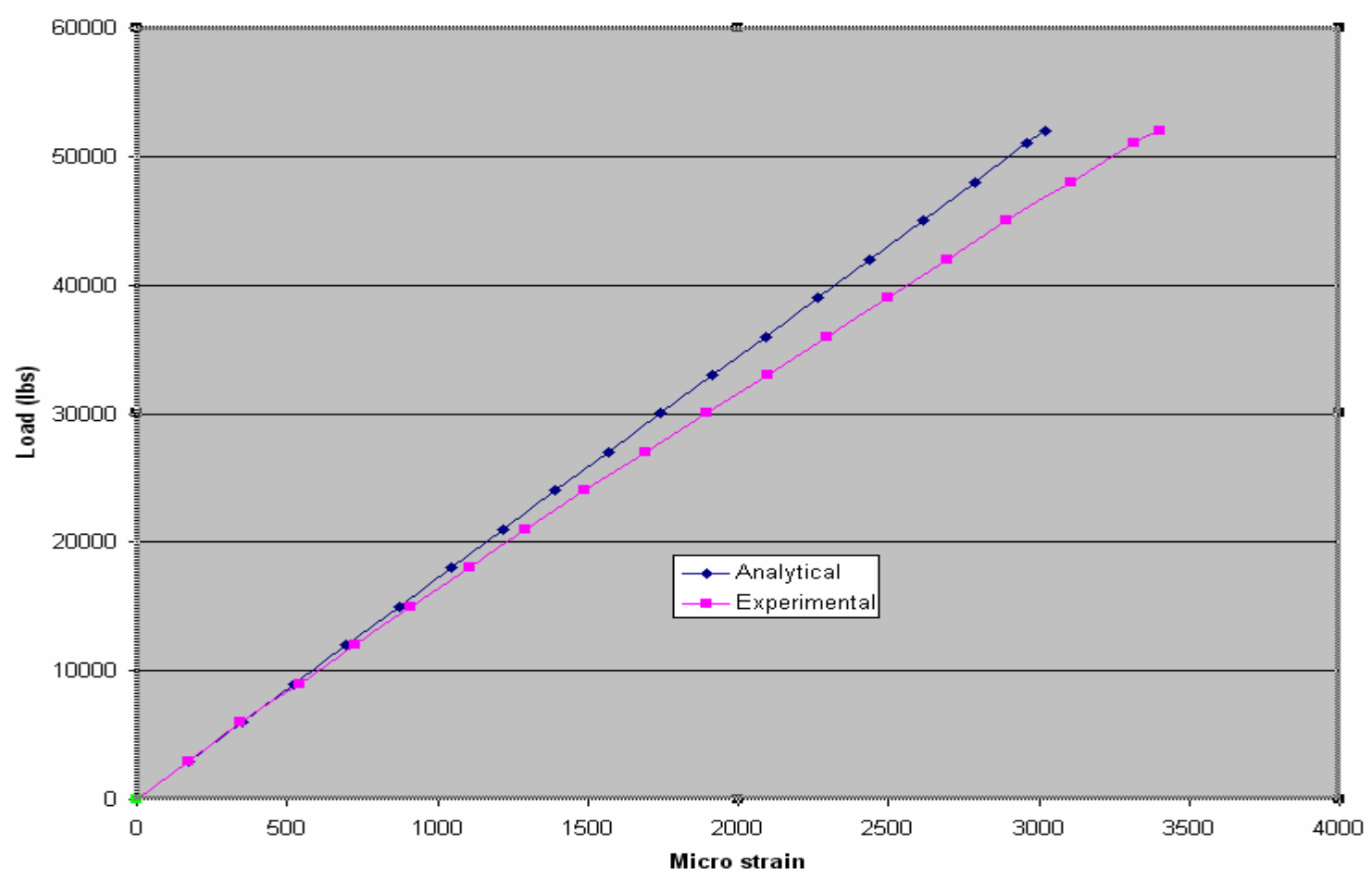

Fig. 5.7 Graph plotted between strain and central patch load

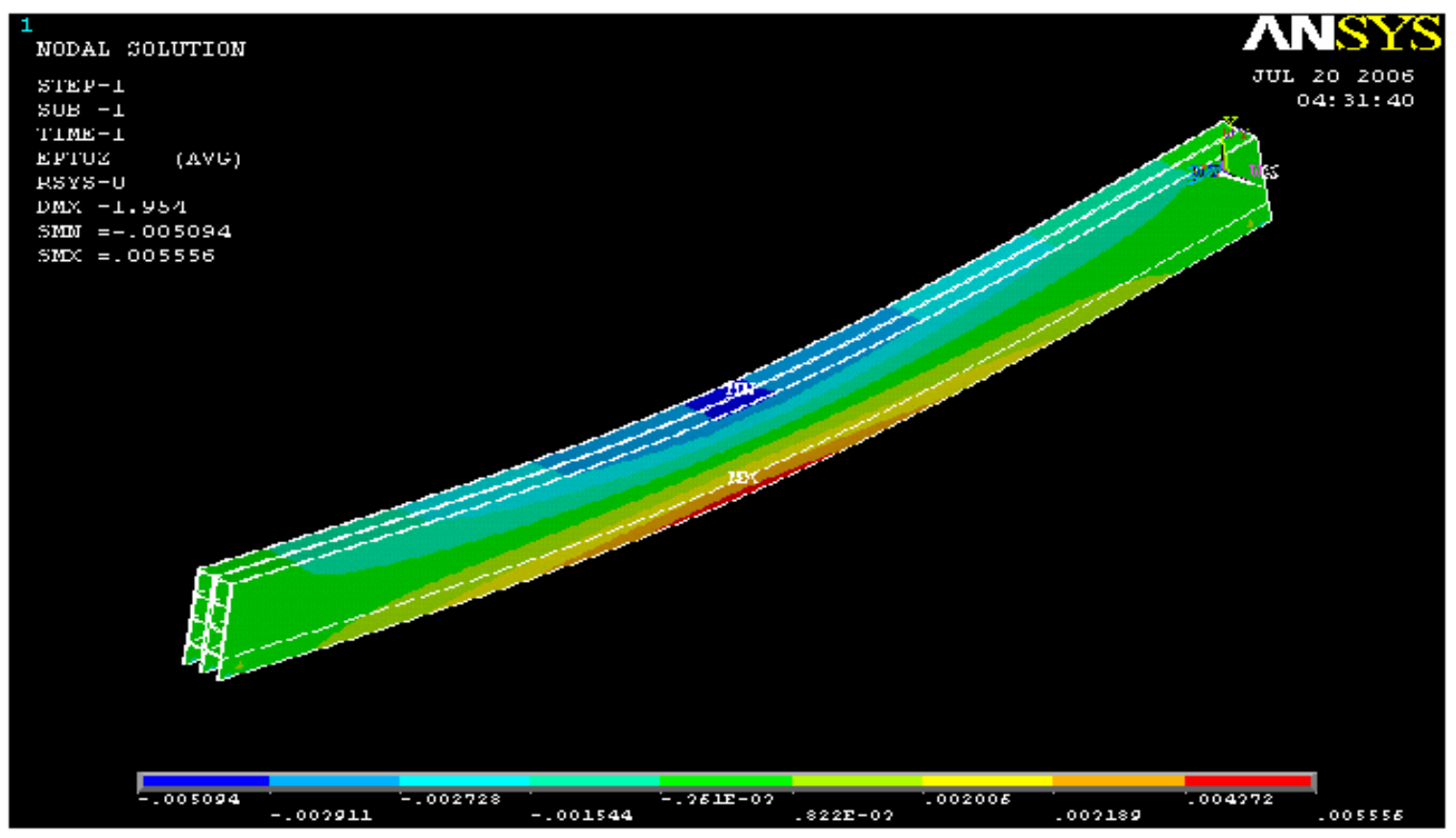

Fig. 5.8 Contour plot of strain $\left(\varepsilon_{z}\right)$ of double FRP beam under a patch load of 52 kips 


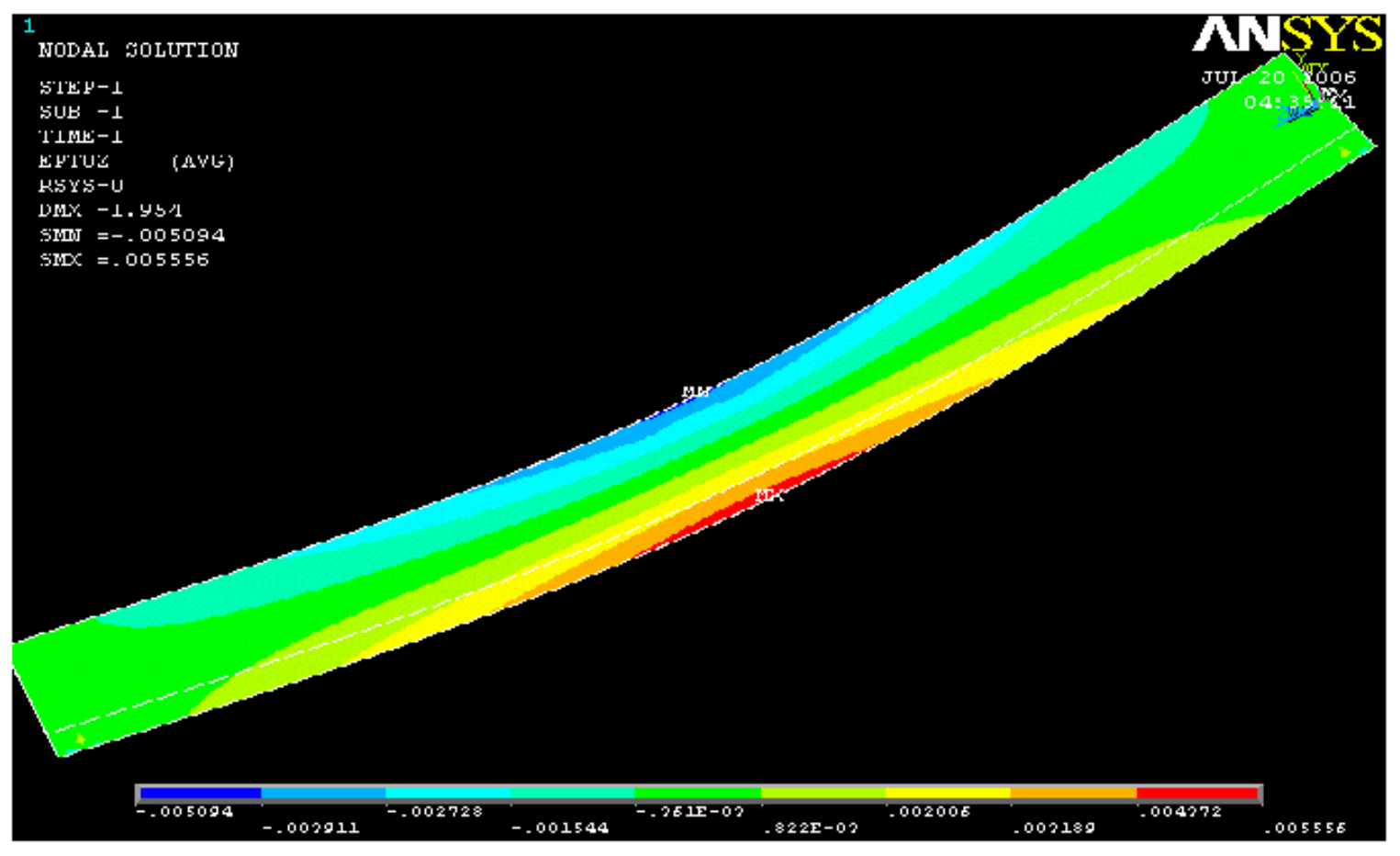

Fig. 5.9 Side view of the contour plot of strain $\left(\varepsilon_{z}\right)$ of double FRP beam

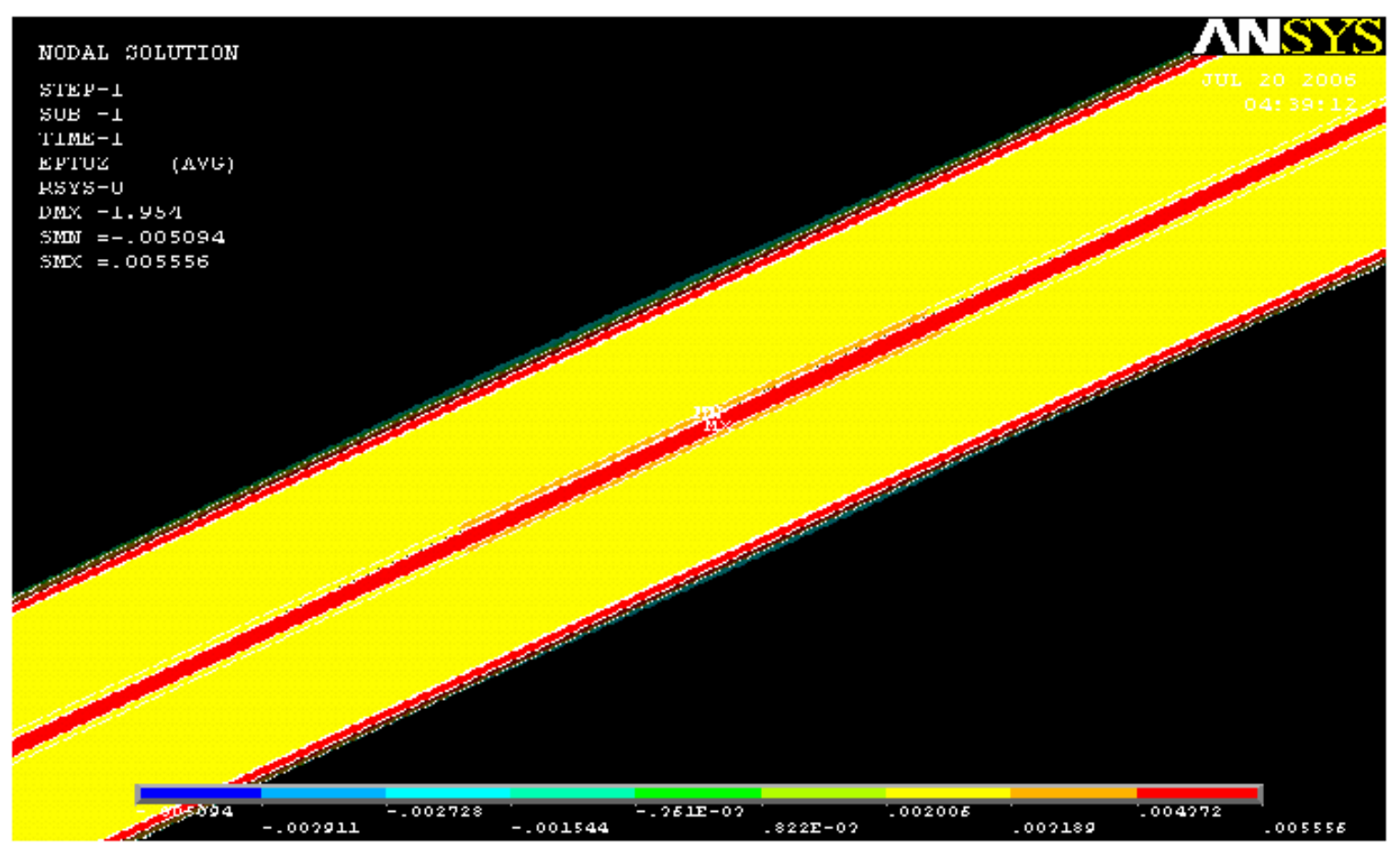

Fig. 5.10 Bottom view of the contour plot of strain $\left(\varepsilon_{z}\right)$ of double FRP beam 
A table consisting of analytical stress and strain values observed at the mid section in the bottom flange of the FRP double beam for the corresponding load values is presented below followed by the graph, plotted between stress and corresponding strain values at the mid section of the double beam, with stress on $Y$-axis and strain on $X$-axis.

Table 5.4 Stress and strain values of double FRP beam for central patch load

\begin{tabular}{|c|c|c|}
\hline Applied load (kips) & Stress (psi) & Micro-strain $\left(\varepsilon_{z}\right)$ \\
\hline 0 & 0 & 0 \\
\hline 3 & 563.97 & 174.19 \\
\hline 6 & 1127.95 & 348.38 \\
\hline 9 & 1691.97 & 522.57 \\
\hline 12 & 2255.95 & 696.76 \\
\hline 15 & 2819.90 & 870.95 \\
\hline 18 & 3383.77 & 1045.10 \\
\hline 21 & 3947.77 & 1219.30 \\
\hline 24 & 4511.77 & 1393.50 \\
\hline 27 & 5075.77 & 1567.70 \\
\hline 30 & 5639.77 & 1741.90 \\
\hline 33 & 6203.77 & 1916.10 \\
\hline 36 & 6767.75 & 2090.30 \\
\hline 39 & 7331.72 & 2264.50 \\
\hline 42 & 7895.70 & 2438.70 \\
\hline 45 & 8459.67 & 2612.90 \\
\hline 48 & 9023.67 & 2787.10 \\
\hline 51 & 9587.60 & 2961.20 \\
\hline 52 & 9775.60 & 3019.30 \\
\hline
\end{tabular}




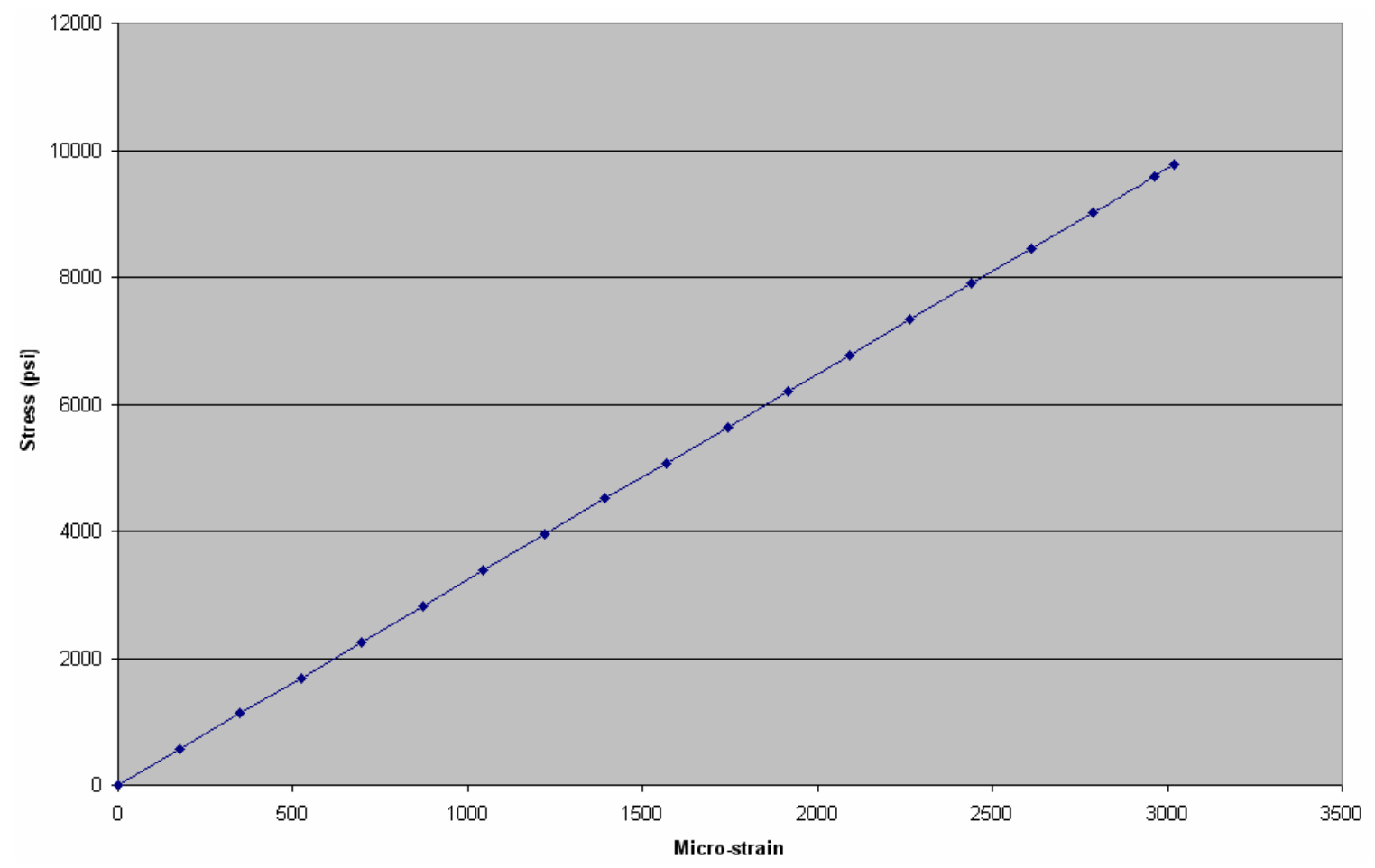

Fig. 5.11 Stress-strain curve for a central patch load

Figure 5.11 indicates that the curve is a linear curve starting from the origin. The stress value increases linearly with increase in the strain value at the mid section in the bottom flange of the double FRP beam.

\subsubsection{Bending stiffness based on strain}

Using Eq. (3.35) and the slope from Fig. 5.7 the value of equivalent flexural rigidity based on strain is found to be $12.07 \times 10^{9} \mathrm{lb}^{*} \mathrm{in}^{2}$ which is in close match with the value obtained in the experimental tests conducted by Punyamurthula (2004).

Table 5.5 Equivalent flexural rigidity of double FRP beam based on strain

\begin{tabular}{|c|c|c|}
\hline Type & $\begin{array}{c}\text { Experimental } \\
\text { Punyamurthula (2004) }\end{array}$ & Analytical \\
\hline $\begin{array}{c}\text { Equivalent Flexural } \\
\text { Rigidity, } \mathbf{E}_{\mathbf{z}} \mathbf{I}_{\mathbf{x}}\left(\mathbf{1 0}^{\mathbf{9}}\right) \mathbf{l b}^{*} \mathbf{i n}^{2}\end{array}$ & 11.5 & 12.07 \\
\hline
\end{tabular}




\subsection{FIRST-PLY FAILURE ANALYSIS}

First-ply failure analysis is carried out for a central patch load of 52 kips applied over an area of 6.5 "x 10". Fig. 5.12 displays the failure plot obtained using maximum stress criterion for double FRP beam. The maximum value of ' $\xi$ ' listed in this plot is shown to be 1.7557 , which implies that according to the maximum stress criterion the load at which the first ply fails is equal to $\mathrm{P}=52 / 1.7557=29.6$ kips. From the Fig. 5.12 , it is clear that the failure occurs at the mid span in the extended part of the web.

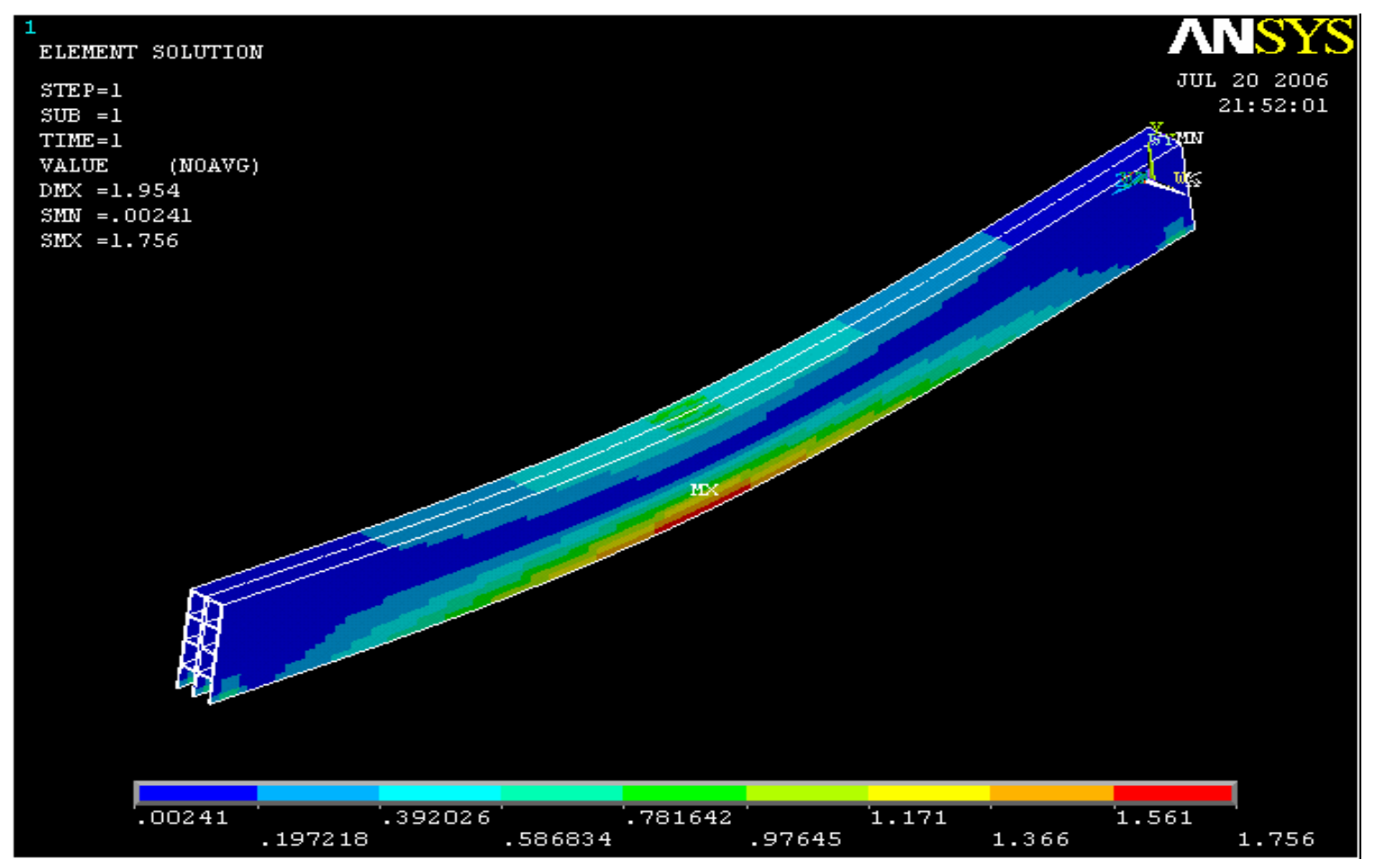

Fig. 5.12 Failure plot of double FRP beam using maximum stress criterion 


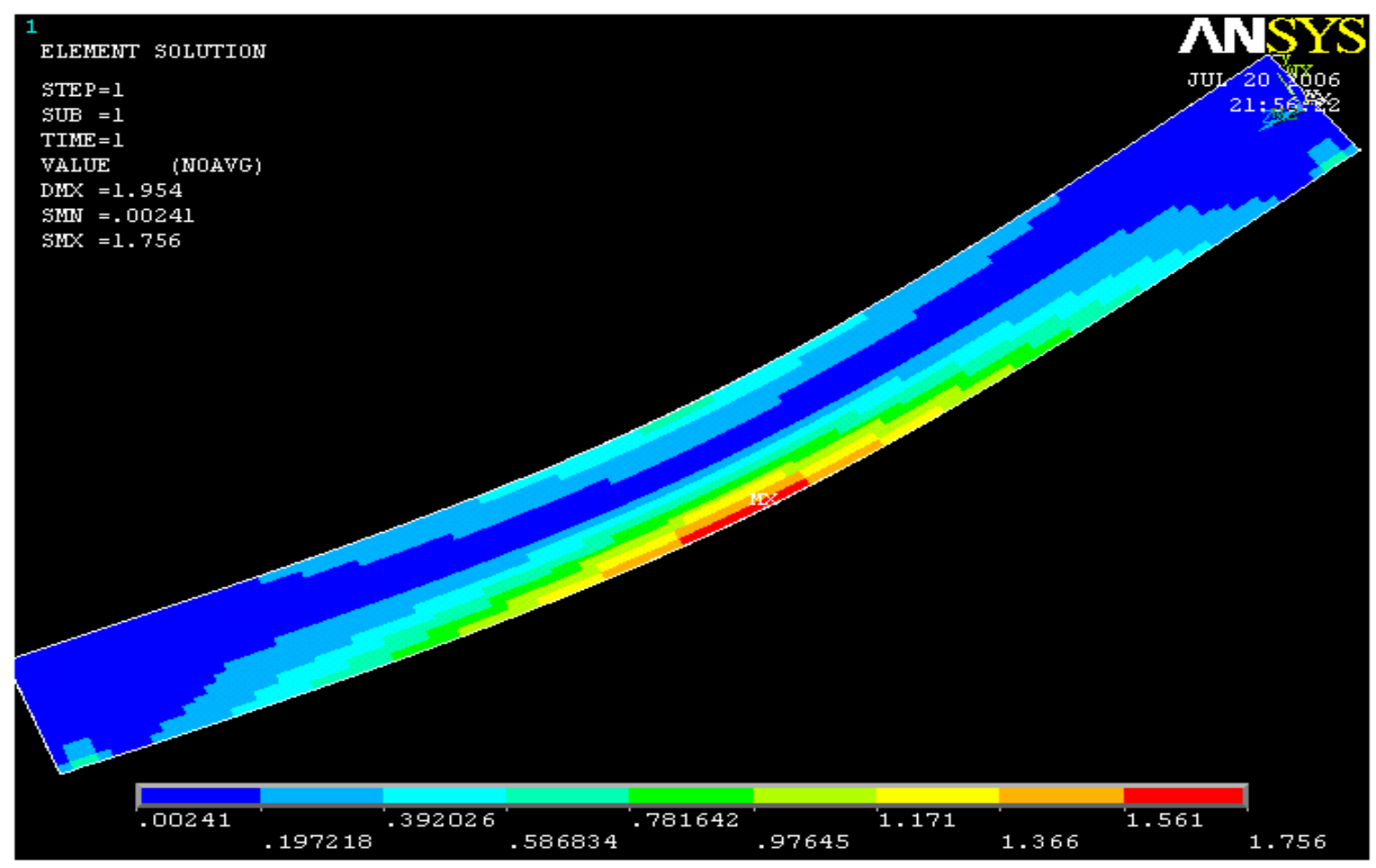

Fig. 5.13 Side view of the failure plot of double FRP beam

Figure 5.14 shows the failure plot obtained using maximum strain criterion. Even this criterion predicts that the first ply in the beam to fail is the $90^{\circ}$ ply, which seems to fail in the transverse direction. The maximum value of ' $\xi$ ' listed in the maximum strain criterion failure plot is 1.7490 as shown in the Fig. 5.14, which implies that the first ply failure load predicted by using this criterion is equal to $P=52 / 1.7490=29.7 \mathrm{kips}$, which is near to the value of 29.6 kips predicted by maximum stress failure criterion. 


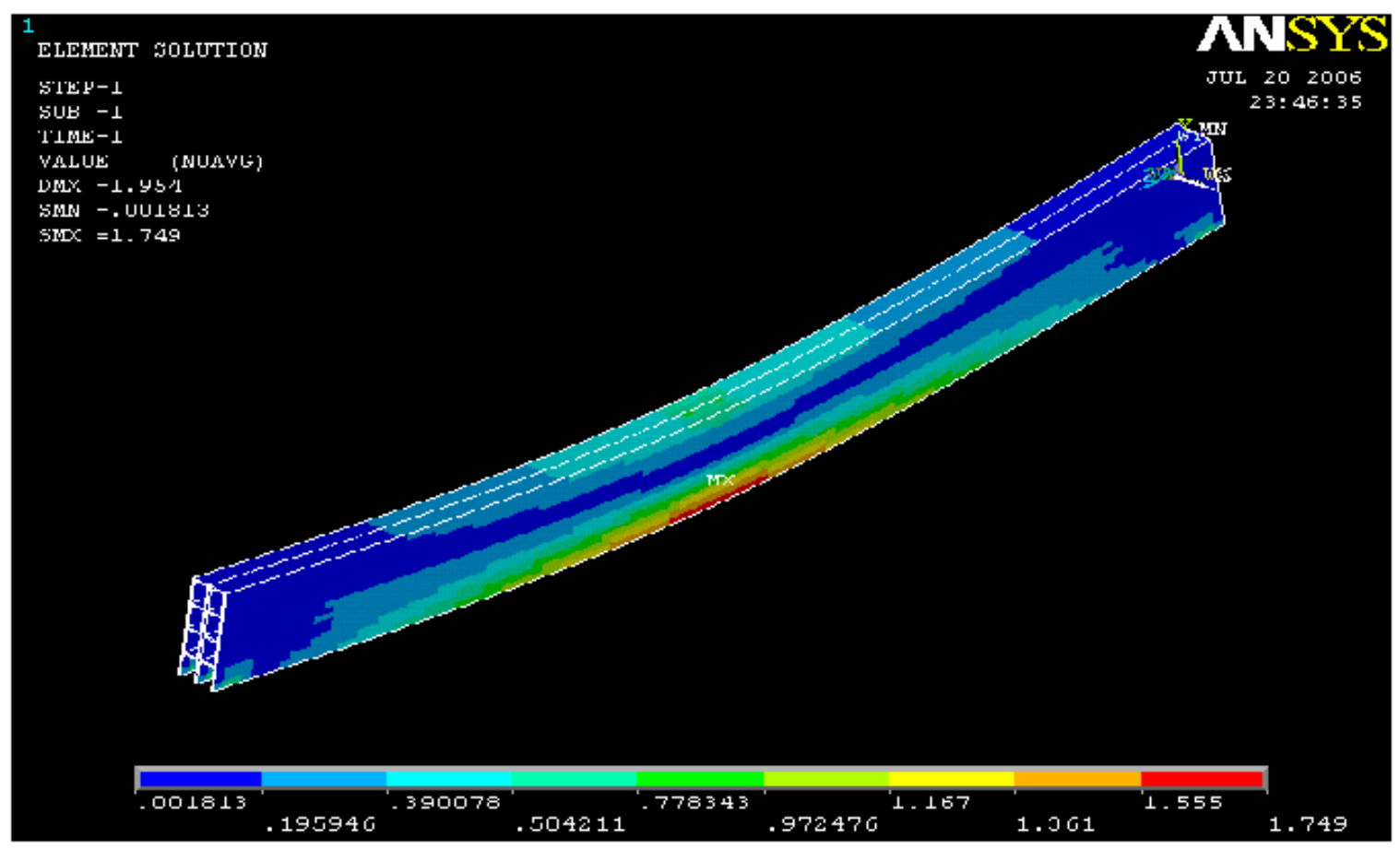

Fig. 5.14 Failure plot of double FRP beam using maximum strain criterion

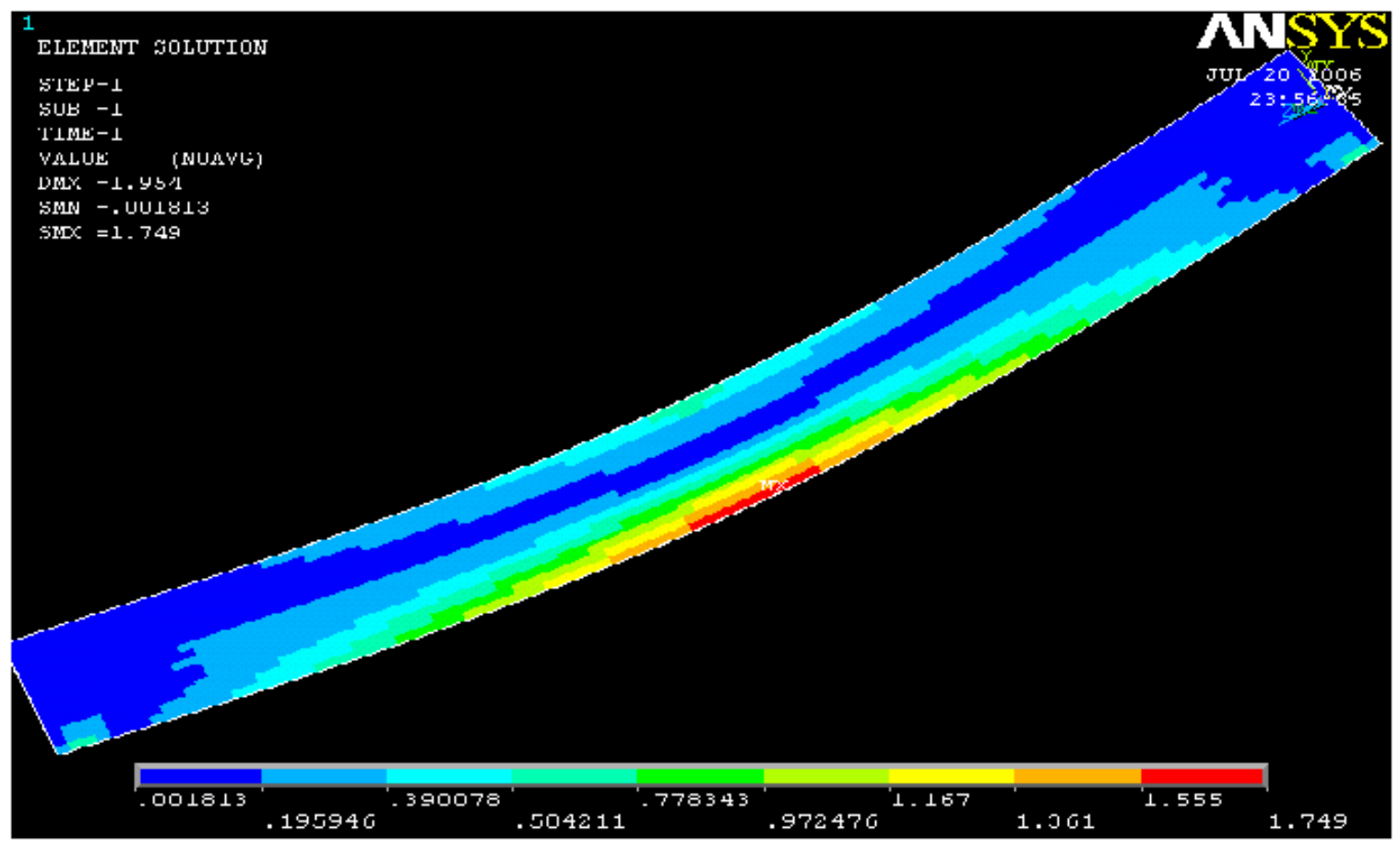

Fig. 5.15 Side view of failure plot of double FRP beam using maximum strain criterion 
Figure 5.16 displays the failure plot of double FRP beam using Tsai-Wu criterion. The maximum value of $\xi$ listed in the Tsai-Wu failure plot is 2.4951, which implies that the first ply failure load is equal to 20.8 kips. The failure occurs in the same location as predicted by maximum stress and maximum strain criteria.

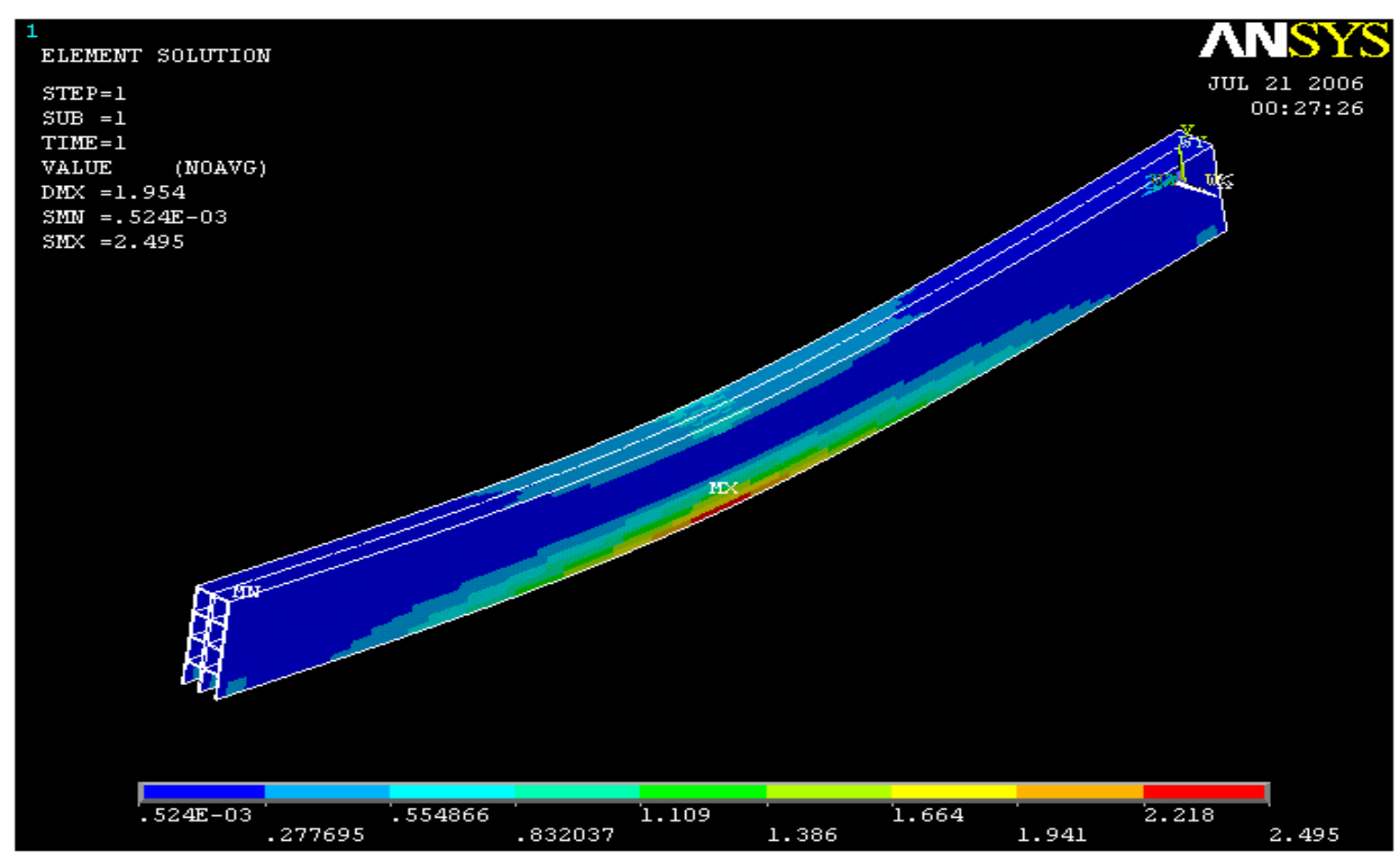

Fig. 5.16 Failure plot of double FRP beam using Tsai-Wu criterion 


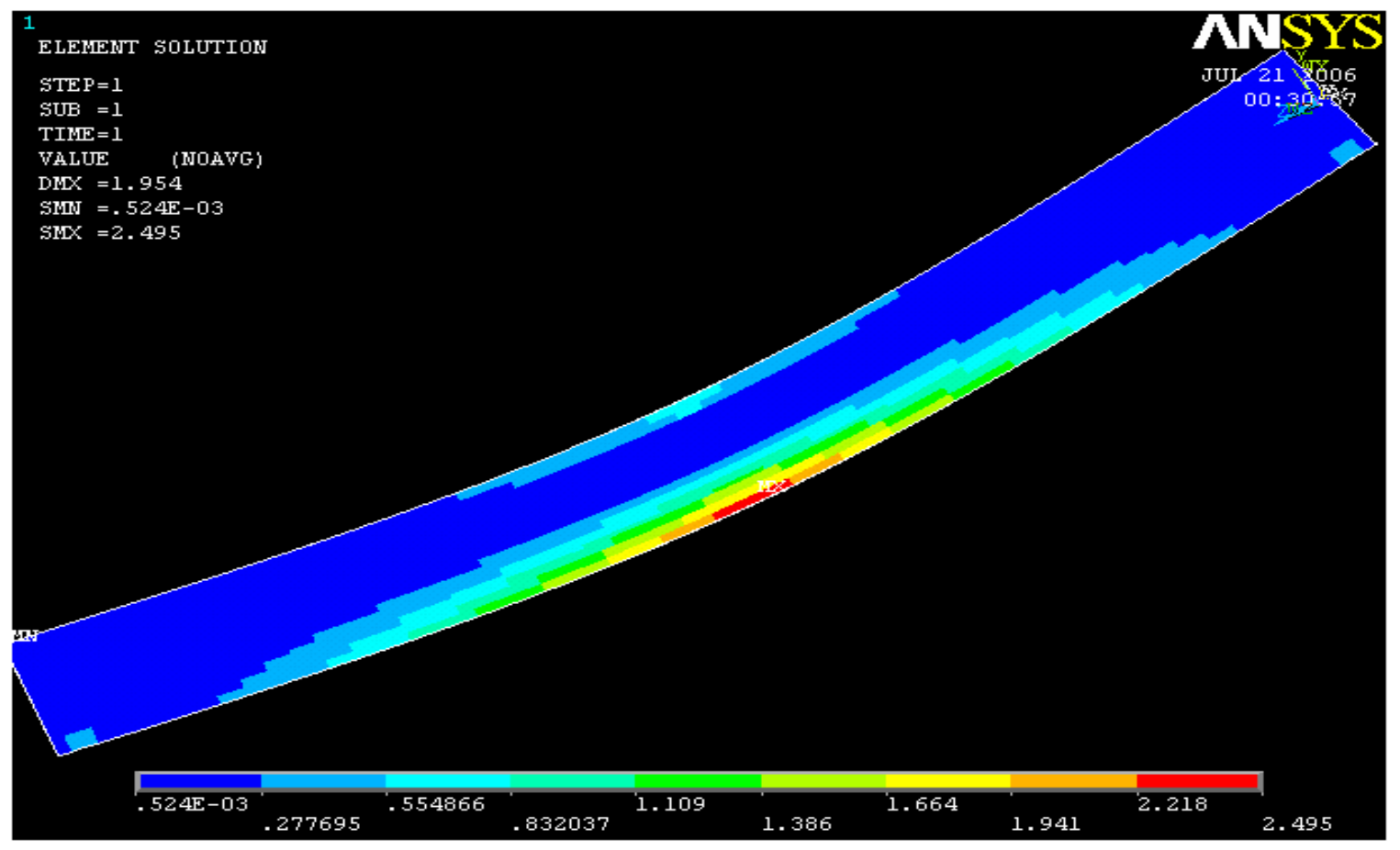

Fig. 5.17 Side view of failure plot of double FRP beam using Tsai-Wu criterion 


\section{CHAPTER 6}

\section{RESPONSE OF TWO-MODULE FRP DECK UNDER}

\section{STATIC LOADING}

\subsection{INTRODUCTION}

In this chapter, structural properties such as the bending stiffness and strength are evaluated by conducting three point bending test on a two-module FRP deck component. The values thus obtained are compared to the values obtained by carrying out finite element analysis of the deck. The test is conducted to know the structural behavior and performance of the deck under varying loads. The strains at various locations on the deck are recorded while the deck is being loaded up to 22 kips. Figure 6.1 displays the cross section of longitudinal component of two modules of FRP deck glued together.

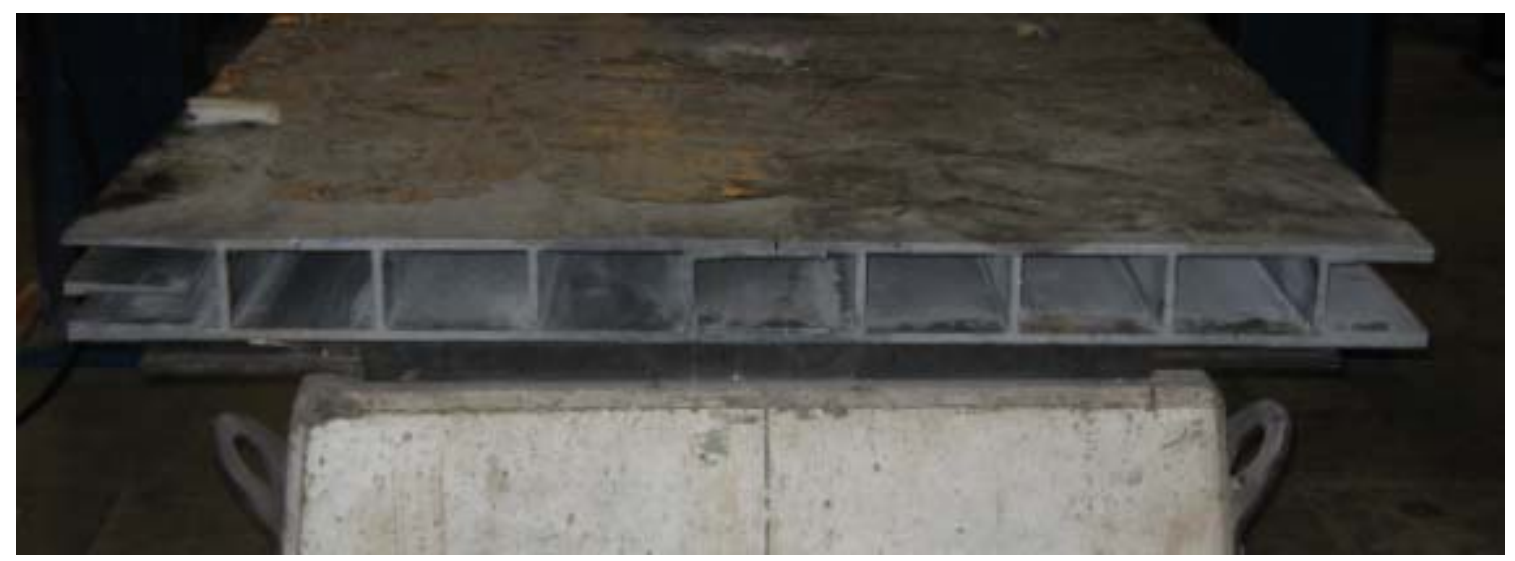

Fig. 6.1 Cross section of two-module FRP deck used in testing 


\subsection{TEST SET-UP}

A bending test is performed on two-module FRP deck whose cross section as shown in the Fig. 6.1. The two-module FRP composite bridge deck system is placed on rigid supports with steel rollers sandwiched between steel plates to simulate simple support conditions. One end of the support is hinged (the steel roller is welded to the bottom of steel plate) and so it is free to rotate with zero horizontal movement, while the other end is free, which means that the steel roller is free to rotate and translate in horizontal direction only. The span between the supports for the longitudinal two-module FRP bridge deck component is maintained at 9 feet.

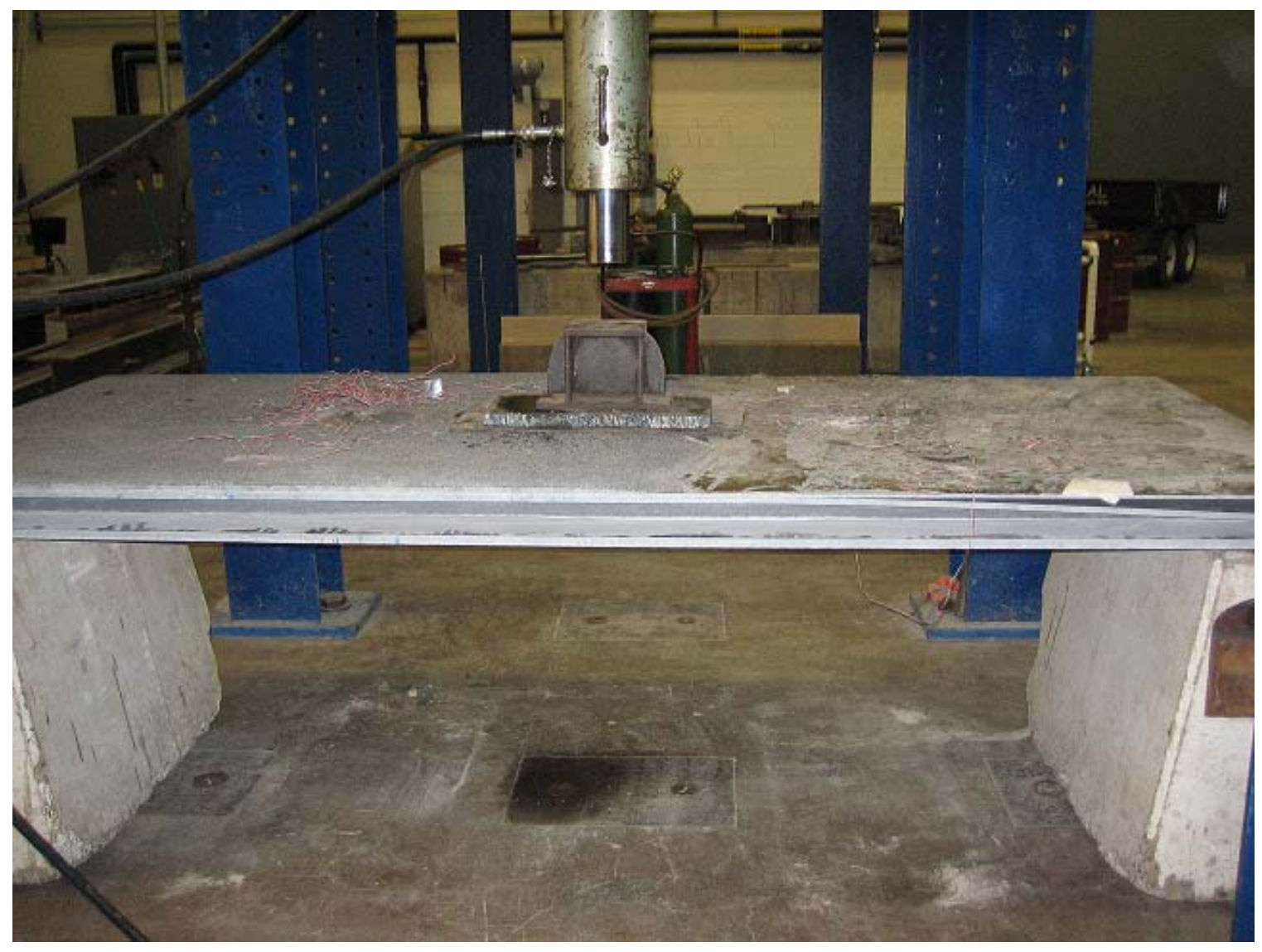

Fig. 6.2 Test set-up for 2 module FRP deck component 


\subsection{TEST PROCEDURE}

A patch load of 10 "x 20 " is applied at the center on the top flange of the twomodule FRP composite deck through a hydraulic jack as shown in Fig. 6.2. A load cell is used to monitor the magnitude of load applied, dial gauge/ LVDT at the bottom and mid span of the test specimen is used to measure the deflection of the deck and strain indicators are used to measure strain at different locations on the two-module deck. All data are taken at constant load intervals.

\subsection{FINITE ELEMENT ANALYSIS OF 2 MODULE FRP DECK}

\subsubsection{Development of Finite Element Model}

As indicated earlier, a finite element model of the two-module FRP deck is generated, which consists about 13200 elements and 20008 nodes, as shown in Fig. 6.3. The orientations of the element coordinate systems of all elements are checked to see if they are aligned in the fiber direction.

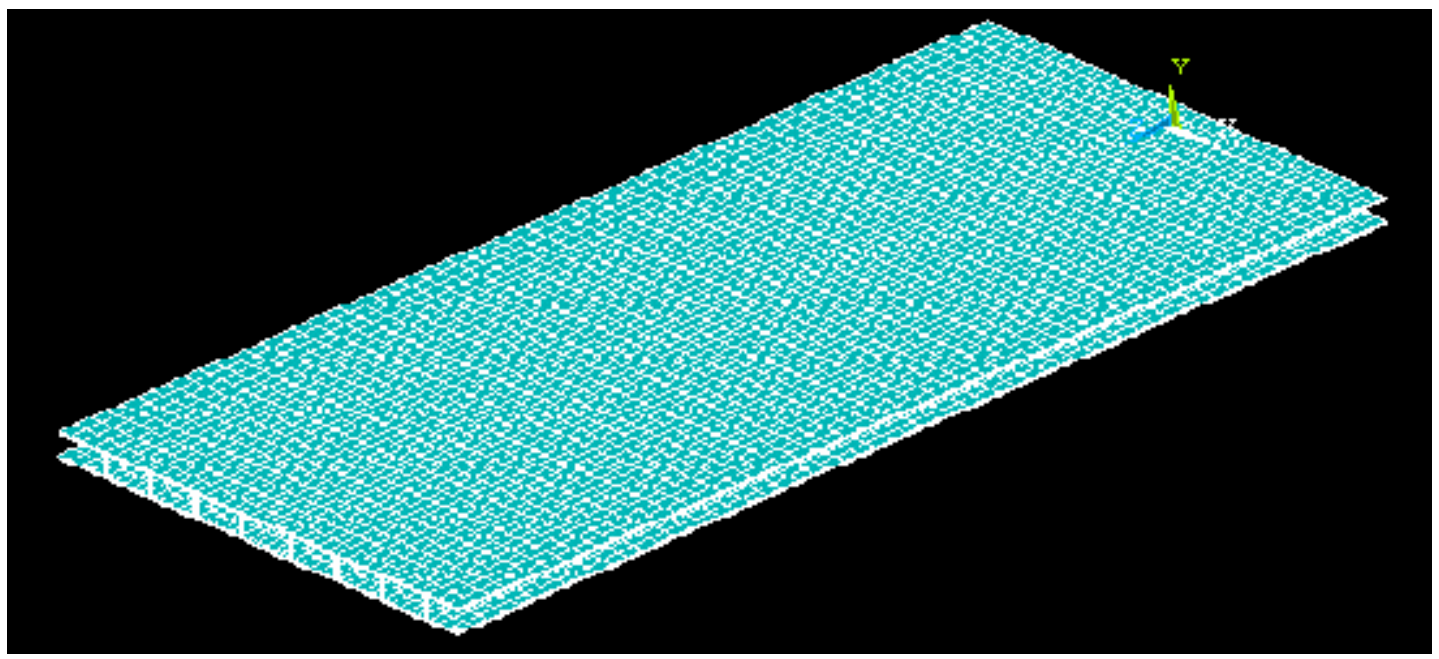

Fig. 6.3 Finite element model of two-module FRP deck system 


\subsubsection{Applied Boundary Conditions and Loads}

The boundary conditions applied on the finite element model are the same as that explained in the experimental test set up. The deck is simply supported with a clear span adjusted to 9 feet. In experimental test a patch load is applied at the center on the top flange of the deck using a steel plate. To get the effect of steel plate, coupling restraints with the same cross section of the steel plate are applied at the center on the top flange of the deck. Figure 6.4 shows the boundary conditions applied on the two-module FRP deck. A surface load of 22 kips over an area of cross section 10"x 20" is applied at the center on the top flange of the deck as shown in the Fig. 6.5.

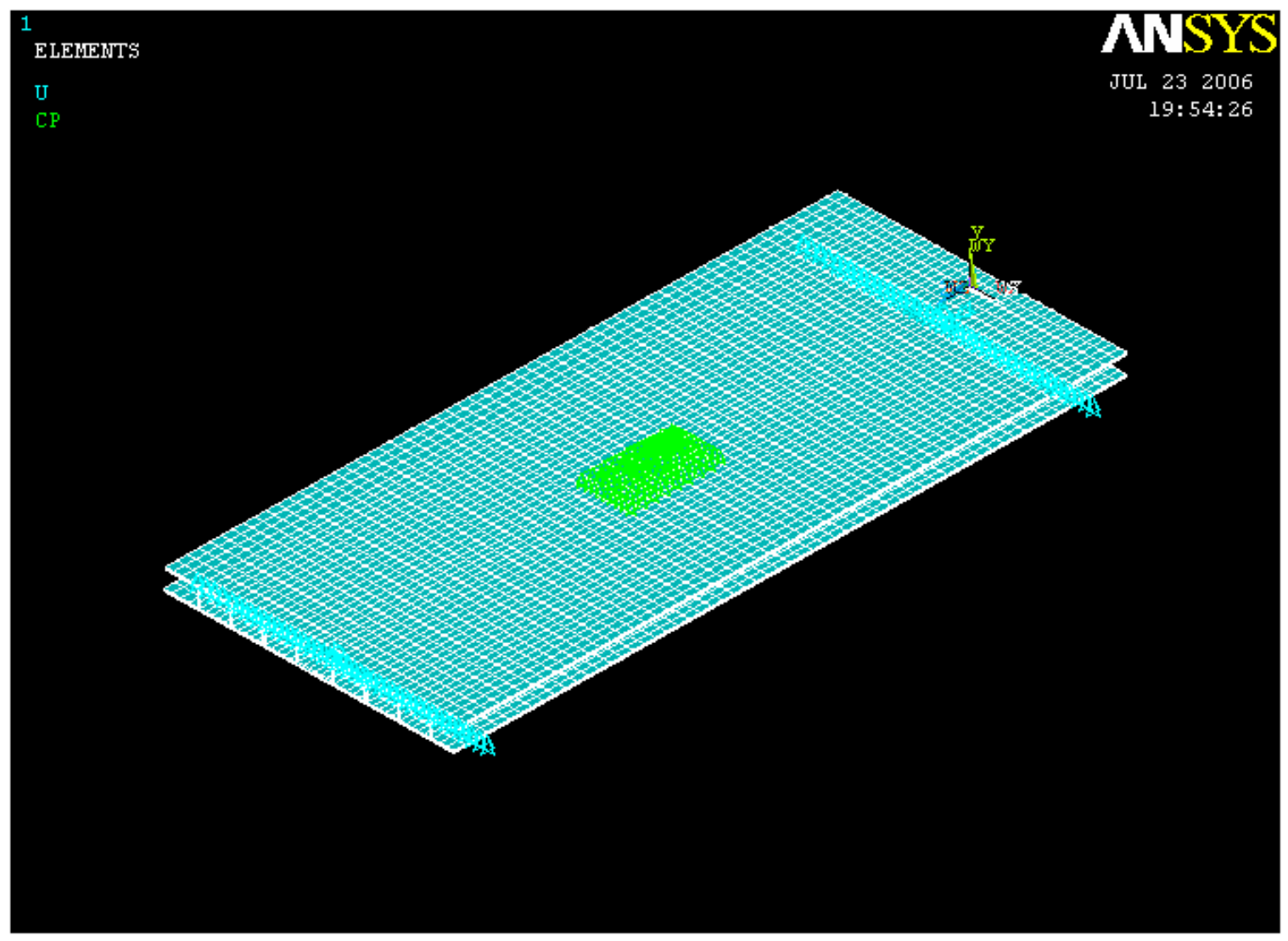

Fig. 6.4 Pictorial representation of boundary conditions applied on two-module FRP deck 


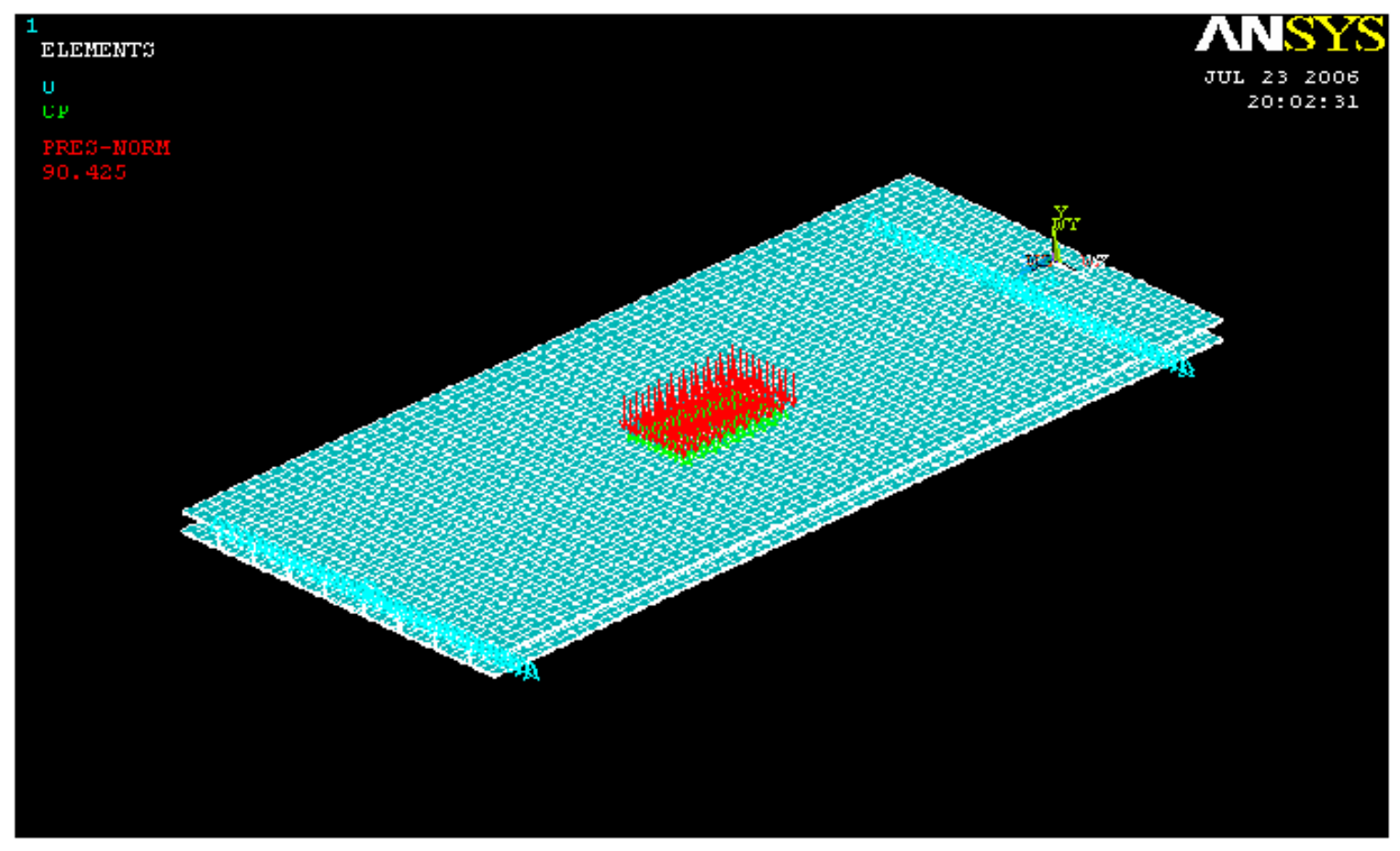

Fig. 6.5 Pictorial Representation of 10"x 20" Patch Load Applied on two-module FRP

deck

\subsubsection{Results}

\subsubsection{Introduction}

For a patch load of up to 22 kips over an area of 6.5 "x 10" applied at the center on the top flange of the double beam, the values of maximum deflection and strains at different locations on the deck for varying load are noted, which are then compared to the experimental values obtained.

\subsubsection{Deflection Analysis}

The two-module FRP deck is simply supported with a span of 108 " between the supports. A patch load over an area of 10"x 20 " is applied at the center on the top flange 
of the double beam. The patch load is gradually increased from 0 to 22 kips and the corresponding values of maximum deflection are noted. Figure 6.6 displays the contour plot of the deflected shape of 2 module FRP deck at the resultant load of 22 kips.

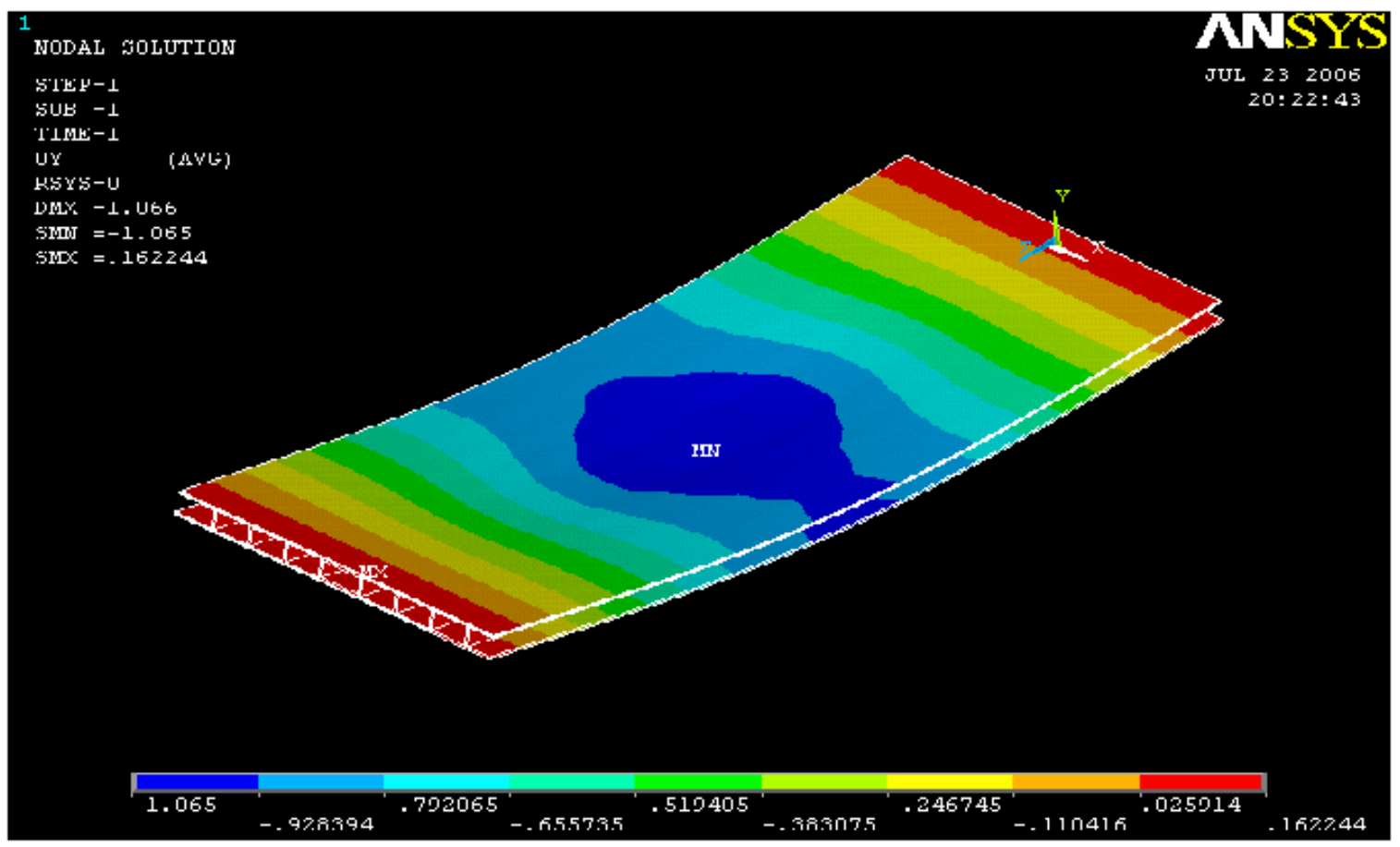

Fig. 6.6 Deflection plot of two-module FRP deck under the patch load of 22 kips 
The analytical and experimental maximum deflection values for the corresponding load values are presented in Table 6.1.

Table 6.1 Maximum deflection values of two-module FRP deck

\begin{tabular}{|c|c|c|}
\hline Applied load (kips) & $\begin{array}{c}\text { Maximum deflection (in.) } \\
\text { Analytical }\end{array}$ & $\begin{array}{c}\text { Maximum deflection (in.) } \\
\text { Experimental }\end{array}$ \\
\hline 0 & 0 & 0 \\
\hline 1 & 0.048 & 0.054 \\
\hline 2 & 0.096 & 0.111 \\
\hline 3 & 0.145 & 0.161 \\
\hline 4 & 0.193 & 0.218 \\
\hline 5 & 0.241 & 0.269 \\
\hline 6 & 0.292 & 0.321 \\
\hline 7 & 0.338 & 0.371 \\
\hline 8 & 0.387 & 0.420 \\
\hline 9 & 0.435 & 0.470 \\
\hline 10 & 0.483 & 0.525 \\
\hline 11 & 0.532 & 0.574 \\
\hline 12 & 0.580 & 0.625 \\
\hline 13 & 0.628 & 0.675 \\
\hline 14 & 0.677 & 0.725 \\
\hline 15 & 0.725 & 0.777 \\
\hline 16 & 0.774 & 0.823 \\
\hline 17 & 0.822 & 0.882 \\
\hline 18 & 0.870 & 0.936 \\
\hline 19 & 0.919 & 0.983 \\
\hline 20 & 0.967 & 1.040 \\
\hline 21 & 1.015 & 1.080 \\
\hline 22 & 1.064 & 1.140 \\
\hline
\end{tabular}


Figure 6.7 shows the graphs plotted between load and maximum deflection that are obtained both analytically and experimentally.

\section{Load Vs Maximum deflection}

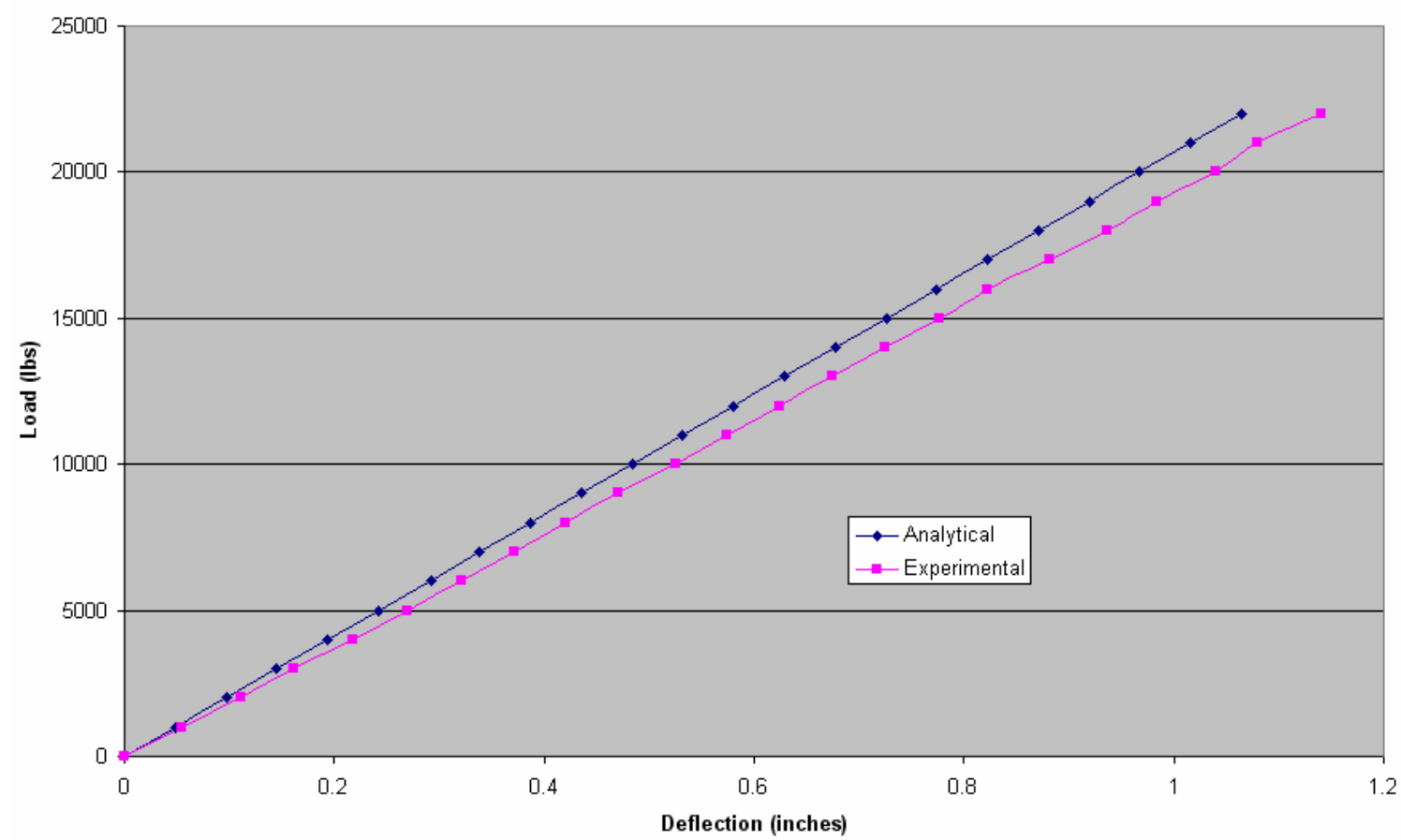

Fig. 6.7 Graph plotted between maximum deflection and central patch load

\subsection{Bending stiffness based on deflection}

Using Eq. (3.33) the bending stiffness value and Young's modulus for the twomodule FRP deck are found to be $5.42 \times 10^{8} \mathrm{lb}^{*} \mathrm{in}^{2}$ and $3.8 \times 10^{6}$ psi, respectively, where as the values obtained in experimental tests are $5.06 \times 10^{8} \mathrm{lb}^{*} \mathrm{in}^{2}$ and $3.62 \times 10^{6} \mathrm{psi}$, respectively. From the experimental results obtained by Punyamurthula (2004) it has been observed that the shear deflection in the deck is approximately $10 \%$ of the total deflection (under three point bending). Hence by excluding the deflection due to shear 
from the total deflection the values of bending stiffness and Young's modulus obtained in experimental tests are given in the Table 6.2.

Table 6.2 Equivalent flexural rigidity and young's modulus of two-module FRP deck component based on deflection

\begin{tabular}{|c|c|c|c|}
\hline \multirow{2}{*}{ Type } & \multicolumn{2}{|c|}{ Experimental } & \multirow{2}{*}{ Analytica } \\
\hline & Including shear & Excluding shear & \\
\hline $\begin{array}{l}\text { Flexural rigidity } \\
\mathbf{E}_{\mathbf{z}} \mathbf{I}_{\mathbf{x}}\left(10^{8}\right) \mathrm{lb}^{*} \mathrm{in}^{2}\end{array}$ & 5.12 & 5.62 & 5.42 \\
\hline $\begin{array}{l}\text { Young's Modulus } \\
\qquad E_{z}\left(10^{6}\right) p s i \\
\left(I_{x}=139.88 \text { in }^{4}\right)\end{array}$ & 3.65 & 4.02 & 3.88 \\
\hline $\begin{array}{c}\text { Young's Modulus } \\
E_{z}\left(10^{6}\right) p s i \\
\left(I_{x}=156.121 \text { in }^{4}\right)\end{array}$ & 3.28 & 3.60 & 3.47 \\
\hline
\end{tabular}

\subsubsection{Strain Analysis}

The strain values at various locations on the deck for the corresponding load values are noted down, which are then compared to the experimental values obtained. Figure 6.8 shows the locations on the deck where the strain gauges are mounted. This figure also displays the direction in which the strain gauges are mounted. 
Top view of the two-module FRP deck
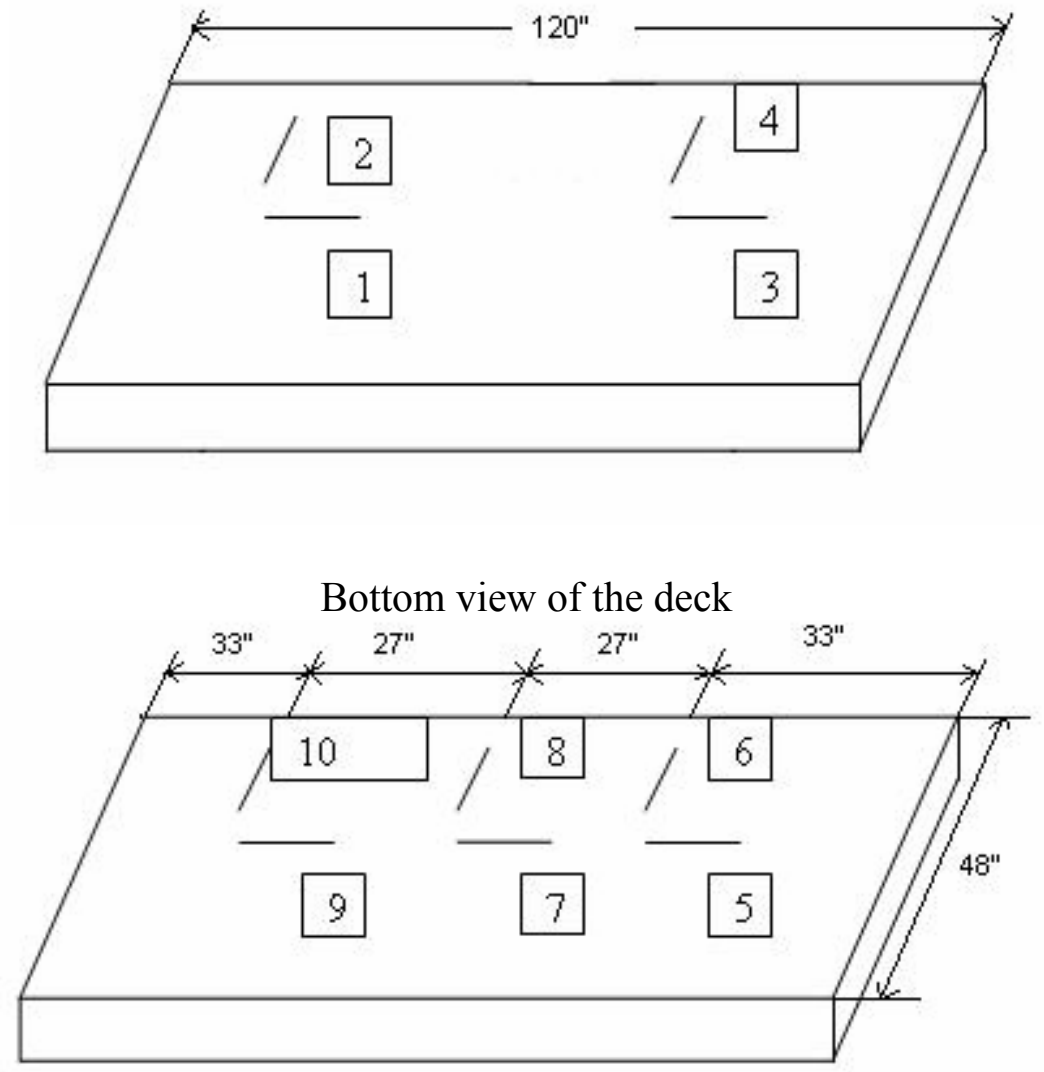

Strain gauges \#1, \#3, \#9, \#7, \#5 measure strain in the 120 " direction (Z) Strain gauges $\# 2, \# 4, \# 10, \# 8, \# 6$ measure strain in the 48 " direction (X)

Fig. 6.8 Position of strain gauges

Table 6.3 summarizes the strain values obtained both analytically and experimentally in the bottom flange in the $Z$ direction (cell direction) at Gauge $\# 7$. 
Table 6.3 Strain values at the Strain Gage \#7 location for a central patch load

\begin{tabular}{|c|c|c|}
\hline Applied load (kips) & $\begin{array}{l}\text { Strain }\left(\varepsilon_{z}\right) \\
\text { Analytical }\end{array}$ & $\begin{array}{c}\text { Strain }\left(\varepsilon_{z}\right) \\
\text { Experimental }\end{array}$ \\
\hline 0 & 0 & 0 \\
\hline 1000 & $6.23 \mathrm{E}-05$ & $6.12 \mathrm{E}-05$ \\
\hline 2000 & 0.000125 & $1.32 \mathrm{E}-04$ \\
\hline 3000 & 0.000187 & 1.97E-04 \\
\hline 4000 & 0.000249 & $2.61 E-04$ \\
\hline 5000 & 0.000311 & $3.28 \mathrm{E}-04$ \\
\hline 6000 & 0.000374 & $4.00 \mathrm{E}-04$ \\
\hline 7000 & 0.000436 & $4.65 \mathrm{E}-04$ \\
\hline 8000 & 0.000498 & $5.33 \mathrm{E}-04$ \\
\hline 9000 & 0.000561 & $5.99 \mathrm{E}-04$ \\
\hline 10000 & 0.000623 & $6.73 E-04$ \\
\hline 11000 & 0.000685 & 7.43E-04 \\
\hline 12000 & 0.000747 & 8.11E-04 \\
\hline 13000 & 0.00081 & 8.77E-04 \\
\hline 14000 & 0.000872 & $9.43 \mathrm{E}-04$ \\
\hline 15000 & 0.000934 & $1.01 \mathrm{E}-03$ \\
\hline 16000 & 0.000997 & $1.08 \mathrm{E}-03$ \\
\hline 17000 & 0.001059 & $1.15 \mathrm{E}-03$ \\
\hline 18000 & 0.001121 & $1.22 \mathrm{E}-03$ \\
\hline 19000 & 0.001184 & $1.29 \mathrm{E}-03$ \\
\hline 20000 & 0.001246 & $1.37 \mathrm{E}-03$ \\
\hline 21000 & 0.001308 & $1.45 \mathrm{E}-03$ \\
\hline 22000 & 0.00137 & $1.51 \mathrm{E}-03$ \\
\hline
\end{tabular}

Fig. 6.9 shows the graph plotted between load applied and the strain recorded for the corresponding load values at the gauge location \#7. 


\section{Load Vs Strain}

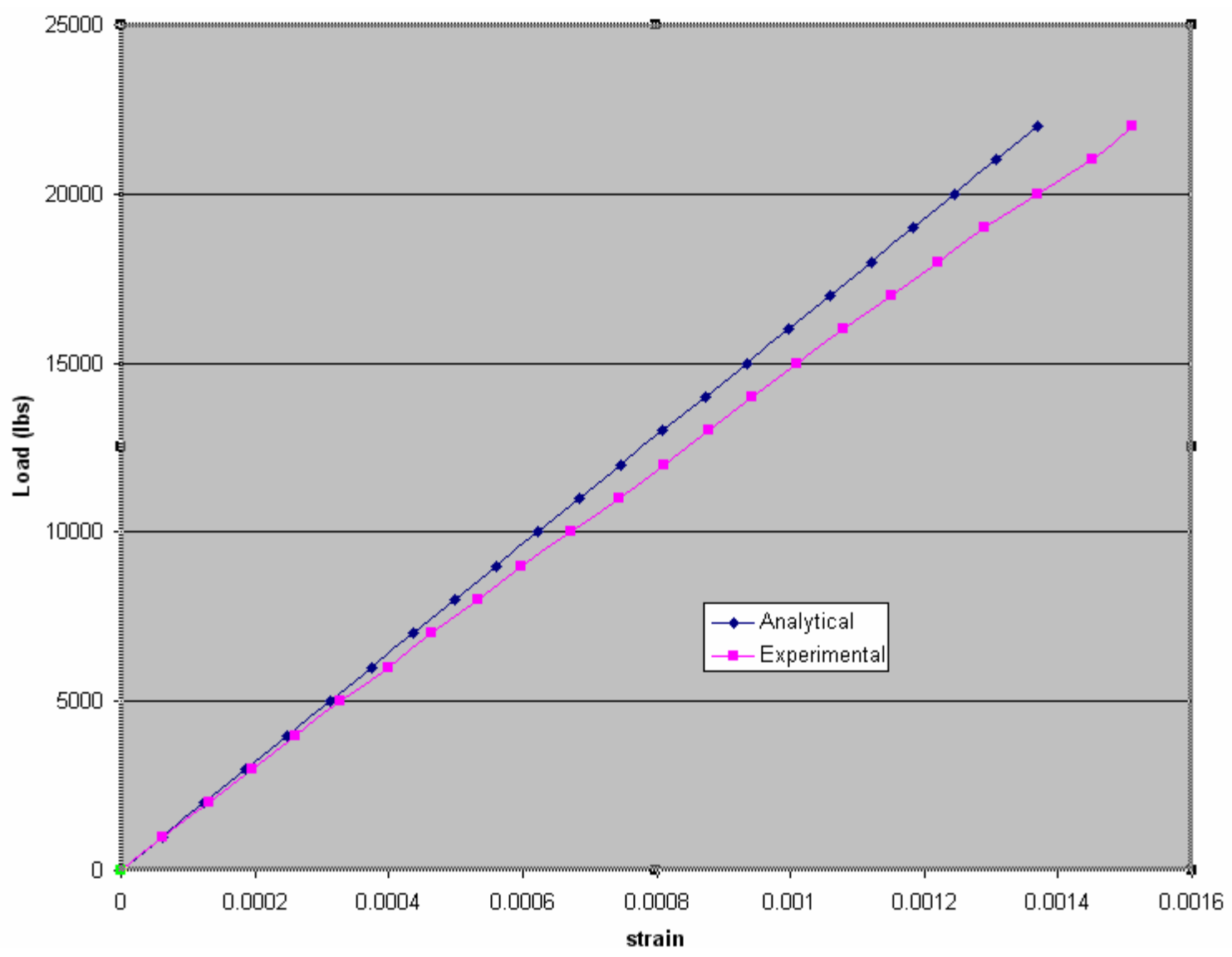

Fig. 6.9 Graph plotted between central patch load and strain at gauge location \#7

A graph plotted between load and corresponding strain values that are obtained both analytically and experimentally is presented in Fig. 5.7. It is clear from the Fig. 5.7 that the analytical curve is linear but the experimental curve exhibits nonlinearity, this is perhaps because of the internal failure of some of the plies in the deck while loading.

Tables 6.4 and 6.5 show the strain values at the other gauge locations shown in Fig. 6.8. Figures $6.10-6.17$ display the graphical plots of load Vs strain values in different directions at various gauge locations on two-module FRP deck. 
Table 6.4 Strain values at locations of strain gauges \#1, \#2, \#9 and \#10 for a central patch load

\begin{tabular}{|c|c|c|c|c|c|c|c|c|}
\hline \multirow{2}{*}{ Load (lbs) } & \multicolumn{2}{|c|}{$\varepsilon_{\mathrm{z}}(\# 1)$} & \multicolumn{2}{|c|}{$\varepsilon_{x}(\# 2)$} & \multicolumn{2}{|c|}{$\varepsilon_{\mathrm{z}}(\# 9)$} & \multicolumn{2}{|c|}{$\varepsilon_{\mathrm{x}}(\# 10)$} \\
\hline & Analytical & Expt. & Analytical & Expt. & Analytical & Expt. & Analytical & Expt. \\
\hline 0 & 0 & 0 & 0 & 0 & 0 & 0 & 0 & 0 \\
\hline 1000 & $-4.3 E-05$ & $-3.23 E-05$ & 2.05E-06 & $1.47 \mathrm{E}-06$ & 4.32E-05 & 2.89E-05 & -1.9E-06 & $-1.34 \mathrm{E}-06$ \\
\hline 2000 & -8.7E-05 & $-6.83 E-05$ & 4.1E-06 & 3.04E-06 & 8.65E-05 & $6.20 \mathrm{E}-05$ & $-3.8 E-06$ & $-3.03 E-06$ \\
\hline 3000 & -0.00013 & $-1.02 \mathrm{E}-04$ & $6.15 E-06$ & 4.82E-06 & 0.00013 & 9.40E-05 & $-5.7 E-06$ & $-4.59 E-06$ \\
\hline 4000 & -0.00017 & $-1.35 E-04$ & $8.2 \mathrm{E}-06$ & 6.70E-06 & 0.000173 & 0.000125 & -7.6E-06 & $-5.81 E-06$ \\
\hline 5000 & -0.00022 & -1.66E-04 & 1.02E-05 & 8.38E-06 & 0.000216 & 0.000157 & $-9.5 E-06$ & $-7.60 \mathrm{E}-06$ \\
\hline 6000 & -0.00026 & $-2.03 E-04$ & 1.23E-05 & $1.04 \mathrm{E}-05$ & 0.000259 & 0.000195 & -1.1E-05 & $-9.58 E-06$ \\
\hline 7000 & -0.0003 & $-2.35 E-04$ & 1.43E-05 & $1.21 \mathrm{E}-05$ & 0.000303 & 0.000224 & -1.3E-05 & -1.12E-05 \\
\hline 8000 & -0.00035 & $-2.71 E-04$ & 1.64E-05 & 1.38E-05 & 0.000346 & 0.000256 & $-1.5 E-05$ & $-1.28 E-05$ \\
\hline 9000 & -0.00039 & $-3.03 E-04$ & 1.84E-05 & $1.59 \mathrm{E}-05$ & 0.000389 & 0.000292 & -1.7E-05 & -1.43E-05 \\
\hline 10000 & -0.00043 & $-3.40 \mathrm{E}-04$ & 2.05E-05 & 1.75E-05 & 0.000432 & 0.000325 & -1.9E-05 & -1.63E-05 \\
\hline 11000 & -0.00048 & $-3.78 E-04$ & $2.25 E-05$ & $1.95 \mathrm{E}-05$ & 0.000476 & 0.000357 & $-2.1 E-05$ & $-1.80 \mathrm{E}-05$ \\
\hline 12000 & -0.00052 & $-4.09 \mathrm{E}-04$ & 2.46E-05 & 2.10E-05 & 0.000519 & 0.000393 & $-2.3 \mathrm{E}-05$ & -1.94E-05 \\
\hline 13000 & -0.00056 & $-4.42 \mathrm{E}-04$ & 2.66E-05 & 2.31E-05 & 0.000562 & 0.000427 & $-2.5 E-05$ & $-2.11 \mathrm{E}-05$ \\
\hline 14000 & -0.00061 & $-4.75 E-04$ & 2.87E-05 & 2.51E-05 & 0.000605 & 0.000459 & -2.7E-05 & $-2.30 \mathrm{E}-05$ \\
\hline 15000 & -0.00065 & $-5.01 E-04$ & 3.07E-05 & 2.71E-05 & 0.000648 & 0.000488 & $-2.8 E-05$ & $-2.48 E-05$ \\
\hline 16000 & -0.00069 & -5.37E-04 & 3.28E-05 & 2.89E-05 & 0.000692 & 0.000523 & $-3 E-05$ & $-2.66 \mathrm{E}-05$ \\
\hline 17000 & -0.00074 & $-5.68 E-04$ & 3.48E-05 & 3.08E-05 & 0.000735 & 0.000555 & $-3.2 E-05$ & $-2.82 E-05$ \\
\hline 18000 & -0.00078 & $-6.02 E-04$ & 3.69E-05 & 3.29E-05 & 0.000778 & 0.000589 & $-3.4 \mathrm{E}-05$ & $-3.00 \mathrm{E}-05$ \\
\hline 19000 & -0.00082 & $-6.34 E-04$ & 3.89E-05 & 3.47E-05 & 0.000821 & 0.000622 & $-3.6 E-05$ & $-3.15 E-05$ \\
\hline 20000 & -0.00087 & $-6.68 E-04$ & 4.1E-05 & 3.66E-05 & 0.000865 & 0.000656 & $-3.8 \mathrm{E}-05$ & $-3.34 \mathrm{E}-05$ \\
\hline 21000 & -0.00091 & -7.04E-04 & 4.3E-05 & 3.87E-05 & 0.000908 & 0.000691 & $-4 E-05$ & $-3.53 E-05$ \\
\hline 22000 & -0.00095 & $-7.35 E-04$ & 4.51E-05 & 4.14E-05 & 0.000951 & 0.000726 & $-4.2 E-05$ & $-3.71 E-05$ \\
\hline
\end{tabular}


Table 6.5 Strain values at locations of strain gauges \#3, \#4, \#5 and \#6 for a central patch load

\begin{tabular}{|c|c|c|c|c|c|c|c|c|}
\hline \multirow{2}{*}{ Load (kips) } & \multicolumn{2}{|c|}{$\mu \varepsilon_{\mathrm{z}}(\# 3)$} & \multicolumn{2}{|c|}{$\mu \varepsilon_{\mathrm{x}}(\# 4)$} & \multicolumn{2}{|c|}{$\mu \varepsilon_{\mathrm{z}}(\# 5)$} & \multicolumn{2}{|c|}{$\mu \varepsilon_{\mathrm{x}}(\# 6)$} \\
\hline & Analytical & Expt. & Analytical & Expt. & Analytical & Expt. & Analytical & Expt. \\
\hline 0 & 0 & 0 & 0 & 0 & 0 & 0 & 0 & 0 \\
\hline 1000 & $-4.3 \mathrm{E}-05$ & $-4.01 E-05$ & 2.0476E-06 & 1.47E-06 & 4.32E-05 & 3.62E-05 & $-1.9 \mathrm{E}-06$ & $-1.34 \mathrm{E}-06$ \\
\hline 2000 & -8.7E-05 & $-8.43 E-05$ & 4.09525E-06 & 3.04E-06 & 8.65E-05 & 7.87E-05 & $-3.8 E-06$ & $-3.03 E-06$ \\
\hline 3000 & -0.00013 & -0.000123 & $6.1429 E-06$ & 4.82E-06 & 0.00013 & 0.000113 & -5.7E-06 & $-4.59 \mathrm{E}-06$ \\
\hline 4000 & -0.00017 & -0.000162 & 8.1905E-06 & 6.70E-06 & 0.000173 & 0.000148 & -7.6E-06 & $-5.81 E-06$ \\
\hline 5000 & -0.00022 & -0.000202 & 1.02383E-05 & 8.38E-06 & 0.000216 & 0.000185 & $-9.5 E-06$ & $-7.60 \mathrm{E}-06$ \\
\hline 6000 & -0.00026 & -0.000243 & 1.22855E-05 & $1.04 \mathrm{E}-05$ & 0.000259 & 0.000225 & -1.1E-05 & $-9.58 E-06$ \\
\hline 7000 & -0.0003 & -0.000282 & 1.43335E-05 & $1.21 \mathrm{E}-05$ & 0.000303 & 0.000261 & -1.3E-05 & -1.12E-05 \\
\hline 8000 & -0.00035 & -0.000322 & 0.000016381 & 1.38E-05 & 0.000346 & 0.000300 & $-1.5 \mathrm{E}-05$ & $-1.28 \mathrm{E}-05$ \\
\hline 9000 & -0.00039 & -0.000360 & 1.84285E-05 & 1.59E-05 & 0.000389 & 0.000337 & -1.7E-05 & -1.43E-05 \\
\hline 10000 & -0.00043 & -0.000402 & 0.000020476 & 1.75E-05 & 0.000432 & 0.000376 & -1.9E-05 & -1.63E-05 \\
\hline 11000 & -0.00048 & -0.000443 & 0.000022524 & 1.95E-05 & 0.000476 & 0.000414 & -2.1E-05 & -1.80E-05 \\
\hline 12000 & -0.00052 & -0.000482 & $2.45715 \mathrm{E}-05$ & 2.10E-05 & 0.000519 & 0.000453 & $-2.3 E-05$ & -1.94E-05 \\
\hline 13000 & -0.00056 & -0.000520 & 0.000026619 & 2.31E-05 & 0.000562 & 0.000492 & $-2.5 \mathrm{E}-05$ & $-2.11 \mathrm{E}-05$ \\
\hline 14000 & -0.00061 & -0.000556 & 2.86665E-05 & 2.51E-05 & 0.000605 & 0.000530 & -2.6E-05 & $-2.30 \mathrm{E}-05$ \\
\hline 15000 & -0.00065 & -0.000592 & 3.07145E-05 & 2.71E-05 & 0.000649 & 0.000563 & $-2.8 \mathrm{E}-05$ & $-2.48 \mathrm{E}-05$ \\
\hline 16000 & -0.00069 & -0.000632 & 3.27625E-05 & 2.89E-05 & 0.000692 & 0.000604 & $-3 E-05$ & $-2.66 \mathrm{E}-05$ \\
\hline 17000 & -0.00074 & -0.000672 & 3.48095E-05 & 3.08E-05 & 0.000735 & 0.000640 & $-3.2 E-05$ & $-2.82 E-05$ \\
\hline 18000 & -0.00078 & -0.000708 & 3.68575E-05 & 3.29E-05 & 0.000778 & 0.000674 & $-3.4 \mathrm{E}-05$ & $-3.00 E-05$ \\
\hline 19000 & -0.00082 & -0.000744 & 0.000038905 & 3.47E-05 & 0.000821 & 0.000716 & $-3.6 E-05$ & $-3.15 E-05$ \\
\hline 20000 & -0.00087 & -0.000780 & 4.09525E-05 & 3.66E-05 & 0.000865 & 0.000753 & -3.8E-05 & $-3.34 \mathrm{E}-05$ \\
\hline 21000 & -0.00091 & -0.000815 & 0.000043 & 3.87E-05 & 0.000908 & 0.000794 & $-4 \mathrm{E}-05$ & $-3.53 E-05$ \\
\hline 22000 & -0.00095 & -0.000854 & 0.000045048 & 4.14E-05 & 0.000951 & 0.000830 & $-4.2 E-05$ & $-3.71 E-05$ \\
\hline
\end{tabular}




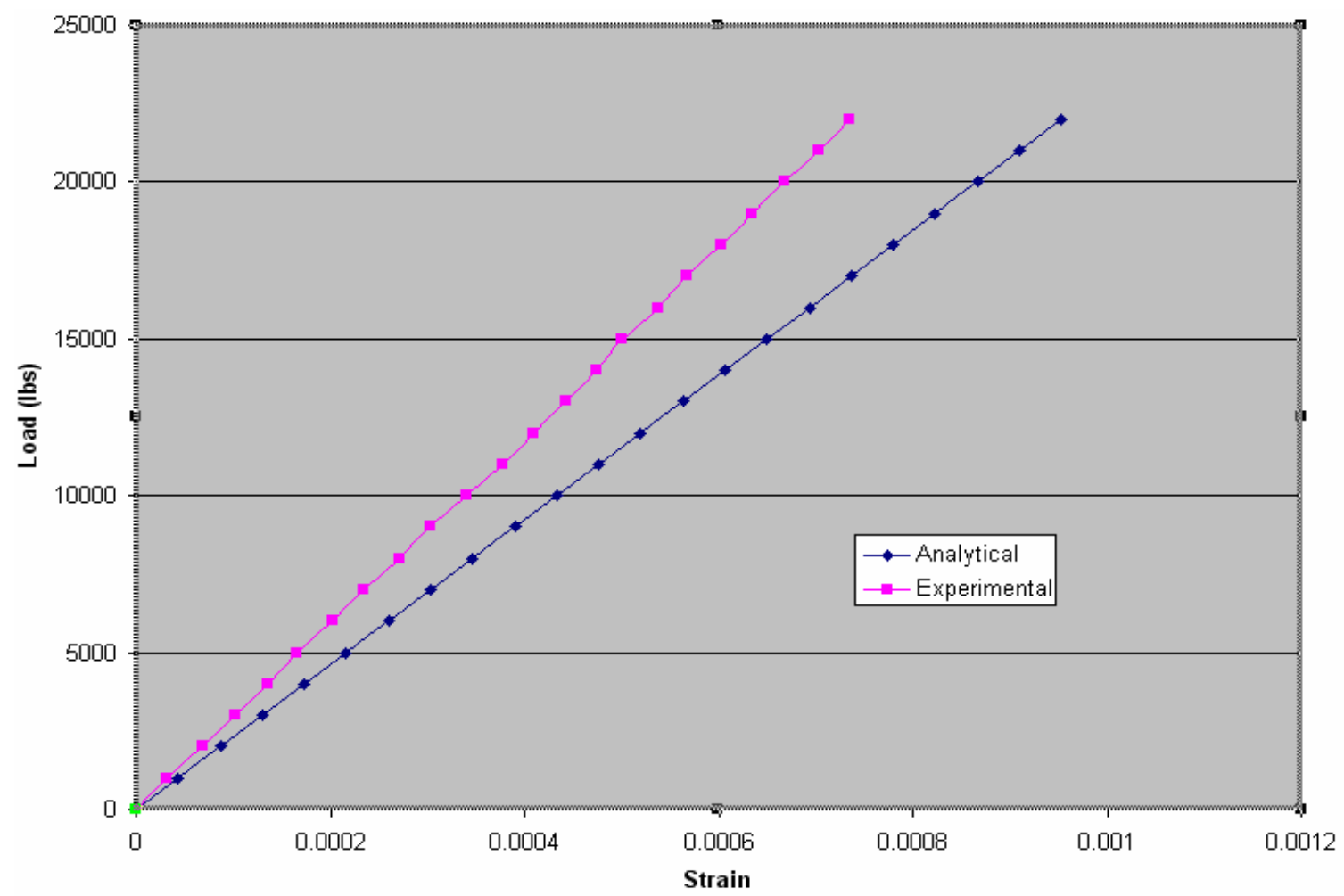

Fig. 6.10 Variation of strain at the gauge \#1 location for a central patch load

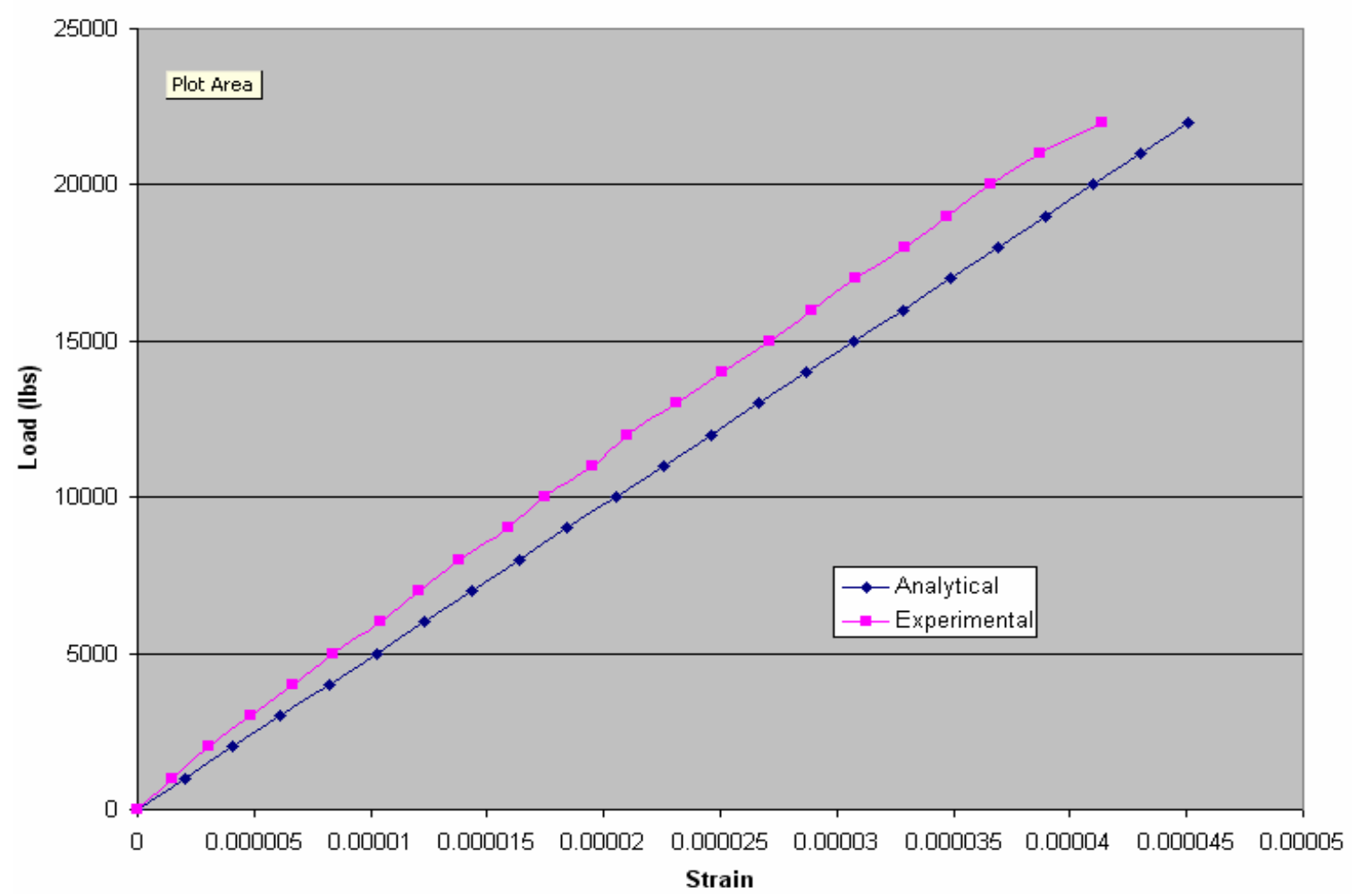

Fig. 6.11 Variation of strain at the gauge \#2 location for a central patch load 


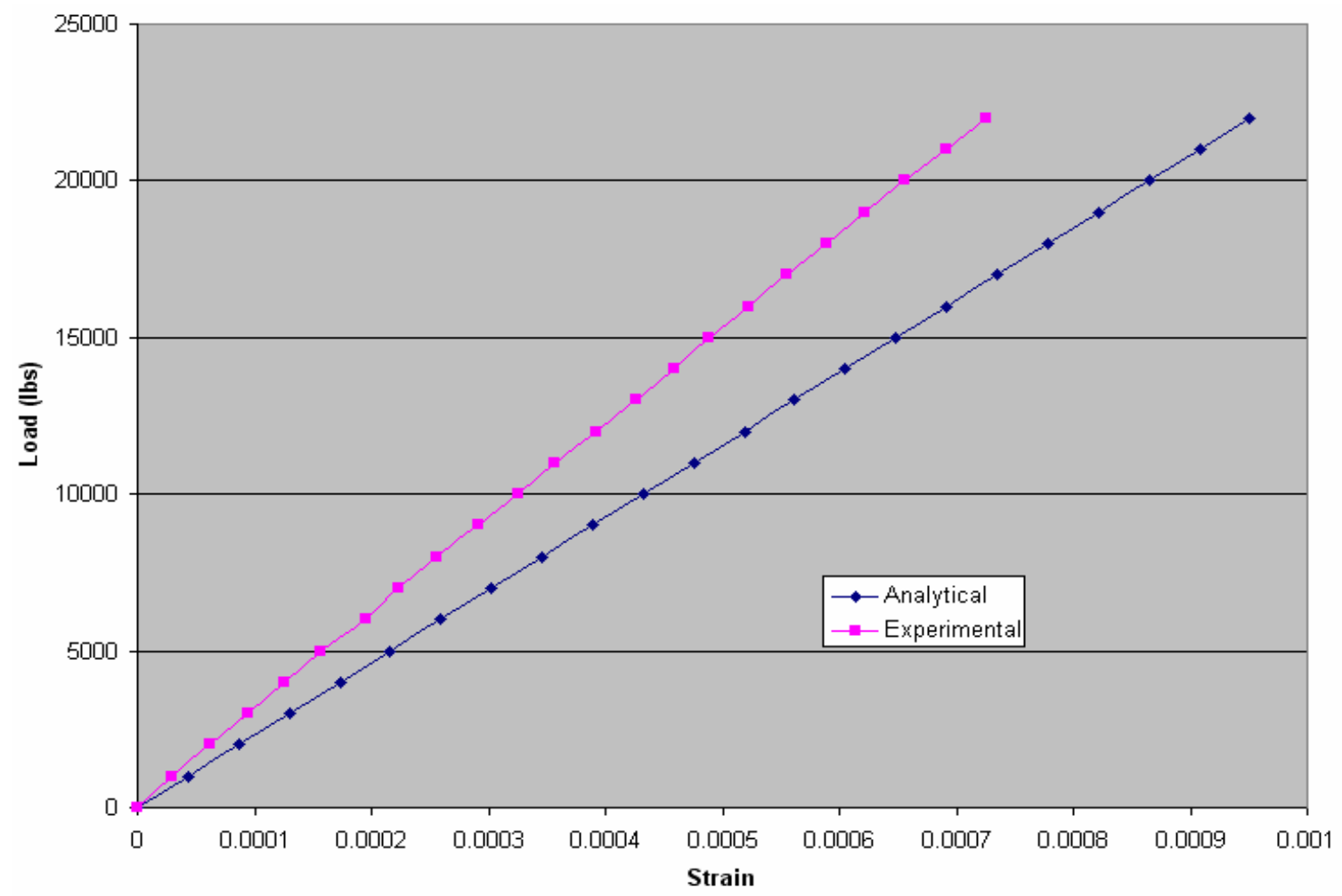

Fig. 6.12 Variation of strain at the gauge \#9 location for a central patch load

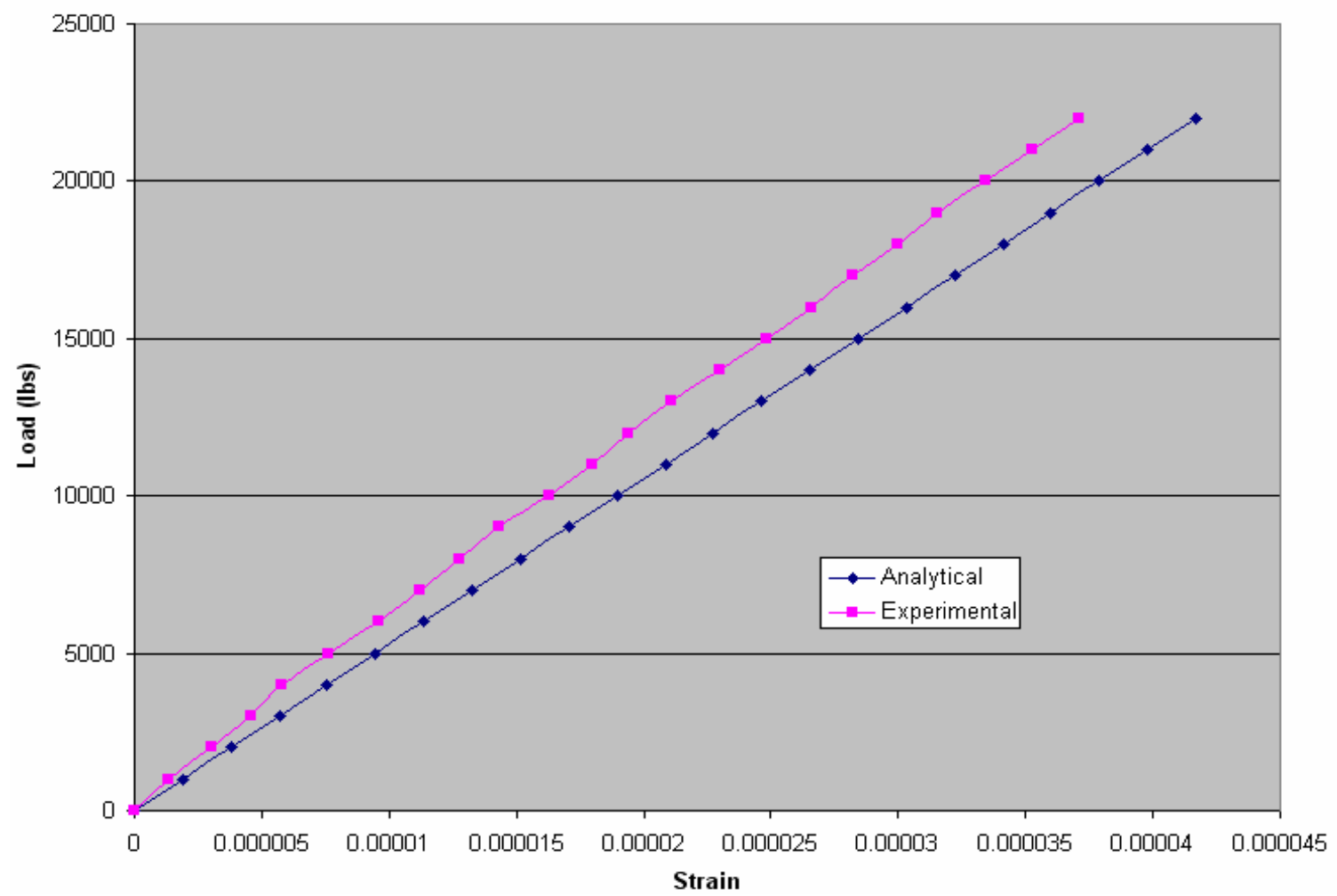

Fig. 6.13 Variation of strain at the gauge \#10 location for a central patch load 


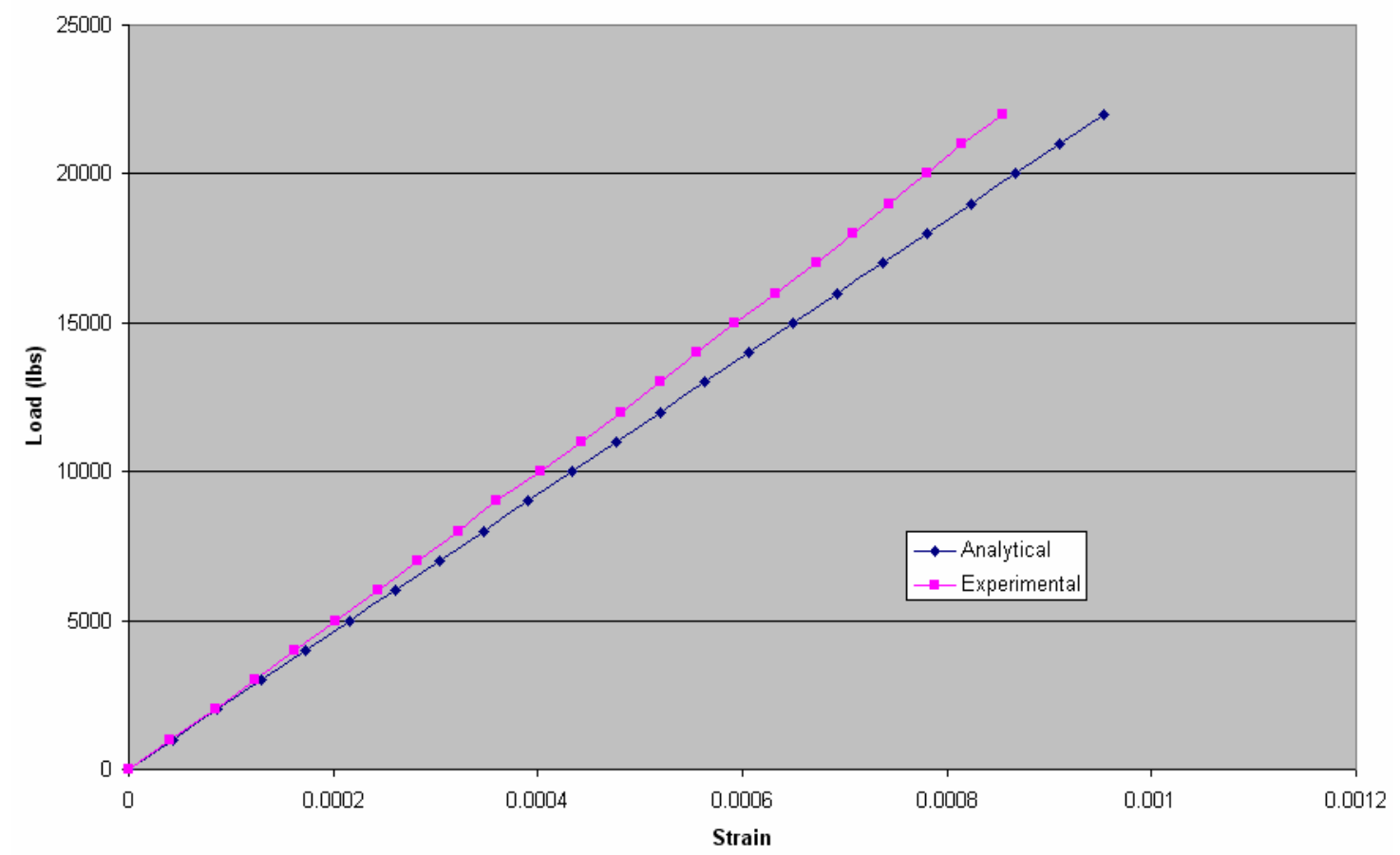

Fig. 6.14 Variation of strain at the gauge \#3 location for a central patch load

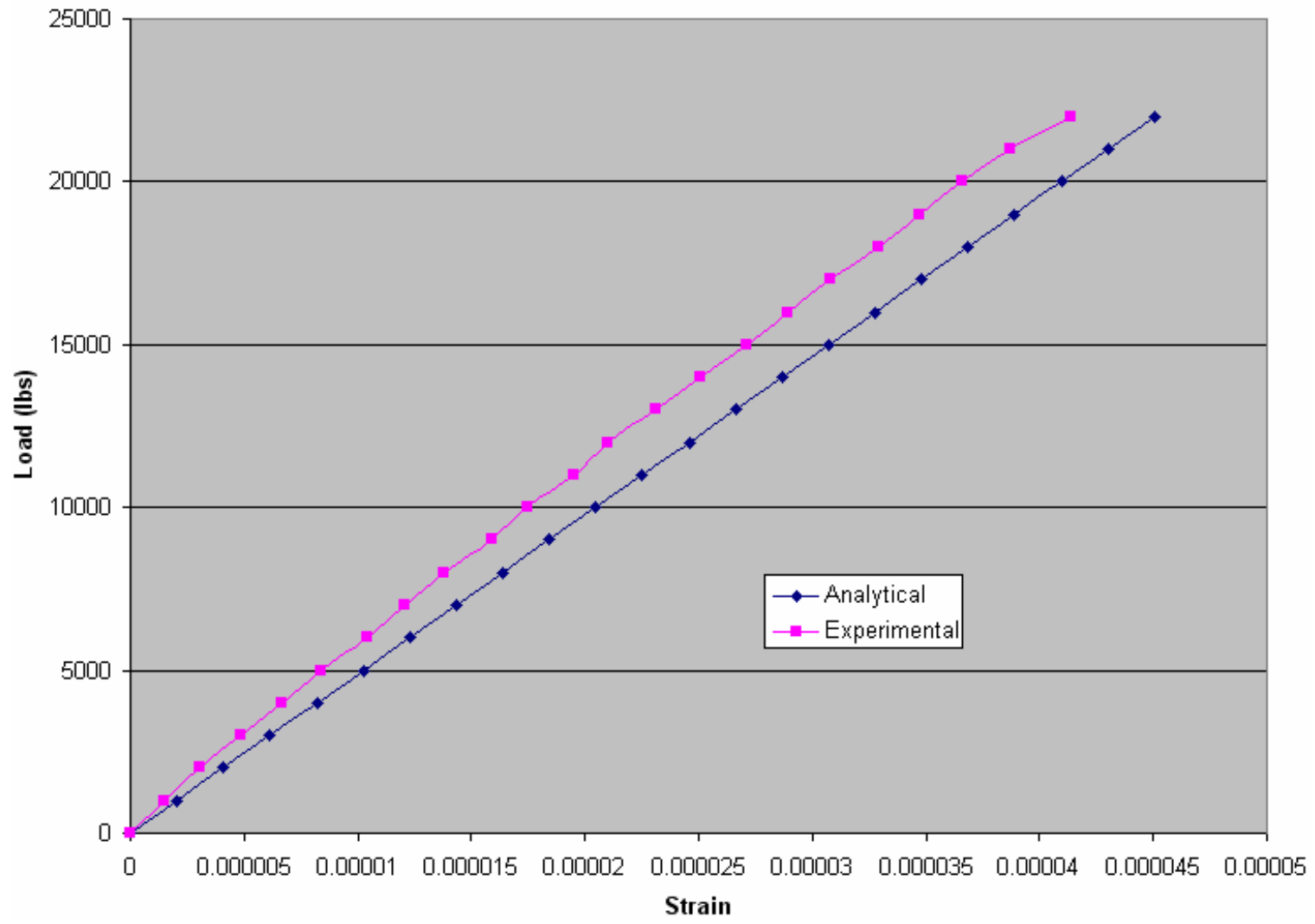

Fig. 6.15 Variation of strain at the gauge \#4 location for a central patch load 


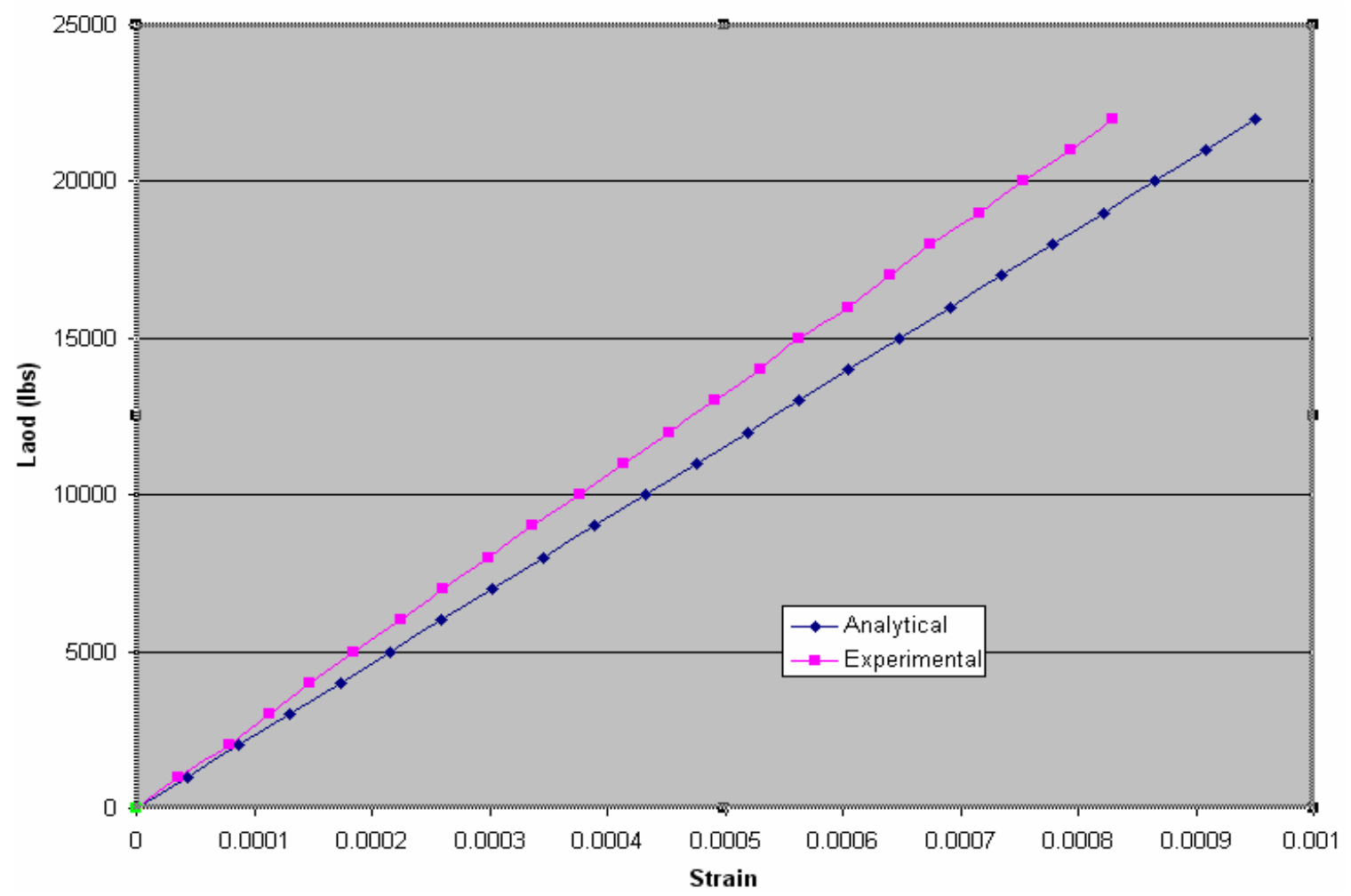

Fig. 6.16 Variation of strain at the gauge \#5 location for a central patch load

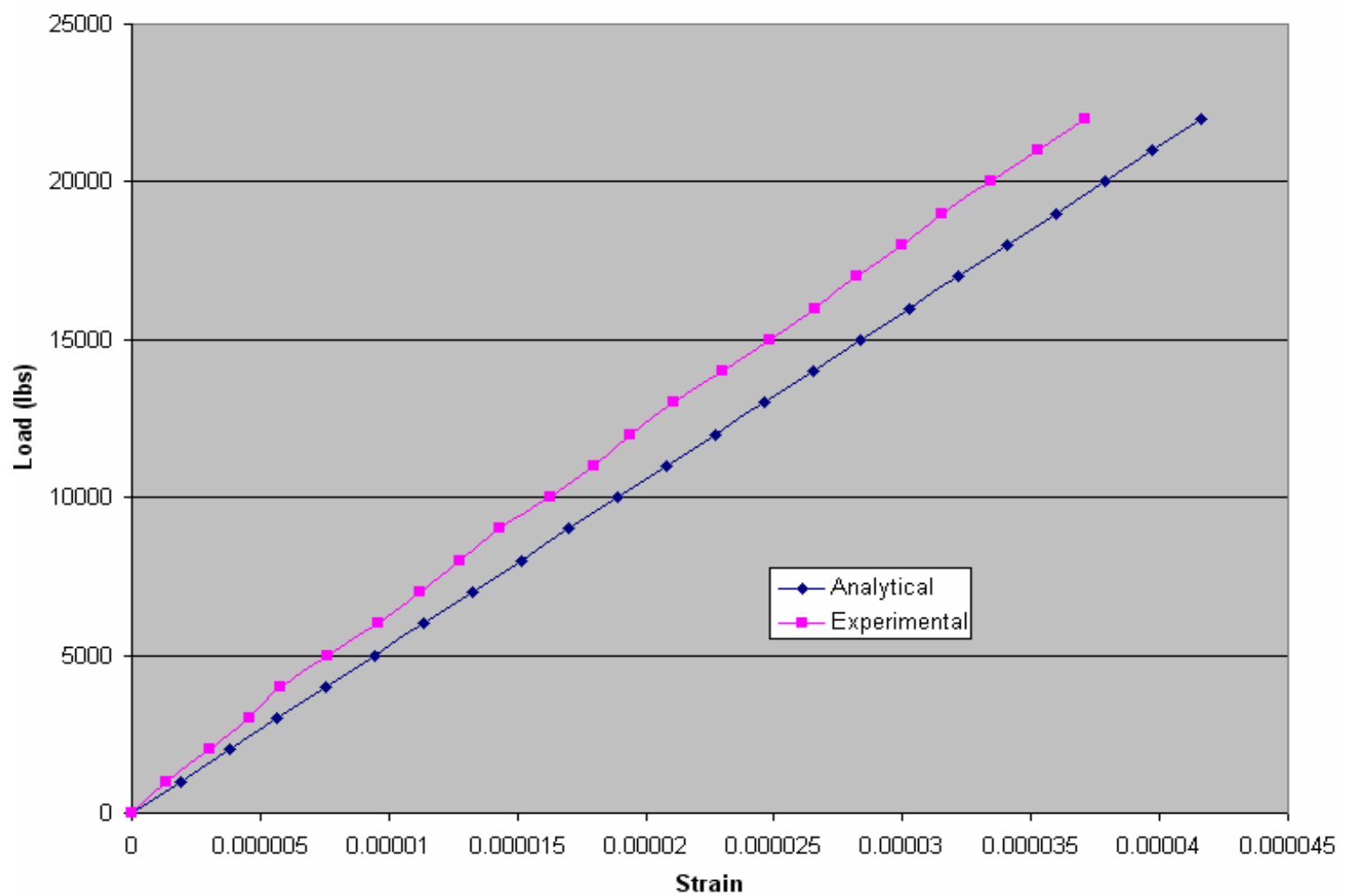

Fig. 6.17 Variation of strain at the gauge \#6 location for a central patch load 
In Figs. $6.10-6.17$ it is observed that the analytical strain values are higher than the experimental strain values which is perhaps because of the wearing surface that is present on the deck. One of the prime reasons for higher analytical strain values than experimental strain values for given load values is because the strain gauges could not record the exact strain values due to the presence of a wearing surface and layer of glue over the deck as shown in Figs 6.1 and 6.2. It is observed from the Figs. $6.10-6.17$, that the analytical curves show linear behavior where as the experimental curves tends to be a bit nonlinear. The strain values in tables $6.3,6.4$ and 6.5 at gauge locations $\# 1, \# 3, \# 9, \# 7$ and \#5 indicate that the top flange of the deck is under compression and the bottom flange is under tension. From the Fig. 6.7 it is observed that the analytical deflection values are close to the experimental deflection values obtained and both analytical and experimental curves exhibit linear behavior and for a given load value maximum deflection is observed at the strain gauge location \#7.

A table consisting of analytical stress and strain values observed at the mid section in the bottom flange of the two-module FRP deck for the corresponding load values is presented below followed by the graph, plotted between stress and corresponding strain values at the mid section of the two-module FRP deck. 
Table 6.6 Stress and strain values of two-module FRP deck for central patch load

\begin{tabular}{|c|c|c|}
\hline Applied load (kips) & Stress (psi) & Strain $\left(\varepsilon_{z}\right)$ \\
\hline 1 & 163.31 & $6.23 \mathrm{E}-05$ \\
\hline 2 & 326.62 & 0.000125 \\
\hline 3 & 489.93 & 0.000187 \\
\hline 4 & 653.24 & 0.000249 \\
\hline 5 & 816.55 & 0.000311 \\
\hline 6 & 979.86 & 0.000374 \\
\hline 7 & 1143.20 & 0.000436 \\
\hline 8 & 1306.50 & 0.000498 \\
\hline 9 & 1469.80 & 0.000561 \\
\hline 10 & 1633.10 & 0.000623 \\
\hline 11 & 1796.40 & 0.000685 \\
\hline 12 & 1959.70 & 0.000747 \\
\hline 13 & 2123.00 & 0.000810 \\
\hline 14 & 2286.30 & 0.000872 \\
\hline 15 & 2449.60 & 0.000934 \\
\hline 16 & 2613.00 & 0.000997 \\
\hline 17 & 2776.30 & 0.001059 \\
\hline 18 & 2939.60 & 0.001121 \\
\hline 19 & 3102.90 & 0.001184 \\
\hline 20 & 3266.20 & 0.001246 \\
\hline 21 & 3429.50 & 0.001308 \\
\hline 22 & 3592.80 & 0.001370 \\
\hline
\end{tabular}




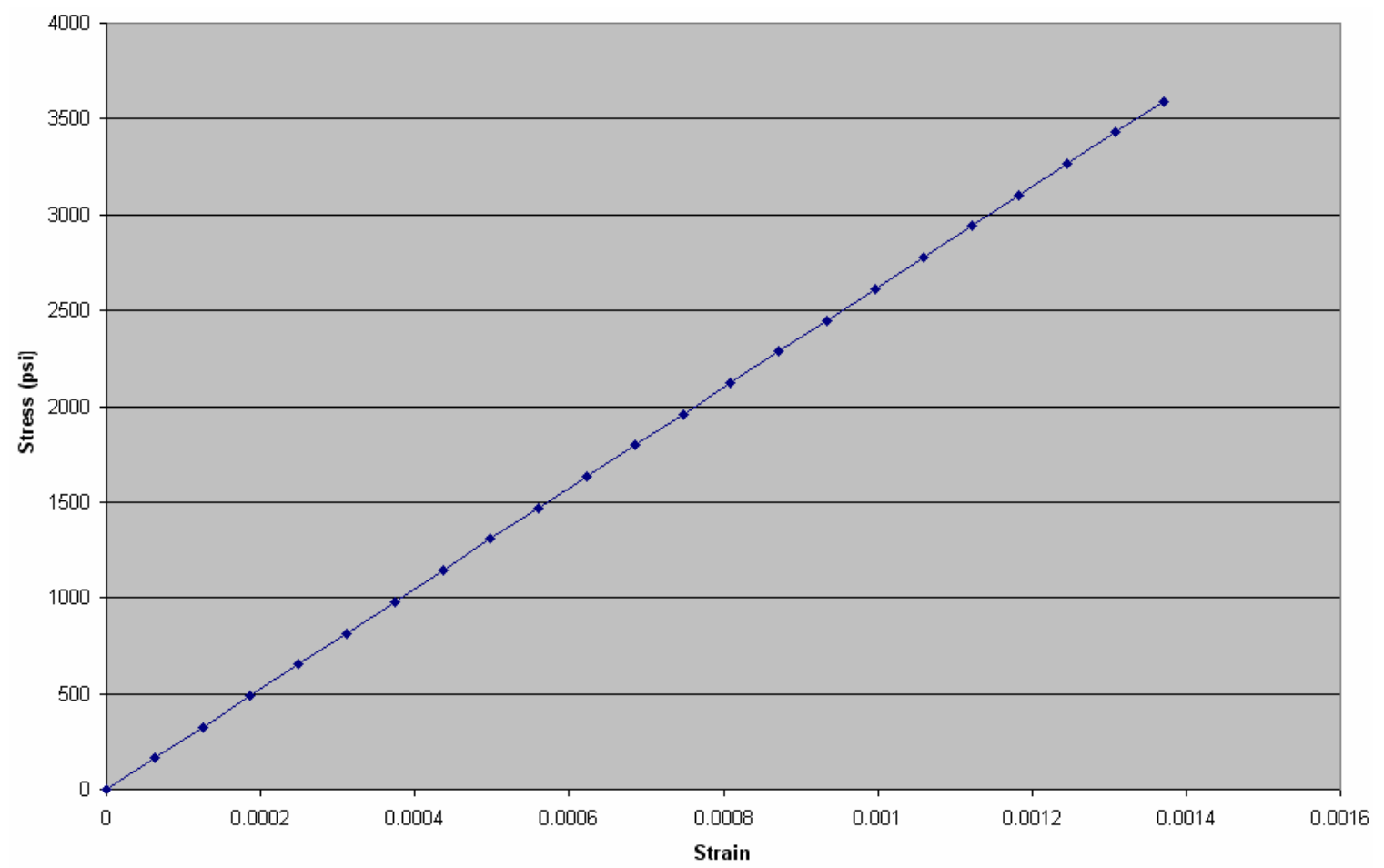

Fig. 6.18 Stress-strain curve for a central patch load

Figure 6.18 signifies that the analytical curve is a linear curve starting from the origin. The stress value increases linearly with increase in the strain value at the mid section in the bottom flange of the two-module FRP deck.

\subsection{Bending stiffness based on strain}

Using Eq. (3.35) and the slope from Fig. 6.9 the value of equivalent flexural rigidity based on strain is found to be $8.6 \times 10^{8} \mathrm{lb}^{*} \mathrm{in}^{2}$ where the value obtained in experimental tests is $7.81 \times 10^{8} \mathrm{lb}^{*} \mathrm{in}^{2}$ which is about $10 \%$ higher than the analytical value obtained. 
Table 6.7 Equivalent flexural rigidity and Young's modulus of the two-module FRP deck component based on strain

\begin{tabular}{|c|c|c|}
\hline Type & Experimental & Analytical \\
\hline $\begin{array}{l}\text { Equivalent Flexural rigidity } \\
\qquad \mathbf{E}_{\mathbf{Z}} \mathbf{I}_{\mathbf{x}}\left(10^{8}\right) \mathrm{lb}^{\mathrm{b}} * \mathrm{in}^{2}\end{array}$ & 7.81 & 8.6 \\
\hline $\begin{array}{c}\text { Young's Modulus } \\
E_{z}\left(10^{6}\right) \text { psi } \\
\left(I_{x}=139.88 \text { in }^{4}\right)\end{array}$ & 5.5 & 6.1 \\
\hline $\begin{array}{c}\text { Young's Modulus } \\
E_{z}\left(10^{6}\right) \text { psi } \\
\left(I_{x}=156.121 \text { in }^{4}\right)\end{array}$ & 5.1 & 5.6 \\
\hline
\end{tabular}




\section{CHAPTER 7}

\section{CONCLUSIONS AND RECOMMENDATIONS}

\subsection{INTRODUCTION}

Three point bending test has been carried out on the finite element models of mutlicellular shaped FRP composite deck, composite beam and composite double beam. FRP composite deck is made of E-glass Fibers and vinyl ester resin. This deck, whose fiber volume fraction is about $50 \%$ is modeled using a finite element software ANSYS. The results obtained using finite element analysis are compared to the results obtained in experimental tests. This chapter contains conclusions drawn from the present finite element analysis as well as recommendations on future work.

\subsection{CONCLUSIONS}

- Finite element model of Prodeck 4 has been carried out successfully.

- The results obtained in deflection and strain analyses using the finite element model showed good correlation with the experimental results obtained.

- The bending stiffness and Young's modulus values of Prodeck 4 based on deflection are found to be $2.67 \times 10^{8} \mathrm{lb}^{*} \mathrm{in}^{2}$ and $3.82 \times 10^{6}$ psi respectively.

- The equivalent flexural rigidity and Young's modulus values of Prodeck 4 based on strain values are found to be $3.08 \times 10^{8} \mathrm{lb}^{*} \mathrm{in}^{2}$ and $4.40 \times 10^{6}$ psi respectively. They showed good correlation with the experimental values obtained. 
- Since ANSYS software is confined to first ply failure analyses, FPF analyses are carried out on Prodeck 4.

- Failure analyses are performed on Prodeck 4 using maximum stress, maximum strain and Tsai-Wu criteria, it is observed that the layers in the bottom flange in the corners under the patch load are first to fail, and those fibers are $90^{\circ}$ fibers which fail in the transverse direction due to matrix cracking.

- Based on buckling analysis that has been carried in ANSYS using Eigen value buckling method, the critical load value of buckling for the first mode of failure of deck and web are found to be around 600 and 100 kips respectively.

- Three point bending test is carried out on Prodeck 4, which is used as beam. The results obtained in the finite element analysis of FRP beam showed good correlation with the experimental results.

- The bending stiffness value of FRP beam based on deflection is found to be $3.4 \mathrm{x}$ $10^{9} \mathrm{lb}^{*} \mathrm{in}^{2}$ and based on strain values it is $5.92 \times 10^{9} \mathrm{lb}^{*} \mathrm{in}^{2}$.

- Three point bending tests are also carried out on FRP double beam and double deck, and the results obtained using finite element analysis are in good correlation with the experimental results.

- The bending stiffness values based on deflection and strain values of double FRP beam are $6.8 \times 10^{9} \mathrm{lb}^{*} \mathrm{in}^{2}$ and $12.07 \times 10^{9} \mathrm{lb}^{*} \mathrm{in}^{2}$ respectively.

- The bending stiffness and Young's modulus values based on deflection of FRP double deck are $5.42 \times 10^{8} \mathrm{lb}^{*} \mathrm{in}^{2}$ and $3.88 \times 10^{6}$ psi respectively.

- The bending stiffness and Young's modulus values based on strain values of FRP double deck are $8.6 \times 10^{8} 1 \mathrm{~b}^{*} \mathrm{in}^{2}$ and $6.1 \times 10^{6}$ psi respectively. 


\subsection{RECOMMENDATIONS}

- Progressive ply failure of Prodeck 4 could be carried out using other finite element software or supplementing ANSYS with a user defined subroutine.

- Fatigue analysis of Prodeck 4 could be carried out using some other commercial finite element software capable of doing it.

- Buckling analysis of Prodeck 4 could be carried out using non-linear analysis by some other finite element software, since ANSYS allows non-linear curve to be input for isotropic materials only.

- Analysis of two-module FRP deck can be performed incorporating glue properties at the joint of the decks. 


\section{REFERENCES}

ANSYS v 8.1, 2004, "ANSYS theory reference manual."

Azar, W.A. and Plecnik, J.M. (1991), "Structural components, highway bridge deck applications." International Encyclopedia of Composites, Vol. 6, pp. 430-445.

Bakeri, P.A. and Sunder, S.S. (1990), "Concepts for hybrid FRP bridge deck systems." Serviceability and Durability of Construction Materials, Proceedings of the 1st Materials Engineering Congress, Denver, Colorado, U.S., pp. 1006-1015.

Barbero, E.J., (1998), "Introduction to Composite Materials Design.” Taylor and Francis, Philadelphia.

Chandrashekara, K. and Nanni, A., (2000), "Experimental Testing and Modeling of a FRP Bridge." Final Report, Missouri Department of Transportation, Research, Development and Technology.

Deepthi, P., (2004), "Structural Performance of Low-Profile FRP Composite Cellular Modules." Master's Thesis, Dept. of Mechanical and Aerospace Engineering, W.V.U., Morgantown, WV.

Ganga Rao, H.V.S., Shekar, V., (2002), "Specifications for FRP Highway Bridge Applications: Acceptance Test Specifications for FRP Decks and Superstructures," CFC Report to USDOT-FHWA, West Virginia University.

Howard, I., (2002), "Development of Lightweight FRP Bridge Deck Designs and Evaluations." Master's Thesis, Dept. of Civil Engineering, West Virginia University, Morgantown, WV. 
Kumar, P., Chandrashekhara, K., Nanni, A. : "Structural Performance of a FRP Bridge Deck." Construction and Building Materials 18 (2004), p. 35-47.

Nagaraj, V., (1994), "Static and Fatigue Response of Pultruded FRP Beams without and with Splice Connections." Master's Thesis, Dept. of Civil and Environmental Engineering, W.V.U, Moragantown, WV.

Natarajan, V., (2003), "Fatigue Response of Fabric Reinforced Polymeric Composites." Master's Thesis, Dept. of Mechanical Engineering, W.V.U., Morgantown, WV.

Schniepp, T.J., (2002), "Design Manual Development for a Hybrid FRP Double Web Beam and Characterization of Shear Stiffness in FRP Composite Beams." Master's Thesis, Dept. of Engineering Science and Mechanics, Virginia Polytechnic and State University, Blackburg, VA.

Shekar, V., (2000), “Advancement in FRP Composites Using 3-D Stitched Fabrics and Enhancement in FRP bridge Deck Component Properties." Master's Thesis, Dept. of Civil and Environmental Engineering, W.V.U., Morgantown, WV. Sonti, S.S., (1997), "Evaluation of Joint Efficiency and Performance of Multicellular Deck Panel." Master's Thesis, Dept. of Civil and Environmental Engineering, W.V.U., Morgantown, WV.

Suraj, S., (2005), "Finite-Element Modeling of a Composite Bridge Deck." Master's Thesis, Dept. of Mechanical Engineering, W.V.U., Morgantown, WV.

Temeles, A.B., (2001), "Field and Laboratory Tests of a Proposed Bridge Deck Panel Fabricated from Pultruded Fiber Reinforced Polymer Components." 
Master's Thesis, Virginia Polytechnic Institute and State University, Blacksburg, VA.

Zureick, A., (1997), “Fiber-reinforced polymeric bridge decks.” Proceedings of the National Seminar on Advanced Composite Material Bridges, FHWA.

http://www.pubs.asce.org/journals/cc.htmls

http://www.cerf.org/pdfs/collab/durability/1.pdf

http://enac2.epfl.ch/web/doctorants/2004/113.pdf

http://www.compositesworld.com/ct/issues/2005/April/808

http://www.tifac.org.in/news/build.htm

https://www.engr.wisc.edu/cee/faculty/bank lawrence/BakisBanketalJCC150

thpaper.pdf

http://www.virginiadot.org/vtrc/main/online reports/pdf/04-cr12.pdf

http://biblion.epfl.ch/EPFL/theses/2004/3135/EPFL TH3135.pdf

http://campus.umr.edu/maeem/research/projects/materials/exp testing and

modeling of FRP.htm

http://jrp.sagepub.com/cgi/reprint/24/18/1921 